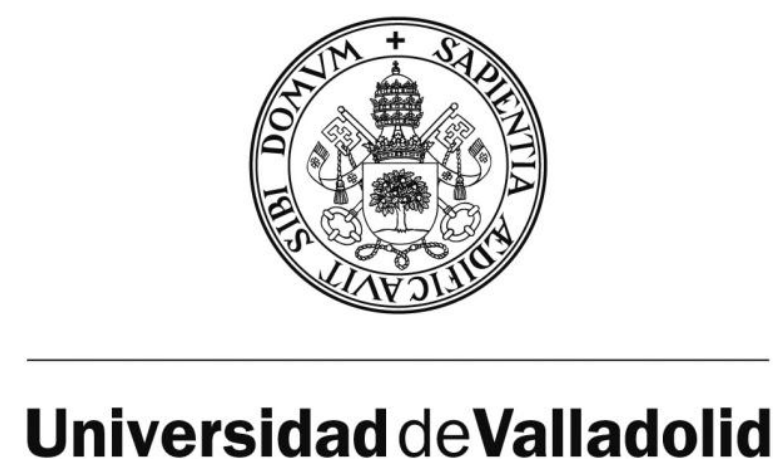

ESCUELA DE INGENIERÍAS INDUSTRIALES

DEPARTAMENTO DE INGENIERÍA QUÍMICA Y TECNOLOGÍA DEL MEDIO AMBIENTE

TESIS DOCTORAL:

\title{
STUDIES OF PROCESS INTENSIFICATION FOR THE RECOVERY OF HIGH MOLECULAR WEIGHT $\beta$-GLUCANS
} FROM CEREALS

Presentada por Óscar Benito Román para optar al grado de doctor por la Universidad de Valladolid

Dirigida por:

Dr.- Ing. Gloria Esther Alonso Sánchez

Prof. María José Cocero Alonso 



\section{ÍNDEX}

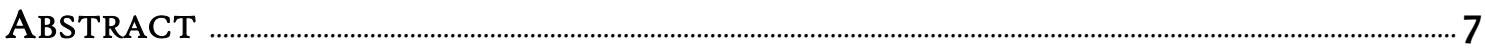

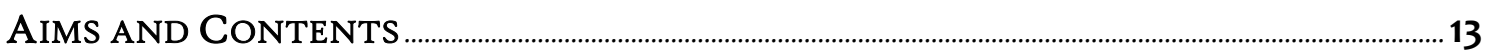

CHAPTER I. OPTIMIZATION OF THE $\beta$-GLUCAN EXTRACTION CONDITIONS FROM DIFFERENT

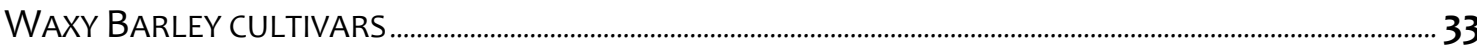

Chapter 2. UltRASOUND-ASSISTEd EXTRACTION OF $\beta$-GLUCANS FROM BARLEY ................................... 53

ChaPter 3. EFFect OF PRESSURE AND TEMPERATURE ON THE DISSOLUTION OF $\beta$ GLUCAN IN PRESSURIZED HOT WATER

Chapter 4. Pressurized Hot Water extraction of $\beta$-glucan from Waxy barley

ChAPTER 5. FIXED-BED EXTRACTION OF $\beta$-GLUCAN FROM CEREALS BY MEANS OF

Pressurized Hot Water

ChAPTER 6. PURIFICATION AND ISOLATION OF B-GLUCANS FROM BARLEY: DOWNSTREAM PROCESS INTENSIFICATION

CHAPTER 7. EVALUATION OF THE $\beta$-gLUCAN EXTRACTION INTENSIFICATION FROM BARLEY:

ENERGY BALANCES OF DIFFERENT EXTRACTION PROCEDURES

CONCLUSIONS

RESUMEN

ANNEX I. Study OF THE ENDOGENOUS $\beta$-GLUCANASE DeACtivation bY MEANS OF BOILING ETHANOL

ANNEX II. $\beta$-GLUCAN ENRICHED PRODUCTS OBTAINED FROM DIFFERENT BARLEY MILLING FRACTIONS AND THEIR MIXTURES

CURriculum Vitae. Óscar Benito RomáN 



\section{ÍNDICE DE CONTENIDOS}

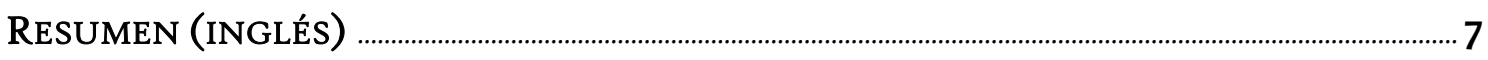

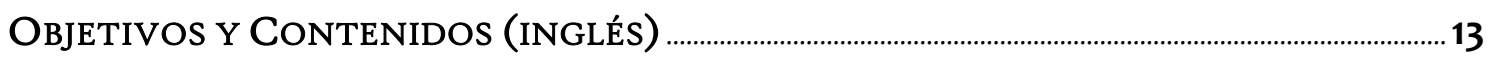

CAPÍTUlO I. OptIMIZACIÓN DE LAS CONDICIONES DE EXTRACCIÓN DE $\beta$-GLUCANOS A PARTIR DE DIFERENTES VARIEDADES DE CEBADA CEROSA EN TANQUE AGITADO

CAPÍTULO 2. EXTRACCIÓN DE $\beta$-GLUCANOS ASISTIDA POR ULTRASONIDOS A PARTIR DE CEBADA CEROSA

CAPÍTULO 3. ESTUdIOS DEL EFECTO DE LA PRESIÓN Y TEMPERATURA EN LA DISOLUCIÓN de $\beta$-glucanos en Agua Caliente Presurizada

Capítulo 4. Extracción de $\beta$-glucanos en Agua Caliente Presurizada a partir DE CEBADA CEROSA

CAPÍtulo 5. EXTRACCión de $\beta$-gLUCANOS de CEREALES EN LECHO FIJO MEDIANTE AGUA CALiente Presurizada

CAPÍtUlO 6. Estudios de INTENSIFICACIÓN DE LA ETAPA DE PURIFICACIÓN Y

CONCENTRACIÓN DE $\beta$-GLUCANOS EXTRAÍDOS DE CEBADA 131

CAPÍTULO 7. EVALUACIÓN DE LA INTENSIFICACIÓN DE LA EXTRACCIÓN DE $\beta$-GLUCANOS A PARTIR DE CEBADA: BALANCES DE ENERGÍA A LOS DIFERENTES PROCESOS DE EXTRACCIÓN.

CONCLUSIONES (INGLÉS). 167

RESUMEN (CASTELLANO) 173

ANEXo I. Estudios de Desactivación De $\beta$-GLUCANASAS MEDIANTE EL EMPLEO DE ETANOL A EBULLICIÓN

ANexo II. Productos enRIQuecidos en $\beta$-GLUCANOS obTenidos a PARTIR DE FRACCIONES DE MOLIENDA DE CEBADA Y DE SUS MEZCLAS 



\section{ABSTRACT}

Studies of process intensification for the recovery of high molecular weight $\beta$-glucans from cereals 

The aim of this PhD Thesis is to make studies in order to develop an efficient process to produce concentrates rich in controlled molecular weight $\beta$-glucans, using cereals as raw material. It is expected to obtain high molecular weight $\beta$-glucans that can be used e. g. as food additive and to obtain low molecular weight $\beta$-glucans to be used e. g. in active compounds formulation processes.

This work was started with the selection of the raw material. It was used barley developed by the Instituto Tecnológico Agrario de Castilla y León (ITACYL; Valladolid, Spain). Two different waxy cultivars from 2006 were used, differing in the composition besides other morphological differences: $\mathrm{H} 13$ (hulless, $4.64 \pm 0.18 \%$ in $\beta$-glucan) and D24 (hulled, $6.02 \pm 0.37 \%$ in $\beta$-glucan).

In chapter 1, a literature review was done and it could be concluded that in the literature there was not any work in which the different process parameters affecting the $\beta$-glucan extraction process were systematically studied. It was selected $55^{\circ} \mathrm{C}$ as the optimal temperature to extract $\beta$-glucan, since a compromise between the $\beta$-glucan solubility and the co-extraction of other species present in the barley (mainly starch) was required, and water was selected as solvent. To study the effect that process parameters had on the extraction yield and molecular weight of $\beta$-glucan and to find of combination of them that maximize the extraction yield were the aims of this chapter. Particle size $(100-250-500 \mu \mathrm{m})$, solvent to solid ratio (5-8-15), stirring rate (200-600-1000rpm) and extraction time (1-3-5hours) were the process parameters studied. After this work it was concluded that particle size had a significantly higher influence on the extraction process than the other parameters studied (stirring rate, extraction time and barley variety), indicating that mass transfer steps are limiting the overall extraction process. The conventional extraction process in the optimal conditions lasted 3 hours (1000rpm stirring rate, solvent to solid ratio of 8 and particle size $100 \mu \mathrm{m}$ ) had an extraction yield of $62.8 \%$ for barley $\mathrm{H} 13$ and $73.4 \%$ for D24. It was also seen that the molecular weight of the extracted $\beta$ glucan was very low, in the range of $45-55 \mathrm{kDa}$, so in order to increase the $\mathrm{MW}$ of the $\beta$-glucan barley should be pretreated in order to deactivate the endogenous $\beta$-glucanases and preserve the native high MW of the $\beta$-glucan.

Barley was boiled in aqueous ethanol for two hours and used as raw material. The $\beta$-glucan extracted from this barley had a significantly higher MW (>400kDa), but the extraction yield decreased dramatically, due to the difficulty to keep the water-barley suspension as a consequence of its high viscosity. Results are shown in annex I. In the annex II, a different pretreatment was tried: barley was milled in order to get different milling fractions, with 
different compositions and particle size. It was seen the importance of the fraction used as raw material, as different extraction yields and product compositions were obtained.

In order to overcome the mass transfer limitations, which could not be solved in the convectional stirred tank process, new extraction processes were proposed. In chapter $2 \beta$ glucans were extracted from barley by means of the ultrasound technology (Ultrasound Assisted Extraction - UAE). Ultrasounds are related to mass transfer intensification processes, increasing the extraction yields and reducing the operation times compared to the conventional processes. In this work pretreated barley was used as raw material. Amplitude of oscillation (60-80-100\%), cycle (pulsed or continuous sonication) and extraction time (3-10-17 minutes) were the process parameters studied. Results revealed that UAE was an efficient process to extract $\beta$-glucans, providing higher extractions yields than the conventional CSTR process in much shorter extraction times, up to 10 minutes. Moreover, the specific energy required in the extraction was substantially lower than in the conventional process (here it was $1460 \mathrm{~kJ} / \mathrm{L})$, which allowed to talk about $\beta$-glucan extraction intensification. On the other hand, high energy outputs ( $>500 \mathrm{~kJ} / \mathrm{L}$ ) involve an important depolymerization of the $\beta$-glucan, not providing increases in the extraction yield. As a consequence of these results, the extraction conditions must be carefully selected in order to maximize extraction yield, molecular weight or both simultaneously.

Chapters $\mathbf{3}$ to 5 are related to the extraction of $\beta$-glucans from pressurized hot water (PHW), in different ways: batch or semi-continuous. PHW term refers to the water in liquid state in the range $100^{\circ} \mathrm{C}$ (boiling point) to $374^{\circ} \mathrm{C}$ (critical point) by the application of pressure. The transport properties of water (such as density, surface tension, viscosity and diffusivity) change dramatically when changing pressure and, specially, temperature. In chapter $\mathbf{3}$, a concentrate of $\beta$-glucans and starch (36.5\% and $25.4 \%$, respectively) was used in order to check its solubility and behavior in the PHW (range of temperature 120 to $170^{\circ} \mathrm{C}$ and range of times 10 to 300 minutes). It was seen that $\beta$-glucan could be dissolved in PHW, but once dissolved a rapid degradation of the molecule occurred: a rapid decrease of the MW was observed as well as the presence of sugar degradation products in the solution. In chapter IV it was done the extraction of $\beta$-glucan from not pretreated barley in a pressurized stirred vessel (batch operation mode). Temperature was changed in the range $\left(135-180^{\circ} \mathrm{C}\right)$ and extraction times in the range (15-75 minutes). The experimental conditions were selected to maximize the extraction yield: results done at $155^{\circ} \mathrm{C}$ for 18 minutes at 50 bar led to an extraction yield of $52.7 \%$ and $\mathrm{MW}$ equal to $200 \mathrm{kDa}$. These results are remarkable, as in one single step high 
molecular weight $\beta$-glucan were extracted in a short extraction process: it was not necessary to perform the deactivation of $\beta$-glucanases pretreatment. In chapter 5, a flow extraction process was studied, and $\beta$-glucan was extracted in a $50 \mathrm{ml}$ semicontinuous extractor (fixed bed). $\beta$-glucan extraction yield was similar to that obtained in the batch process in a $4 \mathrm{ml} / \mathrm{min}$ flow rate of water at $155^{\circ} \mathrm{C}$ for 105 minutes. The major advantage of the fixed-bed extraction process was the preservation and the fractionation of the $\beta$-glucan in terms of $\mathrm{MW}$ during the extraction. The extracted $\beta$-glucan were in the range $500-100 \mathrm{kDa}$, decreasing when increasing the extraction length. In this process no sugar degradation products, such as HMF, were detected. The extraction of $\beta$-glucan from other raw materials was also studied (wheat bran). It was observed similar results for wheat bran, in terms of temperature. The results obtained were used to calculate dimensionless numbers that would allow to do scale-up processes for the fixed-bed extraction of $\beta$-glucan. This research was done at the Technical University Hamburg-Harburg (Hamburg, Germany).

In chapter 6 the purification of the extracted $\beta$-glucan was studied (downstream process). The use of water and its lack of selectivity makes that other species present in barley, specially starch, are coextracted unpurifying the liquid extract. Starch was hydrolyzed by means of $\alpha$ amylase: it was studied the hydrolysis length, the temperature and the enzyme dose. The results allowed to do the hydrolysis in lower times than usual (only 9 minutes) keeping removal efficiencies higher than $90 \%$ with enzyme doses lower than those used in processes found in the literature: $100 \mu \mathrm{L} / \mathrm{g}$ of starch at $55^{\circ} \mathrm{C}$. Traditional processes do the starch hydrolysis at $95^{\circ} \mathrm{C}$ for 1 hour. In a second step, a significant intensification of the process was achieved by dosing the enzyme during the ultrasound assisted extraction step (7 minutes at $55^{\circ} \mathrm{C}$ ), resulting in a starch removal of $90 \%$. An intensification of the extraction and purification processes was successfully accomplished, as they were done simultaneously in one single step and at the same temperature.

In chapter 6 was also studied the separation of the dextrins or sugars formed as a consequence on the starch hydrolysis. These molecules are low molecular weight compared to the $\beta$-glucan, so a membrane process was used to separate them: diafiltration (polysulfone membrane, MWCO 100kDa) done in a tangential flow cell. This operation way allowed to reduce the concentration of oligosaccharides in the solution by $45 \%$ in average (in some cases it was higher than 75\%) in short times, with the subsequent increase in the concentration of $\beta$ glucan. Despite the fast fouling of the membrane observed (decrease of the permeability value, recovered after the cleaning process) it was concluded that the use of membranes to 
purify and concentrate $\beta$-glucans extracted from barley was technical viable. Finally, in chapter 6 it was concluded that the combination of ultrasounds, enzymatic hydrolysis and membrane technology allowed to obtain high purity $\beta$-glucans in simple and easy way, compared to the conventional process (time and energy consuming).

In chapter $\mathbf{7}$ special attention was paid on the energy consumed during the different extraction processes proposed in this thesis. It was evaluated the energy required to pretreat the barley (deactivation of $\beta$-glucanases and milling) and to perform the extraction of the three main processes presented in this work: stirred tank extraction, UAE and bath PHW. The energy consumed was expressed in $k W h$ per gram of $\beta$-glucan extracted. UAE was seen as the best process, as the lowest energy was consumed $(0.14-0.17 \mathrm{kWh} / \mathrm{g} \beta$-glucan in 3 to 15.9 minutes processes) which together with the dramatic reduction of the extraction times lead to talk about a real process intensification compared to the stirred tank extraction $(3 \mathrm{~h}, 0.27 \mathrm{kWh} / \mathrm{g} \beta$ glucan). PHW process was seen as the highest energy consumer (6.0kWh/g $\beta$-glucan). In spite of the good results in extraction time reductions and the lack of pretreatments to obtain high molecular weight (MW) $\beta$-glucan, PHW resulted to be an unfavorable process form an energetic point of view, mainly due to the low barley to water ratio (1:50) used during the extraction. 


\section{AIMS \& CONTENTS}

Studies of process intensification for the recovery of high molecular weight $\beta$-glucans from cereals 

In the recent years there has been an increase in the concern for the control of diseases such as cholesterol, diabetes or obesity by means of natural products. Those natural products that claim to have positive effects on human health are known as nutraceuticals. $(1 \rightarrow 3),(1 \rightarrow 4)-\beta-$ D-glucan, a sort of soluble fiber or dietary fiber, is an example of nutraceutical according to the claims issued by the FDA (Federal Drug Administration, USA; FDA, 2005) and the EFSA (European Food Safety Authority): "Regular consumption of $\beta$-glucans contributes to maintenance of normal blood cholesterol concentrations when ingesting $3 g$ of $\beta$-glucan per day". The EFSA report (EFSA, 2010) attributes this health claim to $\beta$-glucans with molecular weight in the range 50-2000 kDa. These good properties for health make that $\beta$-glucan can be used as food additive (i.e. Brennan and Cleary, 2007; Jacobs et al, 2004; Simmons and Brennan, 2004)

More specifically $\beta$-glucans are a kind of non-starchy long and linear polysaccharides composed of $\beta$-D-glucose units. Glucose molecules are linked by means of the O-glucosidic bond: a $\beta-(1 \rightarrow 4)$ in the $70 \%$ of the cases that is separated by a single $\beta-(1 \rightarrow 3)$ linkage. The structure of the $\beta$-glucan in shown in figure 1 . This polysaccharide can be found in the cell walls of different cereals, such as oat, barley, rye and, in lesser extent, wheat. The range of concentrations of $\beta$-glucans in these cereals is $0.5-11 \%$ (Cui et al, 2011) nevertheless the presence in cereals such as wheat can be considered as residual $(0.5-2 \%)$.

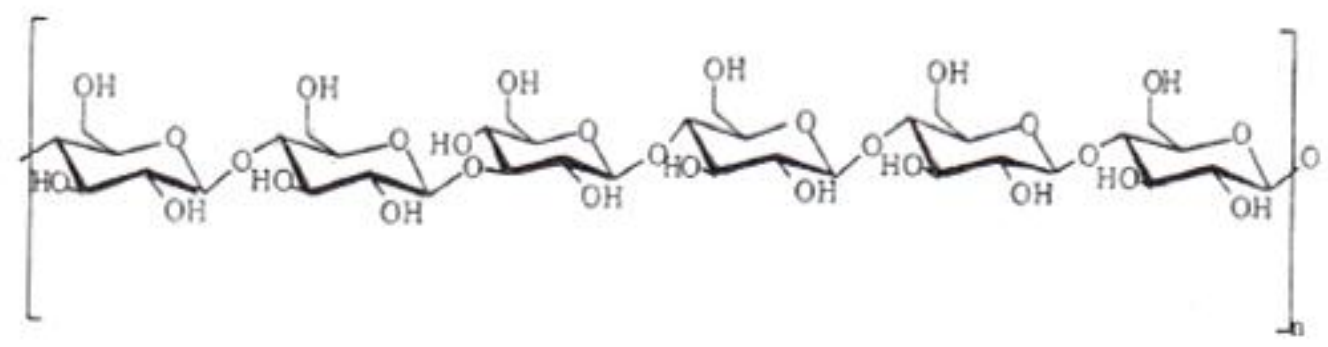

Figure 1. Molecular structure of $(1 \rightarrow 3),(1 \rightarrow 4)-\beta$-D-glucan. From Laroche and Michaud, 2007.

In the literature it is possible to find many different works that attempt to isolate $\beta$-glucans, particularly from oat. However, in the last years there has been a renewed interest in barley due to the development of new varieties genetically modified (Baik and Ullrich, 2008). These new varieties, known as waxy, have a higher content in $\beta$-glucan and proteins and lower content in other species such as starch compared to the conventional barleys. The conventional varieties of barley have around $2-3 \%$ of $\beta$-glucans; in turn, in the new waxy varieties the content can be increased up to $7 \%$. The presence of $\beta$-glucan in higher concentrations, together with the presence of other high value added compounds (such as 
antioxidants) have increase the appeal of barley as source of nutraceuticals, versus the traditional uses in brewery or animal feeding.

$\beta$-glucan recovery processes are complex, as they involve many different stages that can be summarized in three (Laroche and Michaud, 2007): pretreatment of the raw material, extraction and finally purification and isolation step. Each of these single stages is described below:

1. Pretreatments. The aim of this stage is to prepare the raw material for the extraction stage. It can be split in two different pretreatments:

- Milling and selection of the milling fractions: in this pretreatment the particle size of the grain used as source of $\beta$-glucan must be reduced in order to facilitate the contact between the solvent and the $\beta$-glucans, so they can be dissolved. The barley grains can be milled by means of a knives mill: only one milling fraction is obtained. The particle size of the resulting flour will be controlled by changing the length of the milling. On the other hand, if a mill that let the fractionation of the cereal is used, several milling fractions will be obtained, containing each of them a part of the grain. As a consequence each of the generated fractions will have different composition and particle size.

- If the purpose of the treatment is to increase the molecular weight of the extracted $\beta$-glucan, it is necessary to treat the raw material in a way that the endogenous $\beta$-glucanases are inactivated. These enzymes are responsible for the depolymerization on the $\beta$-glucans, and hence responsible for the decrease of their molecular weight.

2. Extraction. The selection of the solvent, as well as the extraction conditions must be carefully done in order to maximize the selectivity and the extraction yield of the $\beta$ glucans. A deep study of the effect that the extraction parameters have on the $\beta$ glucan is required as well as a deep knowledge of the mechanisms that control the $\beta$ glucan extraction process. The right choice of the extraction conditions will simplify the subsequent purification stage.

3. Purification and isolation of the extracted $\beta$-glucan. In the extraction stage, in addition to the $\beta$-glucan, other substances are co-extracted (i.e. starch and proteins). In this 
stage it is necessary to develop processes that are helpful to get rid of the co-extracted substances without affecting the structure of the $\beta$-glucan. Finally, once the $\beta$-glucan is purified it is necessary to concentrate it: it is necessary to get a solid product rich in $\beta$ glucan. In order to get this high purity $\beta$-glucan solid, processes such as freeze-drying or spray drying can be used (solvent removal processes). Alternatively an antisolvent can be used in a way that $\beta$-glucans are precipitated. The antisolvent must be fully miscible with the solvent used in the extraction step, but the $\beta$-glucan must be complete insoluble in it. In the literature, alcohols have been traditionally used as antisolvents. The formed precipitate, which is rich in $\beta$-glucans, must be separated from the solution and dried to be used.

In order to get all the potential nutraceutical properties that $\beta$-glucans have, it is necessary to develop processes that let their efficient recovery from the raw materials where they are trapped in low concentrations. In this thesis work the whole $\beta$-glucan recovery process has been studied from two different varieties of waxy barley. Barley has been selected as source of $\beta$-glucan due to the interest that this cultivar has for the economy of Castilla y León (Spain). Castilla y León is the greatest producer of barley is Spain (2.1 million of tons in 2012). Two different varieties of barley have be used in this work, developed and selected by the Instituto Tecnológico Agrario de Castilla y León (ITACYL) in the frame of the research project "Development of a technically efficient process for the extraction of $\beta$-glucan from barley" signed between the ITACYL and the High Pressure Process Research Group (Department Chemical Engineering and Environmental Technology, University of Valladolid).

The $\beta$-glucan recovery process is complex as it has been previously mentioned, and, in spite of the numerous works that can be found in the literature, there is a lack of systematic studies concerning all the parameters (and their interactions) that are involved in the extraction process. The literature revision of the state of the art reveals that $\beta$-glucans are extracted with water at mild temperatures $\left(25-55^{\circ} \mathrm{C}\right)$ and mainly by suspension of the solid matter in the solvent using mechanical agitation (stirred tanks). Table 1 summarizes the extraction conditions used by other authors in the literature. In some of the cases neither the extraction yield nor the molecular weight of the extracted $\beta$-glucan are reported. Moreover, a discussion of the obtained results based on the mass transfer fundamentals (external transport, internal diffusion and solubility equilibrium) is missed. This information is required from an engineering point of view to understand the $\beta$-glucan extraction mechanism and to accomplish the scaleup process. The lack of these valuable data complicates the comparison between processes 
and the scale-up from laboratory scale to industry. Moreover, another critical parameter for a process to be competitive at industrial scale, the energy consumption, is not reported in any of the works summarized in table 1.

Table 1. Operating conditions used by other researchers in the aqueous extraction of $\beta$-glucan from barley

\begin{tabular}{|c|c|c|c|c|c|c|}
\hline Researcher & Solvent & $\begin{array}{l}\text { Max Ext } \\
\text { Yield (\%) }\end{array}$ & s:f ratio & $\begin{array}{l}\text { Ext time } \\
\text { (h) }\end{array}$ & $\mathrm{T}\left({ }^{\circ} \mathrm{C}\right)$ & Barley \\
\hline \multirow{3}{*}{ Bhatty (1993) } & $\begin{array}{l}\text { Water, } \\
\mathrm{pH} 10\end{array}$ & 61 & $10: 1$ & 0.5 & 45 & \multirow{3}{*}{$\begin{array}{l}\text { HL-N-4.5\% } \\
\text { HL-W-11.3\% }\end{array}$} \\
\hline & $\begin{array}{l}\text { Water, } \\
\text { pH } 7\end{array}$ & 72 & $10: 1$ & \multicolumn{2}{|c|}{$\begin{array}{c}\text { Sequential:40, } 65 \text { and } \\
95\end{array}$} & \\
\hline & $\mathrm{NaOH}, 4 \%$ & 81 & $50: 1$ & 18 & Ambient & \\
\hline Bhatty (1995) & $\mathrm{NaOH}, 1 \mathrm{~N}$ & $73-77$ & $50: 1$ & 1 & Ambient & $\begin{array}{c}\text { HL-N-5.6\% } \\
\text { HL-W-11.3\% }\end{array}$ \\
\hline Saulnier (1994) & Water & $\begin{array}{c}16.6 \\
34\end{array}$ & $6: 1$ & & 40 & $\begin{array}{l}\mathrm{HL}-4.7 \% \\
\mathrm{HL}-5.1 \%\end{array}$ \\
\hline Temelli (1997) & Water & $85^{\mathrm{a}}$ & $10: 1$ & 0.5 & $40-55$ & HL-N-5.7\% \\
\hline Lazaridou et al. (2004) & Water & unknown & $10: 1$ & 2 & 52 & Not supplied \\
\hline Irakli et al. (2004) & Water & unknown & $8: 1$ & 2 & 47 & $\begin{array}{c}6 \text { different } \\
\text { commercial cultivars }\end{array}$ \\
\hline Li et al. (2006) & $\mathrm{NaOH}, 1 \mathrm{M}$ & unknown & $20: 1$ & 3 & 25 & Used wheat \\
\hline Izydorczyk et al. (2000) & Water & 52.7 & $10: 1$ & 0.5 & 25 & HL-W-6.9\% \\
\hline $\begin{array}{l}\text { Burkus and Temelli, } \\
\text { (1998) }\end{array}$ & $\begin{array}{l}\text { Several } \\
\text { Solvents }\end{array}$ & unknown & $12: 1$ & 0.5 & 55 & $\begin{array}{l}\text { HL-N-5.4\% } \\
\text { HL-W-7.0\% }\end{array}$ \\
\hline $\begin{array}{l}\text { Papageorgiou et al. } \\
\text { (2005) }\end{array}$ & Water & unknown & $10: 1$ & 2 & 50 & $\mathrm{H}-\mathrm{N}-4.0 \%$ \\
\hline Andersson et al. (1999) & Water & $53.3^{b}$ & $75: 1$ & 2 & 38 & $\begin{array}{l}\text { H-W-6.1\% } \\
\text { HL-W-5.6\% }\end{array}$ \\
\hline Oscarsson et al. (1996) & Water & $55.2^{\mathrm{b}}$ & $75: 1$ & 2 & 38 & $\begin{array}{l}\text { H-W-5.4\% } \\
\text { HL-W-5.8\% }\end{array}$ \\
\hline Bhatty et al. (1991) & Acidic Media & 44.7 & $10: 1$ & 1 & RT & HL-W-4.7\% \\
\hline \multirow{4}{*}{ Ahmad et al (2009) } & $1 \mathrm{M} \mathrm{NaOH}$ & $78.1^{d}$ & $7: 1$ & 1.5 & 55 & \multirow{4}{*}{$\begin{array}{c}\text { H-not reported } \beta \text { - } \\
\text { glucan content } \\
\text { (soluble dietary fibre } \\
2.86 \% \text { ) }\end{array}$} \\
\hline & $1 \mathrm{M}$ citric acid & $80.4^{d}$ & $7: 1$ & 1.5 & 55 & \\
\hline & water & $83.1^{d}$ & $10: 1$ & 1.5 & 55 & \\
\hline & $\begin{array}{l}\text { Water + } \\
\text { alpha } \\
\text { amylase }\end{array}$ & $81.4^{d}$ & NR & 3 & 40 & \\
\hline
\end{tabular}

a. $\beta$-glucan recovered after precipitation

b./c. Maximum obtained when using waxy hull-less barley

d. maximum $\beta$-glucan recovery. Shows the efficiency of purification process of $\beta$-glucan

KEY for barley column: H: Hulled; HL: Hull-less; W: Waxy; N: Normal genotype; the figure represents the content of $\beta$-glucan.

A more detailed revision of these works, with a deeper discussion of these variables is presented in chapter 1. 
Raw material pretreatments, previous to the $\beta$-glucan extraction, play an important role in the $\beta$-glucan recovery process. Physical treatments (such as milling and fraction selection) have been performed in order to fractionate the grain cereals to obtain one fraction already rich in $\beta$-glucan (Kiryluk et al, 2000; Flores et al, 2005). Yoon et al. 1995, have used these milling fractions for extraction with water, revealing differences in viscosity as function of the milling fraction. Fine grinding fractions produced higher viscosity and higher $\beta$-glucan content extracts than other fractions. One of the main conclusions of the milling works are that the nature of the grain (hulled or hulless) affected the milling process and the $\beta$-glucan distribution among the milling fractions, since it controls the hardness of the grain.

Irakli et al., 2004 introduced the pretreatments with ethanol to inactivate of the endogenous $\beta$-glucanases. Although the increase of molecular weight of extracted $\beta$-glucans has been reported, there is no any evidence about the effect of this treatment on the extraction yield. Other pretreatments that can be found in the literature, such as thermal treatments, were specially studied by Izydorczyk et al 2000. Some of the thermal treatments, such as grain steaming or roasting, did have an effect on the $\beta$-glucan recovery process and on the properties of the $\beta$-glucan liquid extracts, as viscosity profile was stabilized. Because the viscosity is a function of the $\beta$-glucan concentration and molecular weight these treatments can enhance the molecular weight of the $\beta$-glucan or improve the extraction yield or both simultaneously. According to these results, the effect of the pretreatments has to be evaluated over the extraction yield and the molecular weight of the extracted $\beta$-glucan.

Alternative extraction processes (different from stirred tank) to extract $\beta$-glucans from cereals are not reported in the literature. However processes such as Ultrasound Assisted Extraction show good properties related to the mass transfer improvement (lida et al, 2008). Despite these good properties, UAE has never been used to extract $\beta$-glucan from cereals. The use of ultrasounds to enhance extraction processes was extensively reviewed by Vilkhu et al, 2008. These authors summarized a significant amount of applications of this procedure for the extraction of different natural molecules (antioxidants, essential oils, polysaccharides...) from a wide variety of matrices. UAE is a potential method to extract $\beta$-glucans from cereals. In the literature there is only one attempt to the use of ultrasounds for the $\beta$-glucan recovery: Izydorczyk et al. 2000 used ultrasounds as a pretreatment; after the sonication of barley a conventional extraction process was carried out. Extraction was improved; nevertheless the energy used was not quantified, and no parameter study was performed. 
Another potential alternative method for the $\beta$-glucan extraction from cereals is the use of Pressurized Hot Water (PHW) as solvent, as probes the huge number of works that claim to use PHW to extract high added value compounds (bioactive and nutraceuticals, essential oils, lipids, carotenoids, proteins, polysaccharides) from plants or food matrixes (Kronholm et al, 2007; Teo et al, 2010; Mustafa and Turner, 2010). More specifically PHW has been used in a few works to extract polysaccharides from natural matrix: Ho et al, 2007 extracted lignans, proteins and carbohydrates from flaxseed meal; Buranov and Mazza, 2010 extracted hemicelluloses from flax shives; Askin et al. 2010 extracted (1-3),(1-6)- $\beta$-D-glucans from Ganoderma lucidum fungus; Cacace and Mazza 2006 used PHW to extract lignans from whole flaxseed; Hata et al, 2008 focused their research in the extraction of total sugars, proteins and antioxidant activity from defatted rice bran and Song et al, 2011 extracted hemicelluloses from spruce woods. PHW term refers to the water in liquid state in the range $100^{\circ} \mathrm{C}$ (boiling point) to $374^{\circ} \mathrm{C}$ (critical point) by the application of pressure; the change in temperature and pressure induces changes in the physical properties of the water (i.e. density, viscosity or surface tension) that affect the mass transfer properties and weakens the hydrogen bonds between the polysaccharide and the matrix.

Finally, once the $\beta$-glucans have been extracted it is necessary to separate them from other species that are inevitably co-extracted (such as proteins or starch). Starch has been traditionally treated with $\alpha$-amlyase at temperatures around $90-95^{\circ} \mathrm{C}$. Table 2 summarizes the main attempts to get rid of the dissolved starch, but in any of the works shown in this table the concentration of starch in the solution after the extraction is reported. As a basis for the development of purification processes it is required to know the concentrations of the other species that go with the $\beta$-glucan in the liquid extracts. 
Table 2. Enzyme and hydrolysis conditions used by other researchers to remove starch in the $\beta$-glucan purification process

\begin{tabular}{|c|c|c|c|}
\hline Researcher & Enzyme & Dose $(\mu \mathrm{L} / \mathrm{mL}$ extract) & Hydrolysis conditions \\
\hline Bhatty (1993) & Termamyl & 10 & $96^{\circ} \mathrm{C}, 1 \mathrm{~h}$ \\
\hline Bhatty (1995) & Termamyl 120L & 1 & $96^{\circ} \mathrm{C}, 1 \mathrm{~h}, \mathrm{pH} 6.5,70 \mathrm{ppm} \mathrm{CaCl}$ \\
\hline Temelli (1997) & No enzyme was used & - & - \\
\hline Burkus, Temelli (1998) & Termamyl 120LN & NR & NR \\
\hline Izydorczyk et al. (1998) & $\begin{array}{l}\alpha \text {-amylase (porcine } \\
\text { pancreas-SIGMA) }\end{array}$ & NR & $35^{\circ} \mathrm{C}, 24 \mathrm{~h}, \mathrm{pH} 6.5$ \\
\hline Izydorczyk et al. (2000) & $\alpha$-amylase & $40 \mathrm{U} / \mathrm{ml}$ & NR \\
\hline Lazaridou et al. (2004) & Termamyl 120L & 10 & $95^{\circ} \mathrm{C}, 3 \mathrm{~h}, \mathrm{pH} 4.5$ \\
\hline Irakli et al. (2004) & Termamyl & 7 & $90^{\circ} \mathrm{C}, 2 \mathrm{~h}, \mathrm{pH} 5.0$ \\
\hline Papageorgiou et al. (2005) & Termamyl 120L & NR & $90^{\circ} \mathrm{C}, 3 \mathrm{~h}, \mathrm{pH} 4.5$ \\
\hline Li et al. (2006) & $\begin{array}{l}\text { Thermal stable } \\
\text { amylase }\end{array}$ & $12,5 \% w / w$ & $90^{\circ} \mathrm{C}, 30 \mathrm{~min}, \mathrm{pH} 6.5-7.0$ \\
\hline Knutsen et al. (2007) & Termamyl & 6 & $100^{\circ} \mathrm{C}, 2$ hours \\
\hline Lazaridou et al. (2008) & $\begin{array}{c}\alpha \text {-amylse (porcine } \\
\text { pancreas-SIGMA) }\end{array}$ & $100 U$ & $\begin{array}{l}35^{\circ} \mathrm{C} \text {, all night, } \mathrm{pH} 6.5,100 \mathrm{mM} \\
\mathrm{CaCl}_{2}\end{array}$ \\
\hline
\end{tabular}

As it can be seen in table 2, starch hydrolysis is done at higher temperature than the extraction step, lasting from 1 to 3 hours. The oligosaccharides and small molecules present in the solution must be separated from the high molecular weight $\beta$-glucan. Some authors have used dialysis: Lazaridou et al., (Lazaridou et al. 2004), Irakli et al. (Irakli et al., 2004) dialyzed the liquid extract for 3 days; Knutsen and Holtekjølen (Knutsen and Holtekjølen, 2007), dialyzed the sample with 12kDa cut-off semipermeable membrane; Izydorczyk et al. (Izydorczyk et al., 2000) performed an extensive dialysis on the extract to perform this separation. Dialysis is a traditional method for removing microsolutes from solutions; however it is a transport diffusion-controlled process (based on differences in concentrations between two solutions) and intensive in time and economical resources consumption. Other processes based on the membrane technology (such as ultrafiltration or diafiltration) must be considered, in order to provide simple and economically more favorable processes to recover $\beta$-glucans from cereals. As far as the author's knowledge, there is only one published paper where UF is used to recover $\beta$-glucans from a solution (Patsioura et al, 2011). In this work the operation mode was studied together with the effect of the membrane material and the concentration of the feeding solution. According to those authors, polysulfone membrane, transmembrane pressure $\leq 2$ bar and $\beta$-glucan concentrations below $0.6 \mathrm{~g} / \mathrm{L}$ were the optimal conditions to apply the UF to recover $\beta$-glucans. 
The literature review, extensively done and shown in chapters 1 to 7 of this thesis, and summarized in the previous paragraphs, shows that $\beta$-glucan have been traditionally extracted from cereals with water at ambient pressure using stirred tanks, but there are other processes that can be potentially used to extract $\beta$-glucans improving mass transfer and reducing time and energy consumptions (process intensification). Moreover, a critical analysis of the previous published works, regarding to the $\beta$-glucan recovery processes, reveals the need of a research work in which the mechanisms (mass transfer) that control the extraction of $\beta$-glucan and the interactions between the factors affecting the extraction process are studied. The knowledge about mass transfer mechanism and solubility will lead to the understanding of the $\beta$-glucan extraction mechanisms and to the development of new processes to obtain tailor-made $\beta$ glucan concentrates (controlled molecular weight) that can be used as food additive or in high value formulation processes. Finally, in order to develop a high scale production of $\beta$-glucan concentrates, the consumption of energy in the different processes proposed must be evaluated. All these needs regarding the $\beta$-glucan extraction processes detected after the literature review, are faced in this thesis. 
The AIM OF THIS WORK is to make studies in order to develop an efficient process to produce concentrates rich in controlled molecular weight $\beta$-glucans, using cereals as raw material. It is expected to obtain high molecular weight $\beta$-glucans that can be used as food additive and to obtain low molecular weight $\beta$-glucans to be used in active compounds formulation processes.

In order to accomplish the aforementioned aim, the following partial objectives have been established:

- Selection of the raw material.

- To develop processes to obtain milling fractions differing in the particle size and the composition.

- To develop processes to obtain various molecular weight $\beta$-glucans concentrates according to the final use, based on the raw materials and milling fractions selected.

- To develop efficient $\beta$-glucan extraction processes, evaluated in terms of extraction yield, molecular weight of the extracted $\beta$-glucan and specific energy consumed:

- To study the process parameters (temperature, $\mathrm{pH}$, particle size, stirring rate, solvent to solid ratio) in a conventional extraction process (stirred tank) and to propose a set of extraction conditions that maximize the extraction yield. To quantify the effect that the proposed extraction conditions have on the molecular weight.

- To develop extraction processes that enhance the mass transfer and led to the intensification of the $\beta$-glucan extraction process:

- Ultrasound assisted extraction: study of the process parameters (amplitude, cycle and time) and their effect on the molecular weight and extraction yield as a function of the specific energy consumed in the extraction process.

- Pressurized hot water extraction: to develop batch and semicontinuous (fixed-bed) extraction processes using PHW as solvent.

- To study the purification and isolation of the extracted $\beta$-glucan: 
- To study the removal of the co-extracted starch by means of enzymes amylases. To study the effect that temperature, incubation time and enzyme dose have on the removal efficiency of the starch and on the molecular weight of the $\beta$-glucan.

- To study alternative purification processes that involve an intensification of the purification stage.

- To separate the starch hydrolysis products (low molecular weight) from the solution that contains the high molecular weight $\beta$-glucan by means of a membrane process (ultrafiltration - diafiltration)-

- To concentrate/isolate the high purity $\beta$-glucans by means of antisolvents (precipitation) or by means of spray drying. 
This thesis work has been divided in 7 chapters: in each of them it is faced the aforementioned challenges and objectives. In each chapter an extensive literature review was done in order to know the state of the art. The main contents of each chapter are described below.

This $\mathrm{PhD}$ thesis has started in the frame of a research project financed by the regional government in order to upgrade the cultivar of barley in the region of Castilla y León (Spain) by the extraction of an important biopolymer ( $\beta$-glucan) with a potential use as food ingredient. The literature review performed at the beginning of the PhD work has revealed that most of the papers were focused on oat as raw material, and most of the papers were related to rheological properties of $\beta$-glucans and their role in diet and health. Water or alkali were used as solvents for the extraction, and the whole process consisted always in a large number of steps performed in stirred tanks, time consuming, with important divergences on experimental results and with limited extraction efficiencies. Most of the works used the conditions published by Wood et al. $(1978,1989)$ for oat at a laboratory scale. This literature review showed the lack of a process engineering work of the whole process, from the grain to the dry concentrated product, and this was therefore, the main starting point of this $\mathrm{PhD}$ thesis.

In chapter 1 , “OPTIMIZATION OF THE $\beta$-glUCAN EXTRACTION CONDITIONS FROM DIFFERENT WAXY BARLEY CULTIVARS", the effect of operational variables (temperature, $\mathrm{pH}$, particle size, solvent: flour ratio, stirring rate and extraction time) on the extraction was studied by using a conventional extractor (stirred tank) and optimized in order to maximize the extraction yield. Although in principle those operational variables do not affect the molecular weight of the extracted $\beta$ glucans, the selection of a suitable pretreatment (selection of milling fraction and/or $\beta$ glucanases deactivation) is a key point to extract $\beta$-glucans with high molecular weight, that otherwise, they are the most desirable products as food ingredients. The study of these pretreatments is described in Annexes I and II. Results obtained in this chapter revealed that extraction is limited by mass transfer, since diffusion and stirring are the most influent parameters and long extraction times ( 3 hours) are needed to maximize extraction yield. The co-extraction and gelatinization of starch limits the extraction temperature and therefore the dissolution of $\beta$-glucans with high molecular weight.

In chapter 2, "Ultrasound-Assisted Extraction of $\beta$-Glucans from Barley", an alternative process to extract $\beta$-glucans from barley has been studied to overcome the mass transfer limitations found in the conventional batch operation in the stirred tank. In this case, $\beta$-glucans have been extracted by means of ultrasounds where the phenomenon of cavitation produces intense shear forces and changes in the physical properties that permit the solvent to 
penetrate deeper in the solid, increasing the diffusion rate of $\beta$-glucans to the solvent. Ultrasound assisted extraction (UAE) is affected by the amplitude of oscillation, pulses and time, indeed, the energy that effectively is deliver to the extraction mass. Those operational variables have been studied in the case of UAE and their effect on extraction effect and molecular weight is deeply discussed in this chapter. UAE supposes a real intensification of the extraction process in terms of operational time reduction, but maximum extraction yield is still below $70 \%$. Because $\beta$-glucans are minor components of the barley grain, extraction efficiency must be increased in order to make a competitive process at an industrial scale. Solubility of high molecular weight $\beta$-glucans can be improved with temperature, and for this purpose, pressurized hot water (PHW), liquid water in the range 100 to $190^{\circ} \mathrm{C}$, has been used as solvent

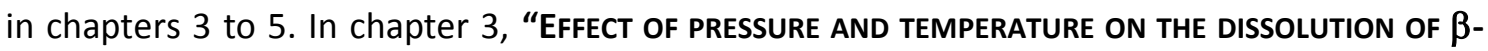
glucan in Pressurized Hot Water" the dissolution of $\beta$-glucans and starch in PHW has been studied, in order to select the range of operational variables (temperature, pressure and time) and limit the hydrolysis of the $\beta$-glucans. In chapter 4 , “Pressurized HOT WATER EXTRACTION OF $\beta$ GLUCANS FROM WAXY BARLEY", $\beta$-glucans have been extracted from barley using PHW in a pressurized vessel (operation mode: batch). The effect of extraction time, temperature and pressure on the extraction yield and molecular weight of the extracted $\beta$-glucan has been studied. Two opposite phenomenon must be controlled in this process, the $\beta$-glucan solubilization from the solid matrix and the hydrolysis of the $\beta$-glucans in order to preserve the molecular weight. Experimental results have revealed that it is possible to extract high molecular weight $\beta$-glucans by using PHW as solvent by controlling the hydrolysis and more precisely the severity factor (combination of temperature and time). Moreover, PHW deactivate $\beta$-glucanases without the need of any pretreatment. In order to improve this process for scaling-up, and to extend this process to other raw materials, in chapter 5, "FIXEDBed extraction of $\beta$-glucan from Cereals by means of Pressurized Hot Water", a flow process was used to extract $\beta$-glucans from different cereals: barley, wheat bran and de-starched barley. Extraction was done in a fixed-bed extractor (operation mode: semi-continuous), and PHW flowrate, operation time and temperature have been studied in this flow operations, and results are discussed in terms of extraction yield and molecular weight, leading to efficiencies of $87 \%$.

The purification and isolation step was studied in chapter 6: "PURIFICATION AND ISOLATION OF $\beta$-GLUCANS FROM BARLEY: DOWNSTREAM PROCESS INTENSIFICATION". In this chapter the removal of the co-extracted starch by enzymatic hydrolysis has been studied. Enzyme dosing, pH, temperature and incubation time have been optimized for starch removal from the aqueous 
extracts. Starch hydrolysis products (dextrins, and simpler sucroses) must be removed from the extract before $\beta$-glucan concentration, and this step has been successfully performed by a membrane process (ultrafiltration - diafiltration), and results are presented in chapter 6 . The next step is solvent removal ( $\beta$-glucan concentration) that has been performed by alcoholic precipitation (antisolvent) or spray drying. Operational conditions have been studied for the both concentration processes.

The process engineering point of view of this $\mathrm{PhD}$ thesis has been concluded by a final chapter (number 7), "Evaluation of the $\beta$-glucan extraction intensification from barley: energy BALANCES OF DIFFERENT EXTRACTION PROCEDURES" where a comparison between the different extraction processes (stirred tank, ultrasound assisted extraction and batch PHW extraction was done) in terms of intensive energy consumption ( $\mathrm{kW} \cdot \mathrm{h}$ per gram of extracted $\beta$-glucan) has been carried out. This intensive parameter is a tool to show the viability of each process and its scaling-up. 


\section{REFERENCES USED IN THIS SECTION}

Ahmad, A., Anjum, F.M., Zahoor, T.; Nawaz, H., Din, A. 2009. Physicochemical and functional properties of barley $\beta$-glucan as affected by different extraction procedures. International Journal of Food Science and Technology 44, 181-187

Andersson, A.A.M., Elfverson, C., Andersson, R., Regner, S., Aman, P., 1999. Chemical and physical characteristics of different barley samples. Journal of the Science of Food and Agriculture 79, 979-986.

Askin R., Sasaki M., Goto M. 2010. Recovery of water soluble compounds from Ganoderma lucidum by hydrothermal treatment. Food and Bioproducts Processing 88, 291-297

Baik, B.K., Ullrich, S.E. 2008. Barley for food: characteristics, improvement, and renewed interest. Review. Journal of Cereal Science 48, 233-242

Bhatty, R.S., 1993. Extraction and Enrichment of (1-3),(1-4)- $\beta$-D-Glucan from Barley and Oat Brans. Cereal Chemistry 70(1), 73-77.

Bhatty, R.S., 1995. Laboratory and pilot plant extraction and purification of $\beta$-glucans from hull-less Barley and oat brans. Journal of Cereal Science 22, 163-170.

Bhatty, R.S., McGregor, A. W., Rossnagel, B.G., 1991. Total and acid-soluble $\beta$-glucan content of hulless barley and its relationship to acid-extract viscosity. Cereal Chemistry 68(3), 221-227.

Brennan, C. S., Cleary, L. J. (2007). Utilisation Glucagel ${ }^{\circledR}$ in the $\beta$-glucan enrichment of breads: A physicochemical and nutritional evaluation. Food Research International 40(2), 291-296

Buranov, A.U., Mazza, G. 2010. Extraction and characterization of hemicelluloses from flax shives by different methods. Carbohydrate Polymers 79, 17-25

Burkus, Z., Temelli, F. (1998).Effect of extraction conditions on yield, composition, and viscosity stability of barley $\beta$-glucan gum. Cereal Chemistry 75(6),805-809

Burkus, Z., Temelli, F., 1998. Effect of extraction conditions on yield, composition, and viscosity stability of barley $\beta$-glucan gum. Cereal Chemistry 75(6), 805-809.

Cacace J.E., Mazza G. (2006). Pressurized low polarity water extraction of lignans from whole flaxseed, Journal of Food Engineering 77, 1087-1095.

Cui, S.W., Wang, Q., Zhang, M. 2011. Chapter 11: $\beta$-glucans. Renewable Resources for Functional Polymers and Biomaterials. The Royal Society of Chemistry, 319-345. 
EFSA Panel on Dietetic Products, Nutrition and Allergies (2010). Scientific Opinion on the substantiation of a health claim related to oat beta-glucan and lowering blood cholesterol and reduced risk of (coronary) heart disease pursuant to Article 14 of Regulation (EC) No 1924/2006. EFSA Journal, 8[12] (2010) 1885.

FDA, 21 CFR Part 101: Food labeling, health claims; soluble dietary fiber from certain foods and coronary heart disease. Federal Register 70[246] (2005) 76150-76162.

Flores, R.A., Hicks, K.B., Eustace, D.W., Phillips, J. 2005. High-starch and high $\beta$-glucan barley fractions milled with experimental mills. Cereal Chemistry 82(6), 727-733

Hata S., Wiboonsirikul J., Maeda A., Kimura Y., Adachi S. (2008). Extraction of defatted rice bran by subcritical water treatment, Biochemical Engineering Journal 40, 44-53

Ho, C.H.L., Cacace, J.E., Mazza, G. 2007. Extraction of lignans proteins and carbohydrates from flaxseed meal with pressurized low polarity water. LWT-Food Science and Technology 40, 1637-1647

lida, Y., Tuziuti, T., Yasui, K., Towata, A., \&Kozuka, T. 2008. Control of viscosity in starch and polysaccharide solutions with ultrasound after gelatinization. Innovative Food Science and Emerging Technologies, 9, 140-146

Irakli, M., Biliaderis, C.G., Izydorczyk, M.S., Papadoyannis, I.N., 2004. Isolation, structural features and rheological properties of water-extractable $\beta$-glucans from different Greek barley cultivars. Journal of the Science of Food and Agriculture 84, 1170-1178.

Izydorczyk M. S., Storsley, J., Labossiere D., MacGregor A. W., Rossnagel B.G., 2000. Variation in total and soluble $\beta$-glucan content in hulless barley: effects of thermal, physical and enzymic treatments. Journal of Agricultural and Food Chemistry 48, 982-989.

Izydorczyk, M.S.,Macri, L.J.,MacGregor, A.W. (1998). Structure and physicochemical properties ofbarley non-starch polysaccharides-I. Water extractable $\beta$-glucans and arabinoxylans. Carbohydrate Polymers 35, 249-258

Jacobs, M. S., Izydorczyk, M. S., Preston, K. R., Dexter, J. E. 2008. Evaluation of baking procedures and wheat flours for incorporation of high dietary fibre barley fractions into bread. Journal of the Science of Food and Agriculture 88, 558-568.

Kiryluk, J., Kawka, A., Gasiorowski, H., Chalcarz, A., Aniola, J., 2000. Milling of barley to obtain $\beta$-glucan enriched products. Nahrung 44(4), 238-241. 
Knutsen, S.H., Holtekjølen, A.K. 2007. Preparation and analysis of dietary fiber constituents in wholegrain from hulled and hull-less barley. Food Chemistry 102, 707-715

Kronholm, J., Hartonen, H., Riekkola, M.L. 2007. Analytical extraction with water at elevated temperatures and pressures, Trends in analytical Chemistry 26, 396-411

Laroche, C., Michaud, P. 2007. New developments and prospective applications for $\beta-(1,3)$ glucans. Recent Patents on Biotechnology 1, 59-73.

Lazaridou, A., Biliaderis, C.G., Micha-Screttas, M., Steele, B.R., 2004. A comparative study on structure-function relations of mixed- linkage (1-3), (1-4) linear $\beta$-D-glucans. Food Hydrocolloids $18,837-855$.

Lazaridou, A.,Chornick, T.,Biliaderis, C.G., Izydorczyk, M.S. 2008. Sequential solvent extraction and structural characterization of polysaccharides from the endosperm cell walls of barley grown in different environments. Carbohydrate Polymers 73, 621-639

Li, W., Cui, S.W., Kakuda, Y., 2006. Extraction, fractionation, structural and physical characterization of wheat $\beta$-D-glucans. Carbohydrate Polymers $63,408-416$.

Mustafa, A., Turner, C. 2010. Pressurized liquid extraction as a green approach in food and herbal plants extraction: A review. AnalyticaChimica Acta 703, 8-18

Oscarsson, M., Andersson, R., Salomonsson, A.C., Aman P., 1996. Chemical Composition of Barley Samples Focusing on Dietary Fibre Components. Journal of Cereal Science 24, 161-170.

Papageorgiou, M., Lakhdara, N., Lazaridou, A., Biliaderis, C.G., Izydorczyk, MS., 2005. Water extractable (1-3,1-4)- $\beta$-D-glucans from barley and oats: An intervarietal study on their structural features and rheological behaviour. Journal of Cereal Science 42(2), 213-224.

Patsioura, A., Galanakis, C.M., Gekas, V. 2011. Ultrafiltration optimization for the recovery of $\beta$-glucan from oat mill waste. Journal of Membrane Science $373,53-63$

Saulnier, L., Gévaudan, S., Thibault, J.F., 1994. Extraction and partial characterisation of $\beta$ glucan from the endosperms of two barley cultivars. Journal of Cereal Science 19, 171-178

Symons, L.J., Brennan, C.S. 2004. The physicochemical and nutritional evaluation of wheat breads supplemented with (1-3),(1-4)- $\beta$-D-glucan rich fractions from barley. Journal of Food Science 69(6), 463-467 
Song T., Pranovich A., Holmbon B. 2011. Effects of pH control with phthalate buffers on hotwater extraction of hemicelluloses from spruce wood. Bioresource Technology 102, 1051810523

Temelli, F., 1997. Extraction and functional properties of barley $\beta$-glucan as affected by temperature and pH. Journal of Food Science 62(6), 1194-1197

Teo, C.C., Tan, S.N., Hong Yong, J.W., Hew, C.S., Ong, E.S. 2010. Pressurized hot water extraction (PHWE).Review. Journal of Chromatography A 1217, 2484-2494

Vilkhu, K., Mawson, R., Simons, L., Bates, D. (2008). Applications and opportunities for ultrasound assisted extraction in the food industry - A review. Innovative Food Science and Emerging Technologies 9, 161-169

Wood, P. J., Siddiqui, I. R., Paton, D., 1978. Extraction of high-viscosity gums from oats. Cereal Chemistry 55, 1038-1049

Wood, P. J., Weisz, J., Fedec, P., Burrows, V. D., 1989. Large-scale preparation and properties of oat fractions enriched in (1-3)(1-4)- $\beta$-D-glucan. Cereal Chemistry 66(2), 97-103

Yoon, S.H., Berglund, P.T., Fastnaught, C.E. 1995. Evaluation of selected barley cultivars and their fractions for $\beta$-glucan enrichment and viscosity. Cereal Chemistry 72(2), 187-190 



\section{ChAPTER 1}

\section{Optimization of the $\beta$-glucan}

extraction conditions from different waxy barley cultivars 



\title{
Optimization of the $\beta$-glucan extraction conditions from different waxy barley cultivars ${ }^{1}$
}

\begin{abstract}
The purpose of this work is to provide a complete and systematic study of the influence of several operational parameters on the aqueous extraction of $\beta$-glucan from barley, and to find an optimal combination of factors that maximize the extraction yield. Temperature, $\mathrm{pH}$, extraction time, particle size, stirring rate and solvent:flour ratio were identified as the critical factors affecting the extraction process. Preliminary experiments were useful to set the extraction temperature at $55^{\circ} \mathrm{C}$ (the maximum extractability of $\beta$-glucan below gelatinization temperature of starch), and $\mathrm{pH}$ close to neutrality. In order to determine the optimal combination of the other four factors, a Taguchi experimental design approach was used: four variables (three levels each one) in $L_{9}$ orthogonal array. Nine different trials were conducted in duplicate for two different waxy barley cultivars: D24 (hulled; 6.02\% $\beta$-glucan) and H13 (hulless; $4.64 \% \beta$-glucan). The optimal conditions obtained from the signal to noise ratio analysis were: particle size, $100 \mu \mathrm{m}$; solvent:flour ratio equal to 5; stirring rate, $1000 \mathrm{rpm}$ and extraction time, 3 hours. The confirmatory experiment conducted in the optimal conditions provided an extraction yield of $73.4 \pm 1.2 \%$ for barley D24 and $62.3 \pm 1.8 \%$ for $\mathrm{H} 13$, being valid these conditions regardless the composition of the used barley.
\end{abstract}

Keywords: $\beta$-glucan extraction, barley, experimental design

Abbreviations: Ad.: Dimensionless; $\beta$-glucan: $(1 \rightarrow 3),(1 \rightarrow 4)-\beta$-D-glucan; DB: Dry matter Basis

\footnotetext{
${ }^{1}$ Journal of Cereal Science 53 (2011), 271-276
} 


\section{INTRODUCTION}

$\beta$-glucans are non-starchy polysaccharides composed of $(1 \rightarrow 3),(1 \rightarrow 4)$ mixed linked glucose units. They are located mainly in the cell walls of the endosperm and the aleurone layer of different cereal grains, specially oats and barleys (Irakli et al., 2004). In general, $\beta$-glucans are a major component of the soluble dietary fibre and they influence the nutritional values and functional properties of food. In that sense, several studies (Newman et al., 1989) have revealed that $\beta$-glucans are involved in the hypocholesterolaemic properties of oat and barley foods. Although the mechanism is not fully understood, the hypocholesterolaemic properties seem to result from the increased intestinal viscosity created by the $\beta$-glucan (Bengtsson et al., 1990). Recently, the FDA (Food and Drug Administration, USA) has included $\beta$-glucans in the list of products that contribute to cholesterol diminution in blood, and it has also indicated how to label the products that contain these polymers, in order to point up the positive effects on human health (Baik et al., 2008). High intakes of cereal fibre (or whole grain) also seem to diminish the coronary heart disease, diabetes (Lu et al., 2004) and risk of cancer (Han et al., 2004). New cultivars, such as waxy barley, are therefore focused on obtaining barley with high $\beta$-glucan content, which can be introduced into human cereal-based food. In this sense, this represents an opportunity for agriculture-based economics.

As $\beta$-glucan is a minor component (3-7\%) of barley grains, it is necessary to develop a procedure for its isolation and concentration. Although the amount of procedures reported in literature is large, all of them can be grouped in two categories as it is suggested by Vasanthan et al. (2008): those experiments carried out in dry conditions, and those performed in wet conditions. Dry processing technologies include dry milling and sieving techniques (Kiryluk et al., 2000), achieving a final product that contains a $15.2 \%$ in $\beta$-glucan, as the best result, and dry milling and air classification (Vasanthan and Bhatty, 1995). Wet procedures are more complex, since they involve at least two or three stages (Brennan, 2005): cereal bran or flour is used as raw material, which is put in contact with a solvent (usually water, aqueous solvent at basic $\mathrm{pH}$ or semi-alcoholic solution), obtaining an aqueous extract as a result. This aqueous extract contains other species apart from $\beta$-glucan (such as starch, proteins and fats), making necessary a purification step. For this purpose, $\beta$-glucans are precipitated by addition of an alcohol as anti-solvent, or separated by other procedures, for instance freezing-thawing the extract (Morgan, 1998). The precipitate obtained in this way, once isolated and dried, results in a product that contains from 20 to $70 \%$ of $\beta$-glucan. 
Wet techniques have been traditionally followed, as proves the large amount of results reported. Usually, researchers have used as basis for their experiments the conditions published by Wood et al. $(1978,1989)$ for oat. Since then, extraction conditions have been repeatedly modified in order to enhance the final extraction yield. Due to the wide range in operational conditions and the differences in the cereal raw material used by authors in the literature, it is very difficult to compare the published results being, sometimes, contradictory. According to literature, temperature, $\mathrm{pH}$, extraction time, solvent:flour ratio and solvent have been identified as the critical parameters on the $\beta$-glucan extraction performance. In most papers, particle size distribution of flour has not been considered and stirring rate effect has never been studied. The most remarkable operational conditions used by researchers, and the main characteristics of the tested barleys, are presented in table 1. Important differences can be observed, revealing the need of an appropriate study of the extraction variables, suitable for all varieties of barley. Moreover, as far as authors' knowledge, an experimental design approach (for instance Taguchi's methodology) to study the optimization of operational variables in the $\beta$-glucan extraction process has never been published.

All in all, the purpose of this work has been to provide a complete and systematic study of the influence of several operational parameters on the aqueous $\beta$-glucan extraction from barley, and to find an optimal combination of factors that maximize the extraction yield. Temperature, $\mathrm{pH}$, extraction time, particle size, stirring rate and solvent:flour ratio, have been studied in this work for two different barley cultivars, both of them waxy type: D24 (hulled; 6.02\% $\beta$-glucan) and $\mathrm{H} 13$ (hulless; 4.64\% $\beta$-glucan). A Taguchi experimental design approach has been followed. One of the key points of this methodology is to design a process robust against uncontrollable environmental changes (also known as noise factors). One uncontrollable factor affecting this extraction process is the composition of barley, which can vary for either genetic or environmental reasons (Baik, 2008). By using this methodology, the conditions found as optimal could be applied regardless the composition of barley. 
Table 1. Operating conditions used by other researchers in the aqueous extraction of $\beta$-glucan from barley

\begin{tabular}{|c|c|c|c|c|c|c|}
\hline Researcher & Solvent & $\begin{array}{l}\text { Max Ext } \\
\text { Yield (\%) }\end{array}$ & s:f ratio & $\begin{array}{l}\text { Ext time } \\
\text { (h) }\end{array}$ & $\mathrm{T}\left({ }^{\circ} \mathrm{C}\right)$ & Barley \\
\hline \multirow{3}{*}{ Bhatty (1993) } & $\begin{array}{l}\text { Water, } \\
\text { pH } 10\end{array}$ & 61 & $10: 1$ & 0.5 & 45 & \multirow{3}{*}{$\begin{array}{l}\text { HL-N-4.5\% } \\
\text { HL-W-11.3\% }\end{array}$} \\
\hline & $\begin{array}{c}\text { Water, } \\
\mathrm{pH} 7\end{array}$ & 72 & $10: 1$ & \multicolumn{2}{|c|}{$\begin{array}{c}\text { Sequential:40, } 65 \text { and } \\
95\end{array}$} & \\
\hline & $\mathrm{NaOH}, 4 \%$ & 81 & $50: 1$ & 18 & Ambient & \\
\hline Bhatty (1995) & $\mathrm{NaOH}, 1 \mathrm{~N}$ & $73-77$ & $50: 1$ & 1 & Ambient & $\begin{array}{c}\text { HL-N-5.6\% } \\
\text { HL-W-11.3\% }\end{array}$ \\
\hline Saulnier (1994) & Water & $\begin{array}{c}16.6 \\
34\end{array}$ & $6: 1$ & & 40 & $\begin{array}{l}\mathrm{HL}-4.7 \% \\
\mathrm{HL}-5.1 \%\end{array}$ \\
\hline Temelli (1997) & Water & $85^{\mathrm{a}}$ & $10: 1$ & 0.5 & $40-55$ & HL-N-5.7\% \\
\hline Lazaridou et al. (2004) & Water & unknown & $10: 1$ & 2 & 52 & Not supplied \\
\hline Irakli et al. (2004) & Water & unknown & $8: 1$ & 2 & 47 & $\begin{array}{c}6 \text { different } \\
\text { commercial cultivars }\end{array}$ \\
\hline Li et al. (2006) & $\mathrm{NaOH}, 1 \mathrm{M}$ & unknown & $20: 1$ & 3 & 25 & Used wheat \\
\hline Izydorczyk et al. (2000) & Water & 52.7 & $10: 1$ & 0.5 & 25 & HL-W-6.9\% \\
\hline $\begin{array}{l}\text { Burkus andTemelli, } \\
\text { (1998) }\end{array}$ & $\begin{array}{l}\text { Several } \\
\text { Solvents }\end{array}$ & unknown & $12: 1$ & 0.5 & 55 & $\begin{array}{l}\text { HL-N-5.4\% } \\
\text { HL-W-7.0\% }\end{array}$ \\
\hline $\begin{array}{l}\text { Papageorgiou et al. } \\
(2005)\end{array}$ & Water & unknown & $10: 1$ & 2 & 50 & $\mathrm{H}-\mathrm{N}-4.0 \%$ \\
\hline Andersson et al. (1999) & Water & $53.3^{b}$ & $75: 1$ & 2 & 38 & $\begin{array}{l}\text { H-W-6.1\% } \\
\text { HL-W-5.6\% }\end{array}$ \\
\hline Oscarsson et al. (1996) & Water & $55.2^{\mathrm{b}}$ & $75: 1$ & 2 & 38 & $\begin{array}{l}\text { H-W-5.4\% } \\
\text { HL-W-5.8\% }\end{array}$ \\
\hline Bhatty et al. (1991) & Acidic Media & 44.7 & $10: 1$ & 1 & RT & HL-W-4.7\% \\
\hline
\end{tabular}

a. $\beta$-glucan recovered after precipitation

b./c. Maximum obtained when using waxy hull-less barley

KEY for barley column: H: Hulled; HL: Hull-less; W: Waxy; N: Normal genotype; the figure represents the content of $\beta$-glucan. 


\section{MATERIALS AND METHODS}

\subsection{Raw material}

Two barley cultivars, both of them waxy type, have been used in this work. The variety H13 (commercially known as GALIS) is a hull-less barley with a $\beta$-glucan content of $4.64 \pm 0.16 \%$ and a $58.5 \pm 3.6 \%$ of starch, whereas the variety D24 (commercially designed as FIALI) is a hulled barley with higher content in $\beta$-glucans $(6.02 \pm 0.37 \%)$ and lower starch content $(50.3 \pm 3.2 \%)$.

These grains were provided by the ITACyL (Instituto Tecnológico Agrario de Castilla y León; Valladolid, Spain), selected from a larger number of barley varieties that have been developed and grown by themselves in the region of Castilla y León. Both of them correspond to a genetic modification and mixture of the Merlin and Volga barley varieties, and they belong to the 2006 harvests.

\subsection{Experimental Section}

\subsubsection{Extraction procedure}

General procedure for the $\beta$-glucan extraction is described below: $25 \mathrm{~g}$ of the desired particle size flour were suspended in the required amount of water to reach the suitable solvent:flour ratio in a jacked glass reactor (1litre, Afora, Spain). Temperature was kept constant (at the desired value) by means of a heating bath (Lauda Ecoline Staredition E100, Lauda, Germany), while solid-liquid mixture was suspended by means of mechanical stirring (Heidolph RZR2021 stirrer, Germany). After the desired extraction time, the resultant mixture was centrifuged (Kubota 5100, Japan) for $10 \mathrm{~min}$ at $5500 \mathrm{rpm}$. Solid material was separated and dried overnight at $105^{\circ} \mathrm{C}$ (JP Selecta mod.381, oven), being stored in a sealed plastic tube until the moment of being analysed.

\subsection{2. $\beta$-glucan solubility determination}

The solubility of $\beta$-glucans has been determined to be compared with the amount of $\beta$-glucan extracted from barley flours. Solubility represents the maximum amount of $\beta$-glucan that can be dissolved in water to form a homogenous solution under controlled conditions of temperature, pressure and molecular weight of the polymer. Generally the highest solubility values were achieved with the lowest molecular weight of $\beta$-glucans. In this work, a $40 \mathrm{kDa}$ molecular weight standard, from Megazyme International Ltd. (Ireland), has been used for the determination of $\beta$-glucan solubility. This molecular weight is comparable to that obtained from barley $\mathrm{H} 13$ and D24 in this work (see section 3.1.1). In the solubility tests, 1 gram of this 
standard was initially added to $150 \mathrm{ml}$ of distilled water, and stirred at the desired temperature. After 5 hours, liquid was centrifuged (5500rpm, 10min) to remove not-dissolved $\beta$-glucan. $\beta$-glucan concentration was then measured in the supernatant using the Megazyme assay kit, following a suitable modification of the general procedure. The concentration was expressed as "g of $\beta$-glucan/100g of solution".

\subsection{Chemical analysis}

$\beta$-glucan and starch analysis were conducted using the $\beta$-glucan enzymatic assay kit "Mixedlinkage beta-glucan" and "Total Starch", respectively, both of them supplied by Megazyme International Ltd., Ireland. Determination of these two species was done in the exhausted barley recovered after the extraction. The efficiency of the extraction process at different conditions was evaluated in terms of extracted $\beta$-glucan according to the following definition:

$$
\text { Extraction yield }(\%)=\frac{\% \beta-\text { glucan in raw barley }(\mathrm{db})-\% \beta-\text { glucan in exhausted barley }(\mathrm{db})}{\% \beta-\text { glucan in raw barley }(\mathrm{db})} \times 100
$$

Standard method for moisture determination of the samples (SM2540) was taken from APHAAWWA-WPCF, 1992. All results of chemical analysis, performed in duplicate, are reported on a dry matter basis $(\mathrm{db})$.

Molecular weight of $\beta$-glucan was determined by Size Exclusion Chromatography (HPLC-SEC) using a chromatography system that consisted of an isocratic pump (Waters 1515), an automatic injector (Waters 717), guard column (Waters Ultrahydrogel Guard Column) and a GPC column (Waters Ultrahydrogel 1000) and a differential refractive index detector (Waters 410). The column was kept at $35^{\circ} \mathrm{C}$, and flow rate of the mobile phase $\left(0.1 \mathrm{M} \mathrm{NaNO}{ }_{3}+0.02 \%\right.$ $\mathrm{NaN}_{3}$ ) was set at $0.6 \mathrm{ml} \cdot \mathrm{min}^{-1}$. The $\beta$-glucan molecular weight standards were purchased from Megazyme International Ltd. (Ireland), and were in the range 40 to $359 \mathrm{kDa}$.

\subsection{Optimization based on Taguchi's experimental design}

Taguchi experimental design approach has been used for optimization of extraction variables. It is a robust methodology against uncontrollable environmental changes (also known as noise factors), as it is the case of raw material variability. The extraction yield of $\beta$-glucans (calculated according equation (1)) was the response variable to be maximized. Initially six factors were identified as critical: temperature, $\mathrm{pH}$, extraction time, particle size, stirring rate and solvent:flour ratio (s:f ratio). Temperature and $\mathrm{pH}$ where excluded from the orthogonal array and studied separately, according to preliminary results, presented in section 3.1. The four remaining factors, with three different levels were selected to perform the experimental 
design. These factors and levels are: $A=$ Particle Size $(100,250$ and $500 \mu \mathrm{m}), \mathrm{B}=\mathrm{s}: \mathrm{f}$ ratio $(5,8$, 15; dimensionless), $C=$ Stirring rate $(200,600,1000 \mathrm{rpm})$ and $D=$ Extraction Time $(1,3,5 \mathrm{~h})$. Three levels for each control factor were selected to prevent information losses (the presence of non-linear relation between factors and the output variable).

From all the different orthogonal arrays available, an $L_{9}$ array fitted perfectly. Table 2 presents the orthogonal array selected, as well as the experiment performed in each trial. Barley composition was considered as a noise factor (as composition of barley is uncontrollable), and was set at two levels: variety D24, level 1 and variety $\mathrm{H} 13$ as level 2 . These changes in composition might affect the extraction process performance, so it is necessary to find an optimal combination of factors and levels not affected by the raw material.

Table 2. Experimental L9 (34) orthogonal array with two level noise factor (barley variety). Table includes extraction yield calculated for each of the nine trials and noise level

\begin{tabular}{|c|c|c|c|c|cc|cc|}
\hline \multirow{2}{*}{ TRIAL } & \multicolumn{5}{|c|}{ Factors and Levels } & \multicolumn{2}{c|}{$\beta$-glucan extraction yield (\%) } \\
\cline { 2 - 9 } & $\begin{array}{c}\text { Particle Size } \\
(\boldsymbol{\mu m})\end{array}$ & $\begin{array}{c}\text { s:f ratio } \\
\text { (ad.) }\end{array}$ & $\begin{array}{c}\text { Stirring Rate } \\
(\mathbf{r p m})\end{array}$ & $\begin{array}{c}\text { Time } \\
\text { (h) }\end{array}$ & \multicolumn{2}{|c|}{ D24 } & \multicolumn{2}{|c|}{ H13 } \\
\hline $\mathbf{1}$ & 100 & 5 & 200 & 1 & 54.0 & 50.1 & 43.6 & 40.4 \\
$\mathbf{2}$ & 100 & 8 & 600 & 3 & 65.4 & 61.4 & 52.0 & 51.5 \\
$\mathbf{3}$ & 100 & 15 & 1000 & 5 & 72.4 & 68.7 & 59.4 & 57.4 \\
$\mathbf{4}$ & 250 & 5 & 600 & 5 & 55.1 & 57.9 & 51.5 & 49.2 \\
$\mathbf{5}$ & 250 & 8 & 1000 & 1 & 56.3 & 59.4 & 44.9 & 51.1 \\
$\mathbf{6}$ & 250 & 15 & 200 & 3 & 63.1 & 61.3 & 52.0 & 50.0 \\
$\mathbf{7}$ & 500 & 5 & 1000 & 3 & 55.3 & 53.0 & 43.6 & 47.2 \\
$\mathbf{8}$ & 500 & 8 & 200 & 5 & 38.2 & 41.3 & 31.5 & 30.0 \\
$\mathbf{9}$ & 500 & 15 & 600 & 1 & 39.3 & 35.3 & 35.2 & 31.5 \\
\hline
\end{tabular}

All the experiments were carried out, in duplicate, for each variety of barley, leading to a total of 36 experiments for the experimental design. Finally, optimization was done by calculating the signal to noise ratio ( $\mathrm{S} / \mathrm{N}$ ratio), under the condition "larger is better", and according equation (2). This means that the optimal level of each factor is that one that gives the greatest $\mathrm{S} / \mathrm{N}$ ratio. In a Taguchi experimental design the $\mathrm{S} / \mathrm{N}$ ratio is used to evaluate the variation of the response around the mean due to experimental noise.

$$
\frac{\mathrm{S}}{\mathrm{N}}=-10 \log \left(\frac{1}{\mathrm{~N}} \sum_{\mathrm{i}=1}^{\mathrm{n}} \frac{1}{\mathrm{y}^{2}}\right)
$$




\section{RESULTS}

\subsection{Preliminary results}

\subsubsection{Effect of temperature}

Extraction temperature was varied in the range 35 to $75^{\circ} \mathrm{C}$, for the two varieties of tested barleys, H13 and D24. The rest of the experimental conditions were set constant at a determined level along the different tests (particle size $500 \mu \mathrm{m}, 5$ hours extraction time, solvent:flour ratio of 10 and stirring rate 500rpm). Experimental results have shown a constant increase in the extraction yield of $\beta$-glucans when increasing the temperature, as it is shown in figure 1a. Similar results have been reported by other researchers, when using either oat or barley as raw material (Wood et al., 1978; Temelli, 1997). Dawkins and Nnanna (1993) suggested that $\beta$-glucan extraction yield increases linearly with temperature and $\mathrm{pH}$ for oat bran and rolled oats. According to the experimental results presented in figure $1 \mathrm{a}$, this linearity does not remain beyond $55 \stackrel{\circ}{\circ}$ where depletion in the expected extraction yield is observed. Higher temperatures although increase the amount of $\beta$-glucans extracted, lead to an important raise of the concentration of starch in the liquid extract: from less than $0.1 \%$ at $55^{\circ} \mathrm{C}$ to $1.0 \%$ at $65^{\circ} \mathrm{C}$ and $1.1 \%$ at $75^{\circ} \mathrm{C}$. This increment in concentration of starch produced an increase of viscosity of the suspension limiting the external transport step. Moreover, solidliquid separation was very difficult since the resulting liquid extract was extremely viscous. 

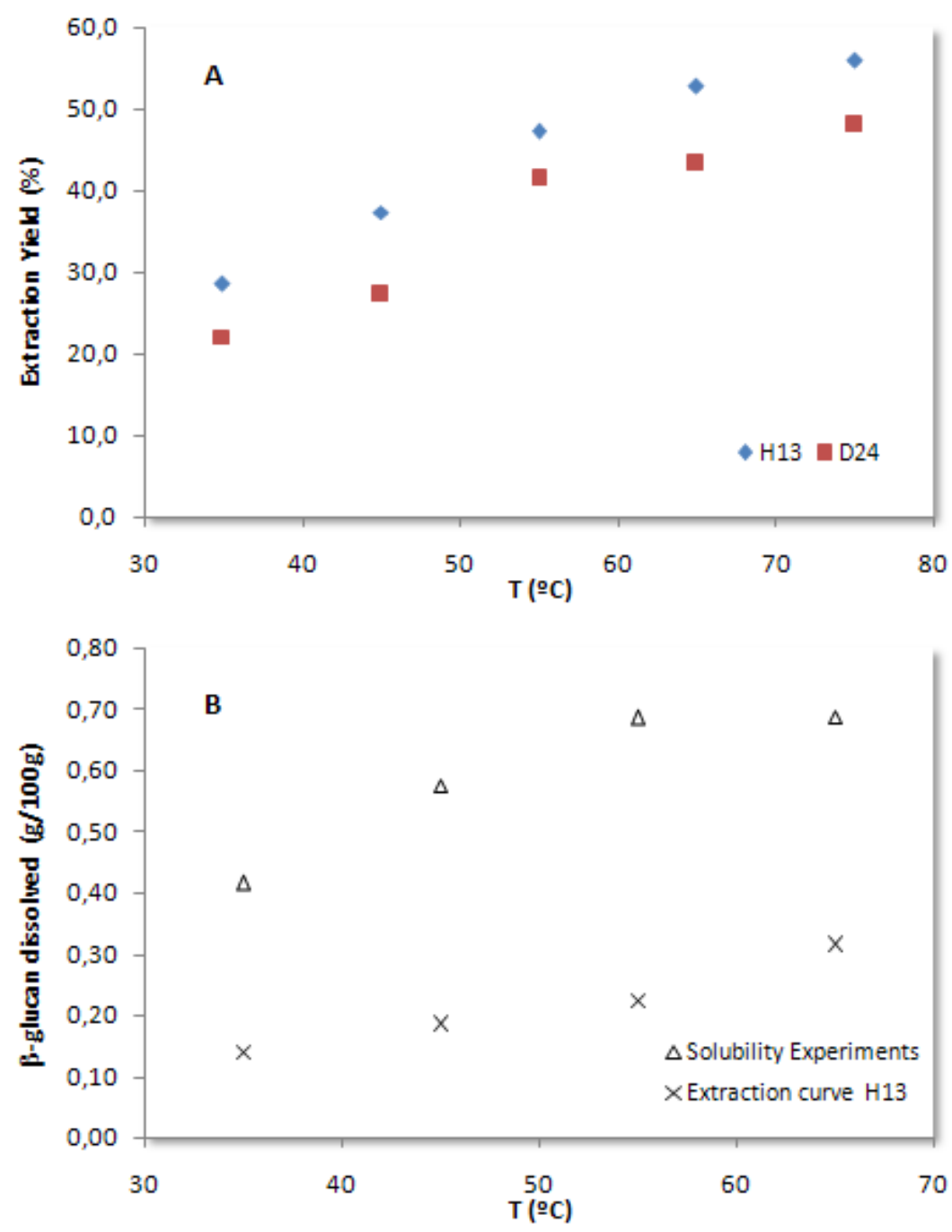

Figure 1. (a) Effect of temperature on $\beta$-glucan extraction yield for two different varieties of barley (Extraction time 5 hours; Particle size $500 \mu \mathrm{m}$; stirring rate 500rpm and solvent:flour ratio of 10); (b) Comparison of the solubility curve and extraction curve of barley $\mathrm{H} 13$

$\beta$-glucans extracted at different temperatures were isolated from liquid extracts and measured their molecular weight. No significant differences were observed, being around $40 \mathrm{kDa}$ for $\mathrm{H} 13$ barley and $55 \mathrm{kDa}$ for D24. The low values of molecular weight measured were attributed to the action of $\beta$-glucanases, endogenous enzymes involved in depolymerization of $\beta$-glucans that were not deactivated as previous step to the extraction stage.

Solubility experiments were performed with a double purpose: the first one was to validate the behaviour of $\beta$-glucan with temperature. The second one was to show whether the extraction yield had achieved the maximum at each temperature, or on the contrary there had been other factors that had limited the extraction step. In figure $1 \mathrm{~b}$, solubility trend with temperature is compared with the extraction curve of $\beta$-glucan from barley $\mathrm{H} 13$. In this figure, it can be seen that extraction curve is far away from solubility curve, which represents the 
maximum amount of $\beta$-glucan that can be dissolved at each temperature. This fact indicates that mass transfer steps are limiting the extraction process. So, in order to improve $\beta$-glucan extraction processes flour particle size and agitation must be considered for improving internal diffusion and external mass transfer respectively.

Solubility curve reveals that maximum solubilisation of $\beta$-glucans was achieved at $55^{\circ} \mathrm{C}$ and a further increase of temperature did not contribute to raise significantly the maximum amount of $\beta$-glucan dissolved. $\beta$-glucan extraction yield is increased with temperature up to $75^{\circ} \mathrm{C}$, but optimum value is $55^{\circ} \mathrm{C}$. For temperatures above $55^{\circ} \mathrm{C}$, the maximum solubility of $\beta$-glucans in water does not increase significantly, and co-extraction of starch contaminates the extracts and hinders the stirring and the ulterior solid liquid separation and purification processes. Starch gelatinization, which occurs at $63^{\circ} \mathrm{C}$ (Wood et al., 1978), was set as a critical parameter limiting the final $\beta$-glucan recovery, affecting both the extraction performance and later isolation of $\beta$-glucan.

\subsubsection{Effect of $p H$}

The influence of $\mathrm{pH}$ value was also studied. In these experiments, $\mathrm{pH}$ was increased by addition of $\mathrm{NaOH}, 1 \mathrm{M}$. The rest of the experimental conditions were set at a determined level (particle size $500 \mu \mathrm{m}, 5$ hours extraction time, solvent:flour ratio of 10 and stirring rate 500rpm), and were kept constant along the different tests carried out. All the experiments were conducted in duplicate. A slight increase in extraction yield has been observed when water was led to $\mathrm{pH}$ 8. This result is in total agreement with some results found in the literature (Bhatty, 1993; Temelli, 1997). Nevertheless, a further increase in $\mathrm{pH}$ to values around 11 caused a moderate reduction in the amount of $\beta$-glucans extracted. Temelli (1997) reported the same trend when studying the $\mathrm{pH}$ effect on $\beta$-glucan recovery at different temperatures. In that work $\mathrm{pH}$ was modified in the range 7-10 with $\mathrm{Na}_{2} \mathrm{CO}_{3} ; 20 \% \mathrm{w} / \mathrm{v}$. Independently of the considered temperature, the percentage of the recovered $\beta$-glucan decreased when $\mathrm{pH}$ was above 9. However the same author reported an increment in viscosity with $\mathrm{pH}$ at a given temperature. This behaviour suggested that basic $\mathrm{pH}$ may inactivate $\beta$-glucanases causing an increase of molecular weight of the extracted $\beta$-glucans. This increment of molecular weight could explain the reported decrease in $\beta$-glucans extractability.

\subsection{Optimization}

Optimization was done according to Taguchi's methodology presented in section 2.4. Table 2 summarizes the results obtained for the 36 experiments carried out. Figure 2 shows the effect 
of controlled factor levels on $\beta$-glucan extraction for each noise factor (barley varieties $\mathrm{H} 13$ and D24). As it is shown in figure 2 , the effect that each controlled factor has on the $\beta$-glucan extraction, presents a similar trend for the two tested barley cultivars. In all the studied cases, better extraction results were observed for variety D24, which contains higher amount of $\beta$ glucan, remarking that barley variety influences noticeably the extraction yield. An even higher influence can be attributed to the particle size of the barley flour used in the extraction, as well as the stirring rate. On the other hand, the effect of the amount of solvent used in the extraction has practically no influence on the final extraction yield. Extraction time was a dependent factor up to three hours. Longer extraction times did not increase the amount of $\beta$ glucan co-extracted, indicating that, after three hours, equilibrium had been reached.

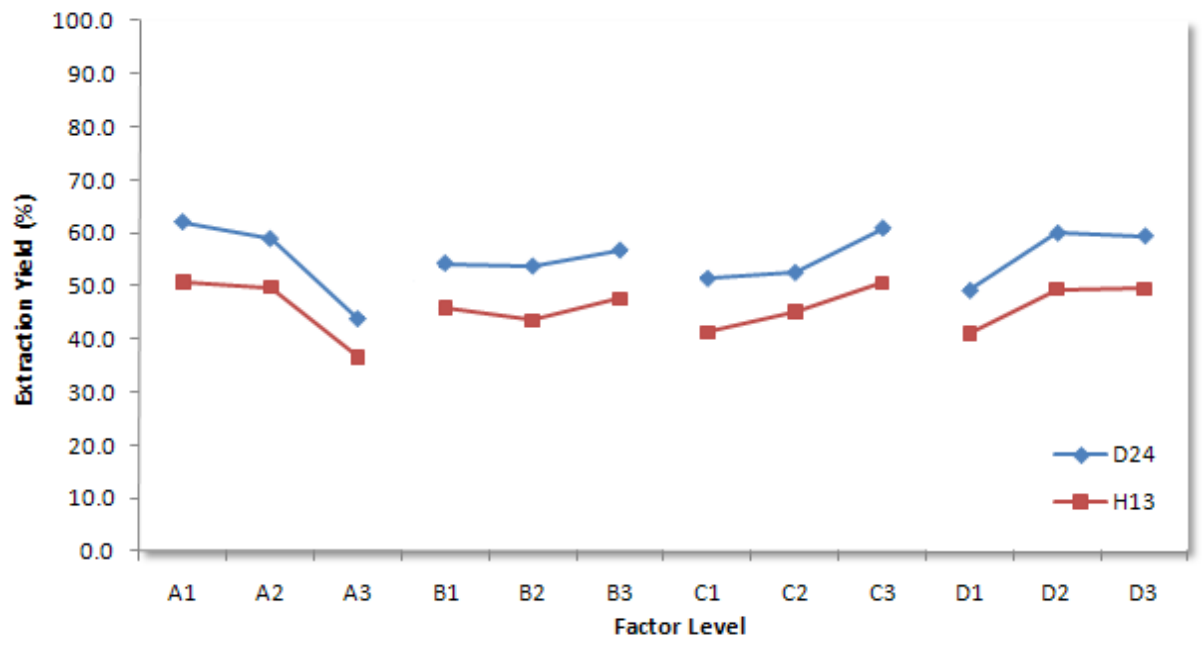

Figure 2. Effects of control factors on response variable for each level of noise

All these results were confirmed when an analysis of variance was performed (table 3 ). Statistical analysis was performed using the software Statgraphic Plus for Windows (v5.1). The analysis of the calculated F-Ratio (variance ratio) revealed that all the factors studied were statistically significant (at 95\% confidence level). When contribution of each factor on the total variance was calculated, it was seen that the most influent factor was particle size (contribution of $47 \%$ ), followed by variety of barley (19\%). Particle size has a dramatic influence on the extraction yield, being necessary a small particle size flour to perform a successful extraction process. The use of high stirring rates also contributed to enhance the extractability of $\beta$-glucans, not happening the same with the extraction time: extraction time influences the extraction process up to 3 hours; longer extraction times not increase the extractability of $\beta$-glucans (the total contribution to the variance of this factor is $14 \%$ ). Nevertheless, the solid:flour ratio had a very limited influence on the $\beta$-glucan extractability process (only 1.9\%). This is an important result, as wet extraction of $\beta$-glucan consumes large 
amounts of water which is necessary to remove in further isolation/purification steps. As the influence of the s:f ratio is limited, the selection of the optimal value for this factor can be done from a technical and economical point of view: operating at low s:f ratios (i.e. 5), will simplify the subsequent purification process. Finally, ANOVA table (table 3 ) reveals the small contribution that residual error (3.8\%) has on the $\beta$-glucan extractability, which means that almost all variability observed can be attributed to the factors selected to perform the experiment.

Table 3. Results of analysis of variance (ANOVA)

\begin{tabular}{|c|c|c|c|c|c|c|}
\hline VARIATION SOURCE & $\begin{array}{l}\text { Degrees of } \\
\text { freedom }\end{array}$ & $\begin{array}{l}\text { Sum of } \\
\text { Squares }\end{array}$ & $\begin{array}{l}\text { Mean } \\
\text { Square }\end{array}$ & F-Ratio $^{a}$ & P-Value & $\begin{array}{c}\text { Contribution } \\
\text { (\%) }\end{array}$ \\
\hline A, Particle Size & 2 & 1878.4 & 939.2 & 161.97 & 0.0000 & 47.0 \\
\hline B, s:f ratio & 2 & 76.2572 & 38.1286 & 6.58 & 0.0049 & 1.9 \\
\hline C, Stirring rate & 2 & 573.829 & 286.914 & 49.48 & 0.0000 & 14.3 \\
\hline D, Time & 2 & 559.294 & 279.647 & 48.23 & 0.0000 & 14.0 \\
\hline E, Variety & 1 & 760.84 & 760.84 & 131.21 & 0.0000 & 19.0 \\
\hline RESIDUAL & 26 & 150.762 & 5.79855 & - & - & 3.8 \\
\hline TOTAL (corrected) & 35 & 3999.38 & & & & \\
\hline
\end{tabular}

All F-ratios are based on the residual mean square error.

${ }^{a}$ Critical Variance ratio for a 95\% confidence level is 3.37 (2d.f.) or 4.24 (1d.f.)

${ }^{b}$ Contribution is defined as $100 \times$ (pooled sum of squares/total sum of squares)

In order to obtain the optimal combination of factors, the signal-to-noise parameter was calculated according to equation (2). From this calculation, (results presented in figure 3), it was determined that the optimal combination of factors maximizing the extraction yield in spite of the barley composition was: A1-B1-C3-D2 ( particle size $100 \mu \mathrm{m}$; s:f ratio 5; stirring rate 1000rpm and extraction time of 3 hours). 


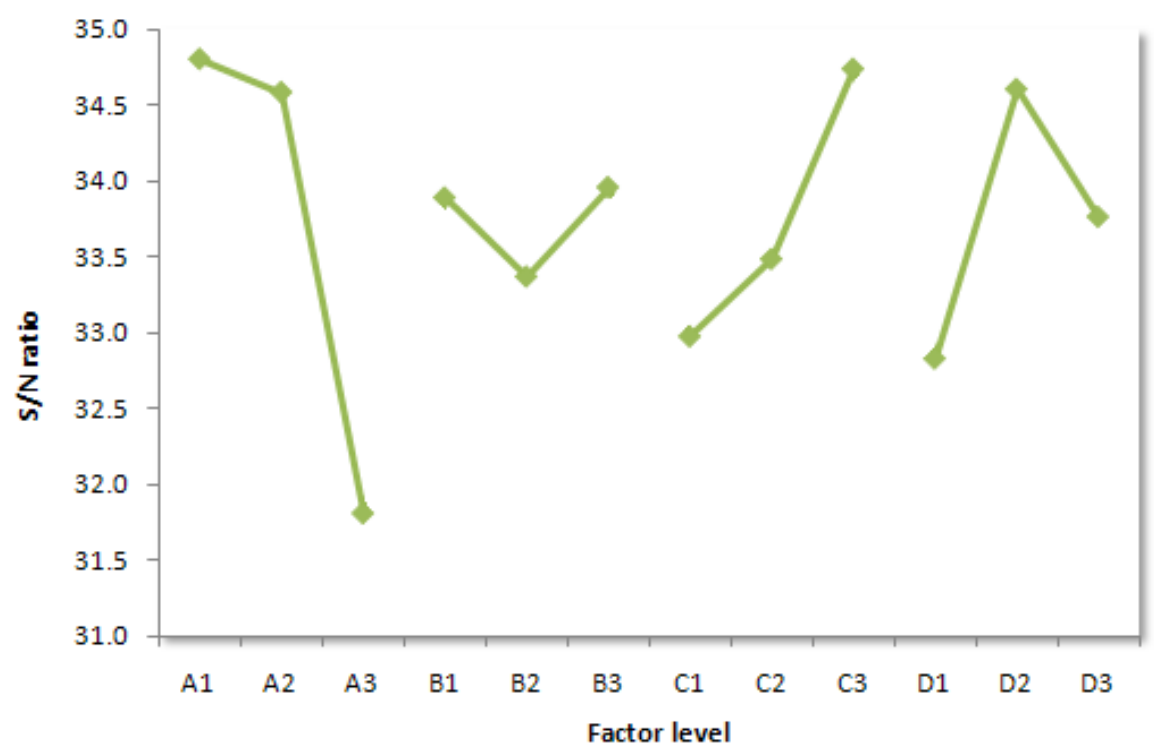

Figure 3. Effects of control factors on the $S / N$ ratio for $\beta$-glucan extraction data

\subsection{Confirmatory experiment}

As can be verified in table 2 , the combination of factors found after the $S / N$ ratio calculation as optimal (A1-B1-C3-D2) had not been tested previously. As a consequence it was necessary to perform a confirmatory experiment to probe the reliability of the results obtained, for both varieties of barley. The extraction yield obtained was $73.4 \pm 1.2 \%$ for barley D24 and $62.3 \pm 1.8 \%$ for $\mathrm{H} 13$, slightly higher than the maximum observed in trial number 3 of the experimental design, proving the reliability of the statistical analysis. The molecular weight of the $\beta$-glucan extracted under the optimal conditions for both varieties was measured. No significant differences in the molecular weight of the $\beta$-glucan extracted from the different barley varieties were observed. The molecular weight measured was $45 \mathrm{kDa}$ for the $\beta$-glucan obtained from barley $\mathrm{H} 13$ and 55kDa when extracted from D24. A low molecular weight polymer was recovered, since no initial pre-treatment was performed to deactivate endogenous $\beta$ glucanase, enzyme responsible for the depolymerization of $\beta$-glucans. 


\section{CONCLUSIONS}

$\beta$-glucan extraction using hot water as solvent is influenced by a large number of parameters affecting mass transfer steps (external transport and internal diffusion) and equilibrium. All of them were considered in this work, unlike previous published works. Several experiments were performed in order to study the influence of them and to obtain useful engineering information. The initial experiments were useful to find $55^{\circ} \mathrm{C}$ as the optimal temperature and to scorn $\mathrm{pH}$ as a critical variable for the $\beta$-glucan extraction process. From all the parameters included in the Taguchi's experimental design, it was demonstrated that particle size has a significantly higher influence on the extraction process than the other parameters studied (stirring rate, extraction time and barley variety), indicating that mass transfer steps are limiting the overall extraction process. In order to get satisfying results, it is mandatory to perform the extraction from small particle size flour. Solvent to flour ratio, although the statistical analysis performed revealed that its effect was statistically significant, in practical terms can be concluded that it is not a critical factor affecting the process. The final decision on the selection of the level of this parameter will be made considering the later purification step, since a lower amount of water during the extraction, simplifies and reduces operating costs in the subsequent $\beta$-glucan concentration process. The results obtained for the two tested barleys had the same trend; which means that the proposed operating conditions can be extrapolated to other barley cultivars. Finally, those results obtained under the optimal conditions revealed a higher extraction yield for the two varieties of barley selected in this work compared with those reported by other researchers, which means that these varieties of barley grown up at the Castilla y León region (Spain), are excellent raw materials for $\beta$-glucan obtention.

\section{ACKNOWLEDGEMENTS}

This work has been carried out with the economical support of the coordinated research project ITACYL-Universidad de Valladolid, ref: VA-14-C2-1. 


\section{BIBLIOGRAPHY}

APHA-AWWA-WPCF, 1992. Métodos Normalizados para el Análisis de aguas potables y residuales, $17^{\text {th }}$. Ediciones Díaz de Santos S.A., Madrid, Spain.

Andersson, A.A.M., Elfverson, C., Andersson, R., Regner, S., Aman, P., 1999. Chemical and physical characteristics of different barley samples. Journal of the Science of Food and Agriculture 79, 979-986.

Baik, B.K., Ullrich, S.E., 2008. Barley for food: characteristics, improvement, and renewed interest. Journal of Cereal Science 48, 233-242.

Bengtsson, S., Åman, P., Graham, H., Newman, C.W., Newman, R.K., 1990. Chemical Studies on mixed-linked $\beta$-glucans in hull-less barley cultivars giving different hypocholesterolaemic responses in chickens. Journal of the Science of Food and Agriculture 52(4), 435-445.

Bhatty, R.S., McGregor, A. W., Rossnagel, B.G., 1991. Total and acid-soluble $\beta$-glucan content of hulless barley and its relationship to acid-extract viscosity. Cereal Chemistry 68(3), 221-227.

Bhatty, R.S., 1993. Extraction and Enrichment of (1-3),(1-4)- $\beta$-D-Glucan from Barley and Oat Brans. Cereal Chemistry 70(1), 73-77.

Bhatty, R.S., 1995. Laboratory and pilot plant extraction and purification of $\beta$-glucans from hull-less Barley and oat brans. Journal of Cereal Science 22, 163-170.

Brennan, C.S., Cleary, L.J., 2005. The potential use of cereal (1-3,1-4)-- $\beta$-D-glucans as functional food ingredients. Journal of Cereal Science 42(1), 1-13.

Burkus, Z., Temelli, F., 1998. Effect of extraction conditions on yield, composition, and viscosity stability of barley $\beta$-glucan gum. Cereal Chemistry 75(6), 805-809.

Dawkins, N.L., Nnanna, I.A., 1993. Oat gum and $\beta$-glucan extraction from oat bran and rolled oats: Temperature and pH effects. Journal of Food Science 58(3), 562-566.

Han, S.H., Lee, K.W., Moon, K.H., Jo, C.H., Rhee, C., 2004. In vitro study of barley sorption degrees for $\mathrm{Hg}, \mathrm{Cd}$ and $\mathrm{Pb}$ and the anti-mutagenic activity of dietary fiber from barley. Food Science and Biotechnology 13(5), 609-612. 
Irakli, M., Biliaderis, C.G., Izydorczyk, M.S., Papadoyannis, I.N., 2004. Isolation, structural features and rheological properties of water-extractable $\beta$-glucans from different Greek barley cultivars. Journal of the Science of Food and Agriculture 84, 1170-1178.

Izydorczyk M. S., Storsley, J., Labossiere D., MacGregor A. W., Rossnagel B.G., 2000. Variation in total and soluble $\beta$-glucan content in hulless barley: effects of thermal, physical and enzymic treatments. Journal of Agricultural and Food Chemistry 48, 982-989.

Kiryluk, J., Kawka, A., Gasiorowski, H., Chalcarz, A., Aniola, J., 2000. Milling of barley to obtain $\beta$-glucan enriched products. Nahrung 44(4), 238-241.

Lazaridou, A., Biliaderis, C.G., Micha-Screttas, M., Steele, B.R., 2004. A comparative study on structure-function relations of mixed- linkage (1-3), (1-4) linear $\beta$-D-glucans. Food Hydrocolloids $18,837-855$.

Li, W., Cui, S.W., Kakuda, Y., 2006. Extraction, fractionation, structural and physical characterization of wheat $\beta$-D-glucans. Carbohydrate Polymers 63, 408-416.

Lu, Z.X., Walker, K.Z., Muir, J.G. O'Dea, K. (2004). Arabinoxylan fibre improves metabolic control in people with Type II diabetes. European Journal of Clinical Nutrition 58(4), 621-628.

Morgan, K.R., 1998. $\beta$-glucan products and extraction processes from cereals. Patent International Publication Number WO 98/13056.

Newman, R.K., Newman, C.W., Graham, H., 1989. The hypocholesterolemic function of barley $\beta$-glucans. Cereal Foods World 34, 883-886.

Oscarsson, M., Andersson, R., Salomonsson, A.C., Aman P., 1996. Chemical Composition of Barley Samples Focusing on Dietary Fibre Components. Journal of Cereal Science 24, 161-170.

Papageorgiou, M., Lakhdara, N., Lazaridou, A., Biliaderis, C.G., Izydorczyk, MS., 2005. Water extractable (1-3,1-4)- $\beta$-D-glucans from barley and oats: An intervarietal study on their structural features and rheological behaviour. Journal of Cereal Science 42(2), 213-224.

Saulnier, L., Gévaudan, S., Thibault, J.F., 1994. Extraction and partial characterisation of $\beta$ glucan from the endosperms of two barley cultivars. Journal of Cereal Science 19, 171-178.

Temelli, F., 1997. Extraction and functional properties of barley $\beta$-glucan as affected by temperature and pH. Journal of Food Science 62(6), 1194-1197. 
Vasanthan, T., Bhatty, R.S., 1995. Starch purification after pin milling and air classification of waxy, normal, and high amylose. Cereal Chemistry 72(4), 379-384.

Vasanthan T., Temelli, F., 2008. Grain fractionation technologies for cereal $\beta$-glucan concentation. Food Research International 41, 876-881.

Wood, P. J., Siddiqui, I. R., Paton, D., 1978. Extraction of high-viscosity gums from oats. Cereal Chemistry 55, 1038-1049.

Wood, P. J., Weisz, J., Fedec, P., Burrows, V. D., 1989. Large-scale preparation and properties of oat fractions enriched in (1-3)(1-4)- $\beta$-D-glucan. Cereal Chemistry 66(2), 97-103. 



\title{
CHAPTER 2
}

\section{Ultrasound-Assisted Extraction of}

\author{
$\beta$-Glucans from Barley
}





\title{
Ultrasound-Assisted Extraction of $\beta$-Glucans from Barley ${ }^{1}$
}

\begin{abstract}
The effect of operational variables on the ultrasound assisted extraction (UAE) of $\beta$-glucans from barley has been studied. The selected sonication variables were amplitude, time and cycle, and their combination represents different amounts of energy. The RSM Box-Behnken approach has been used to maximize both extraction yield and molecular weight (MW) of extracted $\beta$-glucans. The final results of the UAE reveal that the extraction yield depends on amplitude and especially on time; nevertheless MW decreases with time. The maximum extraction yield (66.1\%) is achieved when delivering the maximum amount of energy (962.5 $\mathrm{kJ} / \mathrm{L})$, leading at the same time to the lowest MW $(269 \mathrm{kDa})$. A reduction in the intensity of the treatment (energy output of $170 \mathrm{~kJ} / \mathrm{L}$ ) decreases the extraction yield up to $44.3 \%$ but increases the $\beta$-glucan MW to $461 \mathrm{kDa}$. The UAE process slightly improves the extraction yield of $\beta$ glucans and their MW compared to that obtained in a stirred tank extraction ( 3 hours, $55^{\circ} \mathrm{C}$ and $1000 \mathrm{rpm})$, the main effect of ultrasounds is related with the reduction of process time and energy consumption ( 3 minutes versus 3 hours and $170 \mathrm{~kJ} / \mathrm{L}$ versus $1460 \mathrm{~kJ} / \mathrm{L}$ ), what means a real process intensification, very interesting for the scale-up of the process.
\end{abstract}

Keywords: $\beta$-glucans, ultrasound assisted extraction, barley, RSM

\footnotetext{
${ }^{1}$ LWT-Food Science and Technology 50 (2013), 57-63
} 


\section{INTRODUCTION}

$\beta$-glucans (mixed linkage $(1 \rightarrow 3)(1 \rightarrow 4)-\beta$-D-glucans) are non-starchy, long and linear polysaccharides composed of $\beta$-D-glucose units. Glucose molecules are linked by means of the O-glucosidic bond: a $\beta-(1 \rightarrow 4)$ in the $70 \%$ of the cases that is separated by a single $\beta-(1 \rightarrow 3)$ linkage. They are constituents of the cell walls of different cereals, such as barley $(\sim 7 \mathrm{~g} / 100 \mathrm{~g})$, oat $(\sim 5 \mathrm{~g} / 100 \mathrm{~g})$, rye and wheat $(\sim 1-2 \mathrm{~g} / 100 \mathrm{~g})$ and they are a major component of the soluble fiber. Soluble $\beta$-glucans have been reported to reduce plasma cholesterol and postprandial serum glucose levels in humans and animals (Newman, Lewis, Newman, Boik \& Ramage 1989; McIntosh, Whyte, McArthur \& Nestel, 1991; Wood, 2007; Keenan, Goulson, Shamliyan, Knutson, Kolberg \& Curry, 2007), and they have been subject of health claims as food constituents by the FDA (United States Federal Drug Administration) and the EFSA (European Food Safe Authority). The claimed effect attributed to $\beta$-glucans from barley and oat can be summarized by: "Regular consumption of $\beta$-glucans contributes to maintenance of normal blood cholesterol concentrations when ingesting $3 g$ of $\beta$-glucan per day" (FDA, 2005) (EFSA, 2010). The EFSA report (EFSA, 2010) attributes this health claim to $\beta$-glucans with molecular weight in the range $50-2000 \mathrm{kDa}$. The cholesterol lowering potential of cereal fiber is considered to result from effects manifested in the upper gastrointestinal tract. These, in turn, may be related to the ability of cereal fiber to form a gel-like network and alter gastrointestinal viscosity (Brennan \& Cleary, 2005). Viscosity is affected by a large number of factors, such as concentration and $\mathrm{MW}$ of the $\beta$-glucans, as well as different features affecting the $\beta$-glucan backbone (Izydorczyk \& Dexter, 2008). Therefore, there is a remarkable interest to develop an efficient extraction process of $\beta$-glucans from cereals (barleys in particular due to their high content) with the highest molecular weight in order to preserve the healthy benefits related to the viscosity.

Conventional extraction procedures of polysaccharides are complex and inefficient (Huang \& Ning, 2010), resulting in low yield and time consuming processes that require huge amounts of energy (heating and stirring). $\beta$-glucan extraction processes are not an exception: mass transfer is hindered due to the high viscosity solutions that form, the low concentration in the raw material and the diffusion limitations of the solvent into the cereal flour particles. In a previous work, the authors (Benito-Román, Alonso \& Lucas, 2011) have shown that stirring rate and particle size were the operational variables controlling the extraction process of $\beta$ glucans from two varieties of waxy barley, evidencing mass transfer limitations. In order to improve mass transfer, and hence to improve the $\beta$-glucan extraction process, ultrasounds 
(US) are used in the present work. Ultrasound Assisted Extraction (UAE) is a technique that consists in the application of ultrasounds to the raw material, previously placed in the extraction solvent, using a probe or a US bath (Chemat, Huma, \& Khan, 2011). When liquids are sonicated at high intensities, the sound waves that propagate into the liquid create alternating high pressure (compression) and low pressure (rarefraction) cycles. This continuous high-low pressure cycles create small bubbles or voids in the liquid that collapse violently when they can no longer absorb energy (in a phenomenon named "cavitation"), producing intense local heating, high pressures, liquid jet streams and dramatic heating and cooling rates. Cavitation produces intense shear forces and changes in the physical properties that permit the solvent to penetrate deeper in the solid, increasing the diffusion rate of the desired molecule to the solvent (Wang, Sun, Cao, Tian \& Li, 2008). These are the reasons why sonication has several advantages for the extraction processes related to mass transfer improvement and cell disruption (lida, Tuziuti, Yasui, Towata, \& Kozuka, 2008; Rodríguez-Rojo, Visentin, Maestri \& Cocero, 2012).

The use of ultrasounds to enhance extraction processes was extensively reviewed by Vilkhu, Mawson, Simons \& Bates (2008). These authors summarized a significant amount of applications of this procedure for the extraction of different natural molecules (antioxidants, essential oils, polysaccharides...) from a wide variety of matrices. Among all the possible applications of ultrasounds, the enhancement of the polysaccharide extraction process and the control of their molecular weight (MW) were highlighted in that review work. Extraction performance depends on the amount of delivered energy. In general, high intensity ultrasound treatments lead to a depolymerization of the extracted polymer, which helps to produce homogenous and low MW solutions (Yang, Jiang, Zhao, Shi, \& Wang, 2008). In other research works, sonication has been used to disrupt the structure of different molecular weight polysaccharides. For example, Koda, Taguchi \& Futamura (2011), studied the effect of US on methyl cellulose, pullulan and dextran, concluding that the mechanical effects produced by the sonication were the responsible for the breakage of the polymers. However, the use of ultrasounds for $\beta$-glucan extraction is very limited in the literature. Izydorczyk, Storsley, Labossiere, MacGregor, \& Rossnagel, (2000) have used sonication for physical disruption prior to the extraction (pre-treatment) showing that this pretreatment can increase $\beta$-glucan solubilization, but they have not tried to optimize operational variables. Vårum \& Smidsrød (1988), used ultrasounds to successfully control the molecular weight of $\beta$-glucan solutions (post-treatment), in treatments up to 25 minutes. However, there is no reference about the required energy to get this molecular weight decrease. Ultrasounds have also been used to 
control the viscosity of starch solutions (lida et al., 2008). Viscosity was reduced by two orders of magnitude in a 30 minutes treatment (power output equal to $100 \mathrm{~W}$ ) without remarkable changes in the properties of the starch, besides a molecular weight reduction from $3000 \mathrm{kDa}$ to $500 \mathrm{kDa}$.

The aim of this work is to optimize the ultrasound assisted extraction of $\beta$-glucans from barley. An optimal combination of factors that maximize the amount of extracted $\beta$-glucans with the highest molecular weight is proposed. The obtained results are also discussed and compared to those obtained in a stirred tank extraction process and finally, the energy consumed during the extraction is measured (in both processes) and used as a critical factor to quantify the process intensification achieved with the ultrasounds.

\section{MATERIALS AND METHODS}

\subsection{Raw material}

A waxy genotype variety of barley, provided by ITACyL (Instituto Tecnológico Agrario de Castilla y León; Valladolid, Spain) was used in this work. $\beta$-glucan content of this cultivar was $6.25 \pm 0.25 \%$ and starch content was $50.3 \pm 3.2 \%$, both expressed in dry basis. Prior to the extraction procedure, barley flour was boiled with ethanol $(80 \%, v / v)$ under reflux for two hours in order to inactivate $\beta$-glucanases, enzymes responsible for the enzymatic hydrolysis of $\beta$-glucans. Once dried, agglomerates were broken down by milling. Particle size of the barley flour was measured by laser scattering (Mastersizer 2000, Malvern Instruments, Ltd.), resulting an average size of $240 \pm 4 \mu \mathrm{m}$. This treated barley flour constitutes the raw material for all the extraction experiments described in the present work.

\subsection{Experimental section}

\subsubsection{Extraction in Stirred Tank}

The barley flour was extracted under mechanical agitation in a stirred tank extractor. In such conventional extraction, $20 \mathrm{~g}$ of barley flour were suspended in $200 \mathrm{~mL}$ water in a jacketed glass reactor of $1 \mathrm{~L}$ volume. Temperature was kept at $55^{\circ} \mathrm{C}$ and stirring rate was set at 1000 rpm (Heidolph RZR2021 stirrer, Germany) for three hours. Solid-liquid mixture was then centrifuged (Kubota 5100, Japan) for $9 \mathrm{~min}$ at $5000 \mathrm{rpm}$. Solid phase (exhausted barley) and liquid extract were used to evaluate extraction yield and $\beta$-glucan molecular weight, respectively. 


\subsubsection{Ultrasound assisted extraction (UAE) procedure}

Identical amount of barley flour and water were used for the UAE experiments. Temperature was also fixed at $55^{\circ} \mathrm{C}$. $20 \mathrm{~g}$ of barley flour were suspended in $200 \mathrm{ml}$ of water and located in a $250 \mathrm{~mL}$ jacketed vessel. The suspension was sonicated by means of the UP400S Ultrasonic Processor (400 watts, $24 \mathrm{kHz}$; Hielscher, Germany), equipped with a $22 \mathrm{~mm}$ titanium probe. A cold water flow in the jacket was used to maintain $55^{\circ} \mathrm{C}$. After the extraction step, solid-liquid mixture was centrifuged (Kubota 5100, Japan) for $9 \mathrm{~min}$ at $5000 \mathrm{rpm}$. Solid phase (exhausted barley) and liquid extract were used to evaluate extraction yield and $\beta$-glucan molecular weight, respectively. Temperature in the extraction vessel was monitored using a multichannel fiber optic thermometer (FoTemp 4; OPTOcon AG - Germany). The total energy consumed by the ultrasonic processor was also measured (Energy Check 3000; Voltcarft).

\subsection{Chemical analysis}

For each extraction experiment, $\beta$-glucan content was evaluated in the initial barley flour (raw barley) and in the solid phase after the extraction (exhausted barley) by using the assay kit "Mixed-linkage $\beta$-glucan" from Megazyme International Ltd. $\beta$-glucan extraction yield was evaluated according to equation (1):

Extraction Yield $(\%)=\frac{\% \beta-\text { glucan in raw barley }-\% \beta-\text { glucan in exhausted barley }}{\% \beta-\text { glucan in raw barley }} \times 100$

The content of starch in the barley grain was determined with the "Total Starch assay kit", from Megazyme International Ltd., recognized as a Standard Method for the measurement of total starch in cereal flours and food products. Moisture of solid samples was determined by convective oven drying, according to the method SM2540 described in APHA-AWWA-WPCF, (1992). All the chemical analysis, were performed by duplicate and the results are reported on a dry matter basis (DB).

The molecular weight of $\beta$-glucans in the liquid extract was determined by Size Exclusion Chromatography (HPLC-SEC) using a chromatography system that consists of an isocratic pump (1515; Waters Corporation), an automatic injector (717; Waters Corporation), guard column (SB-G 6; Shodex), a GPC column (SB-804HQ; Shodex) and a differential refractive index detector (410; Waters Corporation). The column was kept at $35^{\circ} \mathrm{C}$, and flow rate of the mobile phase $\left(0.1 \mathrm{M} \mathrm{NaNO}_{3}+0.02 \% \mathrm{NaN}_{3}\right.$ ) was set at $0.5 \mathrm{~mL} \cdot \mathrm{min}^{-1}$. Five different $\mathrm{MW}$ standards from Megazyme International Ltd. in the range 40 to $359 \mathrm{kDa}$ were dissolved in ultrapure water and used to obtain the calibration curve. 
Chromatograms were processed by means of the Breeze Software (Waters Corporation). The whole molecular weight distribution was described by means of weight average $\left(M_{w}\right)$ and number average $\left(M_{n}\right)$ molecular weight; as well as the polydispersity index calculated with this software. Table 1 summarizes the weight average molecular weight $\left(M_{w}\right)$ and polydispersity index (defined as $M_{w} / M_{n}$ ) of the liquid extract for each experiment. In this manuscript, in order to describe the molecular weight distribution of each sample, the average weight molecular weight distribution has been used. The presence of other polysaccharides in the liquid extract, such as starch, may have contributed to the measured molecular distribution.

\subsection{Experimental design}

Box-Behnken experimental design was used in this work: three factors at three levels were considered: $X_{1}$ amplitude $(60,80$ and $100 \%), X_{2}$ extraction time $\left(3,10\right.$ and 17 minutes) and $X_{3}$ cycle $(0.8,0.9$ and 1$)$. The variables were coded according to the equation (2):

$$
x=\frac{X_{j}-X_{0}}{\Delta X}
$$

where $x$ is the coded value, $X_{j}$ is the corresponding actual value, $X_{0}$ is the actual value in the centre of the domain, and $\Delta \mathrm{X}$ is the increment of $X_{j}$ corresponding to a variation of one unit of x. RSM Box-Behnken optimization is more advantageous than the traditional single parameter optimization as it saves time and raw material.

Amplitude term refers to the amplitude of oscillation of the titanium probe. The maximum amplitude of oscillation of the sonotrode used in this work is $100 \mu \mathrm{m}$. The amplitude of oscillation determines the intensity of acceleration, parameter that controls the efficient transformation of energy into cavitation, and hence the performance of the UAE process. Higher amplitudes create higher accelerations that cause higher pressure differences, increasing the probability of bubble formation (cavitation).

Cycle (or pulse) determines if the sonication is continuous (cycle $=1$ ) or pulsed (on/off switching times of the ultrasonic processor). Cycle time is the sum of the pulse duration period ("sonication on") plus the pulse interval period ("sonication off"). For permanent acoustic irradiation, the controller is set to " 1 "; each other setting means shorter sonic radiation times with corresponding breaks: for instance, setting 0.9 means that power discharges 0.9 seconds and pauses 0.1 seconds out of $1 \mathrm{~s}$.

The energy consumption is the product of the power input $(P)$ and the time of exposure $(t)$, according to equation (3). Power is affected by a number of parameters related to the 
ultrasonic processor and the media (such as amplitude of oscillation, cycle, temperature, concentration, pressure, viscosity of the media...). If the power output is divided by the extraction volume, the specific energy is obtained $(\mathrm{kJ} / \mathrm{L})$

$$
E(J)=P(W) \cdot t(s)
$$

The experimental plan consisted of 15 runs, including three repetitions of the center point of the experimental design. All the experiments were randomized. Two response variables were considered in the optimization process: extraction yield (calculated according to equation 1) and molecular weight. All the calculations were done by means of Minitab 15 Statistical Software. The generalized second-order polynomial model proposed for the response surface analysis was as follows:

$$
Y=\beta_{o}+\sum_{j=1}^{k} \beta_{j} X_{j}+\sum_{j=1}^{k} \beta_{j j} X_{j}^{2}+\sum_{i=1}^{k} \sum_{j=1}^{k} \beta_{i j} X_{i} X_{j}
$$

Where $Y$ is the estimated response variable to be optimized, $X_{0}, X_{j}, X_{j j}$ and $X_{i j}$ are the regression coefficients for intercept, linearity, square and interaction, respectively; $X_{j}$ is the coded independent variable and the terms $X_{i} X_{j}$ and $X_{i}^{2}$ represent the interaction and quadratic terms, respectively. An analysis of variance (ANOVA) with 95\% confidence level was done for each response variable in order to test the model significance and suitability. The significance of each coefficient was determined using the F-value test, at a 95\% confidence level. Experimental design and main results are presented in table 1. 
Table 1. Experimental conditions, extraction yield and molecular weight of the extracted $\beta$-glucans from barley in each of the 15 experiments that form the Box-Behnken experimental design.

\begin{tabular}{|c|ccc|cccc|}
\hline \multirow{2}{*}{ TRIAL } & \multicolumn{3}{|c|}{ EXPERIMENTAL CONDITIONS } & \multicolumn{4}{c|}{ EXPERIMENTAL RESULTS } \\
\cline { 2 - 8 } & Amplitude (\%) & Time (min) & Cycle (\%) & Ext Yield (\%) & $\mathbf{M}_{\mathbf{w}}$ (kDa) & $\mathbf{M}_{\mathbf{w}} / \mathbf{M}_{\mathbf{n}}$ & Energy (kJ/L) \\
\hline 1 & 60 & 3 & 0.9 & 40.5 & 434 & 1.64 & 109.5 \\
\hline 2 & 100 & 3 & 0.9 & 51.5 & 401 & 1.69 & 206.5 \\
\hline 3 & 60 & 17 & 0.9 & 63.0 & 278 & 1.79 & 620.5 \\
\hline 4 & 100 & 17 & 0.9 & 65.8 & 262 & 1.83 & 1169.5 \\
\hline 5 & 60 & 10 & 0.8 & 51.7 & 415 & 1.66 & 324.5 \\
\hline 6 & 100 & 10 & 0.8 & 64.6 & 308 & 1.70 & 611.5 \\
\hline 7 & 60 & 10 & 1 & 56.2 & 309 & 1.77 & 405.5 \\
\hline 8 & 100 & 10 & 1 & 61.0 & 289 & 1.77 & 764.5 \\
\hline 9 & 80 & 3 & 0.8 & 43.0 & 447 & 1.69 & 136.0 \\
\hline 10 & 80 & 17 & 0.8 & 62.1 & 322 & 1.80 & 770.0 \\
\hline 11 & 80 & 3 & 1 & 44.3 & 461 & 1.71 & 170.0 \\
\hline 12 & 80 & 17 & 1 & 66.1 & 269 & 1.86 & 962.5 \\
\hline 13 & 80 & 10 & 0.9 & 59.5 & 310 & 1.78 & 509.5 \\
\hline 14 & 80 & 10 & 0.9 & 57.6 & 313 & 1.77 & 509.5 \\
\hline 15 & 80 & 10 & 0.9 & 61.4 & 369 & 1.79 & 509.5 \\
\hline
\end{tabular}

\section{RESULTS AND DISCUSSION}

Table 1 summarizes the operational conditions and experimental results obtained in the 15 runs of the Box-Behnken experimental design for the UAE process. The experimental conditions, the observed responses (extraction yield and $\mathrm{M}_{\mathrm{w}}$ ), the polydispersity index of the molecular weight distribution and the specific energy consumed in each experiment are presented in table 1. Extraction yield has varied in the range $40.5-66.1 \%$ (experiments 1 and 12 ), and $M_{w}$ was in the range $262 \mathrm{kDa}-461 \mathrm{kDa}$ (experiments 4 and 11 ). In the experimental design the energy has varied from $109.5 \mathrm{~kJ} / \mathrm{L}$ in experiment 1 to $1169.5 \mathrm{~kJ} / \mathrm{L}$ in experiment 4.

When the extraction was performed in the stirred tank, according to the conditions described in section 2.2.1, the extraction yield has been $41.5 \%$ and the weight average molecular weight of the extracted $\beta$-glucans was $431 \mathrm{kDa}$.

\subsection{Effect of US variables on the extraction yield}

Experimental results show that extraction yields achieved in the UAE experiments were higher than those obtained in the stirred tank process (41.5\%), except in the case of experiment 1 , in which the lowest energy input was used. These results indicate the feasibility of using ultrasounds to extract $\beta$-glucans from barley. 
Figure 1 shows the main effects plot for the extraction yield, and it includes the effect that a change in one of the process parameters has on the extraction yield. It can be clearly seen that extraction yield is mainly affected by the extraction time and the amplitude of oscillation.

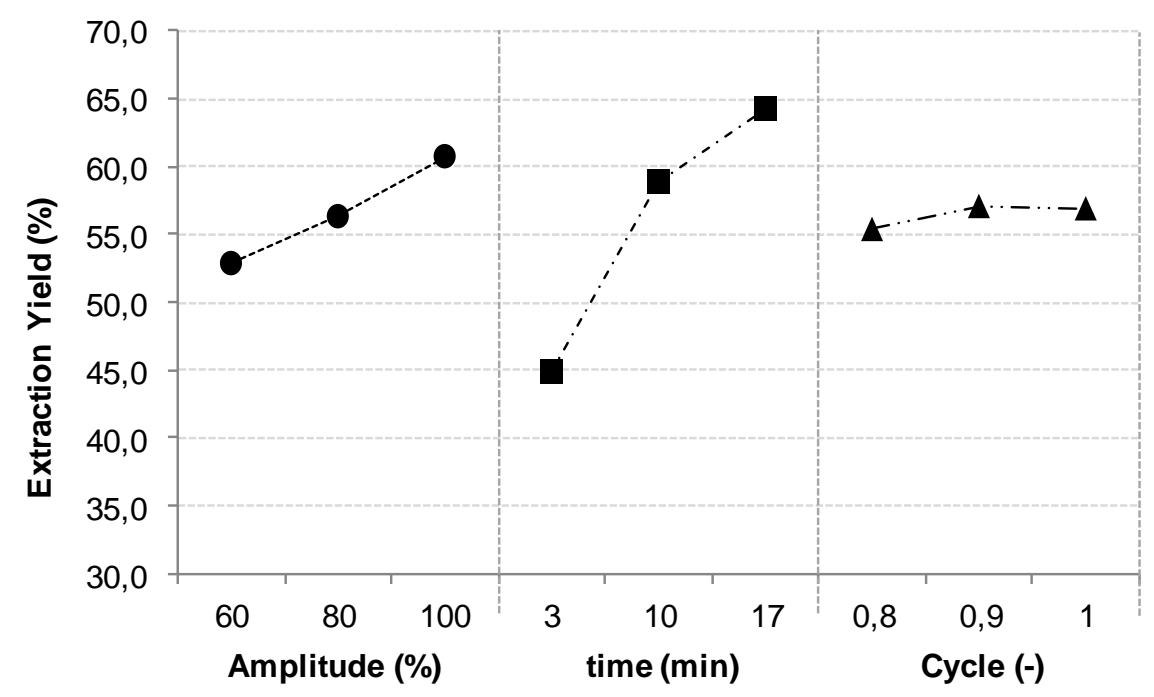

Figure 1. Main effects diagram for extraction yield. Effect of amplitude ( $\bullet$ ), time ( $\boldsymbol{\nabla})$, and cycle ( $\boldsymbol{\Delta}$ ) on the extraction yield

The most significant changes are observed when the extraction time is increased. The longer the extraction time the higher the extraction yield, but its effect on the extraction yield is not completely linear for the experimental range. When extraction time is increased from 3 to 10 minutes, extraction yield increases deeper than in the case of varying the time from 10 to 17 minutes. The amplitude of oscillation controls the intensity of the cavitation, which helps to release the $\beta$-glucan from the matrix where it is trapped; therefore, the higher the amplitude the higher the extraction yield. The effect of the continuous or pulsed sonication is more limited, and its effect will have to be evaluated as a function of the levels of the other factors.

Results of the variance analysis are presented in table 2 , and they can be used to discuss the interaction between factors. 
Table 2. ANOVA table for the extraction yield results

\begin{tabular}{|l|c|c|c|c|c|}
\hline \multicolumn{1}{|c|}{ Source } & SS & DF & Mean Square & F-value & p-Value \\
\hline A:Amplitude & 124.031 & 1 & 124.031 & 45.46 & 0.0011 \\
B:Time & 754.661 & 1 & 754.661 & 276.58 & 0.0000 \\
C:Cycle & 4.805 & 1 & 4.805 & 1.76 & 0.2419 \\
AA & 0.0369 & 1 & 0.0369 & 0.01 & 0.9119 \\
AB & 16.81 & 1 & 16.81 & 6.16 & 0.0557 \\
AC & 16.4025 & 1 & 16.4025 & 6.01 & 0.0578 \\
BB & 71.4831 & 1 & 71.4831 & 26.2 & 0.0037 \\
BC & 1.8225 & 1 & 1.8225 & 0.67 & 0.4509 \\
CC & 5.54077 & 1 & 5.54077 & 2.03 & 0.2135 \\
\hline Total Error & 13.6425 & 5 & 2.7285 & \multicolumn{4}{l}{} \\
Total (corr.) & 1007.52 & 14 & \multicolumn{5}{|l}{}
\end{tabular}

Critical value $\left(F_{0}\right)$ for the F-test: $6.61\left(F_{0.05,1,5}\right)$

From table 2 it can be inferred that Amplitude and time interaction and Amplitude and cycle interaction are statistically significant. The energy consumed in the UAE is very sensitive to the amplitude of oscillation and time. According to the results presented in table 1, the higher the energy consumed the higher the extraction yield. Therefore, in order to maximize the extraction yield high intensity treatments are needed which mean long times and high amplitudes. When these conditions are selected to run the UAE, the effect of the cycle on the extraction yields is almost negligible, as it is shown in figure 2, where contour plots of the interaction between Amplitude *time effect on extraction yield are shown. In all the cases, at a fixed extraction time, the higher the amplitude the higher the extraction yield. At higher cycles (when equals 1 ) this effect is less dramatic than that observed in pulsed sonication (cycle 0.8). From figure 2 it can be concluded that cycle has a clear effect on the extraction yield only at low amplitudes. 

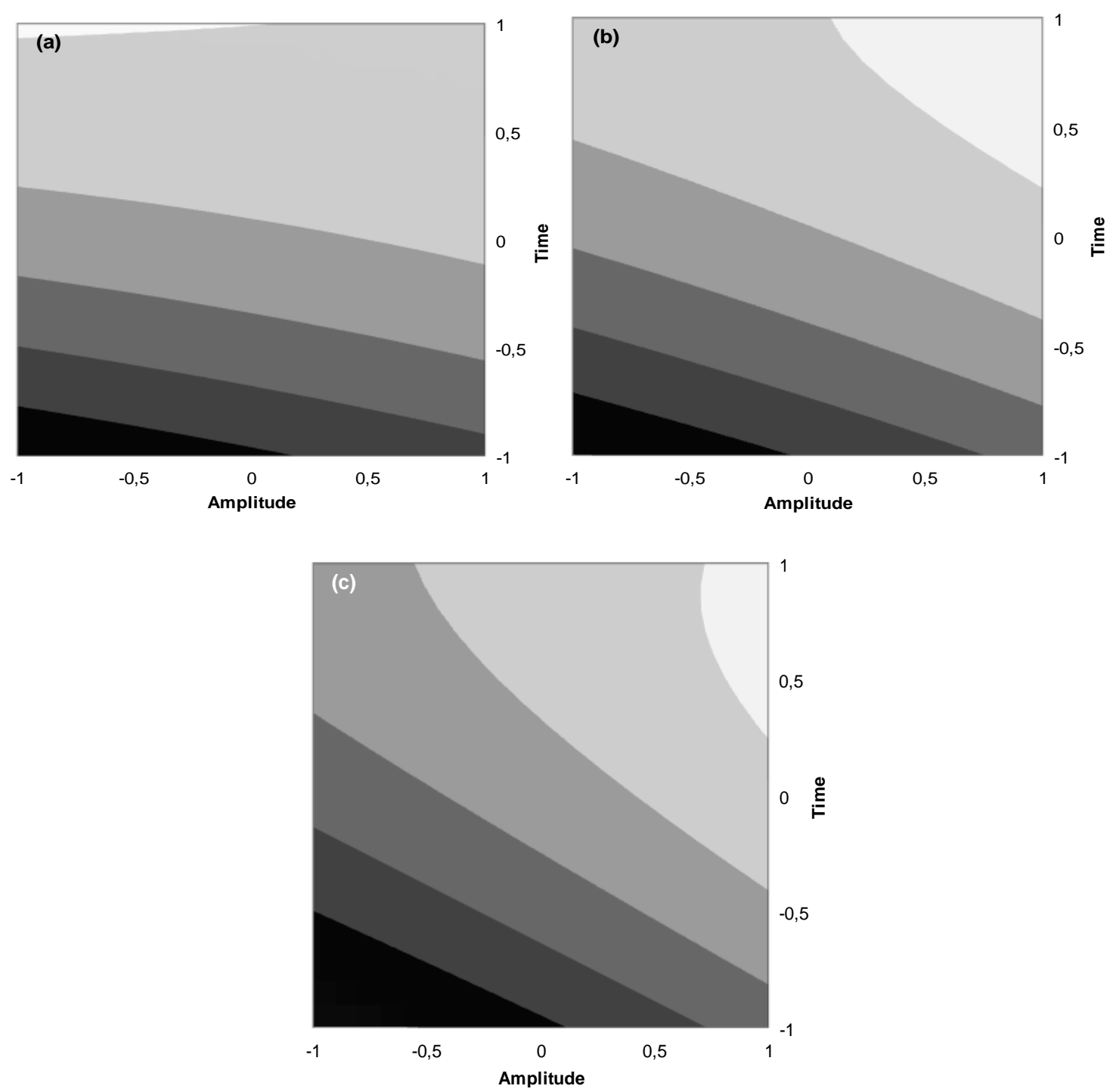

Figure 2. Contour plots for the effects of extraction time and amplitude interaction on the extraction yield, (a) cycle=1, (b) cycle=0.9 and (c) cycle=0.8; key: $\square$ 40-45\%, $\square$ 45-50\%; $\square 50-55 \% ; \square 55-60 \%, \square 0$ $65 \%$ and $\quad 65-68 \%$ extraction yield

Although high intensity treatments contribute to release the $\beta$-glucans from the grain they also produce an important temperature increase in the extraction vessel. In order to prevent temperatures above $60^{\circ} \mathrm{C}$, which lead to starch gelatinization, the extraction vessel demands an effective cooling system that helps to control the temperature. However, it was seen that the use of pulsed sonication can be a useful tool to control the temperature of the system: at high intensity treatments (100\% and 17 minutes) cycle does not affect the extraction yield, but helps to control the temperature of the extraction tank. Sonication in pulses is smoother; therefore temperature increase is much slower and hence much easier to control.

From the study of the experimental factors on the extraction yield it can be concluded that time is the dominant effect, and it can be reduced if the amplitude of oscillation is increased. 
Under these conditions, (high extraction times and high amplitudes) the effect of cycle on the extraction yield is very low, but it helps to control the temperature during the extraction.

\subsection{Effect of US variables on the molecular weight distribution}

Compared to the extraction yield, sonication caused the opposite effect on molecular weight: the higher the intensity, the lower the molecular weight. Therefore, in order to preserve the $\mathrm{MW}$, low intensity treatments should be carried out. Figure 3 shows the main effects plot for molecular weight: it can be seen that MW is affected mainly by time and in lower extent by the amplitude and cycle. In this case, the time is the most influential factor on the molecular weight. Molecular weight of the $\beta$-glucan is affected by the shear forces generated during cavitation: the higher the amplitude of oscillation the more intense cavitation and the lower the molecular weight. If $\beta$-glucan are exposed to the shear forces for long times it will be degraded. Therefore, in order to obtain $\beta$-glucans with high molecular weight, amplitude, time and cycle must be selected carefully.

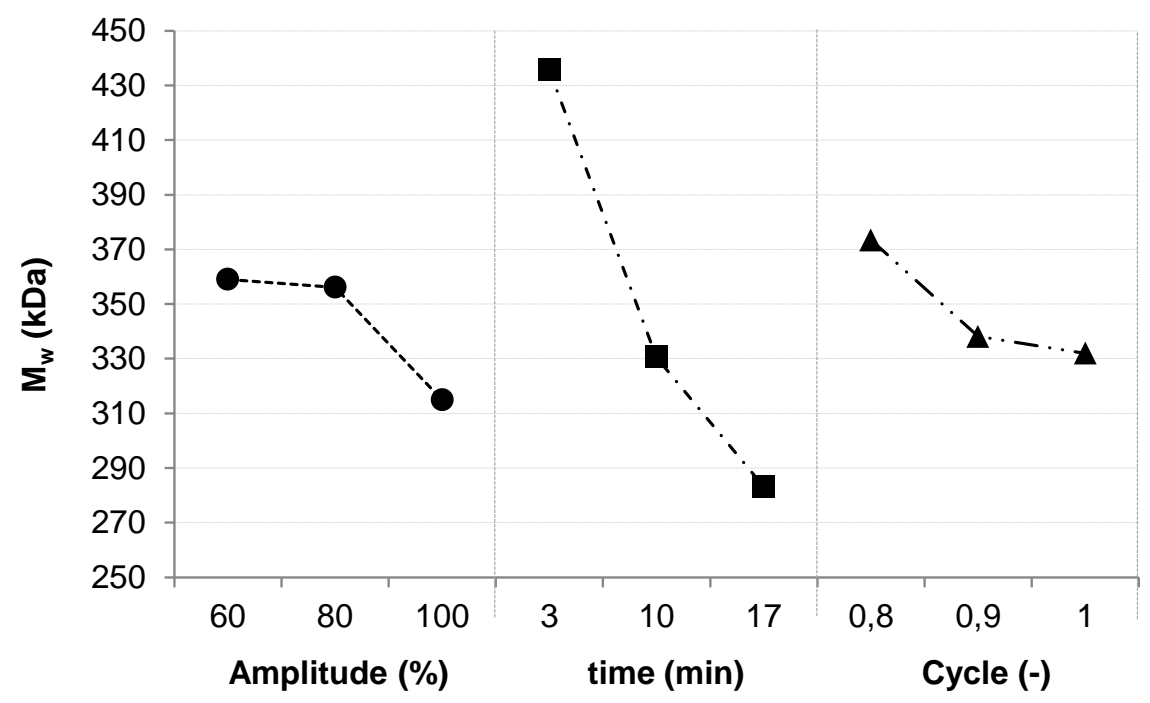

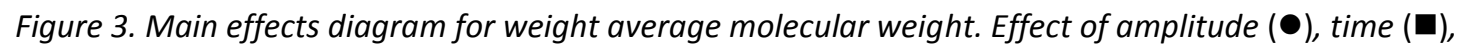
and cycle $(\mathbf{\Delta})$ on the average molecular weight

The interaction of Cycle and amplitude has been established as the most significant interaction between factors (according to the analysis of variance presented in table 3). Moreover, the more energy delivered to the barley the higher the reduction of molecular weight of the extracted $\beta$-glucan. It is in this case that the interaction between factors plays an important role in the final performance of the extracted polymer. 
Table 3. ANOVA table for the weight average molecular weight results

\begin{tabular}{|l|c|c|c|c|c|}
\hline \multicolumn{1}{|c|}{ Source } & SS & DF & Mean Square & F-value & p-Value \\
\hline A:Amplitude & $3.90 \mathrm{E}+06$ & 1 & $3.90 \mathrm{E}+06$ & 4.95 & 0.0766 \\
B:Time & $4.66 \mathrm{E}+07$ & 1 & $4.66 \mathrm{E}+07$ & 59.21 & 0.0006 \\
C:Cycle & $3.44 \mathrm{E}+06$ & 1 & $3.44 \mathrm{E}+06$ & 4.38 & 0.0907 \\
AA & $9.44 \mathrm{E}+05$ & 1 & $9.44 \mathrm{E}+05$ & 1.2 & 0.3234 \\
AB & $6.99 \mathrm{E}+04$ & 1 & $6.99 \mathrm{E}+04$ & 0.09 & 0.7777 \\
AC & $1.86 \mathrm{E}+06$ & 1 & $1.86 \mathrm{E}+06$ & 2.36 & 0.185 \\
BB & $3.05 \mathrm{E}+06$ & 1 & $3.05 \mathrm{E}+06$ & 3.87 & 0.1062 \\
BC & $1.12 \mathrm{E}+06$ & 1 & $1.12 \mathrm{E}+06$ & 1.42 & 0.2868 \\
CC & $8.86 \mathrm{E}+05$ & 1 & $8.86 \mathrm{E}+05$ & 1.13 & 0.3372 \\
\hline Error total & $3.93 \mathrm{E}+06$ & 5 & $7.87 \mathrm{E}+05$ & & \\
Total (corr.) & $6.60 \mathrm{E}+07$ & 14 & \multicolumn{4}{|l}{} \\
\cline { 1 - 3 } &
\end{tabular}

Critical value $\left(F_{0}\right)$ for the F-test: $6.61(F 0.05,1,5)$

Contour plots for cycle and time (Fig. 4) reveal the need of using low intensity treatments (short times, low amplitudes and sonication in pulses) to obtain high molecular weight $\beta$ glucans.
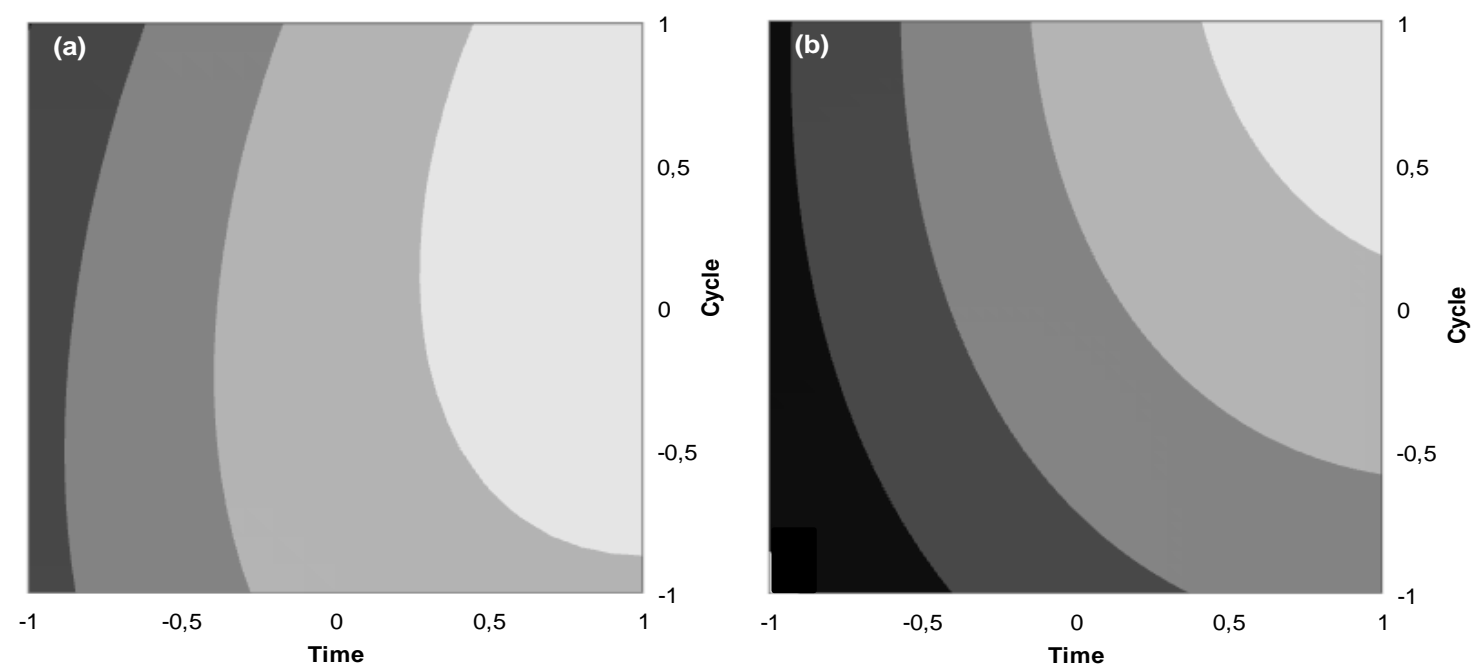

Figure 4. Contour plots for the effects of cycle and time interaction on the weight average molecular

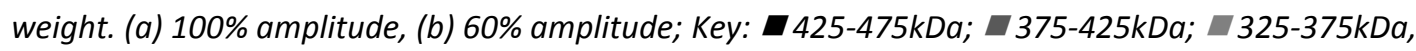
275-325kDa and 225-275kDa

\subsection{Energy in the UAE process}

Extraction yield and weight average molecular weight obtained in each experiment were plotted versus the specific energy input (figure 5). 


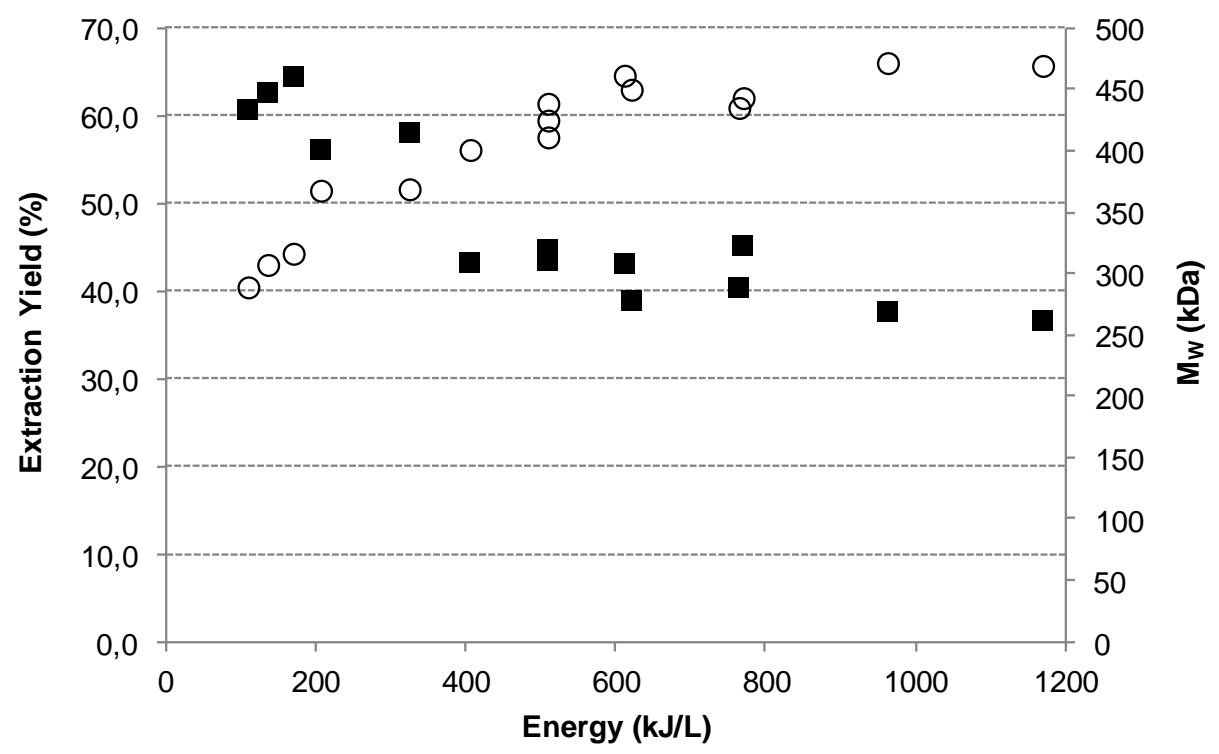

Figure 5. Effect of the energy spent in the UAE process on the extraction yield (O) and the weight average molecular weight $(\mathbf{\square})$ of the extracted $\beta$-glucan

The energy consumed and delivered during the extraction depends on the combination of the operating variables. From figure 5, it can be clearly seen that the spent energy plays an important role both on extraction yield and molecular weight. Increments in the energy delivered increase the extraction yield, up to a maximum value (around $65 \%$ at $650 \mathrm{~kJ} / \mathrm{L}$ ) without further improvements. However, the contrary effect was observed on molecular weight: low energy treatments (below $250 \mathrm{~kJ} / \mathrm{L}$ ) contribute to increase molecular weight. Low intensity treatments involve short extraction times (shorter than 10 minutes) and medium amplitudes.

According to these results it is possible to set a critical value of the energy involved in the UAE process, that makes the rupture of the $\beta$-glucan backbone be a dominant effect instead of solubilization. The most successful results have been obtained in the range $250-425 \mathrm{~kJ} / \mathrm{L}$. Higher intensity treatments (above $500 \mathrm{~kJ} / \mathrm{L}$ ) are only useful for the control of molecular weight of the polymer since they contribute to a partial depolymerization.

The energy requirements in the stirred tank extraction are linked to the maintenance of the flour-water mixture in suspension. The power consumed by the lab stirrer is $27 \mathrm{~W}$ that represents around $1460 \mathrm{~kJ} / \mathrm{L}$ for a 3 hours extraction process, much higher than the energy required for the UAE process. 


\subsection{Model fitting and Optimization}

The data obtained in the Box-Behnken experimental design (described in table 1) for each response variable (extraction yield and molecular weight) were converted into a second-order polynomial equation with three independent variables, according to equation 4 , by using the statistical software Minitab 15. The two resulting polynomial equations are:

Extraction yield $(\%)=59.5+3.94 \mathrm{X}_{1}+9.70 \mathrm{X}_{2}+0.76 \mathrm{X}_{3}+0.08\left(\mathrm{X}_{1}\right)^{2}-4.40\left(\mathrm{X}_{2}\right)^{2}-1.24\left(\mathrm{X}_{3}\right)^{2}-2.08 \mathrm{X}_{1} \mathrm{X}_{2}-$ $2.04 X_{1} X_{3}+0.68 X_{2} X_{3}$

$M_{w}(k D a): \quad 330.8-22.01 X_{1}-76.3 X_{2}-20.7 X_{3}-15.99\left(X_{1}\right)^{2}+28.7\left(X_{2}\right)^{2}+15.5\left(X_{3}\right)^{2}+4.2 X_{1} X_{2}+$ $21.5 X_{1} X_{3}-16.7 X_{2} X_{3}$

The multiple coefficient of correlation $\left(R^{2}\right)$ obtained for each linear regression model (extraction yield and $M_{w}$ ) is 0.9862 and 0.9404 , respectively. This value indicates a close agreement between experimental and predicted values; therefore, based on these polynomial equations (5) and (6), an optimization study was carried out to evaluate the optimal operating conditions that maximize extraction yield, molecular weight and both of them at the same time. In order to verify the optimal parameters proposed by the polynomial equation and the statistical software, experiments were done in those conditions. Table 4 shows the optimal conditions for each individual response with the predicted and experimental values (two replicates of each experiment were done).

Table 4. Predicted and experimental results obtained under the calculated optimum conditions

\begin{tabular}{|c|ccc|cc|cr|}
\cline { 2 - 8 } \multicolumn{1}{c|}{} & \multicolumn{4}{c|}{ Process Variables } & \multicolumn{2}{c|}{ Extraction Yield (\%) } & \multicolumn{2}{c|}{$\mathbf{M}_{\mathbf{W}}(\mathbf{k D a})$} \\
\hline $\begin{array}{c}\text { Maximized } \\
\text { Response }\end{array}$ & $\begin{array}{c}\text { Amplitude } \\
(\%)\end{array}$ & $\begin{array}{c}\text { Time } \\
\text { (min) }\end{array}$ & $\begin{array}{c}\text { Cycle } \\
(-)\end{array}$ & Predicted & Observed & Predicted & Observed \\
\hline Extraction Yield & 100 & 15.9 & 0.9 & 66.9 & $65.6 \pm 1.2$ & 257.9 & $261.4 \pm 7.3$ \\
MW & 60 & 3 & 0.8 & 36.1 & $37.3 \pm 0.7$ & 487.2 & $483.3 \pm 3.2$ \\
Extraction Yield \& MW & 80 & 7.6 & 0.8 & 53.7 & $52.4 \pm 0.9$ & 392.2 & $388.6 \pm 4.6$ \\
\hline
\end{tabular}

As observed in table 4, there is a close agreement between the experimental results and the predicted ones using the polynomial equation. As expected, high intensity treatments lead to low molecular weights but high extraction yields: extraction yield is maximized, and energy consumed around $1055 \mathrm{~kJ} / \mathrm{L}$. If the target is to obtain the highest $\mathrm{MW}$, low intensity treatments are required $(97 \mathrm{~kJ} / \mathrm{L})$. Finally, intermediate energy conditions $(344 \mathrm{~kJ} / \mathrm{L})$ represent a compromise between the amount of $\beta$-glucan extracted and their molecular weight. 


\section{CONCLUSIONS}

Ultrasound assisted extraction have demonstrated to be an efficient process (extraction yield $>40.5 \%$ ) to extract high molecular weight $\beta$-glucans (>260 kDa) from barley. Cavitation created during sonication improves mass transfer limitations of the extraction process. The UAE process requires very short extraction times (3-10minutes) and consumes low amount of energy $(<500 \mathrm{~kJ} / \mathrm{L}$ ). In the design of a UAE process, energy (time, amplitude and cycle as a consequence) must be chosen as a function of the desired final product, in terms of $\beta$-glucan content and molecular weight. The final performance of the process will depend on the features of the desired product. The obtained results have revealed that energy (essentially controlled by time and amplitude) is the critical factor in the UAE process. The most successful results have been obtained in the range $250-425 \mathrm{~kJ} / \mathrm{L}$. Lower intensity treatments allow to obtain $\beta$-glucans with high molecular weight ( $>400 \mathrm{kDa}$ ) but with extraction efficiencies below $50 \%$. However, high intensity treatments (>500 kJ/L) cause an important depolymerization of the $\beta$-glucans, which in some cases can be the purpose. Although the effect of cycle on yield and $\mathrm{MW}$ is limited, it has been seen as a useful mechanism to control the temperature of the system.

\section{ABBREVIATIONS}

$\beta$-glucans: $(1 \rightarrow 3),(1 \rightarrow 4)-\beta$-D-glucan

UAE: Ultrasound Assisted Extraction

US: Ultrasounds

MW: Molecular Weight

$\mathrm{M}_{\mathrm{w}}$ : Weight Average Molecular Weight

$M_{n}$ : Number Average Molecular Weight 


\section{REFERENCES}

APHA-AWWA-WPCF, (1992). Métodos Normalizados para el Análisis de aguas potables y residuales, $17^{\text {th }}$. Ediciones Díaz de Santos S.A., Madrid, Spain.

Benito-Román, O., Alonso, E., \& Lucas, S. (2011). Optimization of the $\beta$-glucan extraction conditions from different waxy barley cultivars. Journal of Cereal Science, 53, 271-276.

Brennan, C.S., \& Cleary, L.J. (2005). The potential use of cereal (1-3,1-4)- $\beta$-D-glucans as functional food ingredients. Journal of Cereal Science, 42(1), 1-13.

Chemat, F., Huma, Z-e., \& Khan, M.K. (2011). Applications of ultrasound in food technology: Processing, preservation and extraction. Ultrasonics Sonochemistry, 18(4), 813-835.

EFSA Panel on Dietetic Products, Nutrition and Allergies (2010). Scientific Opinion on the substantiation of a health claim related to oat beta-glucan and lowering blood cholesterol and reduced risk of (coronary) heart disease pursuant to Article 14 of Regulation (EC) No 1924/2006. EFSA Journal, 8(12),1885.

FDA. (2005). 21 CFR Part 101. Food labeling, health claims; soluble dietary fiber from certain foods and coronary heart disease. Federal Register 70, 246, 76150-76162.

Huang, S-q., \& Ning, Z-x. (2010). Extraction of polysaccharide from Ganodermalucidum and its immune enhancement activity. International Journal of Biological Macromolecules, 47(3), 336341.

lida, Y., Tuziuti, T., Yasui, K., Towata, A., \& Kozuka, T. (2008). Control of viscosity in starch and polysaccharide solutions with ultrasound after gelatinization. Innovative Food Science and Emerging Technologies, 9, 140-146.

Izydorczyk, M. S., Storsley, J., Labossiere, D., MacGregor, A. W. \& Rossnagel, B. G. (2000). Variation in Total and Soluble $\beta$-Glucan Content in Hulless Barley: Effects of Thermal, Physical, and Enzymic Treatments. Journal of Agricultural and Food Chemistry, 48, 982-989.

Izydorczyk, M.S., \& Dexter, J.E. (2008). Barley $\beta$-glucans and arabinoxilans: Molecular structure, physicochemical properties, and uses in food products-a review. Food Research International, $41,850-868$

Keenan, J.M., Goulson, M., Shamliyan, T., Knutson, N., Kolberg, L., \& Curry, L. (2007). The effects of concentrated barley $\beta$-glucan on blood lipids and other CVD risk factors in a population of hypercholesterolaemic men and women. The British journal of nutrition, 97, $1162-1168$. 
Koda, S., Taguchi, K., \& Futamura, K. (2011). Effects of frequency and a radical scavenger on ultrasonic degradationof water-soluble polymers. Ultrasonics Sonochemistry, 18, 276-281

McIntosh, G.H., Whyte, J., McArthur, R., \& Nestel, P.J. (1991). Barley and wheat foods: Influence on plasma cholesterol concentrations in hypercholesterolemic men. American Journal of Clinical Nutrition, 53, 1205-1209.

Newman, R.K., Lewis, S.E., Newman, C.W., Boik, R.J., \& Ramage, R.T. (1989). Hypocholesterolemic effect of barley foods on healthy men. Nutrition Reports International, 39, 749-760.

Rodríguez-Rojo, S., Visentin, A., Maestri, D., \& Cocero M.J. (2012). Assisted extraction of rosemary antioxidants with green solvents. Journal of Food Engineering, 109(1), 98-103.

Vårum, K.M., \& Smidsrød, O. (1988). Partial Chemical and Physical Characterisation of $(1 \rightarrow 3),(1 \rightarrow 4)-\beta-$ D-Glucans from Oat (Avena sativa L.) Aleurone. Carbohydrate Polymers, 9, 103-117.

Vilkhu, K., Mawson, R., Simons, L., \& Bates, D. (2008). Applications and opportunities for ultrasound assisted extraction in the food industry - A review. Innovative Food Science and Emerging Technologies, 9, 161-169.

Wang, J., Sun, B., Cao, Y., Tian, Y., \& Li, X. (2008). Optimization of ultrasound-assisted extraction of phenolic compounds from wheat bran. Food Chemistry, 106, 804-810.

Wood, P.J. (2007). Cereal $\beta$-glucans in diet and health. Journal of Cereal Science, 46, 230-238.

Yang, B.; Jiang, Y.; Zhao, M.; Shi, J.; Wang, L. (2008). Effects of ultrasonic extraction on the physical and chemical properties of polysaccharides from longan fruit pericarp. Polymer Degradation and Stability, 93, 268-272. 


\section{CHAPTER 3}

Effect of pressure and temperature on the dissolution of $\beta$-glucan in Pressurized Hot Water 



\title{
Effect of pressure and temperature on the dissolution of $\beta$-glucan in Pressurized Hot Water
}

\begin{abstract}
The purpose of this work was the study of the dissolution phenomenon of $\beta$-glucan in water at high temperatures and pressures. The concentration of $\beta$-glucan as well as starch and the main degradation sugars and oligosaccharydes (cellobiose, glucose, fructose and HMF) was measured at three different temperatures $\left(120,150,170^{\circ} \mathrm{C}\right)$ after several experimental times (from 10 to $360 \mathrm{~min}$ ). At $120^{\circ} \mathrm{C}$ it was found that the highest $\beta$-glucan concentration was measured after $75 \mathrm{~min}$, and at 150 and $170^{\circ} \mathrm{C}$ optimal times were 45 and 20 minutes respectively. The maximum amount of $\beta$-glucan dissolved in each of the optimal conditions was $1.4,2.1$ and $2.0 \mathrm{~g} / \mathrm{L}$, respectively. Starch concentration decreased very fast at 150 and $170^{\circ} \mathrm{C}$, being stabilized around $100 \mathrm{ppm}$ after one hour. Cellobiose, as the first stage in the degradation of $\beta$-glucan, decreased in all the experiments, regardless the temperature. Other hydrolysis products, such as glucose, tent to decrease leading to the appearance of HMF as final degradation product. The presence of this compound was visually identified as it gave brown color to the solution. Finally it was evaluated the molecular weight of the $\beta$-glucan dissolved in the optimal time for each temperature. An important reduction in the molecular weight was observed, compared to the initial $(450 \mathrm{kDa})$ : at $120^{\circ} \mathrm{C}$ and $75 \mathrm{~min}$, final $\mathrm{MW}$ was $63 \mathrm{kDa}$; at $150^{\circ} \mathrm{C}$ and $45 \mathrm{~min}$ it was reduced up to $8 \mathrm{kDa}$, and at $170^{\circ} \mathrm{C}$ and $20 \mathrm{~min}$ it was only $7 \mathrm{kDa}$.

These results revealed the convenience of the use of PHW to dissolve $\beta$-glucan, as the operation times were reduced and the $\mathrm{MW}$ was controlled (low molecular weight $\beta$-glucan was obtained in one single step without requiring the use of enzymatic hydrolysis). These results will serve as basis for the extraction of $\beta$-glucan from barley using PHW as solvent.
\end{abstract}

Keywords: $\beta$-glucan, starch, barley, pressurized hot water, polysaccharide 


\section{INTRODUCTION}

$\beta$-glucans, a D-glucose linear polymer, are the major fiber constituent of barley. In this polymer glucose is linked to other two or three units by means of $\beta$-(1-4)-0-glucosidic linkage (cellobiose or cellotriose blocks) which in turn are separated by a $\beta$-(1-3)-0-glucosidic linkage. The presence of this 1-3 linkage alters the linear structure of the polymer, allowing the water to get into the different $\beta$-glucan chains and getting it dissolved as a consequence. The final solubility properties of the $\beta$-glucan are affected by a huge number of parameters referring to the molecular structure (Lazaridou et al, 2007): the ratio $\beta-(1-4) / \beta-(1-3)$ linkages; the length of the $\beta-(1-4)$ structures and the molecular weight.

There is an important number of extraction procedures of $\beta$-glucan and according to Vashantan and Temelli (2008) can be classified in two types: dry and wet. Wet extraction processes are the most common and simple as they use water or alkali solutions to extract $\beta$ glucans at temperatures in the range $40-75^{\circ} \mathrm{C}$. Despite of the extensive research performed in the enhancement of the wet procedures, in any of them the solubility of $\beta$-glucan was studied. This kind of studies can be difficult to be carried out, as the solubility of a polymer will depend on its molecular weight; which can change while the dissolution process is taking place. In our own experience (Benito-Román et al, 2011), the study of a conventional extraction process showed an increase of the $\beta$-glucan solubility with temperature. Increases in temperature when extracting $\beta$-glucan from barley present two parallel effects: the increase of $\beta$-glucan solubility and the gelification of starch (Wood et al, 1978). At temperatures above $63^{\circ} \mathrm{C}$ starch gelification occurs: its concentration in water is increased by ten times, leading to an increase of the viscosity of the media. High viscosities reduce the efficiency of the stirring and hence the release and dissolution of $\beta$-glucan is hindered. This is the reason why we decided to set $55^{\circ} \mathrm{C}$ as the best temperature to extract $\beta$-glucan from barley as it was a compromise between the amount of $\beta$-glucan extracted and the amount of starch co-extracted. According to these results a new procedure that helps to increase of the $\beta$-glucan extraction rate reducing the amount of starch is required.

The use of pressurized hot water (PHW) for the $\beta$-glucan extraction appears to be an attractive alternative to increase the solubility of $\beta$-glucans and to avoid mass transfer limitations. The term PHW refers to the water in liquid state in the range $100^{\circ} \mathrm{C}$ (boiling point) and $374^{\circ} \mathrm{C}$ (critical point of water) by the application of pressure. Properties of water change dramatically when changing pressure and, specially, temperature. An increase in temperature affects density, surface tension, viscosity and diffusion; all of them properties involved in mass 
transfer phenomena. PHW presents lower viscosity but higher diffusivity, which favors the diffusion into the vegetal matrix and the release of compounds (Teo et al, 2010) and therefore may help to release the $\beta$-glucan into the solution. The changes of some of the properties are summarized in table 1 . Properties of water at $55^{\circ} \mathrm{C}$ and atmospheric pressure are: density $\left(985.7 \mathrm{~kg} / \mathrm{m}^{3}\right)$; viscosity $(0.8904 \mathrm{cP})$ and dielectric constant $(78.4)$.

Table 1. Properties of water at different temperatures (pressure 20bar)

\begin{tabular}{|c|c|c|c|}
\hline $\begin{array}{c}\text { Temperature } \\
\left({ }^{\circ} \mathbf{C}\right)\end{array}$ & $\begin{array}{c}\text { Density } \\
\left(\mathbf{k g} / \mathbf{m}^{\mathbf{3}}\right)\end{array}$ & $\begin{array}{c}\text { Viscosity } \\
(\mathbf{c P})\end{array}$ & $\begin{array}{c}\text { Dielectric Constant } \\
\mathbf{( - )}\end{array}$ \\
\hline 100 & 961.06 & 0.2830 & 55.515 \\
110 & 953.27 & 0.2556 & 52.998 \\
120 & 944.81 & 0.2326 & 50.594 \\
130 & 935.79 & 0.2131 & 48.299 \\
140 & 926.32 & 0.1965 & 46.105 \\
150 & 916.5 & 0.1821 & 44.009 \\
160 & 906.41 & 0.1697 & 42.004 \\
170 & 896.12 & 0.1589 & 40.083 \\
180 & 885.68 & 0.1495 & 38.242 \\
190 & 875.08 & 0.1411 & 36.472 \\
200 & 864.29 & 0.1337 & 34.768 \\
\hline
\end{tabular}

PHW has been used for a double purpose: first, to extract polysaccharides form a natural matrix, as it helps to weaken the interactions between the target molecule and the matrix; and second PHW has also been involved in the hydrolysis of polysaccharides (i.e. starch) to obtain the monomers that form the polysaccharide (hexoses when the substrate is starch or cellulose; or pentoses form arabinoxylans). There are two signs that would indicate the hydrolysis of $\beta$ glucan: a decrease in the molecular weight and on the other hand the presence of sugar degradation products, such as cellobiose, glucose or in the last term HMF (the final degradation product of hexoses).

As a previous step to the study of the extraction of $\beta$-glucan from barley using $\mathrm{PHW}$ it is necessary to perform an study of how the temperature and pressure affect $\beta$-glucan (as it is the target compound) and starch, as it is the major component of barley and the one that causes more inconveniences to the extraction of $\beta$-glucan. The purpose of the present work was to study the behavior of the $\beta$-glucan in water at high temperatures and pressures. A concentrate of $\beta$-glucan (36.5\% and $25.4 \%$ of starch) was used: all the mass transfer limitations derived from the water diffusing into the solid matrix and the release of the polysaccharide should be avoided in this study. The results obtained in the present work will be used as basis for the extraction of $\beta$-glucan from barley using PHW as solvent. 


\section{MATERIALS AND METHODS}

\subsection{Raw Material}

A high molecular weight $\beta$-glucan concentrate (36.5\% in $\beta$-glucan and $25.4 \%$ in starch) was used in this study. This concentrate was obtained in our laboratory, using waxy barley $(4.8 \%$ in $\beta$-glucan and $52 \%$ in starch, both in dry basis) as primary source of $\beta$-glucan. Barley was pretreated with ethanol under reflux for two hours (flour to ethanol $(80 \% \mathrm{v} / \mathrm{v}$ ) ratio of 1 to 6$)$ in order to deactivate $\beta$-glucanases. The isolation procedure was done at $55^{\circ} \mathrm{C}$ for 3 hours using water as solvent (a detailed description of the isolation procedure can be found at Benito-Román et al, 2011). The liquid extract obtained was dried by means of the Mobile Minor Spray Dryer (GEA NIRO, Denmark). The most significant operating conditions were: dry air inlet temperature, $160{ }^{\circ} \mathrm{C}$; outlet temperature $87-90^{\circ} \mathrm{C}$; atomization wheel spinning at $21000 \mathrm{rpm}$ and sample flow rate to the dryer about $1 \mathrm{~L} / \mathrm{h}$. After all this isolation procedure a concentrate of $450 \mathrm{kDa} \beta$-glucan was obtained.

\subsection{Experimental device}

All the experiments were carried out in a $30 \mathrm{~mL}$ internal volume High-Pressure View Chamber (Eurotechnica GmbH, Germany). Figure 1 shows a picture of the device. Maximum operating pressure and temperature of the device are $300 \mathrm{bar}$ and $500^{\circ} \mathrm{C}$, respectively.

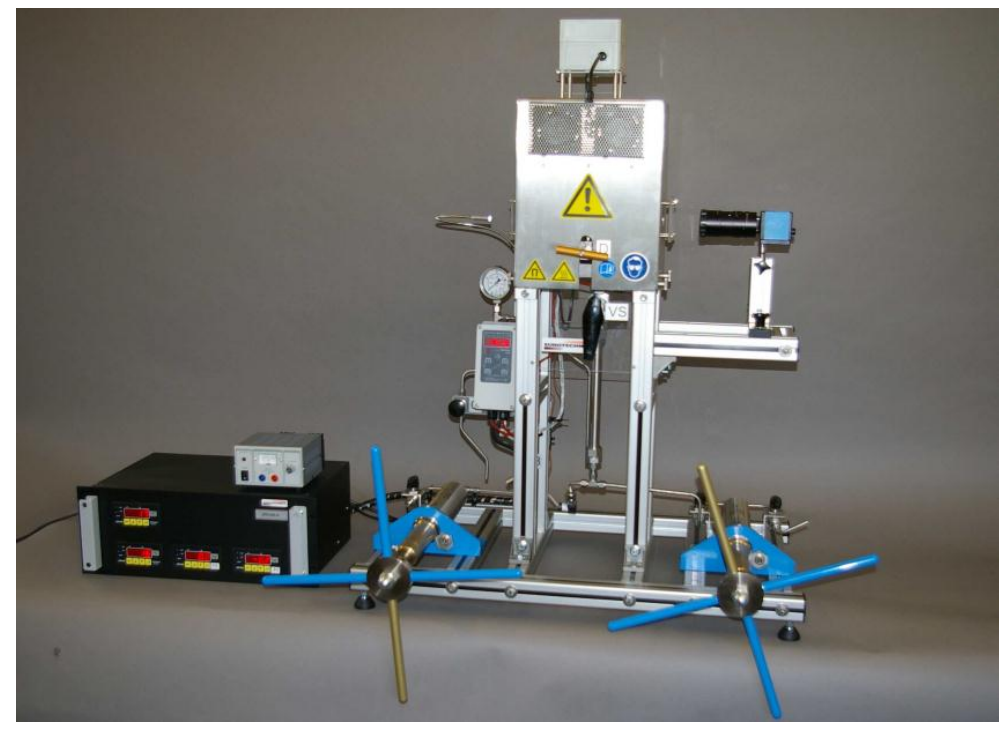

Figure 1. High pressure view chamber.

The experimental set-up consists of two sections: the view chamber itself where water is introduced and adjusted the pressure and temperature, and the area where the solid sample (that has been previously compressed to form a pill) is introduced. This area is filled up with 
water at room temperature and pressurized. These two zones are separated by a valve; once the desired conditions of $\mathrm{P}$ and $\mathrm{T}$ in the chamber are achieved, the valve is opened and the sample is introduced in the view chamber (where stirring can be provided). Finally, after the experiment is concluded a sample of the liquid extract can be taken in order to analyze the compounds that have been dissolved and formed during the experiment.

\subsection{Chemical Analysis}

Megazyme International Ltd "Mixed-linkage $\beta$-glucan" and "Total Starch" assay kits were used to quantify $\beta$-glucan and starch, respectively. Both species were measured in the liquid extract following the standard procedure modifications proposed by Megazyme. Concentration of $\beta$ glucan dissolved was reported in $g$ of $\beta$-glucan $/ \mathbf{1 0 0 g}$ of water. In the mass balance calculations it was considered the variations in density that water experiences when changing temperature and pressure, which results in variations in mass of water introduced in the chamber. Starch dissolved was analyzed following a modification of the general protocol: "starch is present in a soluble form and D-glucose and maltodextrins are present". Results were expressed in $\mathrm{mg} / \mathrm{L}$.

Molecular weight of $\beta$-glucan was determined by Size Exclusion Chromatography (HPLC-SEC) using a chromatography system that consisted of an isocratic pump (Waters 1515), an automatic injector (Waters 717), guard column (ShodexSB-G) and a GPC column (ShodexOHpak SB-804HQ) and a differential refractive index detector (Waters 410). The column was kept at $35^{\circ} \mathrm{C}$, and flow rate of the mobile phase $\left(0.1 \mathrm{M} \mathrm{NaNO}_{3}+0.02 \% \mathrm{NaN}_{3}\right)$ was set at $0.5 \mathrm{~mL} \cdot \mathrm{min}^{-1}$. The $\beta$-glucan molecular weight standards were purchased from Megazyme International Ltd. (Ireland), and were in the range 40-359 kDa.

For the measurement of oligosaccharides and sugars (cellobiose, fructose, glucose and HMF) formed in the extraction process, HPLC was used. Chromatography system was basically the same used for MW determination (pump, injector and detector, including an UV/Visible Detector Waters 2489); column and guard column were purchased to Shodex (model KS-802, guard column KS-G) and set at $60^{\circ} \mathrm{C}$ and mobile phase (MilliQ water) was set at $0.8 \mathrm{~mL} \cdot \mathrm{min}^{-1}$.

\subsection{Experimental Procedure}

In all the experiments a $0.35 \mathrm{~g}$ pill of $\beta$-glucan concentrate was introduced in the view chamber, where it was vigorously stirred. Temperature was changed from 120 to $170^{\circ} \mathrm{C}$ and the experiments lasted from 5 minutes to 6 hours. Also some experiments at $55^{\circ} \mathrm{C}$ and 20 bar were done. They were used as control and basis for the comparison with the results obtained in 
pressurized hot water. In order to keep water in liquid state in all the experiments pressure was kept at 20 bar. After the experiment a $15 \mathrm{~mL}$ sample was taken and used to analyze $\beta$ glucan, starch and sugars contents. This sample was also used to determine the molecular weight of the $\beta$-glucan dissolved after the being exposed to the high temperatures and pressures.

For each temperature it was found the time the maximum amount of $\beta$-glucan was dissolved at. By doing this an optimal combination of time and temperature was obtained. In order to study the solubility of $\beta$-glucan and to explain the by-products formed, it is assumed the hypothesis that first $\beta$-glucan needs time to get dissolved and second and only after being in the solution degradation/hydrolysis begins, resulting in the degradation by-products (mainly sugars).

To evaluate the combined effect to time and temperature the severity factor was introduced, and calculated according to the equation (1):

$$
R_{0}=t \cdot \exp \left(\frac{T-100}{14.75}\right)
$$

\section{RESULTS AND DISCUSSION}

\subsection{Dissolution of $\beta$-glucan}

The effect of temperature and time in the $\beta$-glucan dissolution was studied in this section. A control experiment was performed $\left(55^{\circ} \mathrm{C}\right.$ and $\left.20 \mathrm{bar}\right)$ and other three experiments were performed using pressurized hot water $\left(120,150\right.$ and $\left.170^{\circ} \mathrm{C}\right)$. Results can be observed in figure 2:

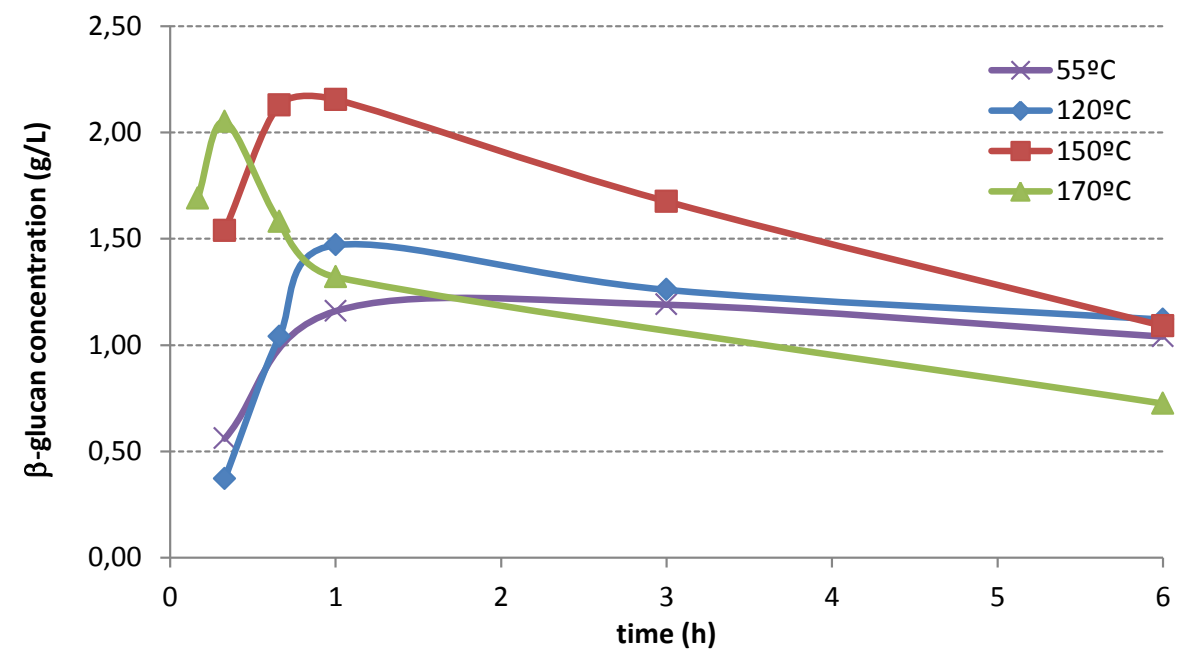

Figure 2. Time evolution of the concentration of $\beta$-glucan at different temperatures. 
It can be seen that, compared to the experiment at $55^{\circ} \mathrm{C}$, the higher the temperature the more $\beta$-glucan dissolved. At $55^{\circ} \mathrm{C}$ the highest concentration in the liquid extract was obtained after 3 hours $(1.19 \mathrm{~g} / \mathrm{L})$; from this time on, the concentration of $\beta$-glucan began to decline very slightly. The similar trend was observed when the extraction of $\beta$-glucan form barley was carried out in a stirred tank at atmospheric pressure, where the maximum was detected at $55^{\circ} \mathrm{C}$, but longer times involved a slight decrease in the extraction yield of $\beta$-glucan $(47.2 \%$ after $3 \mathrm{~h}$ and $44.3 \%$ after $5 \mathrm{~h})$. At atmospheric pressure, and using barley as primary source of $\beta$-glucan the highest concentration of $\beta$-glucan dissolved in water was around $2 \mathrm{~g} / \mathrm{L}$. According to this result, at low temperatures the increase in pressure does not improve the solubility of $\beta$-glucan in water.

However, when temperature was increase above $100^{\circ} \mathrm{C}$ two different phenomena were observed:

1. The maximum amount of $\beta$-glucan was increased significantly at $120^{\circ} \mathrm{C}$ and dramatically above $150^{\circ} \mathrm{C}$

2. This maximum amount of $\beta$-glucan dissolved was achieved in much shorter times, in all the cases below 1 hour. This represents a reduction of more than two hours compared to the low temperature experiment.

PHW helps to increase the amount of $\beta$-glucan dissolved with a reduction of the time required. A correlation between the time where the highest concentration was detected and the temperature was done, resulting in figure 3 :

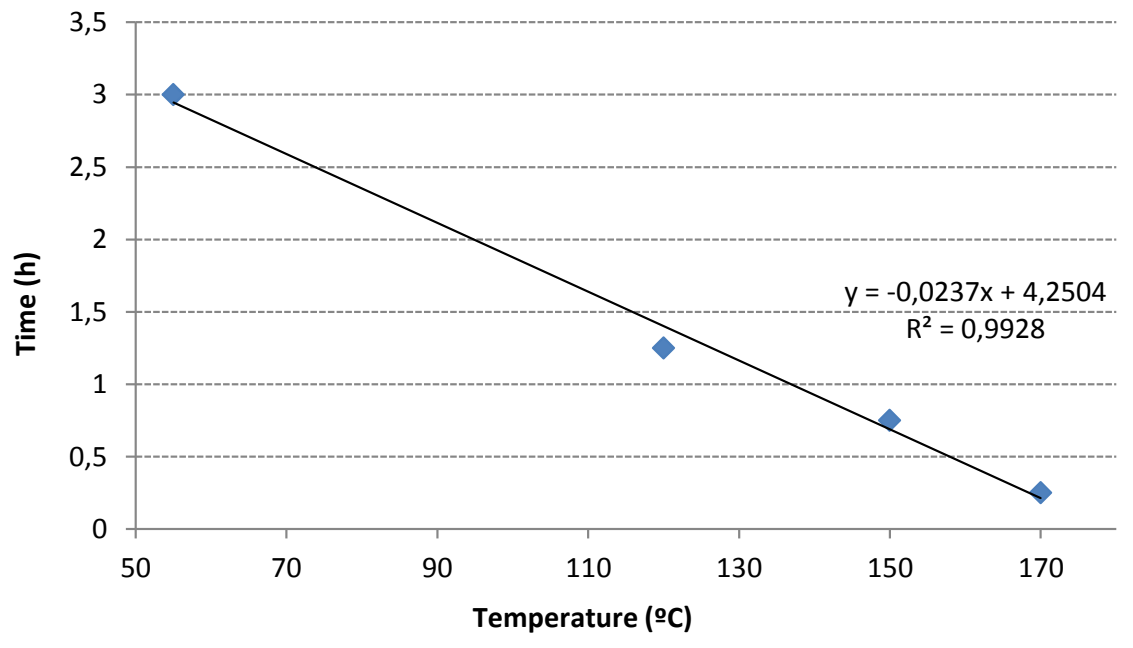

Figure 3. Dependence of operation time the highest concentration of $\beta$-glucan was achieved at with temperature

It was seen a clear relationship between time and temperature, leading to a maximum theoretical temperature that could be used for the dissolution of $\beta$-glucan in PHW. This upper 
limit would be around $180^{\circ} \mathrm{C}$. The presence of this temperature limit can be explained paying attention again to figure 2: when using water at temperatures above $120^{\circ} \mathrm{C}$ a completely different pattern of dissolution is observed compared to that registered at $55^{\circ} \mathrm{C}$. At higher temperatures two zones can be distinguished: a first one where a rapid increase of the amount of $\beta$-glucan dissolved is observed up to the maximum value of concentration is reached, and a second one after the maximum, where the concentration of $\beta$-glucan begins to decrease. The concentration of $\beta$-glucan dissolved after six hours converges in the value $1 \mathrm{~g} / \mathrm{L}$, regardless the temperature. After a closer analysis of the two zones observed, the first zone would indicated the dissolution period, being this period shorter the higher the temperature. On the other hand, the second zone would indicate the degradation of the $\beta$-glucan already dissolved. In order to verify this hypothesis, the main degradation products will be studied.

Figure 4 represents the maximum concentration of $\beta$-glucan measured for each temperature. This data were obtained from figure 2:

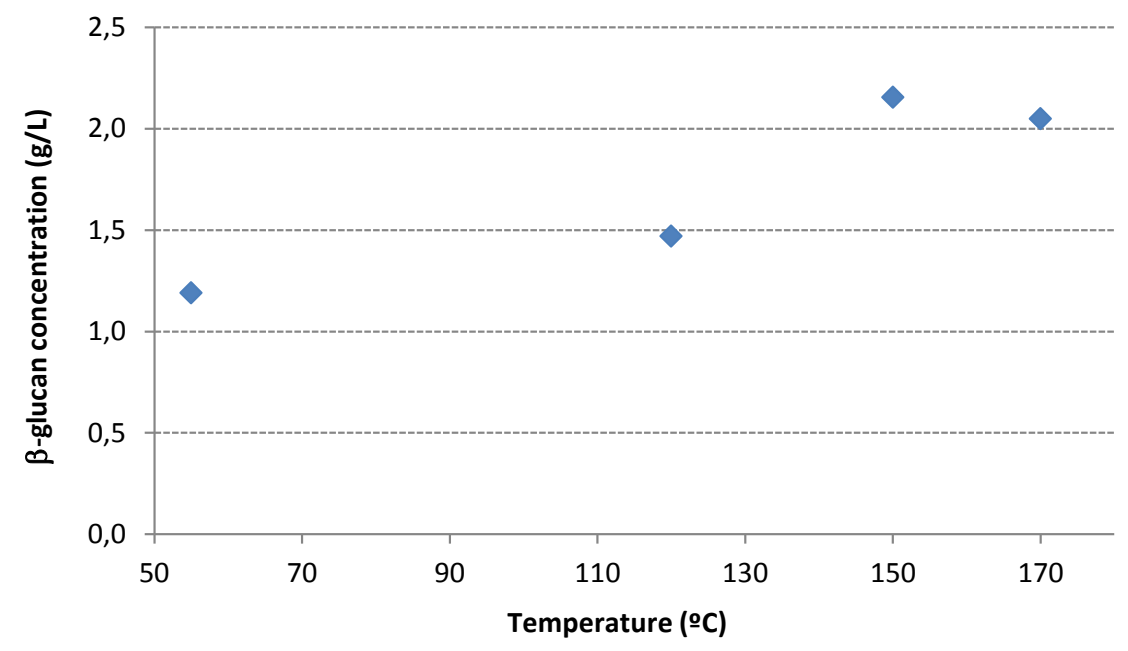

Figure 4. Maximum $\beta$-glucan concentration achieved at each studied temperature.

It can be seen how the temperature enhanced the $\beta$-glucan solubility up to $150^{\circ} \mathrm{C}$; from this moment the concentration of $\beta$-glucan began to decrease.

From these experimental results it can be concluded that temperature accelerates the dissolution of $\beta$-glucan, as probes the clear relationship between the time to get the highest concentration and the temperature. It also shows the second effect that the increase of temperature has on polysaccharides: their degradation. The longer the polymer it is exposed to the PHW, the lower the concentration obtained is. It is not very clear the specific effect that each of the variables have on the $\beta$-glucan dissolution; as at $170^{\circ} \mathrm{C}$, despite of the short times, the maximum concentration measured is lower than that achieved at $150^{\circ} \mathrm{C}$. This would 
indicate that, at short times, the effect of temperature is stronger than time on the $\beta$-glucan concentration achieved. In order to verify this and to evaluate the simultaneous effect that time and temperature have on the concentration of the $\beta$-glucan dissolved, it was represented concentration of $\beta$-glucan versus the logarithm of the severity factor, resulting the following figure:

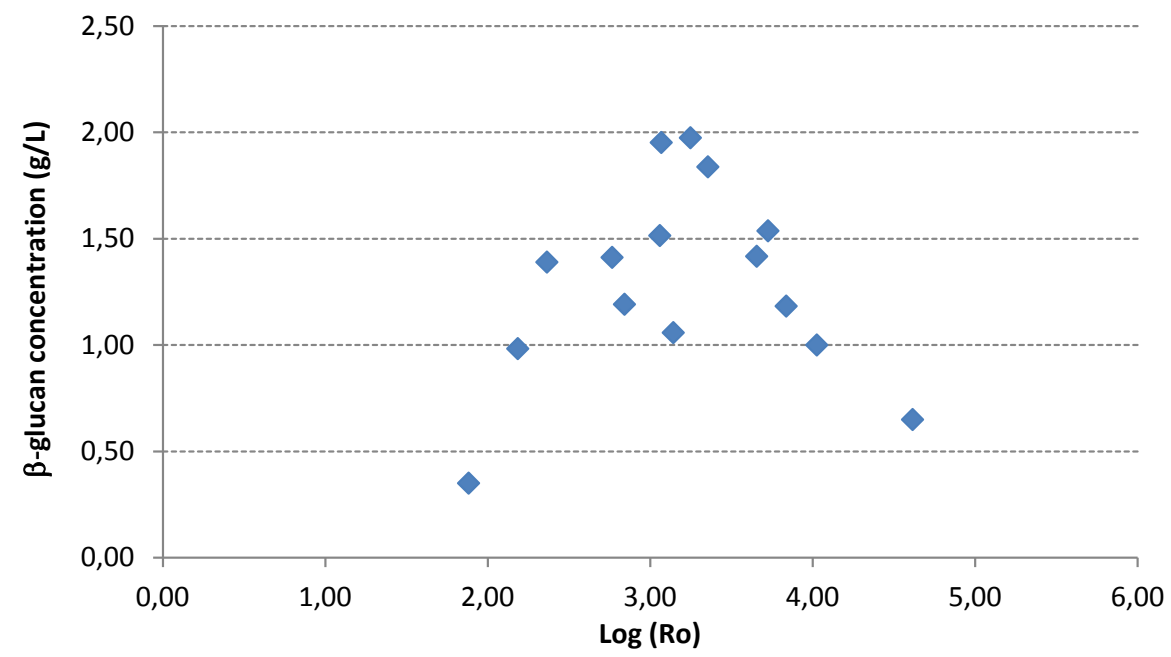

Figure 5. $\beta$-glucan concentration versus the logarithm of the severity factor

The highest value of $\beta$-glucan concentration corresponds to a $\log \mathrm{R}_{0}$ of 3.2 (approximately $150^{\circ} \mathrm{C}$ and 60 minutes extraction time). The combined effect of temperature and time has a strong effect on the $\beta$-glucan concentration as can be seen in figure 4; high intensity conditions are useful to degrade $\beta$-glucan.

\subsection{Evolution of the Starch concentration}

In the conventional extraction process starch co-extraction was seen as the one of the major drawbacks to increase the extraction temperature, as the increase of temperature (above $63^{\circ} \mathrm{C}$ ) led to the gelatinization starch despite the increase in $\beta$-glucan solubility. The behavior of starch at high temperatures it is not well known. The starch concentration at each of the studied temperatures can be observed in figure 6. At high temperatures starch is almost completely dissolved in the very begging of the experiment, afterwards, concentration begins to decrease dramatically. After one hour of experiment starch concentration decreased dramatically. Concentration remained almost constant and below 100ppm after 1 hour at $170^{\circ} \mathrm{C}$ and after 3 hours at $150^{\circ} \mathrm{C}$. Different trend was observed at $120^{\circ} \mathrm{C}$, where the maximum amount of $\beta$-glucan was observed after three hours; from that moment on a rapid decrease in concentration was observed. A quite similar trend was observed at $55^{\circ} \mathrm{C}$ but the concentration of starch was significantly lower. 


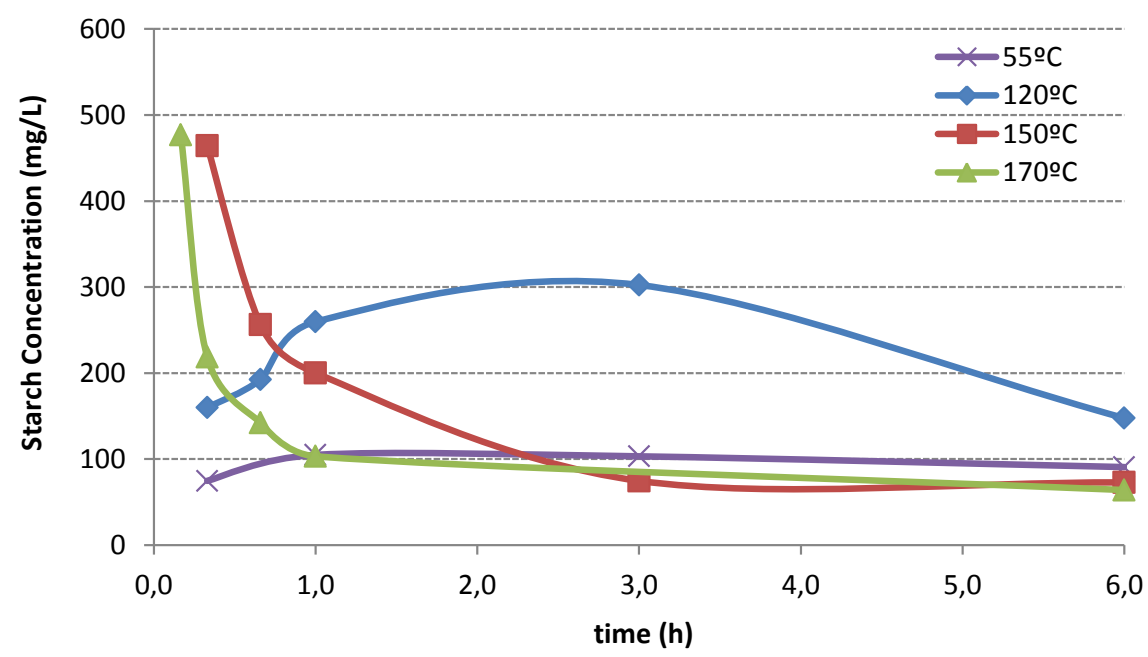

Figure 6. Time evolution of the concentration of the starch dissolved at different temperatures.

At high temperatures starch dissolution is very fast; but almost immediately hydrolysis occurs, as probes the rapid decrease in concentration. At medium temperatures dissolution is slower and the amount of starch dissolved is significantly lower.

At high temperatures the presence of high concentration of starch did not hinder the extraction. It seems that starch granules are rapidly damaged, so after swelling breaks down easily, not affecting the extraction process.

This behavior of starch will have to be evaluated when using barley as raw material; but in case the use of high temperatures helps to increase the amount of $\beta$-glucan dissolved as well as the starch, but in this case, starch is degraded rapidly, which will make easier the downstream process.

\subsection{Hydrolysis by-products}

As a consequence of the exposition to the high temperatures for long times, the degradation of the polysaccharides ( $\beta$-glucan and starch) may occur. Some key degradation compounds are: cellobiose, as the only possibility is to be generated from the $\beta$-glucan degradation; glucose and fructose as they represent the second stage in the degradation of the polysaccharides and finally the presence of HMF would indicate the complete degradation of the hexoses. The presence of this compound makes the solution to have a dark color, the more concentration the darker the solution. Figure 7 shows the evolution in the color of solutions at different temperatures after one hour of processing: 


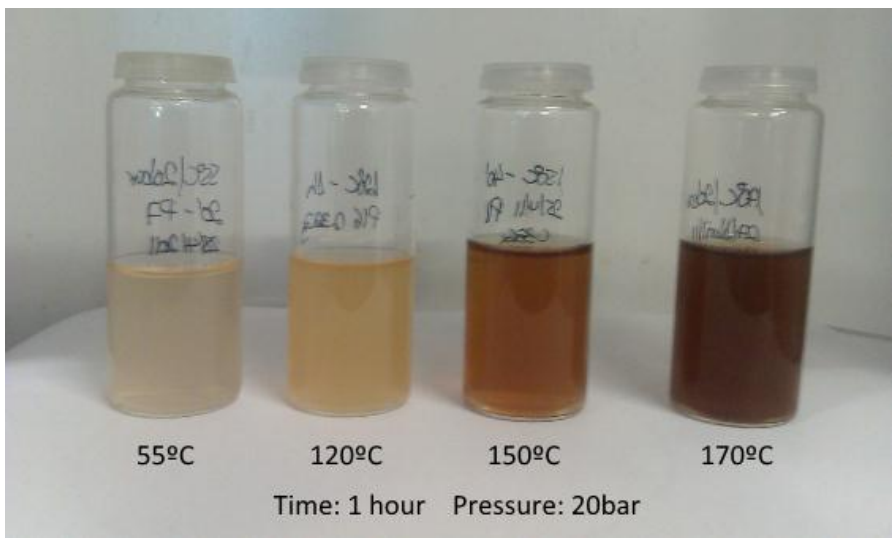

Figure 7. Effect of temperature on the color of liquid extract.

HMF was only detected in the experiments were the $\log R_{0}$ was greater than 3.2 (this corresponds to a conditions of $150^{\circ} \mathrm{C}$ and more than 60 minutes). At $170^{\circ} \mathrm{C}$ was also detected, and in much higher concentrations. If the practical limit for the PHW dissolution of the $\beta$ glucan is the presence of $\mathrm{HMF}$ temperature should be around $150^{\circ} \mathrm{C}$ and times below 60 minutes; is in these conditions were the amount of $\beta$-glucan is maximized, the starch concentration is clearly lower than that of $\beta$-glucan, and the complete degradation of $\beta$-glucan has happened. MHF concentration versus the logarithm of the severity factor is represented in figure 8:

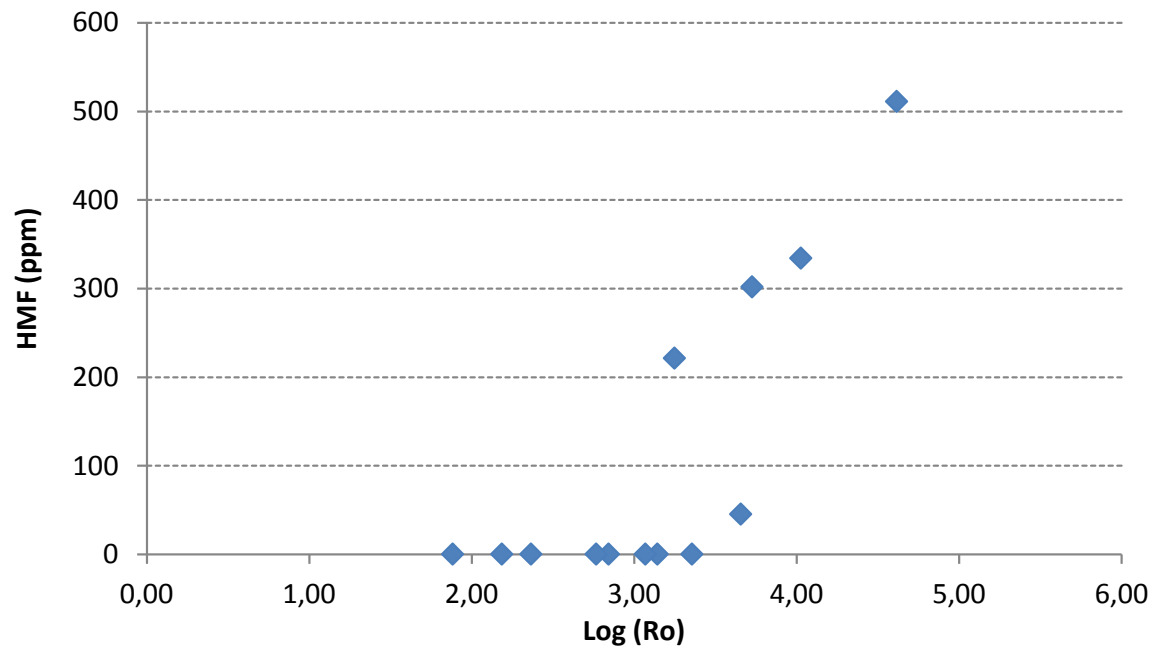

Figure 8. HMF concentration versus the logarithm of the severity factor

As the optimal temperature seems to be $150^{\circ} \mathrm{C}$, the main degradation products will be presented for this temperature. Glucose and cellobiose concentrations are the most significant: 


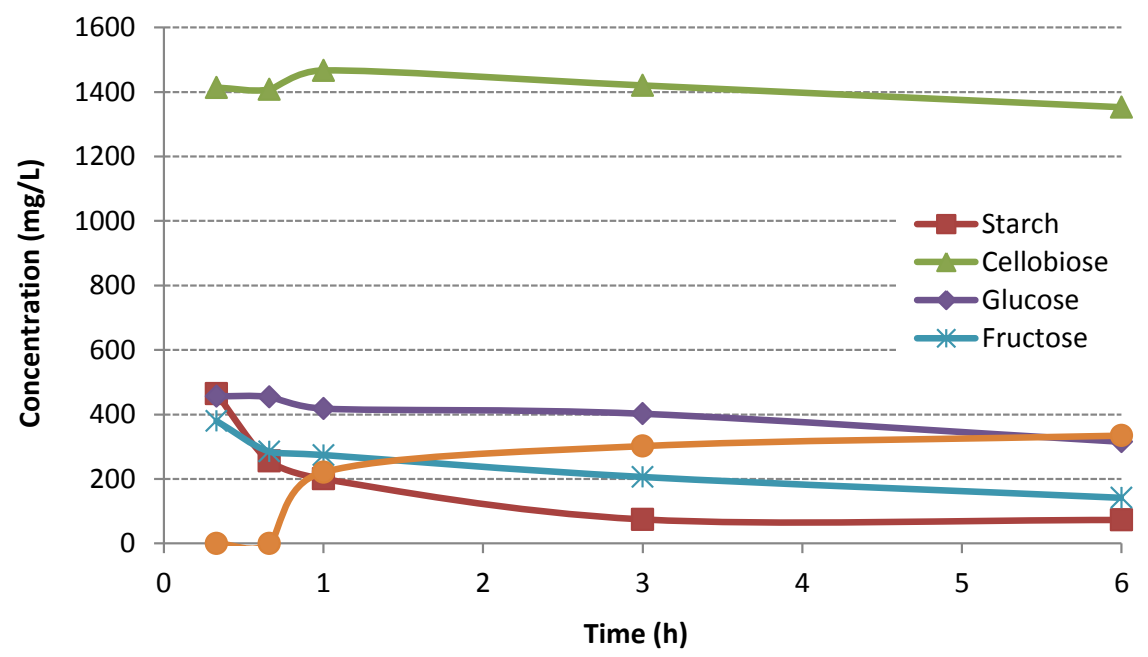

Figure 9. Time evolution of the concentration of several degradation products at $150^{\circ} \mathrm{C}$

Cellobiose concentration presents a slight decrease along the extraction process; as concentration remains almost constant, $\beta$-glucan degradation is quite limited. This means that the increase in the glucose concentration can be attributed to the degradation of starch; whose concentration decreases along the time. Glucose concentration keeps decreasing, as well as fructose; meanwhile HMF concentration is increasing as well as other degradation products such as pyruvaldehyde.

\subsection{Effect on the molecular weight}

For each temperature it was found an optimal time; this is the time the concentration of $\beta$ glucan dissolved was the highest. It was $75 \mathrm{~min}$ for $120^{\circ} \mathrm{C}$; $45 \mathrm{~min}$ for $150^{\circ} \mathrm{C}$ and $20 \mathrm{~min}$ for $170^{\circ} \mathrm{C}$. In these conditions a new experiment was performed to check the effect these conditions of time and temperature have on molecular weight Results are summarized in table 2. It can be seen how temperature helps to the loss of molecular weight; this reduction in molecular weight can be good for applications that require low molecular weight $\beta$-glucan. PHW would help to decrease the molecular weight of the $\beta$-glucan without the requirement of an enzyme or other more complex ways that can be found in literature (enzymatic treatment; ultrasounds, gamma irradiation).

Table 2. $\beta$-glucan maximum concentration and molecular weight obtained in the optimal conditions

\begin{tabular}{|c|c|c|c|c|}
\hline $\mathbf{T}\left({ }^{\circ} \mathbf{C}\right)$ & $\mathbf{t}(\mathbf{h})$ & $\log \left(\mathbf{R}_{\mathbf{o}}\right)$ & $\boldsymbol{\beta}$-glucan (g/L) & $\mathbf{M W}(\mathbf{k D a})$ \\
\hline 120 & 75 & 2.46 & 1.47 & 63 \\
150 & 45 & 3.13 & 2.15 & 8 \\
170 & 15 & 3.24 & 2.05 & 7 \\
\hline
\end{tabular}




\section{CONCLUSIONS}

The present work has to be considered as the first approach to the extraction of $\beta$-glucan from barley using pressurized hot water as solvent. So in this work it was desired to study the behavior of $\beta$-glucan and starch in water at high temperatures. A $\beta$-glucan concentrate was used as raw material, and it was used to study the effect that temperature and pressure have on $\beta$-glucan and starch, mainly. It was seen that water at high temperatures helps to decrease the time it takes to get $\beta$-glucan dissolved and to decrease the amount of starch dissolved. It was also seen that $\beta$-glucan cannot be exposed to the high temperatures for long times as it suffers a severe degradation. This degradation was probed by the presence of HMF (main degradation product from hexoses) and by the reduction in molecular weight observed: initially it was $450 \mathrm{kDa}$; after $45 \mathrm{~min}$ at $150^{\circ} \mathrm{C}$ it was $8 \mathrm{kDa}$ and $7 \mathrm{kDa}$ after $20 \mathrm{~min}$ at $170^{\circ} \mathrm{C}$. High temperatures $\left(170^{\circ} \mathrm{C}\right)$ help to achieve the maximum amount of dissolved $\beta$-glucan in shorter times; even though the maximum amount solubilized is lower than at $150^{\circ} \mathrm{C}$. The best conditions were $150^{\circ} \mathrm{C}$ and times below $45 \mathrm{~min}$.

These results will be useful to delimit the experimental range in terms of temperature (from 120 to $170^{\circ} \mathrm{C}$ ) and time (from 20 to $60 \mathrm{~min}$ ) to be used in the extraction of $\beta$-glucan from barley. In that case it will be evaluate how PHW helps to overcome the mass transfer limitations to the extraction from the vegetable matrix; and the way that molecular weight is affected, as the vegetable matrix and the endogenous $\beta$-glucanases are affected.

\section{REFERENCES}

O. Benito-Román, E. Alonso, S. Lucas, Optimization of the $\beta$-glucan extraction conditions from different waxy barley cultivars, Journal of Cereal Science 53, (2011) 271-276.

A. Lazaridou, G.C. Biliaderis. Molecular aspects of cereal $\beta$-glucan funcionaliy: Physical properties, technological applications and physiological effects. Journal of Cereal Science 46(2), (2007) 101-118.

C.C. Teo, S.N. Tan, J.W. Hong Yong, C.S. Hew, E.S. Ong, Pressurized hot water extraction (PHWE).Review, Journal of Chromatography A 1217, (2010) 2484-2494.

T. Vasanthan, F. Temelli. Grain fractionation technologies for cereal $\beta$-glucan concentation. Food Research International 41, (2008) 876-881. 
P.J. Wood, I.R. Siddiqui, D. Paton. Extraction of high-viscosity gums from oats. Cereal Chemistry 55, (1978)1038-1049. 


\section{CHAPTER 4}

Pressurized hot water extraction of $\beta$-glucans from waxy barley 



\title{
Pressurized hot water extraction of $\beta$-glucans from waxy barley ${ }^{1}$
}

\begin{abstract}
Pressurized hot water (PHW) is a new and promising solvent for the extraction of $\beta$-glucans from cereals. The effect of temperature, extraction time and pressure have been studied for the extraction of $\beta$-glucans from waxy barley (6.0\% in $\beta$-glucans). Extraction yield, molecular weight and degradation products have been evaluated. Temperature $\left(110\right.$ to $\left.180^{\circ} \mathrm{C}\right)$ and extraction time (15 to $75 \mathrm{~min}$ ) showed a strong influence on extraction process. Extraction yield and $\mathrm{MW}$ are optimized for $155^{\circ} \mathrm{C}, 18$ minutes and 50bar, leading to $53.7 \%$ extraction yield and $200 \mathrm{kDa}$. The presence of degradation products, such as HMF, is negligible under these conditions. The comparison between these optimal results and that from a conventional process $\left(55^{\circ} \mathrm{C}, 3 \mathrm{~h}\right.$ and ambient pressure) reveals a big difference in MW (200kDa vs. $55 \mathrm{kDa}$ respectively). PHW causes a significantly reduction in extraction time and an increase of $\beta$ glucan MW of almost 4 times as major benefits.
\end{abstract}

\section{Graphical Abstract}

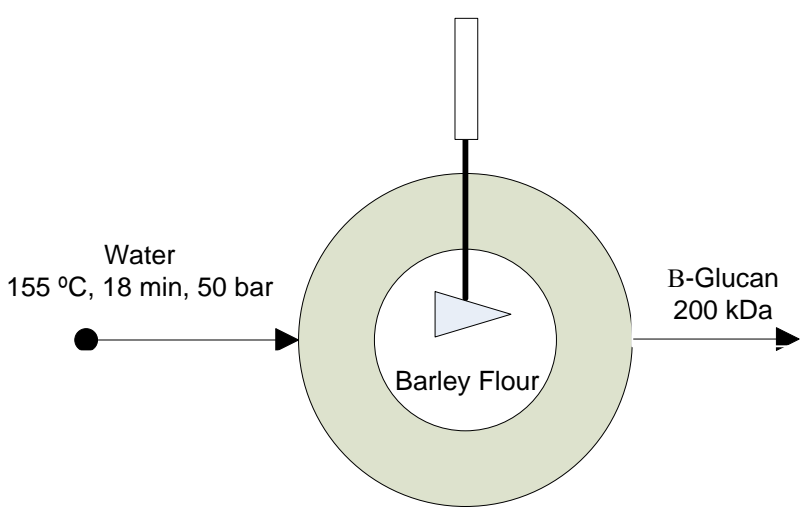

Keywords: $\beta$-glucan; barley; extraction; pressurized hot water

\footnotetext{
${ }^{1}$ The Journal of Supercritical Fluids 73 (2013), 120-125
} 


\section{INTRODUCTION}

$\beta$-glucans (mixed linkage (1-3),(1-4)- $\beta$-D-glucans are non-starchy and non digestible polysaccharides that can be found in the subaleurone layer and cell walls of different cereal grains, such as barley, oat rye or wheat [1]. The presence of the mixed linkages determines the final physical properties of the $\beta$-glucans, such as solubility and viscosity. Moreover, molecular weight and concentration affect the viscosity of the $\beta$-glucan solution [2]. $\beta$-glucans are known to be involved in process related to the reduction in postprandial blood glucose and cholesterol levels $[3,4]$. Recently FDA (United States Federal Drug Administration) and EFSA (European Food Safe Authority) have accepted a health claim in reduction of cholesterol levels, recommending an intake of $3 \mathrm{~g}$ of $\beta$-glucans per day to achieve this positive effect $[5,6]$. In order to use the beneficial effects of cereal beta-glucans for functional food products, betaglucan preparations with high beta-glucan content and high molecular weight have to be available for the food industry at a reasonable prize.

The extraction of $\beta$-glucans from a cereal matrix (such as barley) is complex since they are a minority component of the cereal grain, the used solvents (water at ambient pressure) are not selective and the solid/liquid extraction exhibits important mass transfer limitations [7]. Conventional extraction processes lead to a low molecular weight $\beta$-glucan product, due to the activity of endogenous $\beta$-glucanases responsible of the polysaccharide backbone rupture. When a pretreatment is implemented to increase the molecular weight (such as enzymatic ethanol deactivation) [8], the extraction yield decreases dramatically. All the described reasons make desirable to develop an extraction procedure with a high extraction yield that allows preserving $\beta$-glucan molecular weight in a one single step (without pretreatment). In that sense, the use of Pressurized Hot Water (PHW) as extraction solvent can be a new, versatile and promising technology for this process, since it can provide the medium for $\beta$-glucanases inactivation together with an efficient extraction solvent. Considered by many authors as a "green solvent" [9], PHW has been widely used as solvent in the extraction of high added value compounds (bioactive and nutraceuticals, essential oils, lipids, carotenoids, proteins, polysaccharides) from plants or food matrixes [10-12]. PHW term refers to the water in liquid state in the range $100^{\circ} \mathrm{C}$ (boiling point) to $374^{\circ} \mathrm{C}$ (critical point) by the application of pressure. Density, surface tension, viscosity and diffusion of water change dramatically when changing pressure and, specially, temperature, having an effect on the mass transfer of the extraction process. PHW exhibits lower viscosity but higher diffusivity than water at room temperature, which favors the diffusion into the vegetal matrix and the release of compounds [11]. An increase in temperature also contributes to weaken the hydrogen bonds between the 
carbohydrates and the solid matrix, accelerating the compound desorption. Moreover, high temperatures can contribute either to initiate hydrolysis processes of the already dissolved compounds or to affect the structure of the natural matrix [10]. In the case of polysaccharides, they are broken into their monomers, and these units can then react to form their main degradation products, such as furfural (from pentoses) or 5-(Hydroxymethyl)furfural (HMF), from hexoses [13]. This phenomenon of monosaccharide degradation begins to be significant above $180^{\circ} \mathrm{C}$ [14]. The final performance in the $\beta$-glucan extraction will be a combination of time and temperature; in order to evaluate the simultaneous effect of time and temperature a Severity Factor $\left(R_{0}\right)$ is introduced (1) to compare different treatments:

$$
R_{0}=t \cdot \exp \left(\frac{T-100}{14.75}\right)
$$

where $\mathrm{t}$ is time in minutes and $\mathrm{T}$ is temperature in ${ }^{\circ} \mathrm{C}$. This severity factor was introduced by Overend et al. [15], and was used to evaluate hydrolysis reactions by Schacht et al. [16].

The effect of pressure on the physical properties of PHW is very limited compared to that of temperature. In general, liquids are highly incompressible in the subcritical region, and density and solvation power suffer slight increases with pressure at constant temperature. Theses smooth variations in the physical properties make the pressure to play a secondary role in the extraction process, limited to maintain the water in the liquid form [11], and in most extraction experiments of natural products in the literature, pressure is kept around 50bar to ensure the liquid state. Moreover, given that the pressure is not critical for the extraction, it is not convenient to increase it very much, since the higher the pressure the more tighten the solid matrix, hindering the flow in fixed bed extraction processes [10].

PHW has been used in a few works to extract polysaccharides from natural matrix: Ho et al. [17] extracted lignans, proteins and carbohydrates from flaxseed meal; Buranov and Mazza [18] extracted hemicelluloses from flax shives; Askin et al. [19] extracted (1-3),(1-6)- $\beta$-Dglucans from Ganoderma lucidum fungus; Cacace and Mazza [20] used PHW to extract lignans from whole flaxseed; Hata et al. [21] focused their research in the extraction of total sugars, proteins and antioxidant activity from defatted rice bran and Song et al. [22] extracted hemicelluloses from spruce woods. When the raw material is rich in polysaccharides (cellulose or hemicelluloses) the purpose of the PHW treatment is not only the extraction of polysaccharides, but also their subsequent hydrolysis into their monomeric-sugars, as basis for the production of biofuels [22], and in those cases terms such as "autohydrolysis" or "hydrothermal treatment" are used in the literature. 
The purpose of the present work was to study the effect of operational variables in the extraction of $\beta$-glucans from barley using pressurized hot water as solvent. The influence of temperature, time and pressure on extraction yield and molecular weight of the extracted $\beta$ glucans have been evaluated, together with the degradation products formed as a consequence of the extraction conditions.

\section{MATERIALS AND METHODS}

\subsection{Raw Material}

A Waxy barley developed, grown and provided by ITACyL (Instituto Tecnológico Agrario de Castilla y León, Valladolid, Spain) has been used in this work as raw material. Complete composition of barley is shown in table 1 , being the most significant features the content in $\beta$ glucan $(6.0 \pm 0.3 \%)$ and in starch $(50.3 \pm 3.2 \%)$. Barley was fine milled in the lab, resulting in an average particle size of the $240 \pm 4 \mu \mathrm{m}$ determined by DLS (Mastersizer2000, Malvern Instruments Ltd).

Table 1. Composition of barley used as raw material, (\%) expressed in dry basis

\begin{tabular}{|c|c|c|c|c|c|}
\hline Fats & Ash & Proteins & Starch & $\beta$-glucan & Dietary Fibre \\
\hline $2.8 \pm 0.2$ & $2.1 \pm 0.3$ & $20.0 \pm 1.2$ & $50.3 \pm 3.2$ & $6.0 \pm 0.3$ & $21.0 \pm 2.1$ \\
\hline
\end{tabular}

\subsection{Experimental Section}

Extractions have been performed in a High-Pressure View Chamber Type HPVC 300-HT (Eurotechnica $\mathrm{GmbH}$ ) made of inconel with an internal volume of $30 \mathrm{~mL}$ and stirred via a magnetically coupled agitator. Maximum operating pressure and temperature of this equipment are $300 \mathrm{bar}$ and $500^{\circ} \mathrm{C}$, respectively. A diagram of the experimental set-up is shown in figure 1. In every experiment, $1 \mathrm{~g}$ of barley flour is located inside the high-pressure cell through one of the sapphire windows and after its closure, the chamber is filled up with distilled water and heated up. Once the desired values of pressure and temperature are reached, vigorous stirring is switched-on in order to keep barley flour in suspension. After the desired extraction time, liquid phase is sampled for analysis using the sampling line, and afterwards, the cell content is cooled down and decompressed. The PHW extraction process is compared with a "conventional extraction process" where the extraction is performed with water at $55^{\circ} \mathrm{C}$ and ambient pressure during $3 \mathrm{~h}$ in a mechanically stirred tank. In this "conventional extraction process" the $\beta$-glucan extraction yield was $73.2 \%$ and the average 
molecular weight of the extracted $\beta$-glucans was $55 \mathrm{kDa}$. A detailed description of this "conventional process" can be found at [7].

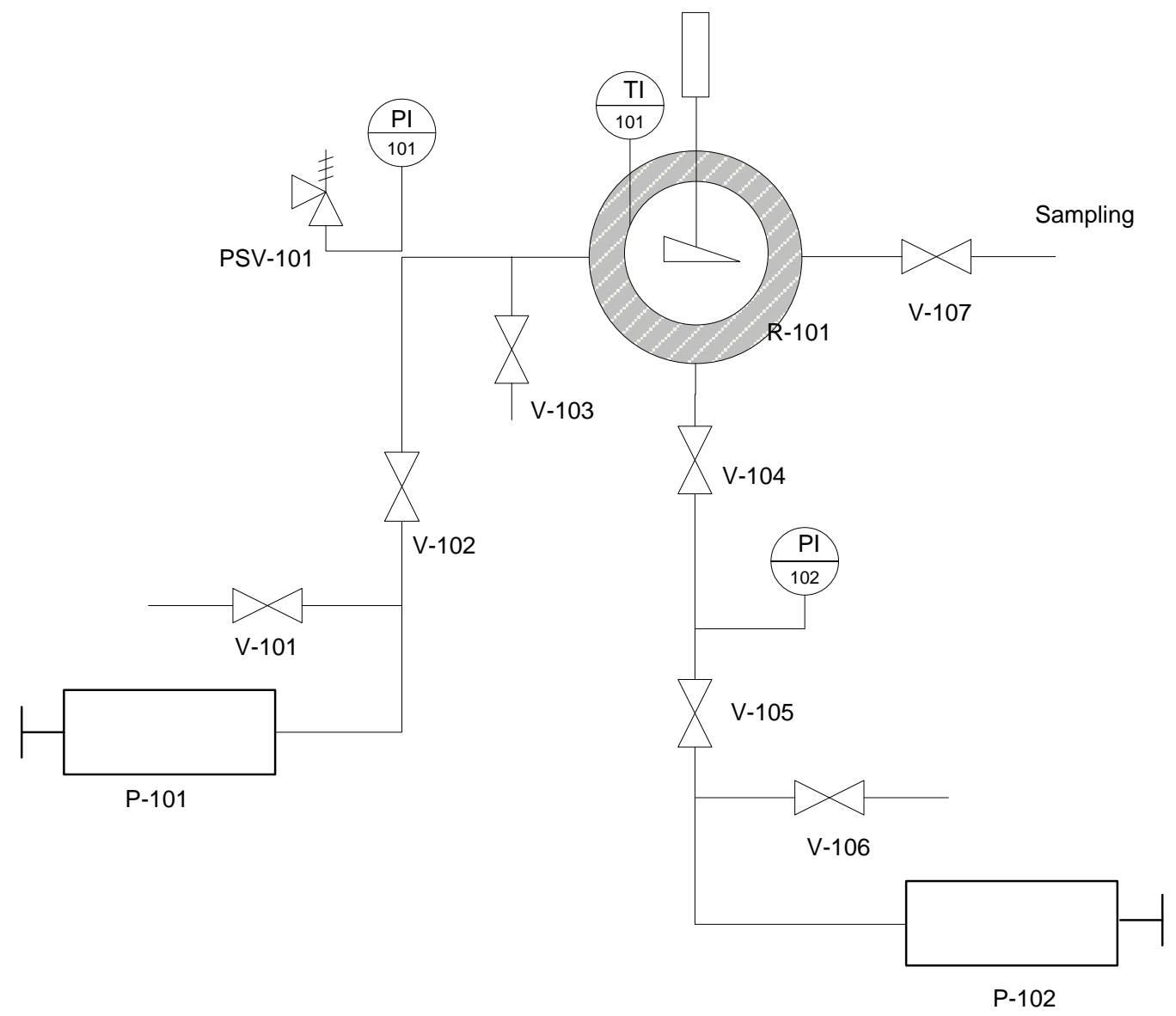

Figure 1. Flow sheet of the high pressure view chamber

\subsection{Chemical Analysis}

The liquid extract sampled from the high-pressure chamber after the desired extraction time, has been analyzed to determine $\beta$-glucan concentration, $\beta$-glucan molecular weight and the presence of other oligosaccharides and sugars.

The amount of $\beta$-glucans in the liquid extract has been determined using the "Mixed-linkage $\beta$ glucan" assay kit from Megazyme International Ltd. From these assays, the concentration of $\beta$ glucans is reported in $g$ of $\beta$-glucan $/ 100 \mathrm{~g}$ of water.

Molecular weight (MW) of $\beta$-glucans has been determined by Size Exclusion Chromatography (HPLC-SEC) using a chromatographic system composed by an isocratic pump (Waters 1515), an automatic injector (Waters 717), and a differential refractive index detector (Waters 410). A combination of guard column (ShodexSB-G) and a GPC column (ShodexOHpak SB-804HQ) has been used for the SEC analysis. The column was kept at $35^{\circ} \mathrm{C}$, and the flow rate of the mobile 
phase $\left(0.1 \mathrm{M} \mathrm{NaNO}_{3}+0.02 \% \mathrm{NaN}_{3}\right)$ was set at $0.5 \mathrm{ml} \cdot \mathrm{min}^{-1}$. The $\beta$-glucan molecular weight standards were purchased from Megazyme International Ltd. (Ireland), and were in the range 40-359kDa.

HPLC has been used for the measurement of oligosaccharides and sugars (cellobiose, fructose, glucose and HMF) formed during the extraction process. Chromatographic system was basically the same as that described for the MW determination, but in this case a UV/Visible Detector (Waters 2489) has been used. Column and guard column were purchased to Shodex (model KS-802, guard column KS-G) and set at $60^{\circ} \mathrm{C}$, and mobile phase (MilliQ water) was set at $0.8 \mathrm{ml} \cdot \mathrm{min}^{-1}$.

\subsection{Experimental Design}

In the initial experiments, pressure was set at 20bar and temperature and extraction time were the selected factors to study the PHW extraction process. A full factorial design approach was used to determine the influence of those two variables at three different levels. Temperature was studied in the range $135-180^{\circ} \mathrm{C}$ and time was varied from 15 to $75 \mathrm{~min}$. Extraction results have been evaluated in terms of $\beta$-glucan extraction yield, $\beta$-glucan Molecular Weight (MW) and degradation products. All the calculations and statistical analysis were done by means of the Statgraphics Statistical Software. A total of nine experiments were carried out plus three repetitions of the central experiment. The set of experiments and the main experimental results are presented in table 2 .

An analysis of variance (ANOVA) with 95\% confidence level was then carried out for the response variable in order to test the model significance and suitability. The significance of each coefficient was determined using the F-test.

In the second part of the experimental work, pressure was varied in the range 20-250 bar keeping constant temperature and time at the levels that maximized extraction yield and MW. 


\section{RESULTS AND DISCUSSION}

\subsection{Effect of temperature and time on the extraction of $\beta$-glucans with PHW}

Table 2 summarizes the operational conditions and the main results of the experiments performed to study the effect of temperature and time in the extraction of $\beta$-glucans from barley with PHW. Extraction yield, together with MW and degradation product concentration are shown in table 2 . 
Table 2. Experimental conditions and experimental results: extraction yield, $\beta$-glucan molecular weight and concentration of the main hydrolysis products. (The logarithm of the severity factor is also shown)

\begin{tabular}{|c|c|c|c|c|c|c|c|c|c|}
\hline \multicolumn{3}{|c|}{ Extraction Conditions } & \multicolumn{2}{|c|}{$\beta$-glucan } & \multicolumn{5}{|c|}{ Concentration (ppm) } \\
\hline $\mathrm{T}\left({ }^{\circ} \mathrm{C}\right)$ & $t(\min )$ & $\log R_{0}$ & Ext. Yield (\%) & $\mathrm{MW}(\mathrm{kDa})$ & Cellobiose & Glucose & Fructose & Pyruvaldehyde & HMF \\
\hline 135,0 & 15 & 2,207 & 43,8 & 186 & 609,7 & 53,9 & 81,6 & nd & nd \\
\hline 135,0 & 45 & 2,684 & 41,5 & 154 & 484,8 & 86,1 & 142,3 & nd & nd \\
\hline 135,0 & 75 & 2,906 & 33,9 & 129 & 441,6 & 69,2 & 144,8 & nd & nd \\
\hline 157,5 & 15 & 2,943 & 50,8 & 228 & 615,2 & 140,7 & 295,9 & 2,1 & 0,6 \\
\hline 157,5 & 45 & 3,420 & 54,0 & 160 & 432,3 & 164,3 & 263,7 & 5,6 & 8,3 \\
\hline 157,5 & 75 & 3,642 & 41,9 & 62 & 365,8 & 176,9 & 229,7 & 7,6 & 30,5 \\
\hline 180,0 & 15 & 3,532 & 37,4 & 86 & 355,7 & 180,5 & 283,9 & 11,8 & 19,8 \\
\hline 180,0 & 45 & 4,009 & 33,9 & 47 & 275,0 & 160,1 & 242,9 & 26,3 & 38,2 \\
\hline 180,0 & 75 & 4,231 & 23,4 & 26 & 194,2 & 149,2 & 206,8 & 41,8 & 62,5 \\
\hline
\end{tabular}

nd: not detected 
In order to evaluate the effect of each variable, as well as the interaction between these two experimental variables, the analysis of variance test (ANOVA) was done by means of the Statistical Software Statgraphics. According to this ANOVA test, the effect of temperature and extraction time on the extraction yield was statistically significant, since F-ratio was higher than the critical value of 4.96 , at a $95 \%$ confidence level.

\subsubsection{Effect of temperature and time on $\beta$-glucan extraction yield}

Temperature and extraction time have shown a dramatic effect on the $\beta$-glucan extraction yield. Temperature affects the extraction process in two different ways: for temperatures up to $155-160^{\circ} \mathrm{C}$ the extraction yield increases with temperature, however, above $160^{\circ} \mathrm{C}$ the amount of dissolved $\beta$-glucans in the liquid extract decreases. The change in the properties of the water when temperature is increased up to $160^{\circ} \mathrm{C}$ helps to weaken the bonds between the target polysaccharide and the barley, promoting $\beta$-glucan release from the cereal matrix. However, further increases in temperature mean a decrease in the concentration of $\beta$-glucan in the final extract and an increase in the concentration of sugar degradation compounds. Hydrolysis kinetics is dramatically accelerated, being this effect dominant over the increase in the solubility.

In addition to high temperatures, long times cause a rapid decrease in the $\beta$-glucan concentration in the liquid extract. The longer the $\beta$-glucan was exposed to the high temperatures the higher is the degradation. The effect of time and temperature on the extraction yield can be observed in figure 2 .

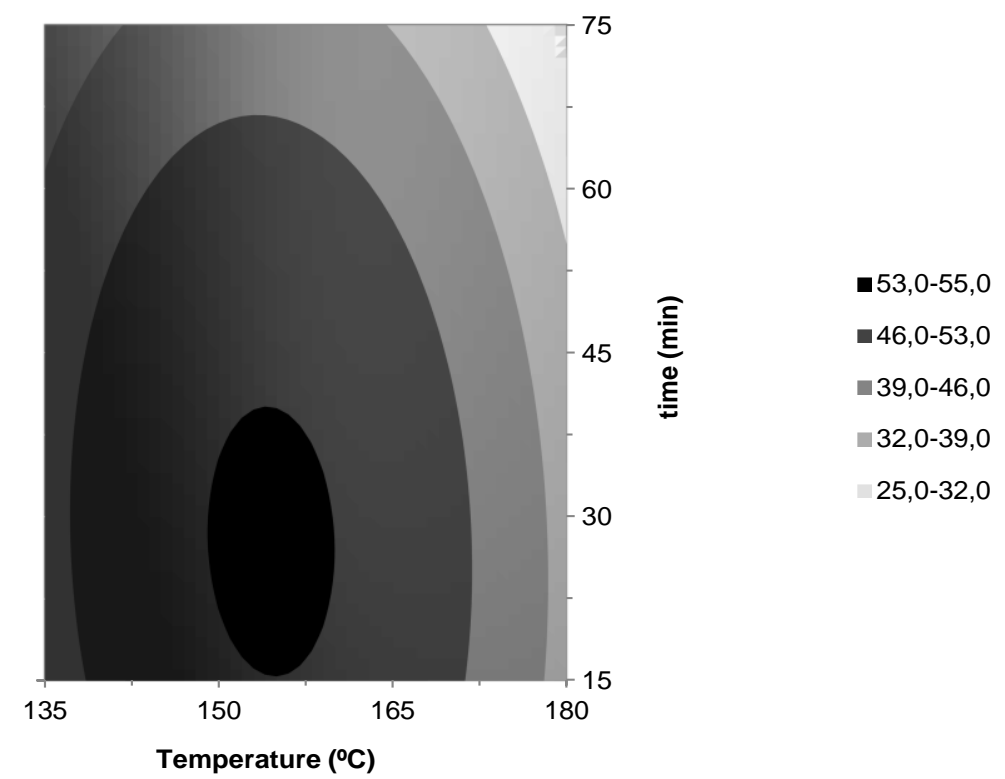

Figure 2. Contour plot for the effect of temperature and time on $\beta$-glucan extraction yield at 20bar. The area inside the solid line corresponds to the experimental range 
In order to evaluate the simultaneous effect of the two studied factors on $\beta$-glucan extraction, the severity factor (equation (1)) has been introduced. In figure 3 extraction yield is plotted versus the logarithm of the severity factor. It can be observed that there is a critical combination of temperature and time that causes the concentration of $\beta$-glucans in the liquid extract begin to decline. This critical value of the logarithm of the severity factor is between 3 and 3.5 (that corresponds to temperatures of $157.5^{\circ} \mathrm{C}$ and times between 20 and 65 minutes).

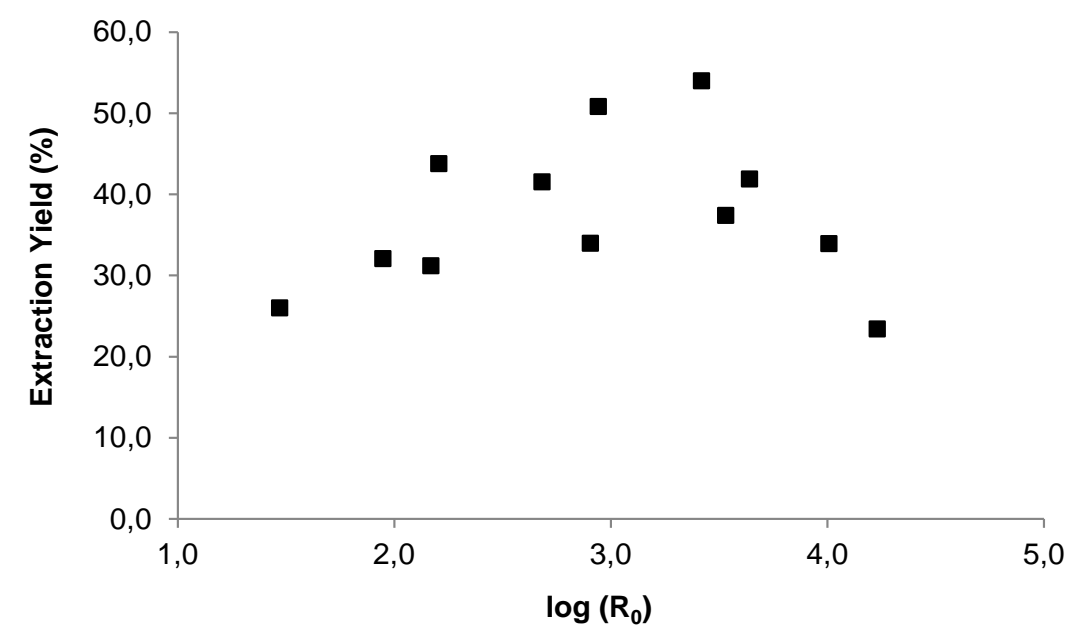

Figure 3. Simultaneous effect of temperature and extraction time in $\beta$-glucan extraction yield. $P=20$ bar

\subsubsection{Effect of temperature and time on $\beta$-glucan molecular weight}

The molecular weight of the extracted $\beta$-glucans is clearly affected by the extraction conditions. The results presented in table 2 show that the extraction carried out at $157.5^{\circ} \mathrm{C}$ for 15 minutes led to the highest molecular weight $(228 \mathrm{kDa})$. An increase of severity of the extraction conditions causes a significant loss of molecular weight. These trends can be easily observed in figure 4. According to figure 4, the highest molecular weights are obtained after short extraction times with temperatures up to $157.5^{\circ} \mathrm{C}$. However, when temperature is further increased, a rapid decrease in the $\mathrm{MW}$ is observed. This means that $\beta$-glucan molecules are temperature resistant up to temperatures in the range $155-160^{\circ} \mathrm{C}$. On the other hand, the time that $\beta$-glucans are exposed to the PHW is crucial for the molecular weight. Once the $\beta$ glucan is dissolved, the depolymerization (evaluated in terms of MW) takes place. The longer the $\beta$-glucan is exposed to the hot water, the higher the decrease in the MW. This discussion is also supported with the analysis of the hydrolysis products presented in section 3.1.3. 


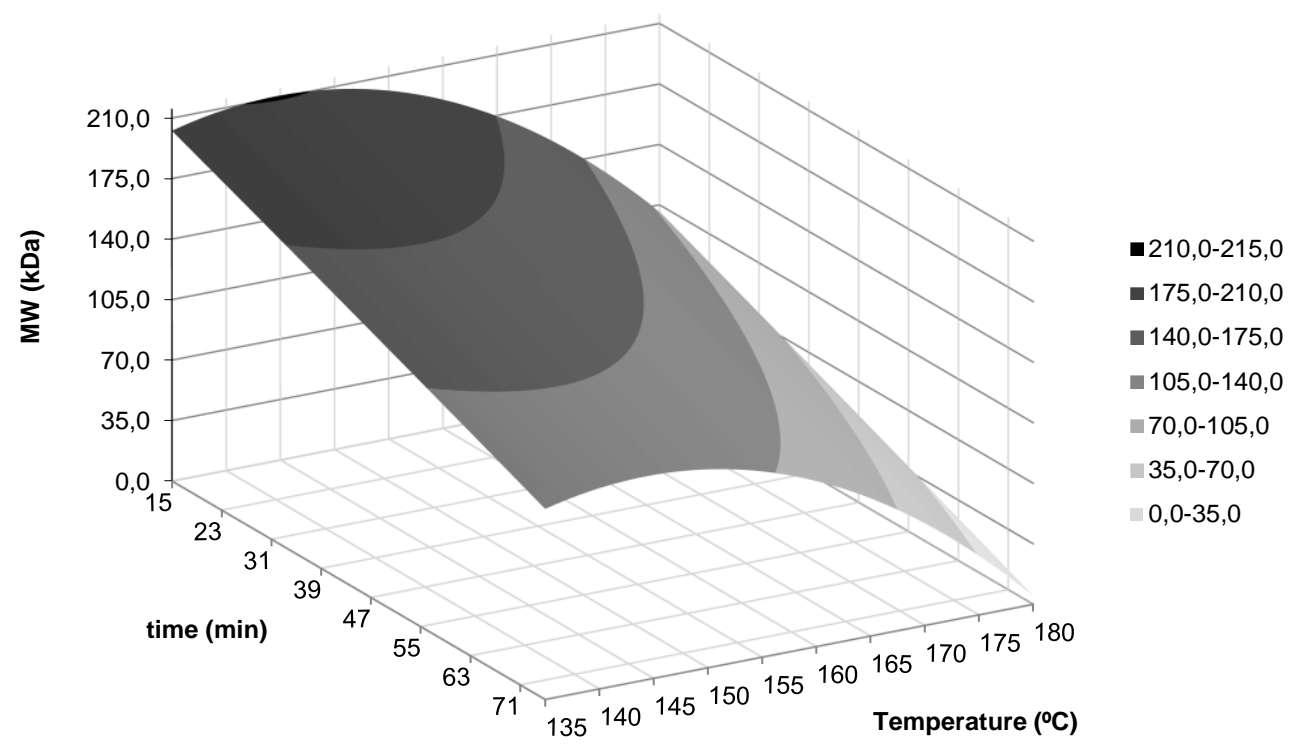

Figure 4. Surface plot for the MW of the extracted $\beta$-glucan as function of the extraction conditions

\subsubsection{Effect of temperature and time on degradation products}

In sections 3.1.1. and 3.1.2., the effect of temperature and time on $\beta$-glucan extraction yield and their molecular weight has been discussed. To complete this discussion it is necessary to evaluate the degradation products that appear during the extraction with PHW. According to the structure of $\beta$-glucans, the presence of cellotriosyl or cellobiose would indicate a first step in the depolymerization process; the presence of glucose a second step in the hydrolysis process, and finally if HMF appears, it would indicate the complete degradation of hexoses. This hydrolysis process is very complex, as there is a huge number of species taking part and different types of reactions (hydrolysis, isomerization, bond cleavage, dehydration) are involved [23].

The main degradation products detected in this work were: cellobiose, glucose, fructose, pyruvaldehyde and HMF. The concentration of these species is represented in figures 5 and 6 versus the logarithm of the severity factor: 


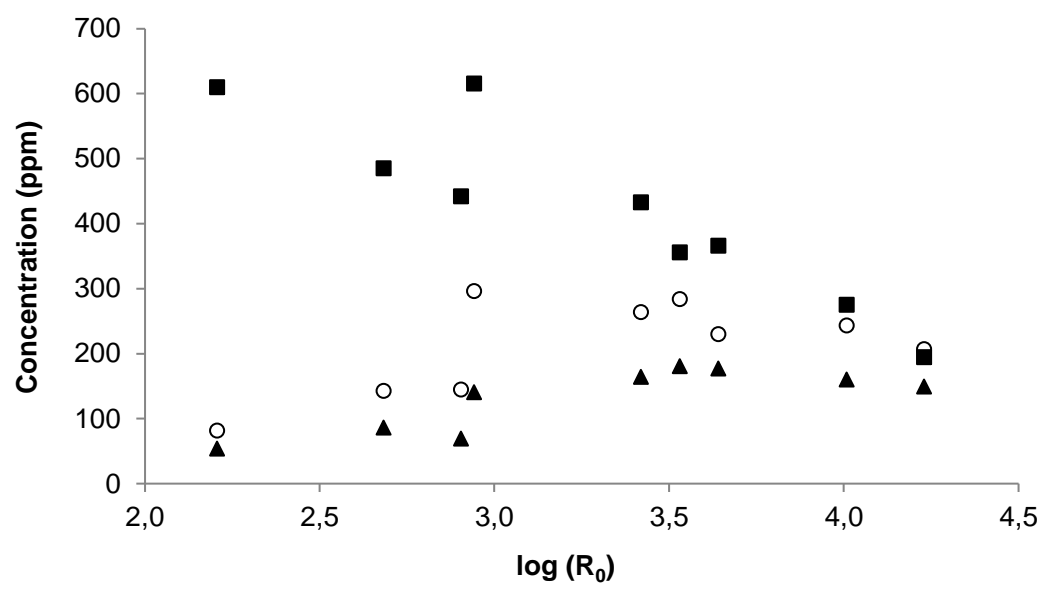

Figure 5. Hydrolysis products determined during the extraction of $\beta$-glucans from barley using PHW as solvent. KEY: cellobiose $(\mathbf{\square})$, fructose $(\mathrm{O})$ and glucose $(\mathbf{\Delta})$

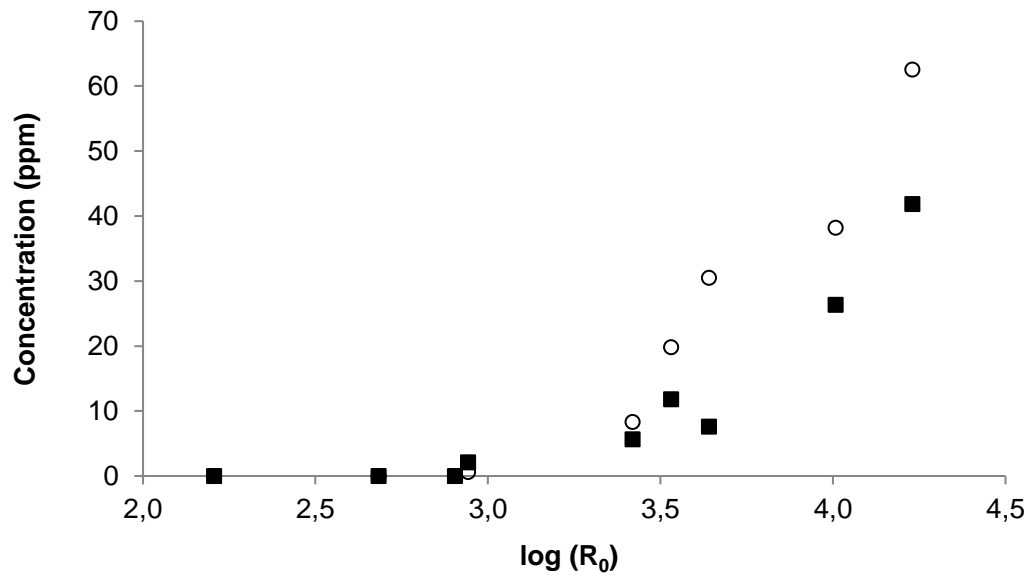

Figure 6. Degradation products determined during the extraction of $\beta$-glucans from barley using PHW as solvent. KEY: pyruvaldehyde ( $\mathbf{\square})$ and $H M F(O)$

In the evolution of degradation products with the severity factor, three different trends can be observed: concentration of cellobiose decreases in all the experiments; the concentrations of glucose and fructose increase up to certain conditions of $R_{0}$, to start to decrease afterwards, and the third trend corresponds to the final degradation products pyruvaldehyde and HMF, whose concentration is zero in the mild experiments but increasing exponentially when much severe conditions are used. According to figures 5 and 6 , the change in this tendency corresponds to $\log \left(R_{0}\right)$ around 3.4 , that fits very well with the value observed to maximize the extraction yield (figure 3 ). This conditions of $\log \left(R_{0}\right)$ correspond to an extraction performed at $157.5^{\circ} \mathrm{C}$ and $45 \mathrm{~min}$, indicating that higher temperatures not only do not help to extract $\beta$ glucans, but also accelerate their decomposition. 


\subsection{Effect of pressure on the extraction yield and molecular weight}

The effect of pressure on the extraction yield and the molecular weight of $\beta$-glucan was tested in the extraction conditions that provided the highest extraction yield $\left(157.5^{\circ} \mathrm{C}\right.$ and 45 minutes). Pressure was varied in the range 20 to 250 bar. The obtained results are shown in figure 7.

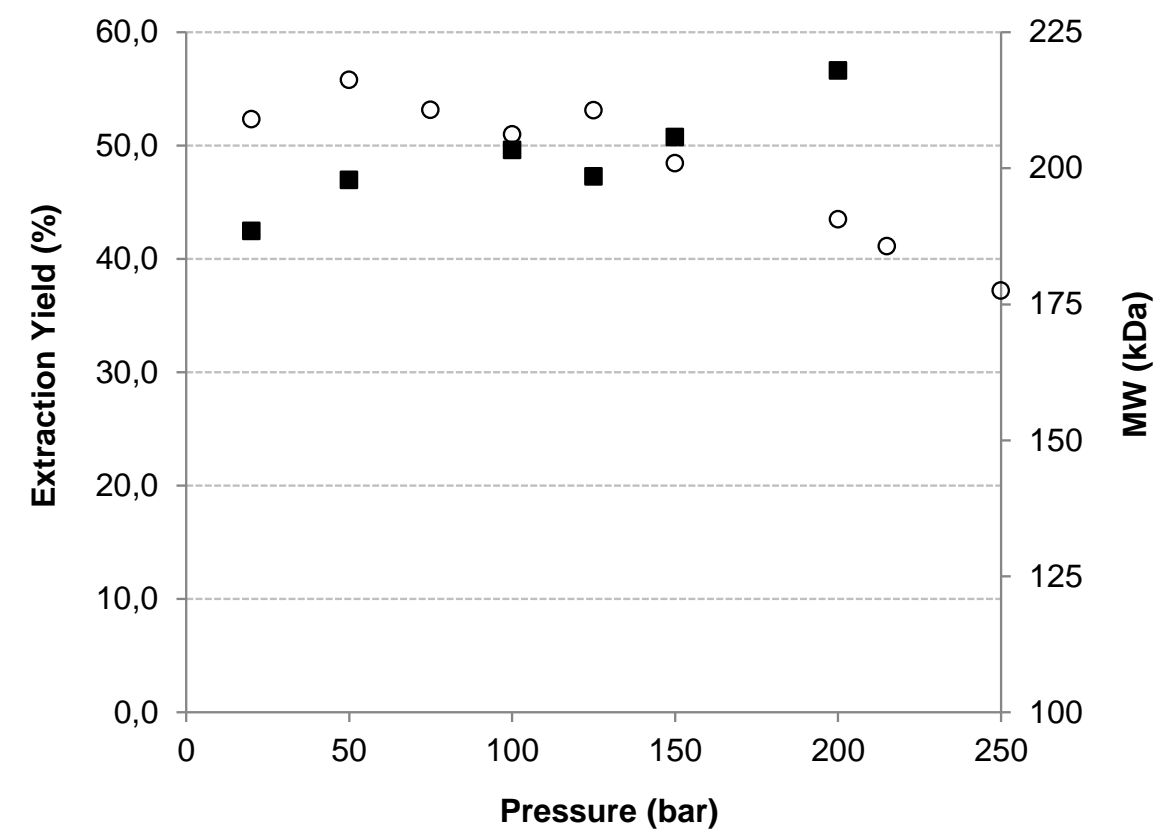

Figure 7. Extraction yield $(\mathrm{O})$ and molecular weight $(\mathbf{\square})$ as function of pressure (at $157.5^{\circ} \mathrm{C}$ and 45 minutes)

An increase in pressure induced a slight increase in the molecular weight of the extracted $\beta$ glucans, despite the reduction in the amount extracted. This increase in the MW must be related to the effect that pressure and temperature play on the $\beta$-glucanases. $\beta$-glucanases are endogenous enzymes present in the barley grain and responsible of $\beta$-glucan hydrolysis. According to the literature, pressure and temperature have opposite effects on the way that protein functional groups interact with water [24], and hence the stability of the enzyme is affected by them. Temperature and pressure can cause stabilization or denaturation effects on enzymes, depending on the initial conditions. Whereas high temperatures can inactivate $\beta$ glucanase activity, for certain temperatures usually below $75^{\circ} \mathrm{C}$, pressure can improve the activity of the enzyme in the depolymerization of $\beta$-glucans, as it has been observed by Buckow et al. [25] in the range $30-75^{\circ} \mathrm{C}$ and $0.1-900 \mathrm{MPa}$. In the present work, the temperature is much higher $\left(157.5^{\circ} \mathrm{C}\right)$ and it causes the denaturalization of $\beta$-glucanases, and pressure contributes to a slight increase on the MW of the extracted $\beta$-glucans. 
On the other hand, an increase in pressure affects negatively the extraction yield. Pressure compresses the barley flour hindering the internal diffusion of the hot water in the solid particles. This effect is deeply for higher pressures (above 50 bar). As it was discussed in section 3.1.2, the extraction time tends to decrease the $\mathrm{MW}$ of the $\beta$-glucans. This phenomenon can be partially compensated by increasing slightly the pressure, up to 50 bar: where extraction yield is not affected and MW is increased.

\subsection{Optimization of the PHW extraction process and comparison with "conventional extraction"}

If the MW and the extraction yield results are simultaneously evaluated, it can be seen that the conditions in which extraction yield and molecular weight are maximum are close. At low temperatures, $\beta$-glucans require long times to be dissolved; but long extraction times affect the $\beta$-glucan MW, as it has been previously described. At high temperatures, $\beta$-glucans are dissolved in shorter times; but for temperatures higher than $160^{\circ} \mathrm{C}$ the dissolved $\beta$-glucans can be easily depolymerized, resulting in a low extraction yield and low molecular weight. According to these results the extraction has to be performed at medium temperatures and relatively short times. Both, molecular weight and extraction yield, are maximized for temperatures in the range $152-155^{\circ} \mathrm{C}$ and extraction times in the range $17-20$ minutes, and pressure of 50 bar. The logarithm of the severity factor calculated for those conditions $\left(155^{\circ} \mathrm{C}\right.$, $18 \mathrm{~min}$ ) is 2.87 . Under these conditions, a confirmatory experiment was run: the extraction yield was $53.7 \%$ and average molecular weight resulted to be $200 \mathrm{kDa}$.

If these results are compared with that obtained with a "conventional extraction process" (described in section 2.2), it can be seen that the molecular weight of $\beta$-glucans extracted with PHW is very high compared to that obtained in the "conventional extraction process" (only 55 $\mathrm{kDa}$ ), in a one single step process, and in a much shorter extraction time (18 min vs. $3 \mathrm{~h}$ ). Therefore, the use of PHW as extraction solvent for $\beta$-glucans from barley represents a real intensification of the process. Water at high temperatures helps to destroy the interactions and bonds between polysaccharides and matrix, favoring the release of $\beta$-glucans to the solvent. Under the selected conditions, $\beta$-glucanases suffer thermal degradation losing their activity, and $\beta$-glucans are not broken down because of their activity. In the PHW extraction, molecular weight is decreased by the combination of temperature and time once the $\beta$ glucans are in solution in the PHW. Therefore, at $155^{\circ} \mathrm{C}$ and $18 \mathrm{~min}$, extraction is efficient enough and depolymerization and degradation are controlled. 


\section{CONCLUSIONS}

It can be concluded from this study that PHW is a suitable solvent to extract $\beta$-glucans from barley, by reducing dramatically the extraction time and by increasing the molecular weight by more than three times compared to the conventional process. There is a practical limit in the extraction of $\beta$-glucan; around $155-160^{\circ} \mathrm{C}$ and 45 minutes. Above these values the degradation of $\beta$-glucans begins to be more important than the amount of extracted $\beta$-glucan, as probes the rapid increase in the sugar degradation products detected and the depletion of $\beta$-glucan concentration observed.

The optimal conditions to extract $\beta$-glucans, high extraction yield and high molecular weight, were $155^{\circ} \mathrm{C}, 18$ minutes and 50 bar, with a extraction yield of $53,7 \%$, a molecular weight of 200 $\mathrm{kDa}$ and degradation products such as HMF were not detected.

\section{ACKNOWLEDGMENTS}

The authors want to thank the University of Valladolid fellowship research program FPI-UVa, for the financial support.

\section{ABBREVIATIONS:}

$\beta$-glucans: $(1 \rightarrow 3),(1 \rightarrow 4)-\beta-D$-glucan

HMF: 5-(Hydroxymethyl)furfural

MW: Molecular Weight

PHW: Pressurized hot water

$\mathrm{R}_{0}$ : Severity factor, defined by equation (1) 


\section{REFERENCES}

[1] S.W. Cui, Q. Wang, M. Zhang, Chapter 11: $\beta$-glucans. Renewable Resources for Functional Polymers and Biomaterials, The Royal Society of Chemistry (Eds.), 2011, pp. 319-345.

[2] P.J. Wood, Cereal $\beta$-glucans in diet and health, Journal of Cereal Science 46 (2007) 230-238.

[3] C.S. Brennan, L.J. Cleary, The potential use of cereal (1-3,1-4)- $\beta$-D-glucans as functional food ingredients, Journal of Cereal Science 42 (2005), 1-13.

[4] M.S. Izydorczyk, J.E. Dexter, Barley $\beta$-glucans and arabinoxilans: Molecular structure, physicochemical properties, and uses in food products-a review, Food Research International $41(2008) 850-868$.

[5] FDA, 21 CFR Part 101: Food labeling, health claims; soluble dietary fiber from certain foods and coronary heart disease. Federal Register 70[246] (2005) 76150-76162.

[6] EFSA Panel on Dietetic Products, Nutrition and Allergies (2010). Scientific Opinion on the substantiation of a health claim related to oat beta-glucan and lowering blood cholesterol and reduced risk of (coronary) heart disease pursuant to Article 14 of Regulation (EC) No 1924/2006. EFSA Journal, 8[12] (2010) 1885.

[7] O. Benito-Román, E. Alonso, S. Lucas, Optimization of the $\beta$-glucan extraction conditions from different waxy barley cultivars, Journal of Cereal Science 53 (2011) 271-276.

[8] M. Irakli, C.G. Biliaderis, M.S. Izydorczyk, I.N. Papadoyannis, Isolation, structural features and rheological properties of water-extractable $\beta$-glucans from different Greek barley cultivars, Journal of the Science of Food and Agriculture 84 (2004) 1170-1178.

[9] T. Ingram, T. Rogalinski, V. Bockemühl, G. Antranikian, G. Brunner, Semi-continuous liquid hot wáter pretreatment of rye Straw. Journal of Supercritical Fluids 48 (2009) 238-246.

[10] J. Kronholm, K. Hartonen, M.L. Riekkola, Analytical extraction with water at elevated temperatures and pressures, Trends in analytical Chemistry 26 (2007) 396-411.

[11] C.C. Teo, S.N. Tan, J.W. Hong Yong, C.S. Hew, E.S. Ong, Pressurized hot water extraction (PHWE).Review, Journal of Chromatography A 1217 (2010) 2484-2494.

[12] A. Mustafa, C. Turner, Pressurized liquid extraction as a green approach in food and herbal plants extraction: A review, AnalyticaChimica Acta 703 (2001) 8-18. 
[13] T. Rogalinski, T. Ingram, G. Brunner, Hydrolysis of lignocellulosic biomass in water under elevated temperatures and pressures, Journal of Supercritical Fluids 47 (2008) 54-63.

[14] S. HaghighatKhajavi, Y. Kimura, T. Oomori, R. Matsuno, S. Adachi, Degradation kinetics of monosaccharides in subcritical water, Journal of Food Engineering 68 (2005) 309-313.

[15] R.P. Overend, E. Chornet, J.A. Gascoigne, Fractionation of lignocellulosics by steamaqueous pretreatments, Philosophical Transactions of the Royal Society A 321 (1987) 523-536.

[16] C. Schacht, C. Zetzl, G. Brunner, From plant materials to ethanol by means of supercritical fluid technology, Journal of Supercritical Fluids 46 (2008) 299-321.

[17] C.H.L. Ho, J.E. Cacace, G. Mazza, Extraction of lignans proteins and carbohydrates from flaxseed meal with pressurized low polarity water, LWT-Food Science and Technology 40 (2007) 1637-1647.

[18] A.U. Buranov, G. Mazza, Extraction and characterization of hemicelluloses from flax shives by different methods, Carbohydrate Polymers 79 (2010) 17-25.

[19] R. Askin, M. Sasaki, M. Goto, Recovery of water soluble compounds from Ganodermalucidum by hydrothermal treatment, Food and Bioproducts Processing 88 (2010) 291-297.

[20] J.E. Cacace, G. Mazza, Pressurized low polarity water extraction of lignans from whole flaxseed, Journal of Food Engineering 77 (2006) 1087-1095.

[21] S. Hata, J. Wiboonsirikul, A. Maeda, Y. Kimura, S. Adachi, Extraction of defatted rice bran by subcritical water treatment, Biochemical Engineering Journal 40 (2008) 44-53.

[22] T. Song, A. Pranovich, B. Holmbon, Effects of pH control with phthalate buffers on hotwater extraction of hemicelluloses from spruce wood, Bioresource Technology 102 (2011) 10518-10523.

[23] B.M. Kabyemela, T. Adschiri, R.M. Malaluan, K. Arai, Glucose and Fructose Decomposition in Subcritical and Supercritical Water: Detailed Reaction Pathway, Mechanisms, and Kinetics, Industrial \& Engineering Chemistry Research 38 (1999) 2888-2895.

[24] M.J. Eisenmenger, J.I. Reyes de Corcuera, J.I., High pressure enhancement of enzymes: A review, Enzyme and Microbial Technology 45 (2009) 331-347. 
[25] R. Buckow, V. Heinz, D. Knorr, Effect of High Hydrostatic Pressure-Temperature combinations on the activity of $\beta$-glucanase from barley malt, Journal of the Institute of Brewing 111 (2005) 282-289. 


\section{ChAPTER 5}

Fixed-bed extraction of $\beta$-glucan

from cereals by means of Pressurized Hot Water 



\title{
Fixed-bed extraction of $\beta$-glucan from cereals by means of Pressurized Hot Water ${ }^{1}$
}

\begin{abstract}
$\beta$-glucans were successfully extracted from different cereals (barley, de-starched barley and wheat bran) in a fixed-bed reactor using pressurized hot water (PHW) as solvent, in the range $110-175^{\circ} \mathrm{C}$, at $20 \mathrm{bar}$. Results were evaluated in terms of extraction yield, molecular weight of the extracted $\beta$-glucans and hydrolysis products.

Optimal extraction conditions were identical for the three raw materials: $155^{\circ} \mathrm{C}, 20 \mathrm{bar}$ and $4 \mathrm{~g} / \mathrm{min}$ of PHW. Under these conditions, almost $100 \%$ of the initial $\beta$-glucans are extracted after $105 \mathrm{~min}$, and molecular weight of the extracted $\beta$-glucans was much higher (up to $500 \mathrm{kDa}$ vs $180 \mathrm{kDa}$ ) comparing with batch operation, revealing the feasibility of the use of fixed-bed reactors for the $\beta$-glucan extraction. Under these conditions no degradation products, such HMF, were detected in the extract.

Fixed-bed extraction is a promising technique for the extraction and fractionation of different molecular weight $\beta$-glucan, as in one single step and short residence times is possible to extract high molecular weight $\beta$-glucan with relatively high extraction yields.
\end{abstract}

Keywords: $\beta$-glucan, barley, fixed-bed extraction, pressurized hot water, polysaccharide

\footnotetext{
${ }^{1}$ The Journal of Supercritical Fluids (submitted)
} 


\section{INTRODUCTION}

$\beta$-glucan, a D-glucose polymer, is a polysaccharide that can be found in the subaleurone and endosperm cell walls of different cereals such as barley and oat and, in a lesser extent, wheat. The structure of this polymer is mainly linear: glucose is linked to other two or three units by means of $\beta$-(1-4)-O-glucosidic linkage (forming cellobiose or cellotriose blocks) which are separated by a $\beta$-(1-3)-O-glucosidic linkage. The final solubility properties of the $\beta$-glucan are affected by several features affecting the molecular structure [1]: the ratio $\beta-(1-4) / \beta-(1-3)$ linkages; the length of the $\beta-(1-4)$ structures and the molecular weight. In the recent years, the introduction of specially developed waxy genotypes has made of barley the cereal with the highest content in $\beta$-glucan (from 3-11\%). This content is higher than the reported in oats (3.2$6.8 \%$ ) and wheat, in which $\beta$-glucans only represent $0.5-1 \%$ of the total weight of the grain [2]. $\beta$-glucans are the major constituent of soluble cereal fiber. The high content in fiber has increased the interest of barley for human consumption purposes in the last years $[3,4]$ due to its potential beneficial effect over several diseases. Recently FDA (United States Federal Drug Administration) and EFSA (European Food Safe Authority) have accepted a health claim in reduction of cholesterol levels, recommending an intake of $3 \mathrm{~g}$ of $\beta$-glucan per day to achieve this positive effect $[5,6]$. On the other hand, wheat has been rarely used as source of $\beta$ glucans due to its extremely low content in them. It is hard to find works in which $\beta$-glucan are extracted from wheat only at Li et al. [7]. Wheat is extensively used for the preparation of bread and other products related to the bakery industry, due to its high content in starch. Only the endosperm of the grain is desired in the bakery industry; so a special milling is required to remove the outer layers of the grain, as well as the aleurone and the remnants of the endosperm. These parts represent around $14-19 \%$ of the kernel, and are known as wheat bran [8]. Apparently, wheat bran is a useless by-product of the milling industry, which has a high content in non-starchy polysaccharides (46\%, being 1.5-2\% $\beta$-glucans); starch (10-20\%); proteins (>20\%) and lignin (up to $8 \%$ ) [9]. The presence of these polysaccharides is seen as a challenge and an opportunity for the biorefinery industry, as the potential content in sugars is high, which can be used to produce bioethanol [10].

The presence of some $\beta$-glucans can contribute to increase the added value of wheat bran, as can be selectively extracted by means of the use of pressurized hot water (PHW). This was demonstrated by Benito-Román et al. [11], where $\beta$-glucans are selectively dissolved by means of PHW in the range $155-160^{\circ} \mathrm{C}$ and mild pressures of 20-50 bar. PHW shows excellent 
properties to be used as a solvent, since it enhances mass transfer and weakens the bonds between polysaccharides or other high added value products and the natural matrix.

PHW term refers to the water in liquid state in the range $100^{\circ} \mathrm{C}$ (boiling point) and $374^{\circ} \mathrm{C}$ (critical point of water) by the application of pressure. Other names that can be found in literature are: "superheated water", "near critical water", "subcritical water", "compressed hot water" or "pressurized low polarity water". Under these conditions, properties of liquid water change dramatically when changing temperature, and in a lesser extent, pressure. The effect that pressure and temperature have on the physicochemical properties of the water and how these parameters affect the pressurized hot water extraction has already been discussed by these authors in a previous work. Nevertheless, the extraction mode (either static or dynamic) has not been reviewed yet. Static mode refers to the batch extraction and the efficiency depends on the partition-equilibrium constant and the solubility of the compound [12]. Dynamic extraction mode, in which fresh water is continuously pumped through the raw material, has two different effects on the extraction: first, the equilibrium is continuously displaced [13]; and second, the solute is pump out of the reactor as soon as it is dissolved so the time it is exposed to the high temperatures it is reduced compared to the static mode; and thus thermal degradation is limited. According to the literature, one of the major drawbacks of the dynamic extraction mode is that it requires higher volumes of solvent than the static mode, which results in the dilution of the target compounds.

Hence the residence time (affected by the volume of the reactor and the flow rate) is the key parameter affecting the dynamic extraction mode, as well as the temperature [14] and the length to diameter ratio of the reactor (in order to prevent channeling, excessive pressure drop and material agglomeration). The final performance of the extraction will be affected by all the parameters mentioned above, which will be selected as function of the target compound and the nature of the matrix where they are trapped [12]. The selection of the extraction conditions will have the purpose to maximize the extraction rate without damaging the target compound.

The purpose of this work was to evaluate the extraction of $\beta$-glucans from barley and wheat bran using pressurized hot water as solvent in a semi-continuous reactor (fixed-bed type), evaluating the effect of operational parameters on mass transfer and solubilization. The obtained results were compared to those obtained in the batch extraction, and the quality of the extracted product was evaluated in terms of molecular weight and the degradation byproducts formed during the extraction (glucose, fructose, xylose, cellobiose and HMF). 


\section{MATERIALS AND METHODS}

\subsection{Raw material}

Two different raw materials were used in this work: wheat bran and barley. Wheat bran was obtained from Biowanze (Belgium) and used directly from the supplier without any processing, with an average particle size of $0.985 \pm 0.040 \mathrm{~mm}$. The content in $\beta$-glucans and starch of this cereal, expressed in dry basis, is 1.7 and $24.5 \%$ respectively. A barley waxy genotype grown and provided by ITACYL (Instituto de Tecnología Agraria de Castilla y León, Spain) has also been used as raw material. It contains $5.4 \%$ in $\beta$-glucan and $52 \%$ in starch (dry basis). Barley grains were milled in the laboratory in order to obtain one single milling fraction that resulted in an average particle size of $1.086 \pm 0.036 \mathrm{~mm}$. Some of the barley was treated with $\alpha$-amylase (from Bacillus licheniformis, 770 units/mg solid, Sigma Aldrich) in order to remove part of the starch before the extraction. After the treatment ( $85^{\circ} \mathrm{C}$, $4 \mathrm{~h}$ in a $\mathrm{pH} 6.5$ phosphate buffer) barley was rinsed and freeze dried. The resulting barley contained $2.9 \%$ and $2.6 \%$ of $\beta$-glucans and starch, respectively.

\subsection{Experimental set-up}

As two different extraction processes were studied in this work (batch and semi-continuous), two different experimental set-ups were used: a pressurized stirred vessel for the batch experiment, located at the Chemical Engineering and Environmental Technology Department in the University of Valladolid (Spain), and a fixed-bed laboratory scale plant for the flow experiments, placed at the Institute for Thermal Separations of the Technical University of Hamburg-Harburg (Germany).

\subsubsection{High-Pressure view chamber}

Extraction was carried out in a $30 \mathrm{~mL}$ internal volume High-Pressure View Chamber (Eurotechnica $\mathrm{GmbH}$ ). Maximum operating pressure and temperature of the device are 300bar and $500^{\circ} \mathrm{C}$, respectively. The experimental extraction procedure can be found at Benito-Román et al. [11]; extractions were performed at $155^{\circ} \mathrm{C}$ and lasted 30 minutes, at constant pressure of 20bar. In each experiment $1 \mathrm{~g}$ of biomass was introduced in the pressurized vessel for the extraction.

\subsubsection{Fixed-bed reactor}

In these experiments, around $11-12$ grams of the cereal were loaded in the $50 \mathrm{~mL}$ reactor (internal diameter $15 \mathrm{~mm}$ ). The reactor was placed in an oven to keep the extraction at the 
desired temperature, which was measured at the oven and at the inlet/outlet of the reactor, in order to get a temperature profile in the reactor during the extraction process. Water was pumped by means of a HPLC pump at a constant flow rate and the pressure in the reactor was controlled by means of a spring loaded back pressure regulator. The liquid extract obtained was cooled down in an ice bath. In order to stop the extraction after 105 minutes, pump was stopped and the reactor was suddenly depressurized. Once the reactor was cooled down, the solid residue was weighted and determined the moisture content, to calculate the mass balances and determine the amount of biomass dissolved during the extraction. The liquid extracts obtained during the extraction at different times were kept at $4^{\circ} \mathrm{C}$, and were used to determine the content in $\beta$-glucan and the analysis of sugars.

A schema of the experimental set-up is shown in figure 1.

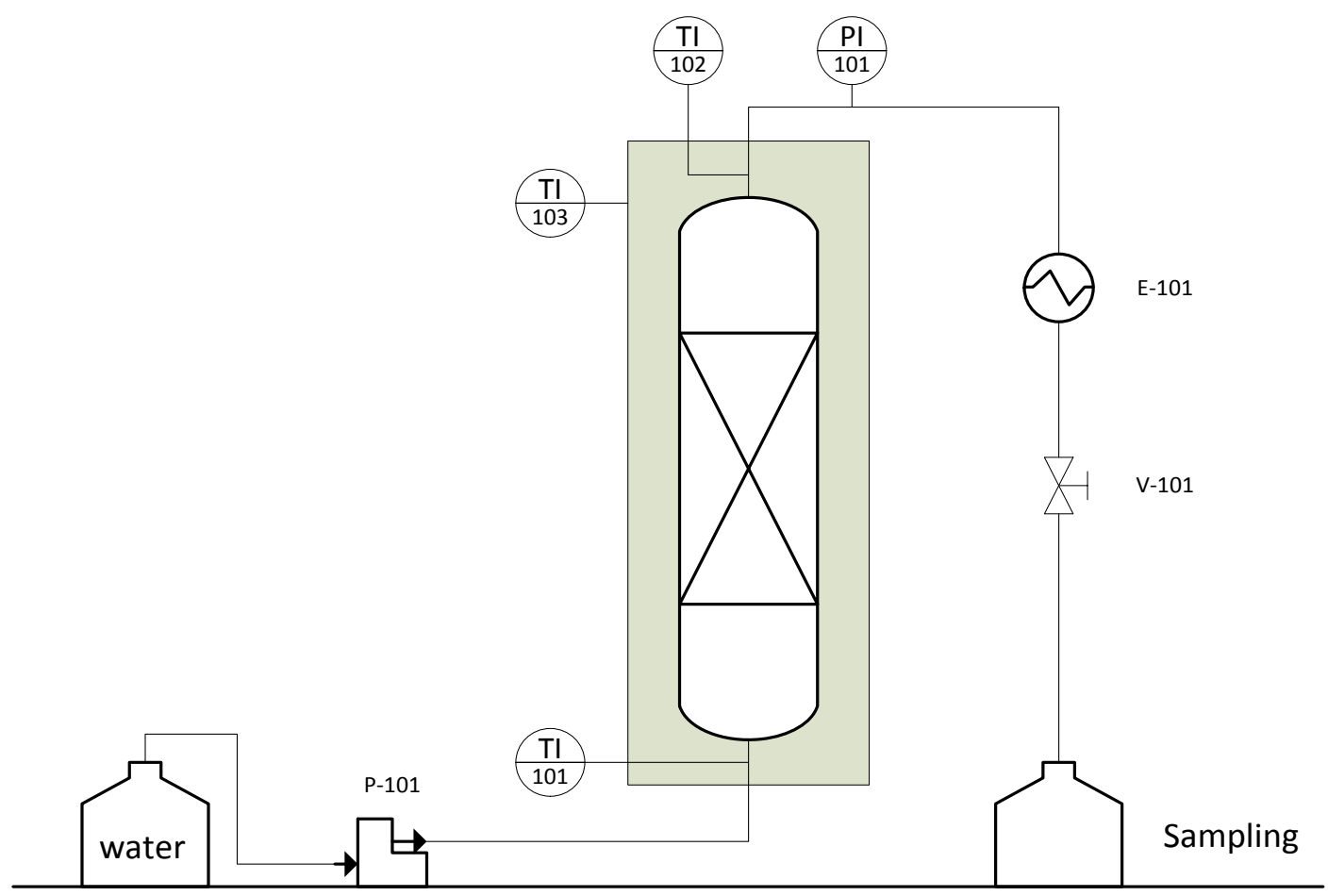

Figure 1. Fixed-bed reactor used in this work.

\section{$2.3 \beta$-glucan analysis}

Megazyme International Ltd "Mixed-linkage $\beta$-glucan" assay kit was used to quantify $\beta$-glucan in the liquid extract following a modification of the standard procedure proposed by Megazyme. Concentration of $\beta$-glucan dissolved was reported in $\mathbf{g}$ of $\beta$-glucan/100g of water. 


\subsection{Molecular weight analysis (GPC)}

Molecular weight of $\beta$-glucan was determined by Size Exclusion Chromatography (HPLC-SEC) using a chromatographic system that consisted of an isocratic pump (Waters 1515), an automatic injector (Waters 717), guard column (Waters) and a GPC column (Ultrahydrogel U500, Waters) and a differential refractive index detector (Waters 410). The column was kept at $35^{\circ} \mathrm{C}$, and flow rate of the mobile phase $\left(0.1 \mathrm{M} \mathrm{NaNO}_{3}+0.02 \% \mathrm{NaN}_{3}\right)$ was set at $0.4 \mathrm{~mL} \cdot \mathrm{min}^{-1}$. The $\beta$-glucan molecular weight standards were purchased from Megazyme International Ltd. (Ireland), and were in the range 40-359 kDa.

In order to isolate the $\beta$-glucan dissolved in the liquid extract, an equal volume of ethanol $(96 \%, v / v)$ was added to the extract, causing the precipitation of the polysaccharides. The formed precipitated was dried overnight at $60^{\circ} \mathrm{C}$, and stored in a sealed vial. Prior to the molecular weight measurement, the precipitate was re-dissolved in ultrapure water (concentration $0.1 \% \mathrm{w} / \mathrm{v}$ ), and filtered (Millipore $0.20 \mu \mathrm{m}$ ). This solution was subsequently injected into the HPLC system.

\subsection{HPLC saccharides analysis}

HPLC was used to analyze the oligosaccharides and sugars (cellobiose, fructose, glucose and HMF) formed during the extraction process. Chromatography system was basically the same as used for molecular weight determination (pump, injector and detector, including an UV/Visible Detector Waters 2489); column and guard column were purchased to Shodex (KS-802, guard column KS-G) and set at $60^{\circ} \mathrm{C}$ and mobile phase (ultrapure water) was set at $0.8 \mathrm{~mL} \cdot \mathrm{min}^{-1}$.

\section{EXPERIMENTAL RESULTS}

\subsection{Batch experiments}

Extraction of barley, wheat bran and de-starched barley were carried out in the conditions described in section 2.2.1. Extraction yield and molecular weight of the extracted $\beta$-glucans are summarized in table 1.

Table 1. Experimental results of the batch experiments

\begin{tabular}{|c|c|c|}
\hline Raw material & Extraction Yield (\%) & Molecular Weight (kDa) \\
\hline Barley & $53.7 \pm 1.3$ & $188 \pm 11$ \\
\hline Wheat Bran & $59.4 \pm 1.8$ & $9 \pm 1$ \\
\hline De-starched barley & $60.6 \pm 1.5$ & $21 \pm 3$ \\
\hline
\end{tabular}


It can be observed that the raw material did affect the molecular weight of the extracted $\beta$ glucan; however extraction yield was not significantly different when changing the raw material. These results were used as basis for the comparison with the results obtained in the fixed bed extractor.

\subsection{Fixed bed experiments}

The effect of operational variables, temperature, time and flow has been evaluated for the three different raw materials. Extraction temperature was studied in the range $110-175^{\circ} \mathrm{C}$ when wheat bran was used as raw material; however, when barley was used the selected temperature was $155^{\circ} \mathrm{C}$ since it was the optimal temperature for the extraction of $\beta$-glucan from barley [11].

\subsubsection{Wheat Bran}

\subsubsection{Effect of flow rate}

Initial experiments had the purpose of testing the effect that flow rate had on the extraction of $\beta$-glucan, and finding the rupture curve (in order to know the maximum extractability of $\beta$ glucans) at $155^{\circ} \mathrm{C}$ and 20 bar. Water was pumped at a constant rate of 4 and 6 grams per minute. The integral extraction curve of $\beta$-glucans under these conditions is presented in figure 2. Three different periods can be distinguished: (1) The cell structure swells (extract non readily accessible for the solvent) up to $30 \mathrm{~min},(2)$ Maximum extraction rate that lasted up to 75 min and (3) Solid depletion: the length of the fixed bed containing the initial content of bglucan is not long enough to enable the maximum loading of the solvent. Maximum extraction yield at $4 \mathrm{~g} / \mathrm{min}$ was $87.3 \pm 0.9 \%$ and $83.4 \pm 1.3 \%$ at $6 \mathrm{~g} / \mathrm{min}$. In both experiments the $90 \%$ of the total $\beta$-glucan were extracted after 105 minutes of experiment. From these results it was possible to set the main conditions for the subsequent experiments: $4 \mathrm{~g} / \mathrm{min}$ (as higher extraction yield was achieved with lower solvent consumption) and maximum extraction time of 105 minutes. The increase in the flow rate did not improve the extraction rate, indicating that under these conditions external mass transfer do not limit the extraction. This result is in agreement with the result observed by Ho et al. [15] when extracting lignans from flaxseed meal. 


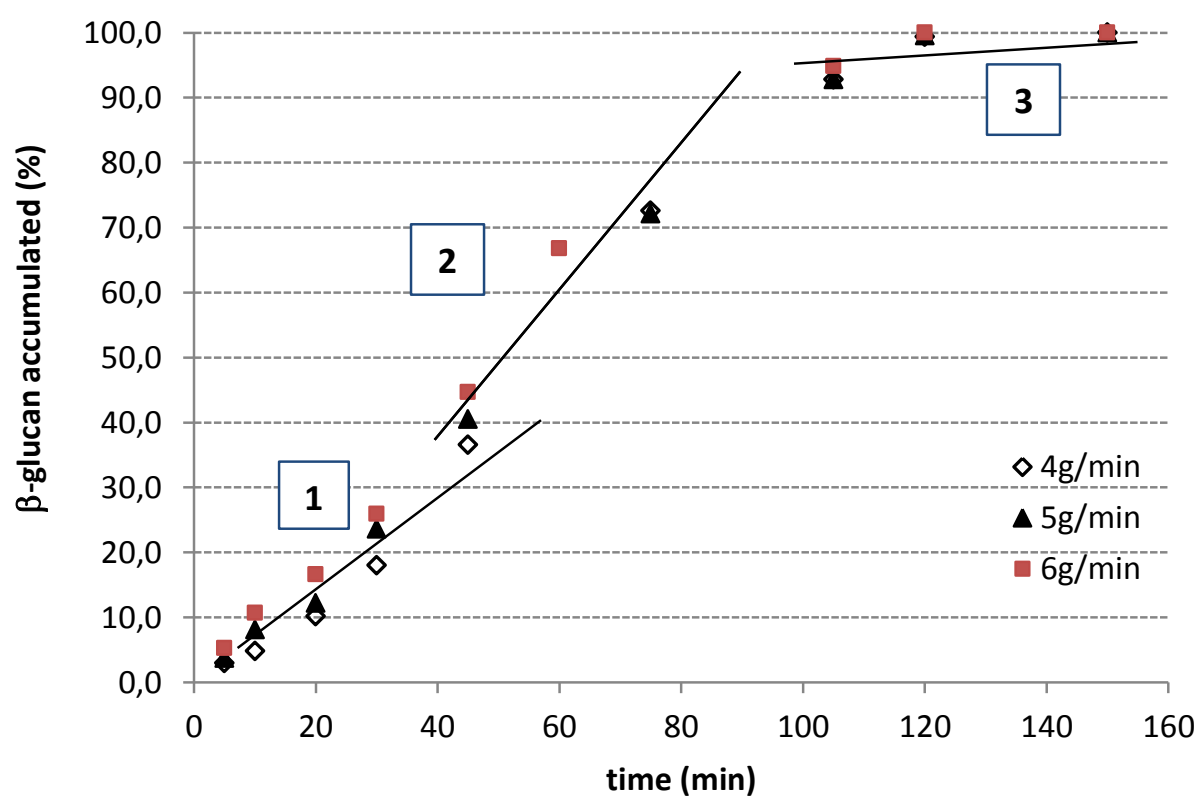

Figure 2. Integral extraction curve. Effect of the flow rate on the $\beta$-glucan extraction at $155^{\circ} \mathrm{C}$ and $20 \mathrm{bar}$

\subsubsection{Effect of temperature}

Extraction yield of $\beta$-glucan from wheat bran was studied at different temperatures, from $110^{\circ} \mathrm{C}$ to $175^{\circ} \mathrm{C}$. Figure 3 shows the extraction curve at each temperature versus the time:

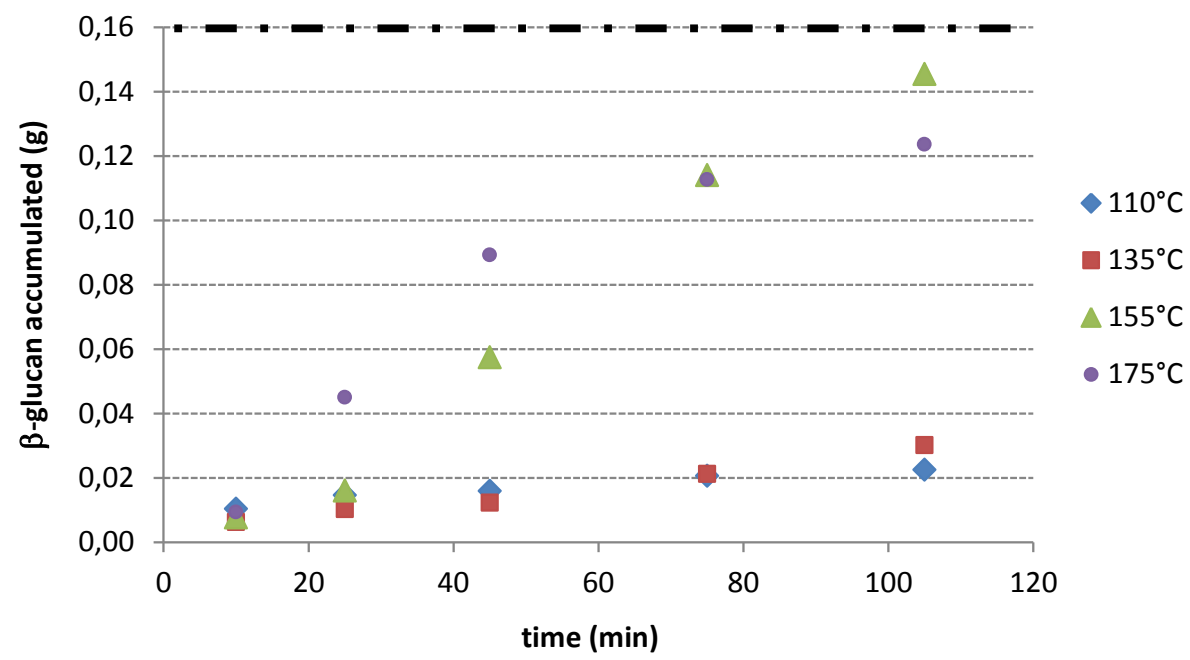

Figure 3. Effect of the temperature on the $\beta$-glucan extraction at different temperature (flow rate $4 \mathrm{~g} / \mathrm{min}$ and pressure 20bar). Black dashed line represents the total amount of $\beta$-glucan in the solid

Temperature has a strong influence on extraction curves, as it can be seen in figure 3. For temperatures below $135^{\circ} \mathrm{C}$ the extraction rate is slow and extraction yield is below $20 \%$ after $105 \mathrm{~min}$. However, for temperatures higher than $150^{\circ} \mathrm{C}$ extraction rate increases dramatically and extraction yields achieve values higher than $80 \%$. Starch and $\beta$-glucan appear to be linked in the edge between endosperm and subaleurone and subsequently, in order to isolate $\beta$ - 
glucans it is necessary to weaken the linkage existent between them. The properties of the PHW (decrease of the viscosity and the surface tension compared to the values at room temperature) and the decrease of the self ionization constant of water $\left(\mathrm{pK}_{\mathrm{w}} ; 14.02\right.$ at $25^{\circ} \mathrm{C}$ and 20bar and 11.61 at $155^{\circ} \mathrm{C}$ and 20bar; IAPWS, 2007)) are supposed to help to weaken this interaction; and so $\beta$-glucan is released and easily extracted at temperatures around 150$160^{\circ} \mathrm{C}$. Moreover, authors have checked that starch is easily dissolved and hydrolyzed in PHW at temperatures lower than $155^{\circ} \mathrm{C}$ and very short times (less than 20 minutes) compared to $\beta$ glucan. The rise in the extraction yield found when increasing the temperature from 135 to $155^{\circ} \mathrm{C}$ in the partial hydrolysis that starch suffers: the linkage between $\beta$-glucan and starch is broken so $\beta$-glucan is released and starch is hydrolyzed. If temperature is increased up to $175^{\circ} \mathrm{C}$ is $\beta$-glucan the polysaccharide that begins to suffer the hydrolysis, decreasing the extraction yield as a consequence.

A strong effect of temperature on the extraction yield was observed, as can be seen in table 2 (that summarizes the extraction yield after 105 minutes versus the temperature). This extraction yield was calculated by measuring the concentration of $\beta$-glucan in the liquid extracts (mass balance to the liquid extract: amount of $\beta$-glucan in the liquid extract divided by the $\beta$-glucans contained in the biomass used in the experiment) according to the equation:

$$
\text { Extraction Yield }(\%)=\frac{\text { mass rate }(\mathrm{g} / \mathrm{min}) \cdot \text { experiment length }(\mathrm{min}) \cdot \beta \text {-glucan concentration }(\mathrm{g} / 100 \mathrm{~g})}{\text { Biomass used }(\mathrm{g}) \cdot \beta \text {-glucan content of biomass }(\mathrm{g} / 100 \mathrm{~g})} \mathrm{X} 100
$$

Table 2. Effect of the temperature on the extraction yield of $\beta$-glucan from wheat bran

\begin{tabular}{|c|c|c|c|c|}
\hline Temperature $\left({ }^{\circ} \mathbf{C}\right)$ & 110 & 135 & 155 & 175 \\
\hline Extraction Yield (\%) & 12.4 & 17.5 & 82.4 & 68.0 \\
\hline
\end{tabular}

The exhausted wheat bran after the extraction was weighted and analyzed, in order to calculate the mass balance to the $\beta$-glucan extracted, and the extraction yield. At temperatures below $155^{\circ} \mathrm{C}$ no significant differences were observed in the $\beta$-glucan extraction yield calculated from the liquid extract and from the solid. However at $175^{\circ} \mathrm{C}$ it was observed an important discrepancy: the amount of $\beta$-glucan detected in the liquid (that had been already dissolved) was much lower than the amount of $\beta$-glucan that had been extracted from the solid (68\% vs. $97 \%$ ). This indicated that part of the $\beta$-glucan that should have been extracted was not present in the liquid, probably due to thermal degradation, either of the biomass or the $\beta$-glucan already dissolved. Figure 4 shows the extraction yield calculated from the liquid and from the solid. 


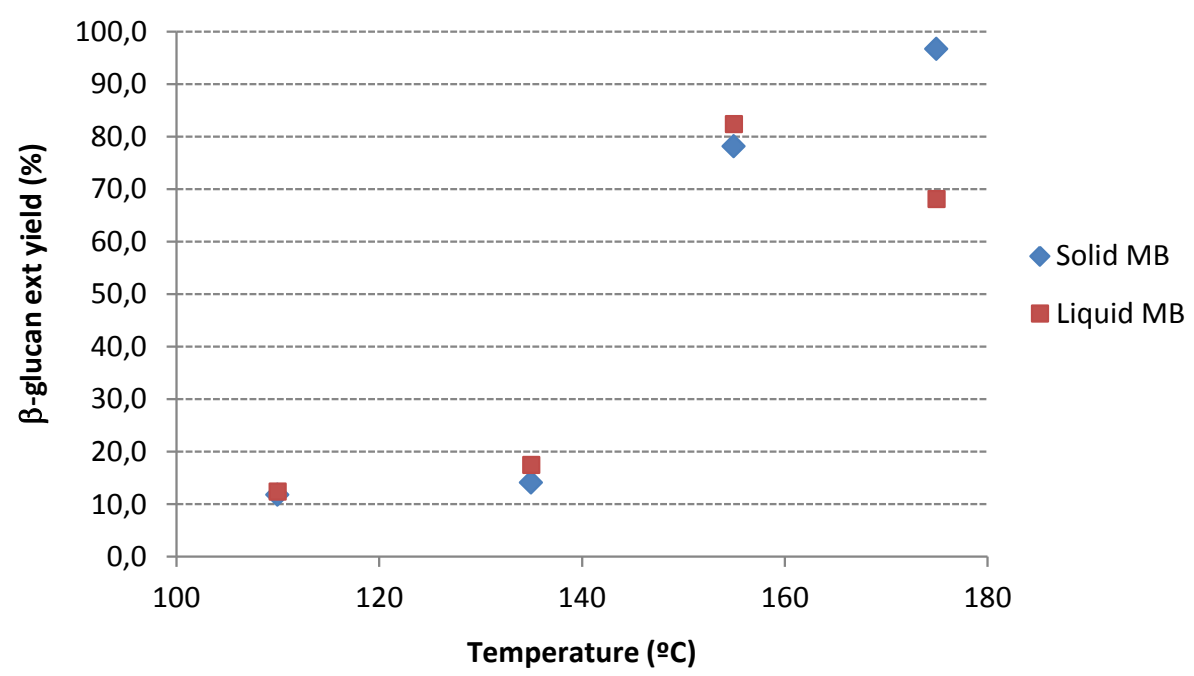

Figure 4. $\beta$-glucan extraction yield as function of the temperature, calculated from the mass balance $(M B)$ to the liquid and to the solid

In order to evaluate the effect of temperature on the biomass and the extracted compounds and formed during the extraction as a consequence of temperature and residence time, the hydrolysis products (sugars and oligosaccharides) were studied. As first step, $\mathrm{pH}$ of the liquid collected during the extraction was measured for each temperature. $\mathrm{pH}$ elution profile can be seen in figure 5 :

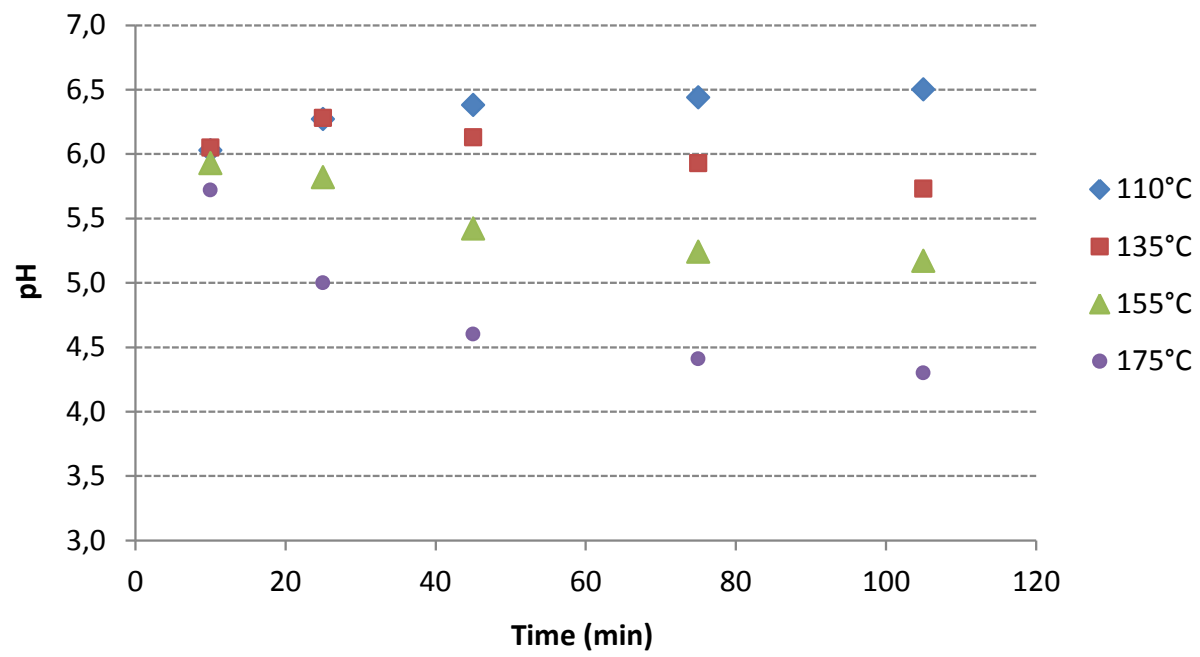

Figure 5. $\mathrm{pH}$ of the liquid extract measured during the extraction of $\beta$-glucan from wheat bran at different temperatures

Two different trends can be observed: at $110^{\circ} \mathrm{C} \mathrm{pH}$ increases slightly during the extraction and at temperatures above, $\mathrm{pH}$ decreases with the time. This decrease is faster the higher the temperature, being clearly acid at $175^{\circ} \mathrm{C}$. This could be indicating that biomass or the polysaccharides dissolved are suffering the effect of time and temperature and are being 
hydrolyzed. In order to probe this hypothesis the sugar degradation products were analyzed and results shown in section 3.2.1.3.

All in all it was clearly seen that the optimal temperature for the extraction of $\beta$-glucan from wheat bran was $155^{\circ} \mathrm{C}$ : below this temperature the amount extracted was extremely low; nevertheless when increasing the temperature up to $175^{\circ} \mathrm{C}$ extraction was initially much faster compared to $155^{\circ} \mathrm{C}$; however the total amount of $\beta$-glucan extracted was lower. This phenomenon could be caused by the degradation that the biomass suffers when it is exposed to high temperatures during the complete extraction process. Biomass in contact with the hot water for long times results in thermal degradation; so instead of happening an extraction process a thermal hydrolysis process of the biomass is taking place in the fixed-bed.

\subsubsection{Hydrolysis products}

The main hydrolysis products were analyzed by HPLC. It was seen a clear decrease of pH the higher the extraction temperature was. The HPLC analysis revealed a dramatic increase in the acid concentration at high temperatures: sugars dissolved in the media were degraded to acids (lactic, acrylic and formic acid were detected). The presence of acids in the media could also contribute to accelerate the hydrolysis of $\beta$-glucan or other polysaccharides present in the barley. Figure 6 shows the amount of lactic, acrylic and formic acid dissolved as function of the temperature.

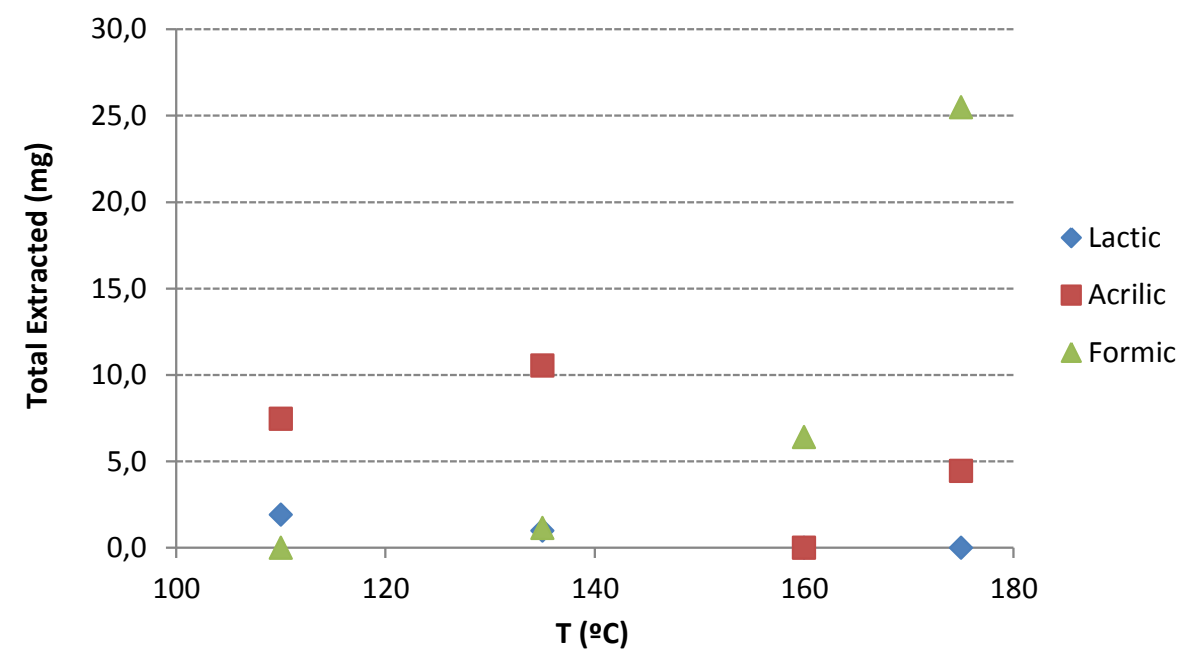

Figure 6. Effect of acid concentration on the $\mathrm{pH}$ of the liquid extract at different temperatures

Glucose, arabinose and xylose (figure 7) were also analyzed. When the trend of the glucose concentration is analyzed, two zones can be distinguished in figure 7 , setting the edge between them at $160^{\circ} \mathrm{C}$. It was observed a decrease in the amount of the glucose dissolved up 
to $160^{\circ} \mathrm{C}$. According to the literature, the compounds that are dissolved between 110 and $160^{\circ} \mathrm{C}$ are those that are easily extracted; such as free glucose and starch. Glucose is easily obtained from starch hydrolysis, at relatively low temperatures. When temperature is increased, the glucose obtained from the hydrolysis of starch is degraded to other compounds, which explains the decrease in the glucose concentration. From $160^{\circ} \mathrm{C}$, the hydrolysis of the hemicelluloses and polysaccharides such as $\beta$-glucan begins, so some glucose is released to the media. This explains the slight increase in the glucose concentration, which can be attributed to the $\beta$-glucan hydrolysis: according to figure 4 , at $175^{\circ} \mathrm{C} \beta$-glucan concentration is lower to that obtained at $155^{\circ} \mathrm{C}$. The mass balance calculated to the solid before and after the extraction revealed that almost all $\beta$-glucan present in the solid should have been dissolved; but all the theoretically dissolved $\beta$-glucan was not detected in the liquid. This probes that the $\beta$-glucan suffered severe thermal hydrolysis at $175^{\circ} \mathrm{C}$

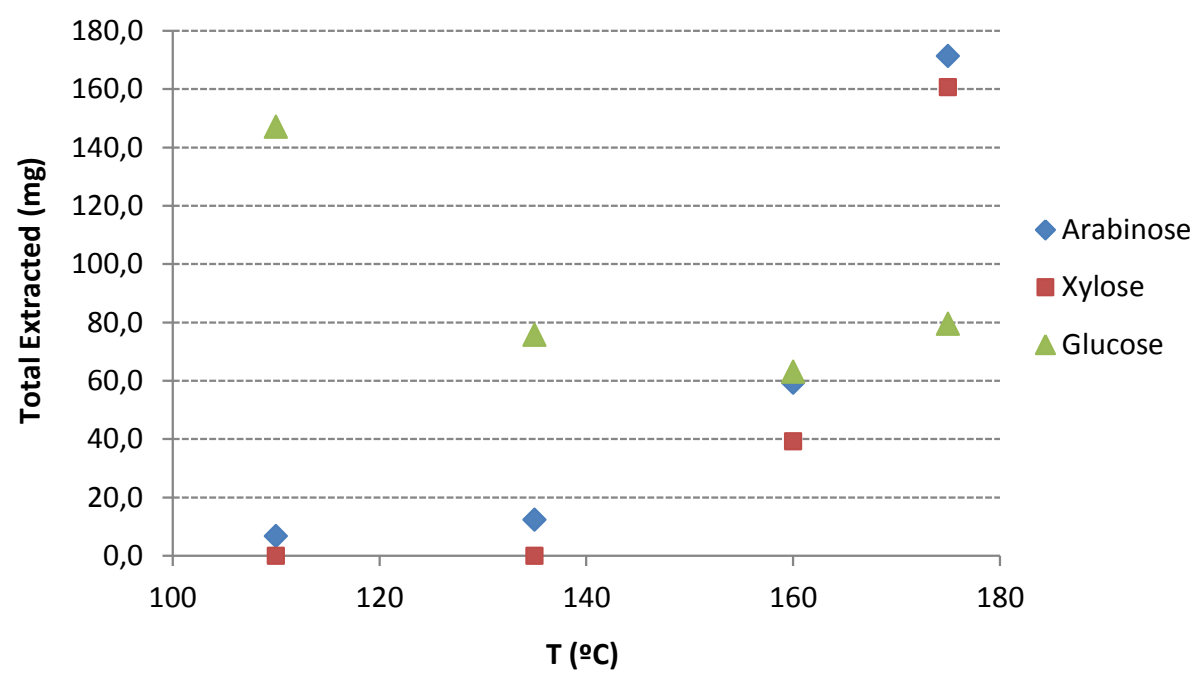

Figure 7. Glucose, arabinose and xylose concentration in the accumulated liquid extract as a function of the temperature

The hydrolysis of other hemicelluloses present in the wheat bran, such as arabinoxylanes, was probed when the analysis of arabinose and xylose was done, as shown in figure 7. It was seen that at $160^{\circ} \mathrm{C}$ the concentration of both pentoses increased dramatically. Compounds such as HMF, which indicate the complete degradation of glucose, were only detected in the samples obtained at $175^{\circ} \mathrm{C}$.

\subsubsection{Barley}

It was clearly seen in batch experiments that the optimal temperature for the $\beta$-glucan extraction from barley was $155^{\circ} \mathrm{C}$. The same result was observed when wheat bran was used 
as source of $\beta$-glucan; so the extraction of $\beta$-glucans from barley in the fixed bed was only studied at $155^{\circ} \mathrm{C}$.

Barley was finely milled (particle size below $0.5 \mathrm{~mm}$ ); the same particle size that was used in the batch experiments. Reactor was loaded with this biomass, and water was pumped. However, no flow was detected through the reactor. Barley presented two drawbacks: first, particle size was very low, so biomass was tighten in excess forming a block. Linked to the low particle size was the high content in starch of the barley. Starch, in finely milled barley, was free to be in contact with the hot water, so it could gelatinize. In this process starch increases the viscosity of the water, hindering the flow through the fixed-bed and clogging the outlet pipes. All these drawbacks led to a complete reconsideration of the extraction process. In order to prevent the starch gelatinization, a coarse milling was carried out, resulting in a higher average particle $(1.086 \pm 0.036 \mathrm{~mm})$. The coarser milling reduced the amount of free starch in the flour. When operating the reactor with this barley at $155^{\circ} \mathrm{C}, 20 \mathrm{bar}$ and $4 \mathrm{~g} / \mathrm{min}$, extraction was successfully performed.

Under the above described conditions, extraction yield was $52.4 \pm 1.4 \%$ and the extraction curve is shown in figure 8 . Samples were taken at minutes 10, 25, 45, 75 and 105 during the extraction. It was analyzed the content in $\beta$-glucan in the liquid extract obtained in each of the five periods, and calculated the $\beta$-glucan extraction rate (expressed in $\mathrm{mg} / \mathrm{min}$ ) in each period. Figure 8 shows the integral extraction curve and the $\beta$-glucan extraction rate in each period $(10,2545,75$ and 105 minutes). Is in the central part of the experiment when most of the $\beta$ glucan is dissolved (from 25 to 75 minutes); revealing the internal mass transfer limitations: $\beta$ glucans needed time to be released from the matrix. In the last period, from 75 to 105 minutes concentration of $\beta$-glucan in the extract began to decline. This trend must be close related to the mass transfer in the reactor: in the first period only a few polysaccharides are extracted; during this time hot water begins to hydrolyze partially the biomass. In the subsequent period, once the biomass is pretreated, $\beta$-glucans are easily relieved from the matrix; and in the last period the concentration of $\beta$-glucan begins to decline as a consequence of the high temperature and pressure conditions. This mechanism must be validated. In order to validate it molecular weight of the $\beta$-glucan extracted in each period is going to be determined, as well as the hydrolysis products formed during the extraction. 


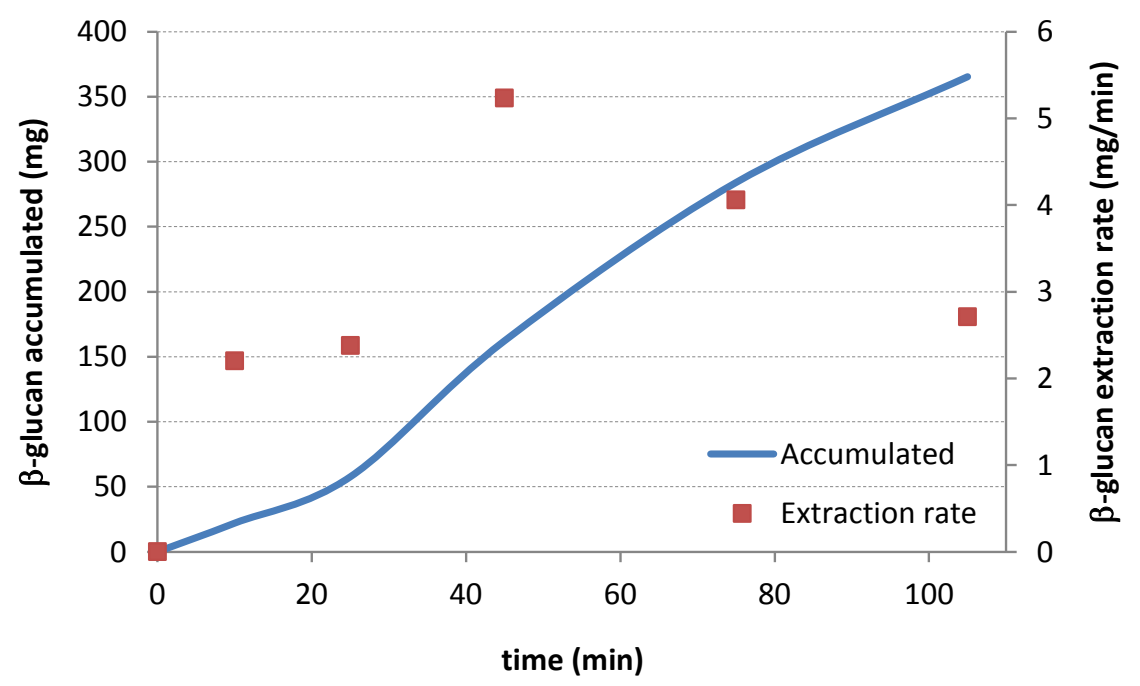

Figure 8. Extraction curve of $\beta$-glucan from barley $\left(155^{\circ} \mathrm{C}, 20 \mathrm{bar}, 4 \mathrm{~g} / \mathrm{min}\right)$

Further experiments, in which pressure was increased up to 50bar, were not useful to increase the extraction yield. In fact, extraction yield was decreased up to $49.4 \pm 0.8 \%$. This result is in the line observed in the batch experiments, in which an increase of the pressure led to the decrease in the extraction yield. The reason must be found in the effect that pressure has on the biomass bed; being more tighten and hindering the flow of the water through it.

The analysis of the hydrolysis products did not show the presence of HMF or other degradation products at $155^{\circ} \mathrm{C}$, the temperature selected for the extraction of $\beta$-glucan. These results were in the line of our previous work, and in the line of the results obtained for wheat bran at the same temperature.

\subsubsection{De-starched barley}

Barley was de-starched by means of a treatment with $\alpha$-amylase. In previous experiments starch was seen as a factor affecting dramatically to the extraction process, so apart from the attempt to decrease its presence by means of the mechanical treatment (coarse milling) an enzymatic treatment was used. Starch was successfully removed (concentration after the treatment was $2.6 \%$ ), but $\beta$-glucan was also affected (mass balances calculations revealed that around $60 \%$ of the initial $\beta$-glucan were lost during the process). Despite of this loss, destarched barley was used in the semi-continuous reactor. Extraction curve for this raw material is shown in figure 9. Extraction yield at $155^{\circ} \mathrm{C}, 20 \mathrm{bar}$ and $4 \mathrm{~g} / \mathrm{min}$ of water was $81.2 \pm 1.2 \%$. Despite of the partial removal of $\beta$-glucans during the enzymatic treatment those that still remain in the raw material are easily extracted as most of the starch has been removed. 


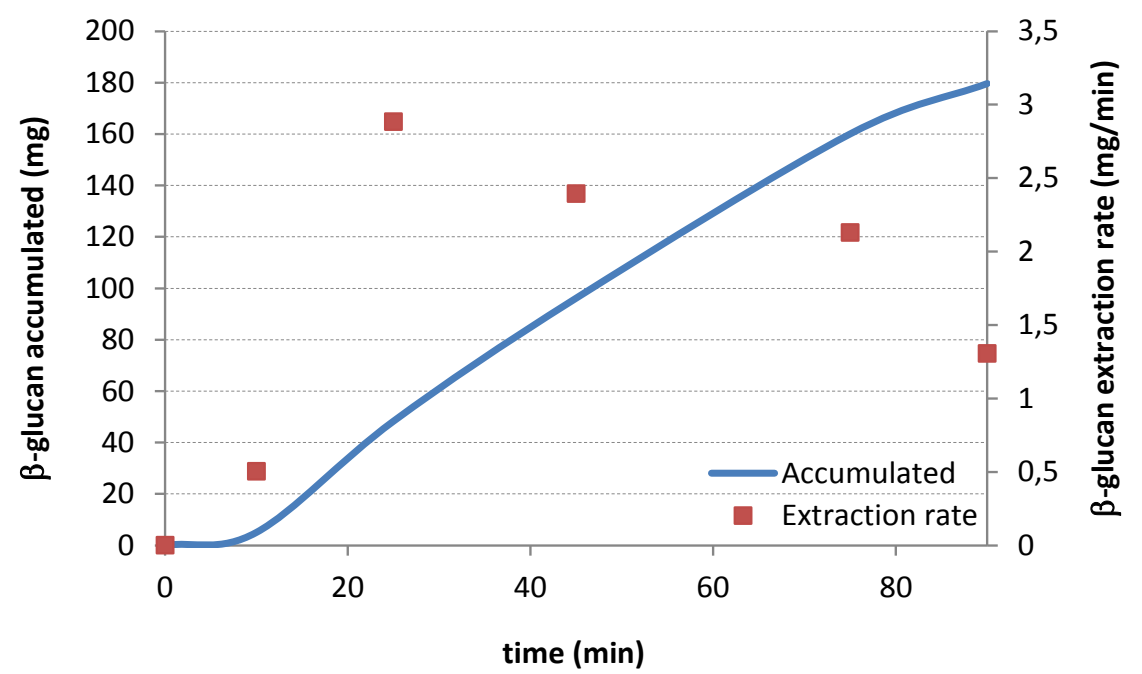

Figure 9. Extraction curve of $\beta$-glucans from de-starched barley $\left(155^{\circ} \mathrm{C}, 20 \mathrm{bar}, 4 \mathrm{~g} / \mathrm{min}\right)$

The extraction curves are very similar for the three tested raw materials: wheat bran, barley and de-starched barley, as it is shown in figure $10.155^{\circ} \mathrm{C}$ and 20 bar are the optimal conditions for the extractions and more than $80 \%$ of the $\beta$-glucans present in the raw material are extracted after 105 min with a flow rate of $4 \mathrm{~g} / \mathrm{min}$ PHW.

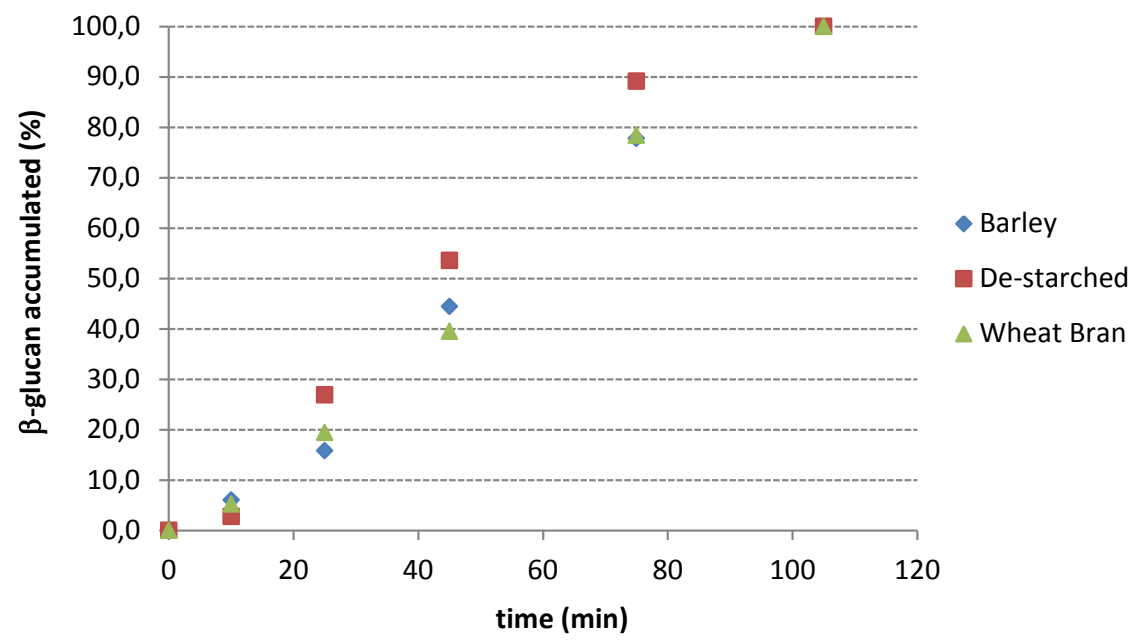

Figure 10. Integral extraction curve for the three different raw materials used in this work. Extraction was done at $155^{\circ} \mathrm{C}, 4 \mathrm{~g} / \mathrm{min}$ and $20 \mathrm{bar}$.

\subsubsection{Molecular weight}

Molecular weight of the liquid extracts obtained at $155^{\circ} \mathrm{C}$ from barley, wheat bran and destarched barley were analyzed. The extraction experiments lasted 105, but samples for the analysis were taken at $10,25,45,75$ and 105 minutes. For the wheat bran, the average molecular weight measured was $373 \mathrm{kDa}$ and for de-starched barley was $247 \mathrm{kDa}$. In the two cases, the molecular weight was much higher than that obtained in the batch extraction. 
Special attention will be paid on the obtained result for the barley. These results are presented in figure 11. It can be seen that the longer the extraction time, the lower the molecular weight. Short extraction times are useful to extract little amounts of high molecular weight $\beta$-glucan. Longer times serve to dissolve $\beta$-glucans, that once dissolved begin to be degraded, and hence lose part of the molecular weight.

It can be concluded that the fixed-bed extraction allows to the fractionation of the $\beta$-glucan extracted in terms of molecular weight, and helps to extract $\beta$-glucan with higher molecular weight than those extracted in the batch process. This is the major advantage of the fixed bed extraction: despite of the lower extraction yield and the higher solvent consumption, the target compounds suffer less degradation and the molecular weight is preserved.

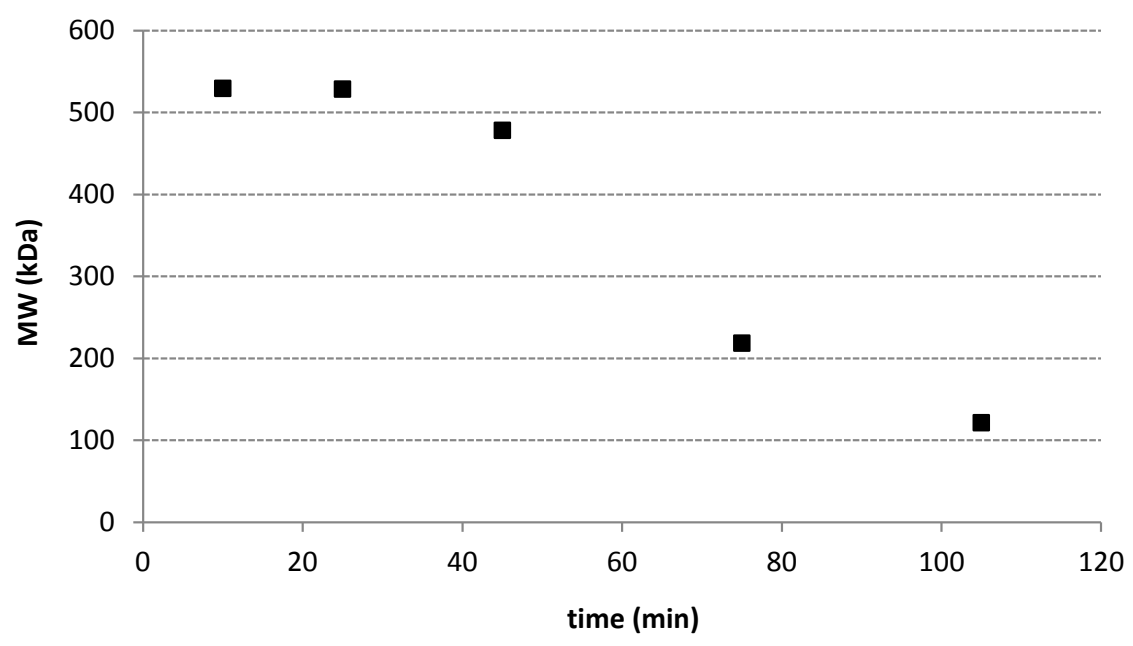

Figure 11. Molecular weight of the extracted $\beta$-glucan from barley $\left(155^{\circ} \mathrm{C}, 20 \mathrm{bar}, 4 \mathrm{~g} / \mathrm{min}\right)$

\section{CONCLUSIONS}

$\beta$-glucans were successfully extracted from three different cereals (barley, wheat bran and destarched barley) in a fixed-bed reactor. In general terms, and compared to the batch extraction, the extraction carried out in the fixed bed reactor led to lower extraction yields but higher molecular weight of the extracted $\beta$-glucan, making possible the achievement of different molecular weight fractions. Fixed bed helps to increase the quality of the extracted $\beta$ glucan, as lower degradation of the target polysaccharide occurs during the extraction, compared to the batch extraction procedures.

Experiments done using wheat bran as source of $\beta$-glucan were useful to establish the suitable experimental conditions for the extraction: $155^{\circ} \mathrm{C}, 20 \mathrm{bar}$ and flow rate $4 \mathrm{~g} / \mathrm{min}$. The study of the hydrolysis products was used to confirm the selected temperature as the optimal, since 
lower degradation of $\beta$-glucan happened. On the other hand it was used to set a correlation between the $\mathrm{pH}$ of the liquid extract and the concentration of acids, formed during the extraction.

Extraction yield achieved when using barley was $52.4 \pm 1.4 \%$, in the conditions described in the previous paragraph. This was slightly lower to that obtained in the batch process; however, molecular weight was significantly increased (up to $500 \mathrm{kDa}$, from $188 \mathrm{kDa}$ ). This result, the increase in the MW justifies the use of the flow process to extract high MW $\beta$-glucan from barley when using PHW as solvent, without needing a pretreatment to de-activate the enzymes responsible for the $\beta$-glucan depolymerization: $\beta$-glucanases.

\section{ACKNOWLEDGEMENTS}

The authors want to thank the University of Valladolid fellowship research program FPI-UVa, for the financial support for the stay at the Technical University of Hamburg-Harburg (TUHH), and to the Institute für Termische Verfahrenstechnik (TUHH) for their technical support. 


\section{REFERENCES}

[1] A. Lazaridou. G.C. Biliaderis. Molecular aspects of cereal $\beta$-glucan functionality: Physical properties, technological applications and physiological effects. Journal of Cereal Science 46(2), (2007) 101-118.

[2] S.W. Cui, Q. Wang, M. Zhang, Chapter 11: $\beta$-glucans. Renewable Resources for Functional Polymers and Biomaterials. The Royal Society of Chemistry, ISBN: 978-1-84973-351-9, 2011 319-345.

[3] M.S. Izydorczyk, J.E. Dexter, J.E. Barley $\beta$-glucans and arabinoxylans: Molecular structure, physicochemical properties, and uses in food products-a Review. Food Research International 41(9), (2008) 850-868

[4] B-K. Baik, S.E. Ullrich, S.E., Barley for food: Characteristics, improvement, and renewed interest. Journal of Cereal Science 48 (2), (2008) 233-242

[5] EFSA Panel on Dietetic Products, Nutrition and Allergies (NDA); Scientific Opinion on the substantiation of health claims related to beta-glucans and maintenance of normal blood cholesterol concentrations (ID 754, 755, 757, 801, 1465, 2934) and maintenance or achievement of a normal body weight (ID 820, 823) pursuant to Article 13(1) of Regulation (EC) No 1924/2006 on request from the European Commission. EFSA Journal 2009; 7(9):1254. [18 pp.]. doi:10.2903/j.efsa.2009.1254

[6] FDA, 21 CFR Part 101: Food labeling, health claims; soluble dietary fiber from certain foods and coronary heart disease. Federal Register 70[246] (2005) 76150-76162.

[7] W. Li, S.W. Cui, Y. Kakuda, Extraction, fractionation, structural and physical characterization of wheat $\beta$-D-glucans. Carbohydrate Polymers 63, (2006) 408-416

[8] B. Palmarola-Andrados, P. Chotěborská, M. Galbe, G. Zacchi, Ethanol production from non-starch carbohydrates of wheat bran. Bioresource Technology 96, (2005) 843-850

[9] Y. Zhang, L. Pitkanen, J. Douglade, M. Tenkanen, C. Remond, C. Joly, Wheat bran arabinoxylans: Chemical structure and film properties of three isolated fractions. Carbohydrate Polymers 86, (2011) 852-859

[10] C. Zetzl, K. Gairola, C. Kirsch, L. Pérez-Cantú, I. Smirnova, High pressure processes in biorefineries. Chemie Ingenieur Technik 83(7), (2011) 1016-1025 
[11] Ó. Benito-Román, E. Alonso, M.J. Cocero, Pressurized hot water extraction of $\beta$-glucans from waxy barley, The Journal of Supercritical Fluids, in press (2012) (DOI: 10.1016/j.supflu.2012.09.014)

[12] J. Kronholm, K. Hartonen, M.L. Riekkola, Analytical extraction with water at elevated temperatures and pressures. Trends in analytical Chemistry 26(5), (2007) 396-411

[13] C.C. Teo, S.N. Tan, J.W. Hong Yong, C.S. Hew, E.S. Ong, Pressurized hot water extraction (PHWE). Review. Journal of Chromatography A 1217, (2010) 2484-2494

[14] C. Pronik, G.Mazza, Design and scale-up of pressurized fluid extractors for food and bioproducts. Journal of Food Engineering 95, (2009) 15-226

[15] C.H.L. Ho, J.E. Cacace, G. Mazza, Extraction of lignans, proteins and carbohydrates from flaxseed meal with pressurized low polarity water. LWT 40, (2007) 1637-1647 



\title{
$\underline{\text { CHAPTER } 6}$
}

\section{Purification and isolation of}

\author{
$\beta$-glucans from barley: downstream
} process intensification 



\title{
Purification and isolation of $\beta$-glucans from barley: downstream process intensification $^{1}$
}

\begin{abstract}
The purpose of this work was to study the purification and isolation (downstream process) of the $\beta$-glucan extracted from waxy barley in an ultrasound assisted extraction process. After the extraction step, $\beta$-glucans are mainly accompanied by starch as the main co-extracted product (average concentration $5.2 \pm 0.1 \mathrm{~g} / \mathrm{L}$ ). Starch is hydrolyzed by means of $\alpha$-amylase; in the present work the hydrolysis length, the temperature and the enzyme dose have been optimized, resulting in removal efficiencies higher than $90 \%$ in very short times (9 minutes) and enzyme doses of $100 \mu \mathrm{L} / \mathrm{g}$ at 55으, compared to the traditional hydrolysis processes that last $1 \mathrm{~h}$ at $95{ }^{\circ} \mathrm{C}$. In a second step, a significant intensification of the process has been achieved by dosing the enzyme during the ultrasound assisted extraction step ( 7 minutes at $55^{\circ} \mathrm{C}$ ), resulting in a starch removal of $90 \%$. An intensification of the extraction and purification processes was successfully accomplished, as they were done simultaneously.

In all the studied conditions, dextrins and other oligosaccharides were formed as a consequence of the enzymatic hydrolysis. In order to separate these low molecular weight molecules, from the $\beta$-glucan $(239 \mathrm{kDa})$, an ultrafiltration process (polysulfone membrane, nominal MWCO $100 \mathrm{kDa}$ ) was tried in a tangential flow cell: diafiltration successfully eliminated more than $45 \%$ of the oligosaccharides present in the liquid, providing a significant increase in the concentration of $\beta$-glucan and with the possibility of improving the percentage of elimination.
\end{abstract}

The combination of these three technologies (ultrasound assisted extraction, enzymatic hydrolysis and diafiltration) allows to get high purity $\beta$-glucan concentrates in a simple and economical way compared to the conventionally used processes.

Keywords: $\beta$-glucan, polysaccharide, purification, intensification, ultrasound, diafiltration, ultrafiltration membranes

\footnotetext{
${ }^{1}$ Separation and Purification Technology (Submitted)
} 


\section{INTRODUCTION}

$(1,3),(1,4)-\beta-D$-glucans, also named mixed linkage $\beta$-glucans or simply $\beta$-glucans, are a sort of non-starchy polysaccharides that can be found in several varieties of cereals, such as barley, oat, rye and wheat, in concentrations from 0.5 to $11 \%$ in dry basis. Although they are considered as dietary fiber, $\beta$-glucans are soluble in water due to the presence of the $(1,3)$-Oglucosidic bonds in the polysaccharide chain.

These biopolymers present good properties for the human health regarding to the control of cholesterol and glucose concentration in blood [1]. Apparently these properties are related to the high viscosity and special behavior of $\beta$-glucans in solution [2], being the viscosity determined by the concentration and molecular weight (MW) of the $\beta$-glucans. $\beta$-glucans have been subjected to health claims by the EFSA (European Food Safety Authority) and FDA (United States Federal Drug Administration) that can be summarized in: "Regular consumption of $\beta$ glucans contributes to maintenance of normal blood cholesterol concentrations when ingesting $3 g$ of $\beta$-glucan per day" $[3,4]$.

The extraction of $\beta$-glucans from cereals is difficult and involves at least three stages [5]: a.) pretreatment of raw cereal (milling and $\beta$-glucanase deactivation in order to preserve the native high $\mathrm{MW}$ of the $\beta$-glucan), b.) extraction of $\beta$-glucans, and finally c.) a purificationisolation step. In previous works the authors have focused on the two front stages, studying the extraction conditions [6] and proposing novel extraction techniques to improve mass transfer and get a real $\beta$-glucan extraction intensification: ultrasound assisted extraction [7] and pressurized hot water [8]. Both the reduction of the extraction times and the increase of the molecular weight compared to the conventional extraction processes (extraction in stirred tank with water at ambient pressure) have been successfully achieved by these authors.

The use of water as solvent and its lack of selectivity cause the co-extraction of other substances such as starch and proteins together with $\beta$-glucans, generating unpurified liquid extracts. This fact makes necessary the development of a procedure to isolate and purify the extracted $\beta$-glucans. Although other authors have used $\alpha$-amylase (EC 3.2.1.1) to hydrolyze the co-extracted starch, in the literature there is not a systematic study of this hydrolysis treatment. The enzymatic removal of starch has been used in numerous works, as it is summarized in table 1, with hydrolysis steps that last from 30 minutes to several hours, to be added to the long extraction steps. These conventional strategies involve that extraction and starch hydrolysis are performed at two different temperatures. Moreover, the starch concentration is not reported in any of these works, neither in the initial extract nor after the 
hydrolysis, and no other parameters affecting the starch hydrolysis have been tested (temperature, dose, hydrolysis length). It is necessary to study the effect that these parameters have on the hydrolysis of the dissolved starch.

Table 1. Enzyme and hydrolysis conditions used by other researchers to remove starch in the $\beta$-glucan purification process

\begin{tabular}{|c|c|c|c|}
\hline Researcher & Enzyme & Dose ( $\mu \mathrm{L} / \mathrm{mL}$ extract) & Hydrolysis conditions \\
\hline Bhatty, [9] & Termamyl & 10 & $96^{\circ} \mathrm{C}, 1 \mathrm{~h}$ \\
\hline Bhatty, [10] & Termamyl 120L & 1 & $96^{\circ} \mathrm{C}, 1 \mathrm{~h}, \mathrm{pH} 6.5,70 \mathrm{ppm} \mathrm{CaCl} 2$ \\
\hline Temelli, [11] & No enzyme was used & - & - \\
\hline Burkus and Temelli, [12] & Termamyl 120LN & NR & NR \\
\hline Izydorczyk et al., [13] & $\begin{array}{c}\alpha \text {-amylase } \\
\text { (porcinepancreas- } \\
\text { SIGMA) }\end{array}$ & NR & $35^{\circ} \mathrm{C}, 24 \mathrm{~h}, \mathrm{pH} 6.5$ \\
\hline Izydorczyk et al.,[14] & $\alpha$-amylase & $40 U / m L$ & NR \\
\hline Lazaridou et al., [15] & Termamyl 120L & 10 & $95^{\circ} \mathrm{C}, 3 \mathrm{~h}, \mathrm{pH} 4.5$ \\
\hline Irakli et al., [2] & Termamyl & 7 & $90^{\circ} \mathrm{C}, 2 \mathrm{~h}, \mathrm{pH} 5.0$ \\
\hline Papageorgiou et al., [16] & Termamyl 120L & NR & $90^{\circ} \mathrm{C}, 3 \mathrm{~h}, \mathrm{pH} 4.5$ \\
\hline Li et al., [17] & $\begin{array}{c}\text { Thermal stable } \\
\text { amylase }\end{array}$ & $12.5 \% \mathrm{w} / \mathrm{w}$ & $90^{\circ} \mathrm{C}, 30 \mathrm{~min}, \mathrm{pH} 6.5-7.0$ \\
\hline Knutsenand Holtekjølen, [18] & Termamyl & 6 & $100^{\circ} \mathrm{C}, 2$ hours \\
\hline Lazaridou et al., [19] & $\begin{array}{l}\alpha \text {-amylse (porcine } \\
\text { pancreas-SIGMA) }\end{array}$ & $100 U$ & $\begin{array}{l}35^{\circ} \mathrm{C} \text {, all night, } \mathrm{pH} 6.5,100 \mathrm{mM} \\
\mathrm{CaCl}_{2}\end{array}$ \\
\hline
\end{tabular}

NOTE. NR = not reported

Dextrins, glucose and other low molecular weight oligosaccharides are the main hydrolysis products from starchy polysaccharides [20]. In order to separate and remove these products from the solution that still contains the high MW $\beta$-glucan, membrane processes are an interesting alternative. Some authors have used dialysis: Lazaridou et al. [15], Irakli et al. [2] dialyzed the liquid extract for 3 days; Knutsen and Holtekjølen [18], dialyzed the sample with $12 \mathrm{kDa}$ cut-off semipermeable membrane; Izydorczyk et al. [14] performed an extensive dialysis on the extract to perform this separation. Dialysis is a traditional method for removing microsolutes from solutions; however it is a transport diffusion-controlled process (based on differences in concentrations between two solutions) and intensive in time and economical resources consumption. Ultrafiltration, a membrane process in which the driving force is pressure, has been traditionally used in food industry to separate macromolecules from small molecules such as sugars, salts, ions, etc. [21]. The solution is forced to pass through the semipermeable membrane; big molecules are retained while small molecules pass through. Despite of being a widely spread process in the industry, as far as the authors' knowledge, there is only one published paper where UF is used to recover $\beta$-glucans from a solution [22]. In this work the operation mode was studied, the effect of the membrane material and the 
concentration of the feeding solution. According to those authors, polysulfone membrane, transmembrane pressure $\leq 2 \mathrm{bar}$ and $\beta$-glucan concentrations below $0.6 \mathrm{~g} / \mathrm{L}$ were the optimal conditions to apply the UF to recover $\beta$-glucans.

To improve the removal of the low MW species present in the solution, diafiltration can be used. Diafiltration is a membrane-based method wherein pore size dictates the retention and elution of material from a sample. In this work, UF membranes were used in a continuous diafiltration process, and fresh water has being added to the ultrafiltered solution to keep its volume and the initial concentration of $\beta$-glucans in the feed stream. Diafiltration presents several advantages over dialysis, such as time reduction (as it is a transport convective with solvent, the dependence with microsolute concentration is lower than in a dialysis process), lower temperature dependence, and no exchange of solvent required [23]. These properties make attractive diafiltration over dialysis when the removal of the low MW hydrolysis products is required, since it saves processing time, water volume and loss of product. However, in membrane separation processes it must be taken into account the membrane fouling which reduces the effectiveness of the process. In this case, the membrane processes with convective transport (ultrafiltration case) favor the fouling due to the possibility of the cake formation on the membrane surface which can be further compressed by the effect of pressure. Although this effect is usually somewhat lower in the case of dialysis, the reduction in mass transfer because of the fouling is mainly conditioned by membrane material and its interaction with solutes in the system [24].

The purpose of this work is to study the $\beta$-glucan downstream process, including the hydrolysis of starch and the removal of the starch hydrolysis compounds by means of the membrane technology. 


\section{MATERIALS AND METHODS}

\subsection{Raw Material and extraction}

$\beta$-glucans were extracted from the coarse bran obtained from milling waxy barley in a Chopin CD1 (Chopin, France) mill. Barley was supplied by ITACyL (Instituto Tecnológico Agrario de Castilla y León, Valladolid, Spain) and boiled with ethanol (80\%, v/v for two hours) in order to deactivate endogenous $\beta$-glucanases. Composition of the barley in dry matter basis is summarized in table 2 :

Table 2. Barley composition (dry basis)

\begin{tabular}{|c|c|c|c|c|}
\hline $\begin{array}{c}\beta \text {-glucan } \\
(\%)\end{array}$ & $\begin{array}{c}\text { Starch } \\
(\%)\end{array}$ & $\begin{array}{c}\text { Proteins } \\
(\%)\end{array}$ & $\begin{array}{c}\text { Fats } \\
(\%)\end{array}$ & $\begin{array}{c}\text { Dietary Fiber } \\
(\mathbf{g} / \mathbf{1 0 0})\end{array}$ \\
\hline $5.5 \pm 0.3$ & $54.1 \pm 1.8$ & $15.1 \pm 0.9$ & $1.2 \pm 0.1$ & $21.0 \pm 1.9$ \\
\hline
\end{tabular}

The so pretreated barley bran has been subjected to an ultrasound assisted extraction with water at 55ㅇ by means of the ultrasound processor UP400S (Hielscher, Germany) and according the procedure described by Benito-Román et al [7]. Operational conditions were set to provide an specific power output of $550 \mathrm{~kJ} / \mathrm{L}$ (amplitude 100\%, 7 minutes, continuous sonication), since this value represents the edge between maximization of the extraction yield and depolymerization of the extracted $\beta$-glucans, as exposed in the aforementioned paper. The liquid extract was then analyzed in order to quantify the $\beta$-glucan and starch content, as well as the molecular weight of the extracted $\beta$-glucans. The average composition of this extracts is summarized in table 3 . Subsequently, this extract was treated with the $\alpha$-amylase, and the concentration of dissolved starch and the MW of $\beta$-glucans were again analyzed, in order to evaluate the effect of the enzymatic treatment.

Table 3. Liquid extract characterization after the US extraction step. Barley to solvent ratio used in the extraction 1:20

\begin{tabular}{|c|c|c|c|}
\hline $\begin{array}{c}\beta \text {-glucan } \\
(\mathbf{g} / \mathbf{L})\end{array}$ & $\begin{array}{c}\text { Starch } \\
(\mathbf{g} / \mathbf{L})\end{array}$ & $\begin{array}{c}\boldsymbol{\beta} \text {-glucan MW } \\
(\mathbf{k D a})\end{array}$ & $\begin{array}{c}\text { Solids content } \\
(\%)\end{array}$ \\
\hline $2.1 \pm 0.2$ & $5.2 \pm 0.1$ & $239 \pm 4$ & $2.1 \pm 0.1$ \\
\hline
\end{tabular}

\subsection{Enzymes and starch hydrolysis}

Different types of $\alpha$-amylase (EC 3.2.1.1) enzymes were tested in these experiments: Bialfa T (120000U/g), Bialfa (300000U/g) and Glucozyme from Biocon Española, S.A. and Termamyl $120 \mathrm{~L}(120 \mathrm{KNU} / \mathrm{g}$, Novozymes, Denmark). These enzymes were tested under the optimal conditions suggested by the supplier (temperature, $\mathrm{pH}$, hardness of the water), in order to select one of them and to perform the whole parameter study. A solution of $\mathrm{CaCl}_{2} \cdot 2 \mathrm{H}_{2} \mathrm{O}(1 \mathrm{M})$ 
was used to change the hardness of the water, as the presence of the ions $\mathrm{Ca}^{2+}$ increases the stability of the enzyme. After this trial experiments, one enzyme was selected analyzing the results in terms of starch removal efficiency (according to equation (1)) and molecular weight of the extracted $\beta$-glucans.

$$
\text { Removal Efficiency }(\%)=\frac{\text { Initial Concentration-Final Concentration }}{\text { Initial Concentration }} \times 100
$$

After the hydrolysis, liquid extract was centrifuged and the supernatant was analyzed (starch and $\mathrm{MW}$ of the dissolved $\beta$-glucan).

\subsection{Chemical Analysis}

$\beta$-glucan content in the liquid extract was determined by means of the assay kit "Mixed linkage $\beta$-glucan", from Megazyme International, Ltd. The starch dissolved was analyzed using the assay kit "Total starch" from Megazyme International, Ltd., following the modification of the general procedure corresponding to the samples in which starch is present in a soluble form and D-glucose and maltodextrines are present.

Molecular weight of the $\beta$-glucan was determined by Size Exclusion Chromatography (HPLCSEC) using a chromatography system that consists of an isocratic pump (1515;Waters Corporation), an automatic injector (717; Waters Corporation), a guard column (Waters Ultrahydrogel Guard Colum), a GPC column (Ultrahydrogel 500, Waters Corporation) and a differential refractive index detector (410; Waters Corporation). The column was kept at $35^{\circ} \mathrm{C}$, and flow rate of the mobile phase $\left(0.1 \mathrm{M} \mathrm{NaNO}_{3}+0.02 \% \mathrm{NaN}_{3}\right)$ was set at $0.4 \mathrm{~mL} \cdot \mathrm{min}^{-1}$. Five different MW $\beta$-glucan standards from Megazyme International Ltd. in the range 40-359 kDa were dissolved in ultrapure water and used to obtain the calibration curve.

\subsection{Downstream process intensification}

One consequence of the hydrolysis optimization performed in this work is the important reduction in the enzymatic treatment time (as it is exposed in section 3.2). As a consequence the authors decided to add the enzyme to the ultrasound assisted extraction vessel during the extraction process, in order to integrate the extraction and the starch hydrolysis in the same step. The enzyme dose (varied in the range $5-30 \mu \mathrm{L} / \mathrm{g}$ of barley bran) and the incubation time (from 1 to 7 minutes that is the maximum sonication time) were studied. Two enzymes were tested: Bialfa T and Termamyl 120L.The solid-liquid mixture after the extraction/hydrolysis was separated by centrifugation: solid was discarded and liquid supernatant was subject of a 
further purification step by means of membranes, in order to separate the $\beta$-glucans from the starch hydrolysis products. A schema of the overall process is shown in figure 1.The starch concentration and the MW of the extracted $\beta$-glucans were evaluated in the liquid after the combined step (extraction + starch hydrolysis) and before the membrane stage.

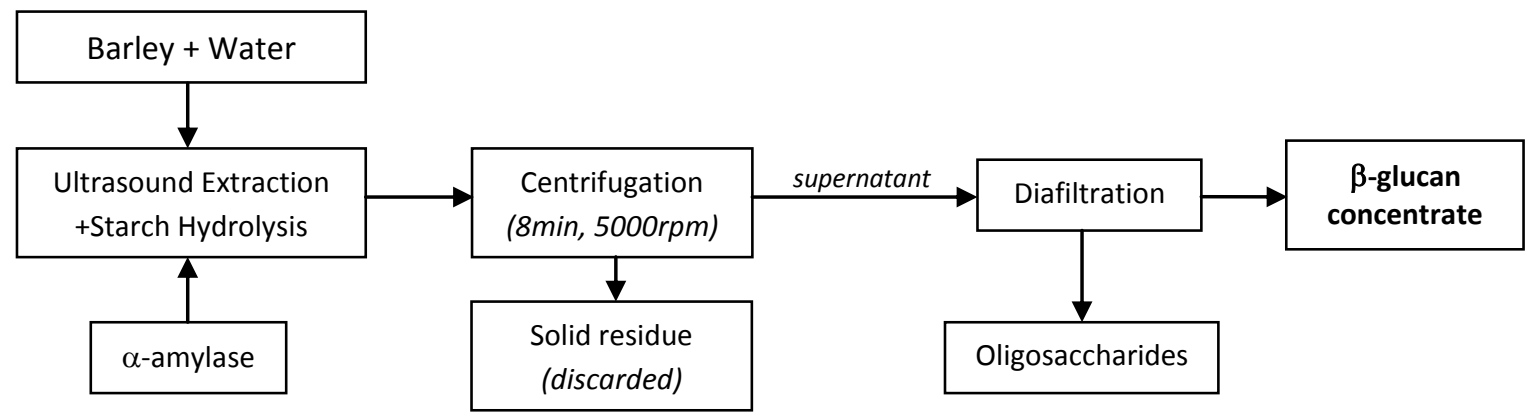

Figure 1. Diagram of the $\beta$-glucan recovery process, after the integration of the extraction and the starch hydrolysis

\subsection{Membrane separation}

The starch and oligosaccharides formed after the enzymatic hydrolysis (figure 1 ) were separated from the $\beta$-glucan solution by means of a membrane process: ultrafiltration (UF). Two commercial UF membranes (Millipore) were initially tested: both of them were made of the same material polysulfone (PS) and differed in the MCWO (Molecular Weight Cut Off): 10 and 100kDa.

Initial experiments were done in a dead-end stirred cell in order to select the suitable membrane. The dead end stirred cell, STERLITECH ${ }^{\text {TM }}$ HP4750, had a volume of $200 \mathrm{~mL}$ and an effective membrane surface area of $14.6 \mathrm{~cm}^{2}$. Inside it was placed a magnetic stirrer to reduce the concentration polarization. The operation conditions were 1 bar of pressure, supplied by $\mathrm{N}_{2}$ and a stirring velocity of $1000 \mathrm{rpm}$. The specific permeability of the membranes $\left(L_{p}\right)$ was calculated according to equation (2):

$$
L_{p}=\frac{J_{w}}{\Delta P}
$$

were $J_{w}$ is the water flux and $\Delta P$ the transmembrane pressure. The observed retention, $R_{\text {obs }}$

$$
R_{o b s}=1-\frac{c_{o}}{c_{p}}
$$


( $c_{0}$ and $c_{p}$ are the feed and permeate concentration respectively) was determined for each of the major solutes at different filtration times to determine the viability of the membrane in the process.

In order to provide an effective separation of $\beta$-glucan (high MW) and starch hydrolysis byproducts, diafiltration was performed in the tangential membrane cell; in this way of operation feed solution is pumped tangentially along the surface of the membrane, to decrease the fouling by surface deposition. The experimental set up consisted of a feeding tank containing the solution, a pump (Tuthill, TXS2), two manometers at the membrane inlet and outlet in order to measure the transmembrane pressure, a valve placed after the membrane cell (Millipore, XX42MT077; specific area $30 \mathrm{~cm}^{2}$ ) and a flow meter to determine the retentate flow rate. The resulting channel has a hydraulic diameter of $0.76 \cdot 10^{-3} \mathrm{~m}$ and a cross section of $2.8 \cdot 10^{-3} \mathrm{~m}^{2}$. Figure 2 shows the experimental set-up. Flow rate was kept at $2 \mathrm{~L} / \mathrm{min}$ and pressure at 2 bar. Diafiltration experiments were done in continuous: fresh water was added to the feeding tank to keep constant the volume of the solution. The diafiltration experiments lasted 4 hours; after that period diafiltration was done and no more fresh water was added to the tank in order to increase the concentration of the solution.

Two different solutions were used in the filtration experiments. Samples $(5 \mathrm{~mL})$ of the retentate and the permeate were taken periodically in order to analyze the sugar, starch and $\beta$-glucan content.

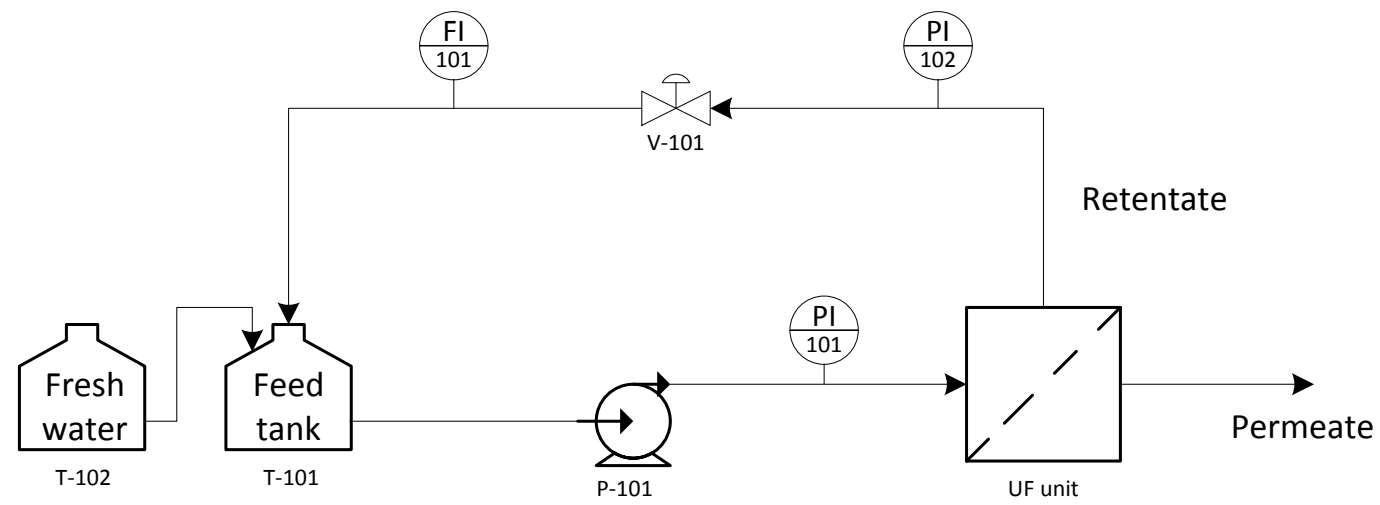

Figure 2. Cross flow UF device for diafiltration process. 


\section{RESULTS AND DISCUSSION}

The aqueous extract from the ultrasound step (see table 3 for characterization) has been treated with commercial enzymes under the conditions suggested by the suppliers. Hydrolysis conditions together with starch removal and $\beta$-glucan $\mathrm{MW}$ after the hydrolysis are presented in table 4.

Table 4. Starch hydrolysis using the operation conditions suggested by the manufacturers.

\begin{tabular}{|l|ccccc|c|c|}
\hline \multicolumn{1}{|c|}{ Enzyme } & $\begin{array}{c}\text { Dose } \\
(\boldsymbol{\mu L} / \mathbf{g} \text { starch) }\end{array}$ & $\begin{array}{c}\mathbf{C a C l}_{\mathbf{2}} \cdot \mathbf{2} \mathbf{H}_{\mathbf{2}} \mathbf{O} \\
(\mathbf{p p m})\end{array}$ & $\begin{array}{c}\text { Incubation } \\
\mathbf{( h )}\end{array}$ & $\begin{array}{c}\mathbf{T} \\
\left({ }^{\circ} \mathbf{C}\right)\end{array}$ & $\begin{array}{c}\mathbf{p H} \\
(-)\end{array}$ & $\begin{array}{c}\text { StarchRemoval } \\
(\%)\end{array}$ & $\begin{array}{c}\boldsymbol{\beta} \text {-glucan } \mathbf{M W} \\
(\mathbf{k D a})\end{array}$ \\
\hline Bialfa T & 1000 & 70 & 1 & 95 & 6.0 & 90.8 & 130 \\
Termamyl 120L & 1000 & 70 & 1 & 95 & 6.3 & 91.2 & 8 \\
Bialfa & 1000 & 250 & 1 & 70 & 6.0 & 90.8 & 7 \\
Glucozyme & 1000 & - & 1 & 55 & 4.3 & 92.7 & 7 \\
\hline
\end{tabular}

These results revealed that all the enzymes possessed a remarkable ability to remove the dissolved starch (efficiencies higher than $90 \%$ in all the cases), but some of them also produced a dramatic reduction on the MW of the extracted $\beta$-glucan. Due to this later aspect, Bialfa T was selected as the most suitable for the purification of the liquid extracts. For Bialfa T, pH was kept at 6.0 by the addition of phosphate buffer ( $50 \mathrm{mM})$.

\subsection{Study of the incubation conditions on the starch efficiency removal using BialfaT}

In a second stage Bialfa $\mathrm{T}$ was tested, keeping the dose (1000 $\mu \mathrm{L}$ enzyme/g starch), temperature and $\mathrm{pH}$ but reducing the incubation times (from 10 to 50 minutes). Results have shown that times as short as 10 minutes are enough for starch removal, since removal efficiency is higher than $90 \%$ for all the studied incubation times. However, a decrease in $\beta$ glucan MW from $229 \mathrm{kDa}$ to $139 \mathrm{kDa}$ is observed when enzymatic treatment time is increased from 10 to 50 minutes, showing that shorter times benefit the purification step in terms of $\beta$-glucan MW. The dose of enzyme has been changed, in the range $75-400 \mu \mathrm{L}$ enzyme/g starch, at a constant incubation time of $10 \mathrm{~min}$. In this case, significant differences in the starch removal efficiencies were observed. A full factorial experimental design was used to determine the combined effect of enzyme dose and incubation times below 10 minutes. These experiments have been performed at a constant temperature of $95^{\circ} \mathrm{C}$, time has been varied in the range 3 to 9 minutes and enzyme dose in the range 10-100 $\mu \mathrm{L}$ enzyme/g starch. After every experiment starch concentration and $\beta$-glucan $\mathrm{MW}$ were determined. Results of starch removal efficiency are presented in figure 3. 


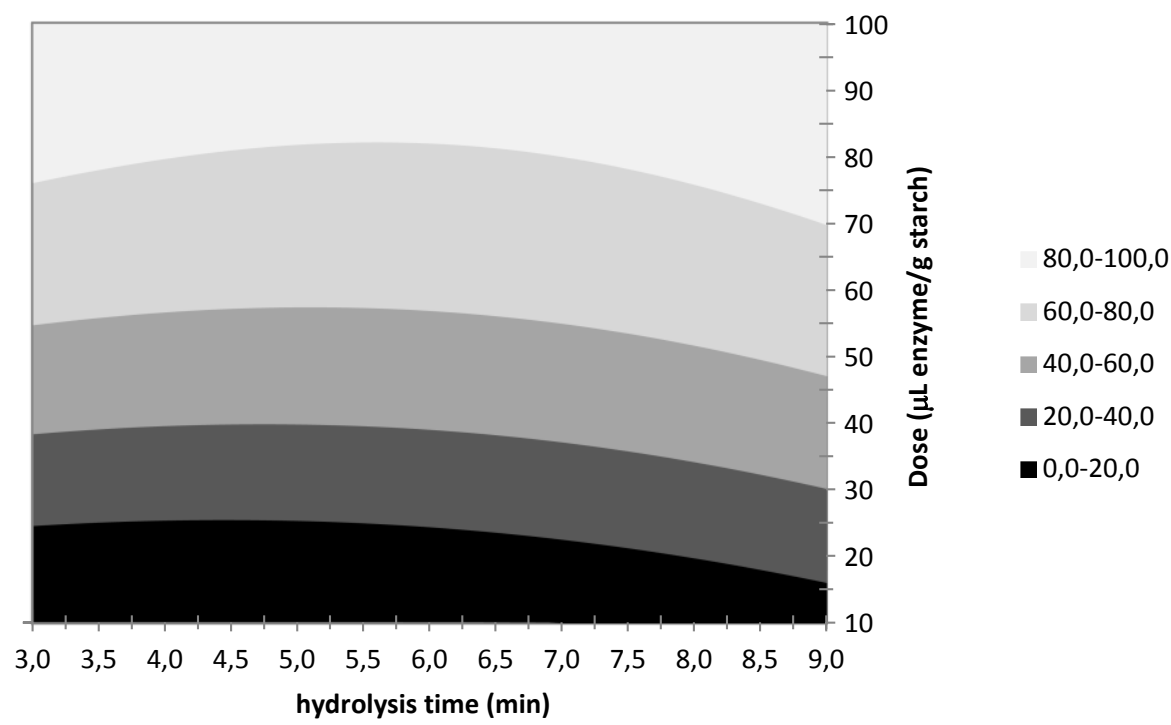

Figure 3. Contour plot for the starch removal efficiency using the enzyme Bialfa $T$ in terms of hydrolysis time and enzyme dose $\left(T=95^{\circ} \mathrm{C}\right)$. The key expresses the \% of starch removal efficiency.

Experimental results have shown that at $95^{\circ} \mathrm{C}$, where the activity of the enzyme is maximum, the hydrolysis time does not affect the removal efficiency being the enzyme dose the critical parameter. Maximum removal was $94 \%$, in a 9 minutes process with a dose of $100 \mu \mathrm{L} / \mathrm{g}$ of dissolved starch. In all cases $\beta$-glucan MW was not affected; only a slight decrease of $5 \%$ was measured (around $232 \pm 3 \mathrm{kDa}$ was the final MW after the hydrolysis). At relatively low doses (100 $\mu \mathrm{L} / \mathrm{g}$ starch) great removal efficiencies were achieved, doses that are significant lower than those recommended by the enzyme supplier. It must be noticed that in the present work, starch is already dissolved in water, and starch and enzyme are in the same phase, and hence mass transfer limitations derived from the presence of two different phases are avoided. The enzyme is free to act on the starch, providing a fast hydrolysis.

A similar experimental plan has been performed at $55^{\circ} \mathrm{C}$, where the activity of the enzyme is $50 \%$ of that at $95^{\circ} \mathrm{C}$. Incubation times have been varied in the range 3 to 9 minutes, and doses have been slightly increased to balance the loss of activity (60 - $125 \mu \mathrm{L}$ enzyme/g starch). Results of the starch removal are shown in figure 4. 


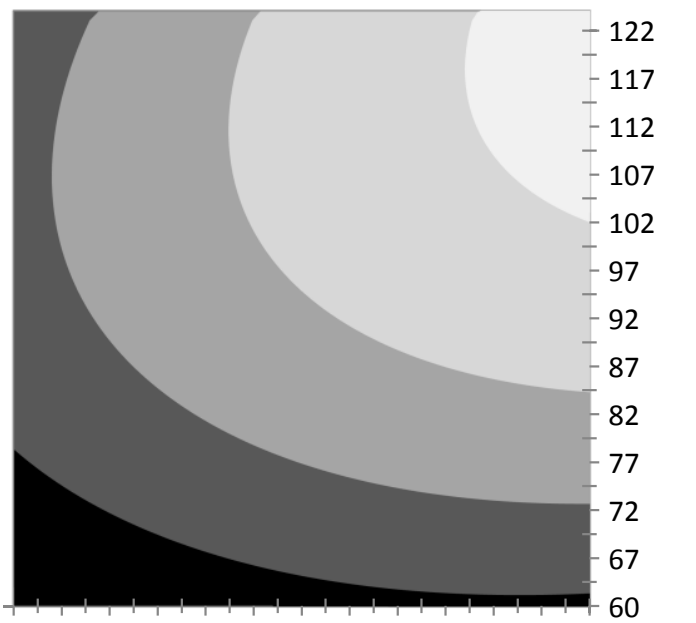

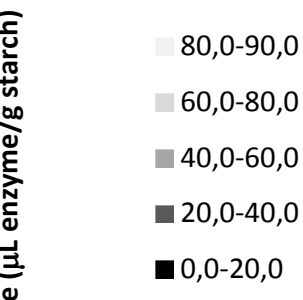

$3,03,54,04,5$ 5,0 5,5 6,0 6,5 7,0 7,5 8,0 8,5 9,0 hydrolysis time $(\mathrm{min})$

Figure 4. Contour plot for the starch removal efficiency using the enzyme Bialfa T in terms of hydrolysis time and enzyme dose $\left(T=55^{\circ} \mathrm{C}\right)$. The key expresses the \% of starch removal efficiency.

At $55^{\circ} \mathrm{C}$, the loss of enzyme activity associated to the temperature was significant, and both parameters (hydrolysis time and enzyme dose) affected starch removal efficiency. The shorter the incubation time the higher the required enzyme dose to get the same removal efficiency. Despite the higher amount of enzyme used, the MW of the $\beta$-glucans slightly decreased, being $229 \pm 3 \mathrm{kDa}$ the lowest determined MW in this set of experiments. These results show that $\beta$ glucan depolymerization is time dependent and below 9 minutes this phenomenon is slow enough to maintain MW of $\beta$-glucans, as it is desirable in this process.

From these results, it can be concluded that, starch can be removed effectively by means of $\alpha$ amylase Bialfa $\mathrm{T}$ at low temperatures $\left(55^{\circ} \mathrm{C}\right)$, short incubation times (below 9 minutes) and relative low enzyme doses, with a very limited effect on the molecular weight of the dissolved $\beta$-glucan.

3.2. Downstream process intensification: integration of the extraction + enzymatic hydrolysis of starch

In order to evaluate the feasibility of the enzyme addition to the extraction vessel simultaneously to the $\beta$-glucan extraction, several experiments were done, changing the enzyme dose and the moment of enzyme dosage. Extraction was done according to the procedure described in section 2.1. (ultrasonic processor, $55^{\circ} \mathrm{C}, 7$ minutes, 10 grams of barley, barley to water ratio 1:20). The amount of enzyme dosed was expressed as $\mu L$ of enzyme per gram of barley and the enzyme was added in minute 0 (starch hydrolysis can start from the beginning of the extraction), 3 and 6 (only one minute of enzymatic hydrolysis). The enzymatic 
activity was stopped by a sudden decrease of $\mathrm{pH}$ down to 2 , by addition of several drops of $\mathrm{HCl}$ 2M. Two different enzymes were tested, Bialfa T and Termamyl 120L. Results are shown below.

Results corresponding to enzyme Bialfa $T$ are shown in figure 5 , where the concentration of starch after the combined extraction + hydrolysis step is plotted as a function of the incubation time and enzyme dose:

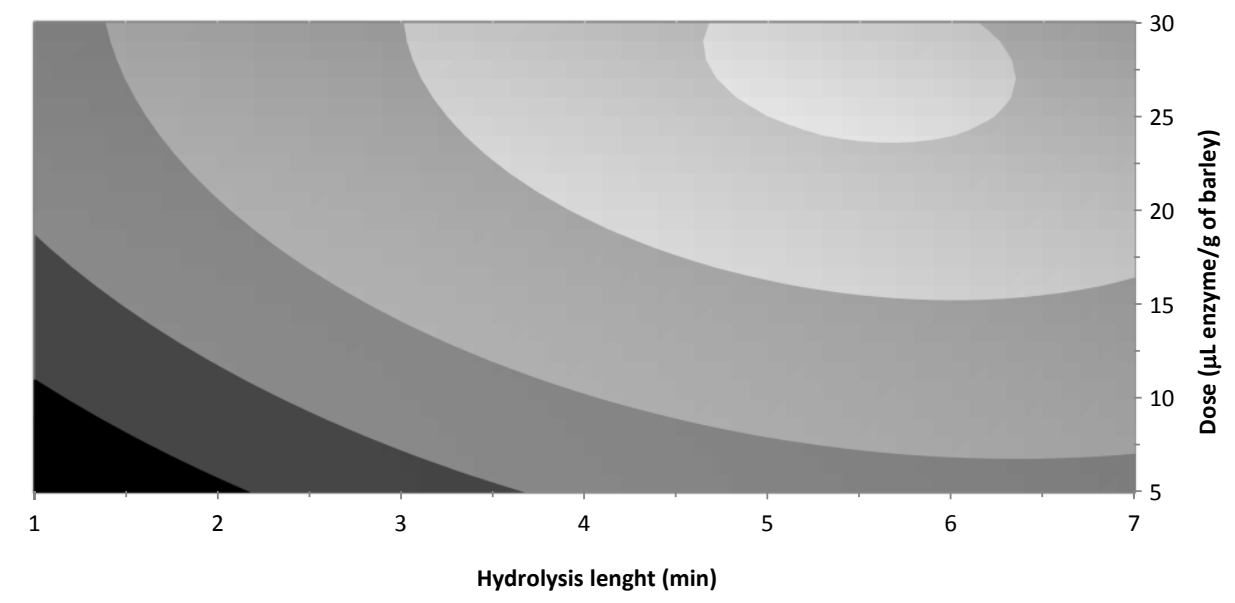

Figure 5. Starch concentration after the extraction + enzymatic hydrolysis performed with Bialfa T. KEY: $\square<0.6 \mathrm{~g} / \mathrm{L} ; \quad 0.6-1.2 \mathrm{~g} / \mathrm{L} ; \square 1.2-2.4 \mathrm{~g} / \mathrm{L} ; \square 2.4-3.6 \mathrm{~g} / \mathrm{L} ; \square 3.6-4.8 \mathrm{~g} / \mathrm{L} ; \square$ 4.8-5.2g/L

The best results, representing the lowest concentration of starch dissolved, were $0.6 \mathrm{~g} / \mathrm{L}$ obtained after 6 minutes of incubation time and a dose of enzyme of $30 \mu \mathrm{L} / \mathrm{g}$ barley. Under these conditions the MW of the extracted $\beta$-glucan was $230 \mathrm{kDa}$.

Results obtained for enzyme Termamyl $120 \mathrm{~L}$ are shown in figure 6, and were slightly better than those obtained for Bialfa T; nevertheless the trend exhibited by the two enzymes in the removal of starch was similar. The lowest concentration of starch was $0.48 \mathrm{~g} / \mathrm{L}$, obtained using a dose of enzyme $25 \mu \mathrm{L} / \mathrm{g}$ of barley and incubation time of 5.5 minutes. Despite the fact that the two enzymes are thermostable they can be used at lower temperatures; Termamyl presents a softer loss of activity due to the temperature decrease. 


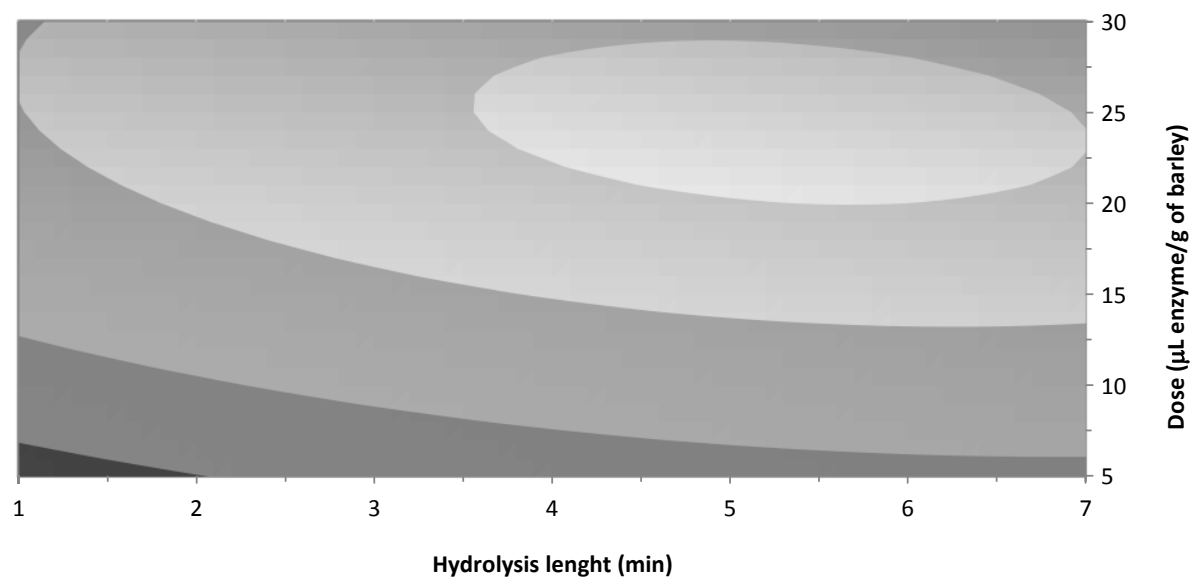

Figure 6. Starch concentration after the extraction+enzymatic hydrolysis done with Termamyl 120L. KEY:

$\square<0.6 \mathrm{~g} / \mathrm{L} ; \quad 0.6-1.2 \mathrm{~g} / \mathrm{L} ; \square 1.2-2.4 \mathrm{~g} / \mathrm{L} ; \quad 2.4-3.6 \mathrm{~g} / \mathrm{L} ; \quad 3.6-4.8 \mathrm{~g} / \mathrm{L}$

These results derived from the combination of extraction + enzymatic hydrolysis process probe that it is possible to integrate the two stages (extraction and starch enzymatic hydrolysis) in one single step. If the enzyme is added during the extraction, starch concentration after this combined step is $0.5 \mathrm{~g} / \mathrm{L}$, with no decrease in the $\beta$-glucan molecular weight. This process is really effective in the removal of starch, as starch is hydrolyzed as soon as it is dissolved. The combination of the extraction + hydrolysis of starch in one single step lasting 7 minutes represents a clear intensification of the $\beta$-glucan extraction process: two process that last 4 hours separately $\left(3\right.$ hours of extraction at $55^{\circ} \mathrm{C}$ in a stirred tank and 1 hour for the starch removal at 95ㅇ) , is performed in one single vessel at $55^{\circ} \mathrm{C}$ for 7 minutes by means of the ultrasound technology, keeping the $\beta$-glucan extraction yield and MW $(53.3 \pm 1.2 \%$ and $224 \pm 7 \mathrm{kDa}$ respectively).

The ratio barley:solvent used in the above described experiments was 1:20. Other different barley:solvent ratios were used (1:13 and 1:10), in order to validate the combined extraction+enzymatic hydrolysis step. Total extraction volume was kept in all the experiments, changing the amount of barley bran to reach the desired barley:solvent ratio. The extraction was carried out using the same ultrasonic processor and the same conditions $\left(55^{\circ} \mathrm{C}, 7\right.$ minutes, $100 \%$ amplitude and continuous sonication). Different doses of the enzyme Termamyl $120 \mathrm{~L}$ (expressed in $\mu \mathrm{L}$ enzyme/g barley) were tested. Results are presented in figure 7: 


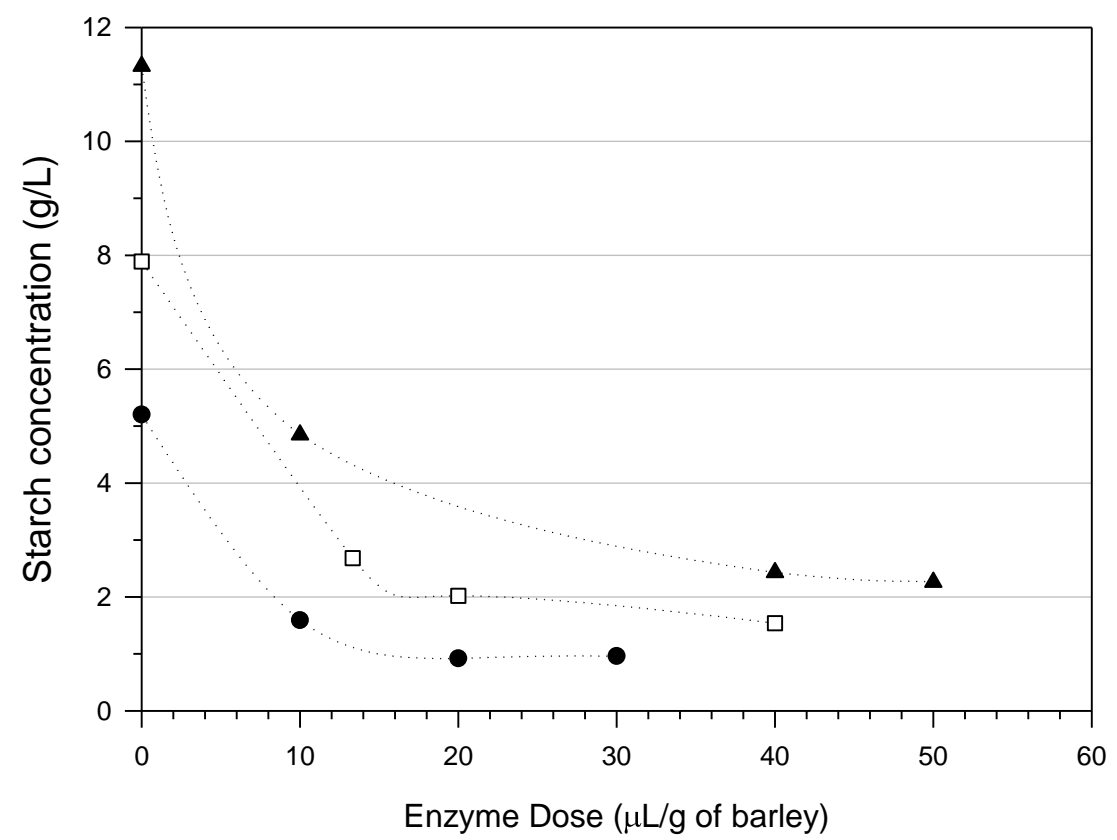

Figure7. Starch concentration after the extraction+enzymatic hydrolysis when changing the dose of enzyme and the barley to solvent ratio during the extraction. KEY: $\bullet$ barley:solvent ratio of 1:20;

$\square$ barley:solvent ratio of 1:13; $\Delta$ barley:solvent ratio of 1:10

When no enzyme is added, $5.2 \mathrm{~g}$ starch/L are dissolved after the 7 minutes sonication time for a barley:solvent ratio of $1: 20,7.9 \mathrm{~g} / \mathrm{L}$ at a ratio $1: 13$ and $11.3 \mathrm{~g} / \mathrm{L}$ when the ratio is $1: 10$. From figure 7 it can be seen that when the barley:solvent ratio is increased the amount of enzyme dose must be increased, in order to remove more starch. In all the studied ratios, the same trend was observed: initially small amounts of enzyme reduced dramatically the concentration of dissolved starch (by $50 \%$ reduction adding $10 \mu \mathrm{L}$ of enzyme per gram of barley); then further increases of enzyme dosage decreased very slowly the concentration of starch, and finally, the addition of enzyme did not improve the starch removal: it was found a limit of degradation that it is around the $85-90 \%$ of the dissolved when no enzyme is added. All in all, the integration of the extraction and enzymatic hydrolysis in one single step was successfully achieved when two different enzymes were tried and when different extraction conditions (barley to solvent ratio changes) were introduced. These results involve a significant improvement of the process developed to extract and isolate $\beta$-glucans from barley.

After the integrated extraction and hydrolysis step, the solid-liquid suspension was centrifuged in order to separate the exhausted barley from the liquid containing the $\beta$-glucan, starch and starch hydrolysis products (among other species). The purification of the supernatant was carried out by membrane technology, as described in the section 3.4 (figure 1). Two different supernatants were used in that section, obtained from extractions performed under the same conditions (temperature $55^{\circ} \mathrm{C}$, length 7 minutes) but with different barley to solvent ratios 
(1:20 and 1:10), that led to supernatants that differed in the solid content and the composition, S1 and S2, whose composition is described in table 5.

Table 5. Composition of the streams used in the membrane separation step:

\begin{tabular}{|c|c|c|c|c|c|}
\hline $\begin{array}{c}\text { Supernatant } \\
\text { ID }\end{array}$ & $\begin{array}{c}\text { Solid Content } \\
(\%)\end{array}$ & $\begin{array}{c}\beta \text {-glucan } \\
(\mathrm{g} / \mathrm{L})\end{array}$ & $\begin{array}{l}\text { Starch } \\
(\mathrm{g} / \mathrm{L})\end{array}$ & $\begin{array}{c}\text { Glucose } \\
\text { (g/L) }\end{array}$ & $\begin{array}{c}\text { Cellobiose } \\
(\mathrm{g} / \mathrm{L})\end{array}$ \\
\hline S1 & 1.2 & 1.95 & 1.95 & 1.31 & 2.86 \\
\hline S2 & 4.5 & 3.05 & 3.08 & 1.83 & 4.52 \\
\hline
\end{tabular}

\subsection{Diafiltration results}

\subsubsection{Membrane selection}

In the dead-end cell, the hydraulic permeability has been measured for the two polysulphone membranes (10 and $100 \mathrm{kDa}$ ), with results of $1.13 \cdot 10^{-5} \mathrm{~m} /$ (bar $\cdot \mathrm{s}$ ) and $2.14 \cdot 10^{-4} \mathrm{~m} /($ bar $\cdot \mathrm{s})$. In principle, a higher permeability makes the membrane more suitable for the process. Also, for the two membranes the extract S1 was used. Three samples of permeate along the time were taken and also for the final retentate. Table 6 shows the observed retention of the three main components ( $\beta$-glucan, cellobiose and glucose) for three filtration times obtained with the two different nominal MWCO membranes. The retention results show that both membranes are suitable since both present total retention of $\beta$-glucans and low retention on glucose and cellobiose. Comparing both membranes it can be seen that the $100 \mathrm{kDa}$ presents a lower retention at all times that the $10 \mathrm{kDa}$ membrane for cellobiose and very similar for the glucose.

Table 6. Observed retention for cellobiose, glucose and $\beta$-glucans at three different times

\begin{tabular}{|c|c|c|c|c|}
\hline MWCO & Component & $\boldsymbol{R}_{\text {obs }}$ (t1) (\%) & $\boldsymbol{R}_{\text {obs }}(\mathbf{t} \mathbf{2})$ (\%) & $\boldsymbol{R}_{\text {obs }}(\mathbf{t 3 )}$ (\%) \\
\hline \multirow{3}{*}{ 10kDa } & Cellobiose & 23.7 & 6.5 & 5.7 \\
& Glucose & 17.5 & 0 & 0 \\
& $\boldsymbol{\beta}$-glucans & 100 & 100 & 100 \\
\hline \multirow{3}{*}{ 100kDa } & Cellobiose & 11.4 & 4.1 & 4.9 \\
& Glucose & 17.5 & 2.3 & 3.0 \\
& $\boldsymbol{\beta}$-glucans & 100 & 100 & 100 \\
\hline
\end{tabular}

According to these results (permeability and retention) the membrane with weight cut-off 100 $\mathrm{kDa}$, was selected for the diafiltration in the cross flow cell.

\subsubsection{Dialfiltration and $\beta$-glucan concentration}

To analyze the feasibility of the process, two $\beta$-glucan extracts with different solid concentration (composition shown in table 5) were filtered for 4 hours. The removal percentages, calculated according to equation (4), of glucose and cellobiose and the final concentration of $\beta$-glucan and starch are shown in table 7. 


$$
\% \text { removal }=\frac{\text { initial concent-final concent-retentate concent }}{\text { initial concent }}
$$

Table 7. $\beta$-glucans and starch final concentration $(\mathrm{g} / \mathrm{L})$ and removal percentage of glucose and cellobiose

\begin{tabular}{|c|c|c|c|c|}
\cline { 2 - 5 } \multicolumn{1}{c|}{} & \multicolumn{2}{c|}{ Final concentration (g/L) } & \multicolumn{2}{c|}{ Removal (\%) } \\
\hline Extract ID & $\beta$-glucans & Starch & Glucose & Cellobiose \\
\hline S1 & 2.17 & 1.41 & 51.7 & 51.5 \\
\hline S2 & 3.98 & 1.32 & 46.2 & 45.4 \\
\hline
\end{tabular}

The percentage removal is very close to the $50 \%$, in the four hours of the experiment without loss of $\beta$-glucans. This means that with only lengthen the time of diafiltration process or increasing the membrane area of the filtration system, it would be possible to eliminate $100 \%$ of glucose and cellobiose. That is, a quick purification process of $\beta$-glucans is obtained.

At the same time it is also necessary, in order of a complete viability analysis of the process, to study the changes in retention properties and flow as a result of the membrane fouling. The figure 8 shows, for the liquid extract S1, the evolution of permeate volume versus time. The nonlinearity means a flux decrease, due mainly to a fouling process on the membrane surface because it seems unlikely that in the diafiltration process an increase of the concentration polarization or viscosity takes place, but on the contrary, as we are losing solutes in the retentate.

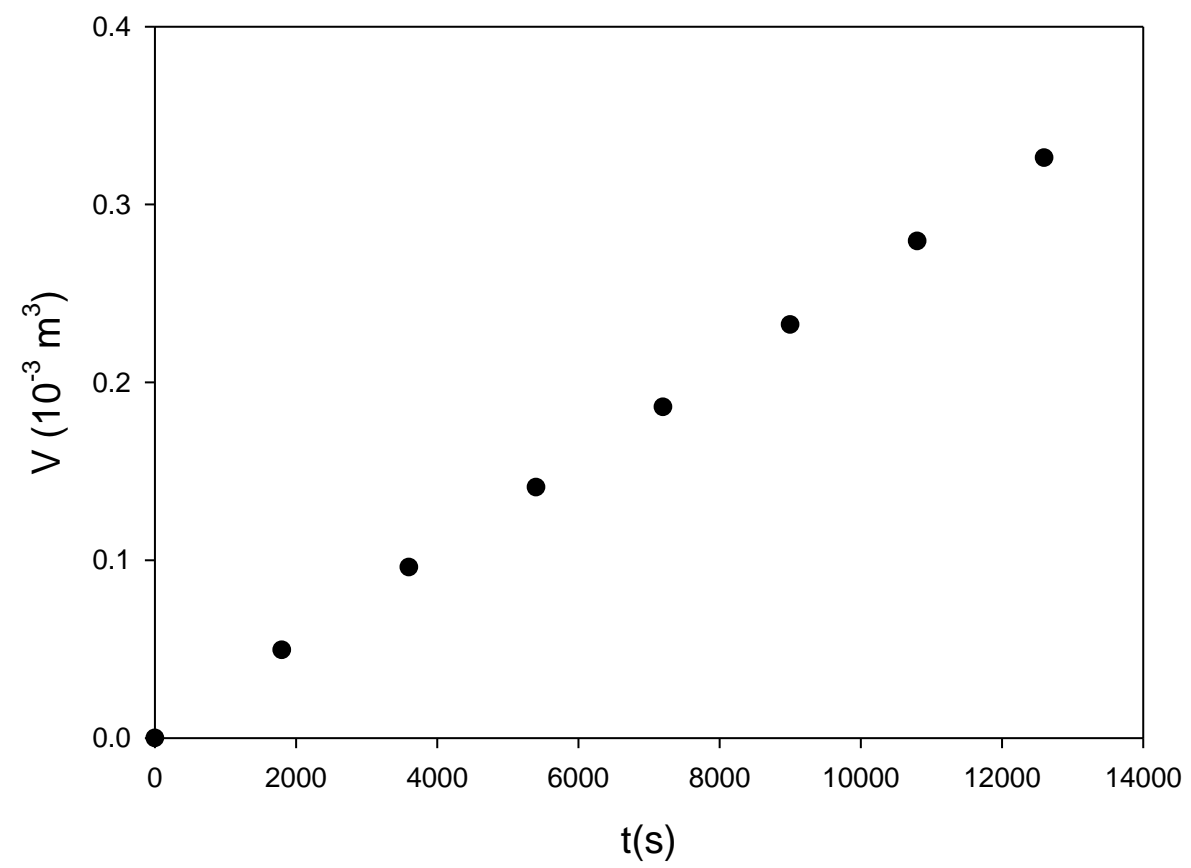

Figure 8. Filtrate volume versus time in the diafiltration process for liquid extract S1

In order to assess the fouling behavior of the investigated system, resistance must be taken into account and calculated according to equation 5[25]: 


$$
R_{\text {total }}=\frac{\Delta P}{\eta J_{v}}
$$

Where $J_{v}$ is the filtrate flux per area unit and $\eta$ is the solution viscosity. The resistance may include, besides the membrane hydraulic resistance $\left(R_{m}\right)$, the resistance due to adsorption, to the pore blocking and to the cake formation.

In a first step in membrane characterization, the water permeability is studied, since its variation, before and after the membrane use it is a good indicative of reversible or irreversible fouling of the membrane. Table 8 shows the values of hydraulic permeability for the new membrane (measured before the first filtration) and for the used membrane, before and after the cleaning process. After a cleaning process the permeability is partially recovered. However the permeability is not totally recovered because an irreversible fouling occurs, which is the issue that could be improved in this filtration process.

Table 8. Hydraulic permeability ( $\mathrm{m} / \mathrm{bar} \cdot \mathrm{s})$ for the new membrane $\left(^{*}\right)$ and for the used membrane, before and after the cleaning process

\begin{tabular}{|c|c|c|c|}
\hline $\begin{array}{c}\text { Supernatant } \\
\text { ID }\end{array}$ & $\begin{array}{c}\text { Before } \\
\text { diafiltration }\end{array}$ & $\begin{array}{c}\text { After } \\
\text { diafiltration }\end{array}$ & $\begin{array}{c}\text { After cleaning } \\
\text { process }\end{array}$ \\
\hline S1 & $2.03 \cdot 10^{-4}\left(^{*}\right)$ & $8.152 \cdot 10^{-6}$ & $5.79 \cdot 10^{-5}$ \\
S2 & $5.79 \cdot 10^{-5}$ & $6.10 \cdot 10^{-6}$ & $5.30 \cdot 10^{-5}$ \\
\hline
\end{tabular}

The study of the $t / V$ (ratio of filtration time and filtrate volume) as a function of total filtrate volume allow us to know the mechanism of fouling. According Schipper and Verdouw [26], the t/V plot can be divided into three regions: (I) pore blocking region, (II) cake formation without compression, and (III) cake formation with compression. In the case that there is only cake formation without compression, the equation proposed is (eq. 6):

$$
\frac{t}{V}=\frac{\eta I}{2 \Delta P A^{2}} V+\frac{\eta R_{m}}{\Delta P A}
$$

Where $I$ is the fouling index, related with the resistance due to the cake formation.

Figure 9 shows the $t / \mathrm{V}$ evolution as a function of the filtered volume for the both concentrations studied in our case (eq. 6). 


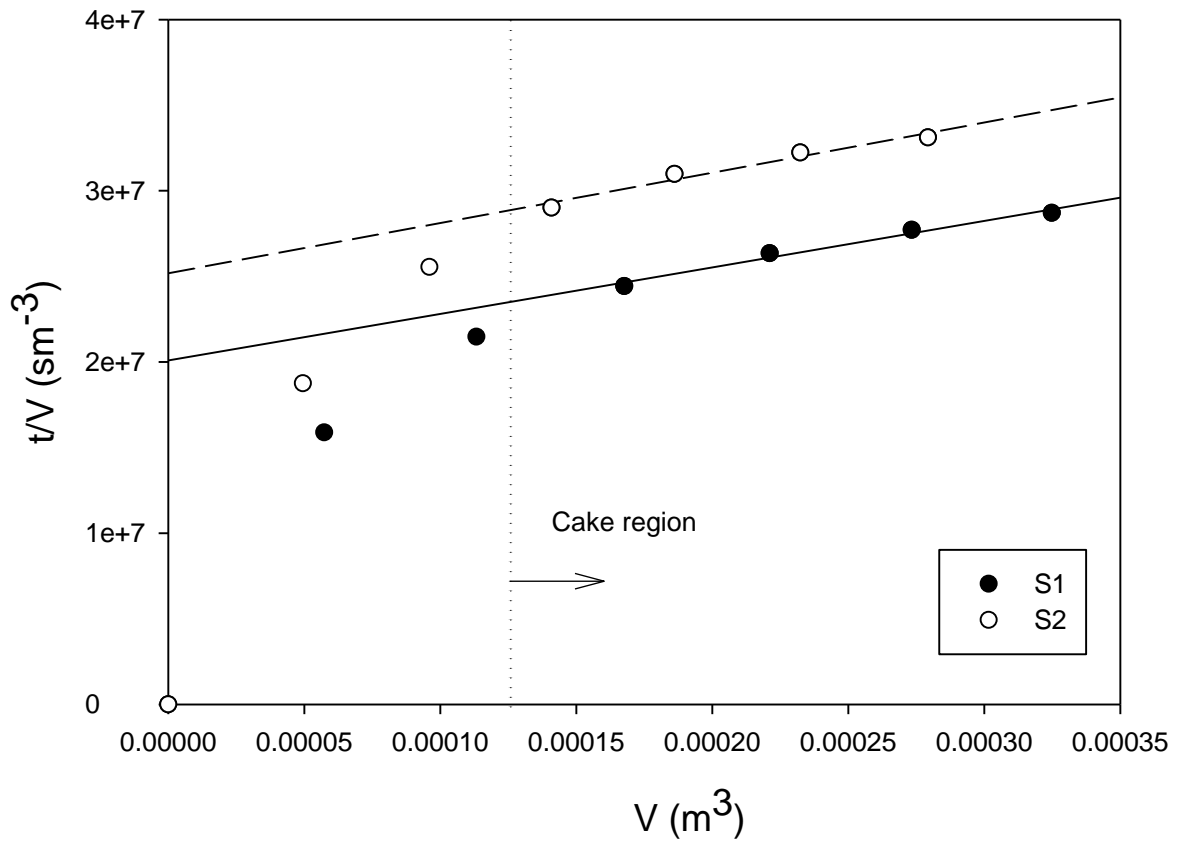

Figure 9.t/V as a function of filtrate volume calculated for the two $\beta$-glucan liquid extracts (S1and S2) used

After a first step of pore blocking, a cake formation takes place. This cake is the responsible for the hydraulic permeability reduction after $\beta$-glucans solution filtration. In any case we see that the slope of the cake area remains constant, which means that in our case there is no compression of the cake. It is also observed that the kinetics of formation of this cake is very similar for both concentrations, which implies that the system allow to work at high concentrations without loss of effectiveness of the process because of the fouling.

Figure 10 shows the total resistance evolution with the time (according eq. 4) for both diafiltrated concentrations. Also it is included the resistance, determined by filtering DI water, for the new membrane, for fouled membrane (after diafiltration processes without cleaning) and for the membrane after the cleaning process. It can be noticed that, after the first use with the feed solution, a resistance remains due to the irreversible fouling even with the cleaning process. As expected, the resistance value versus time is always greater for the solution of higher concentration (S2) which implies a higher cake layer. However, it is significant that in both cases there is a small increase at the beginning of the process, but it grows very slowly for a long time. This is a consequence of the diafiltration process (feed dilution over time by loss of solute through the membrane). 


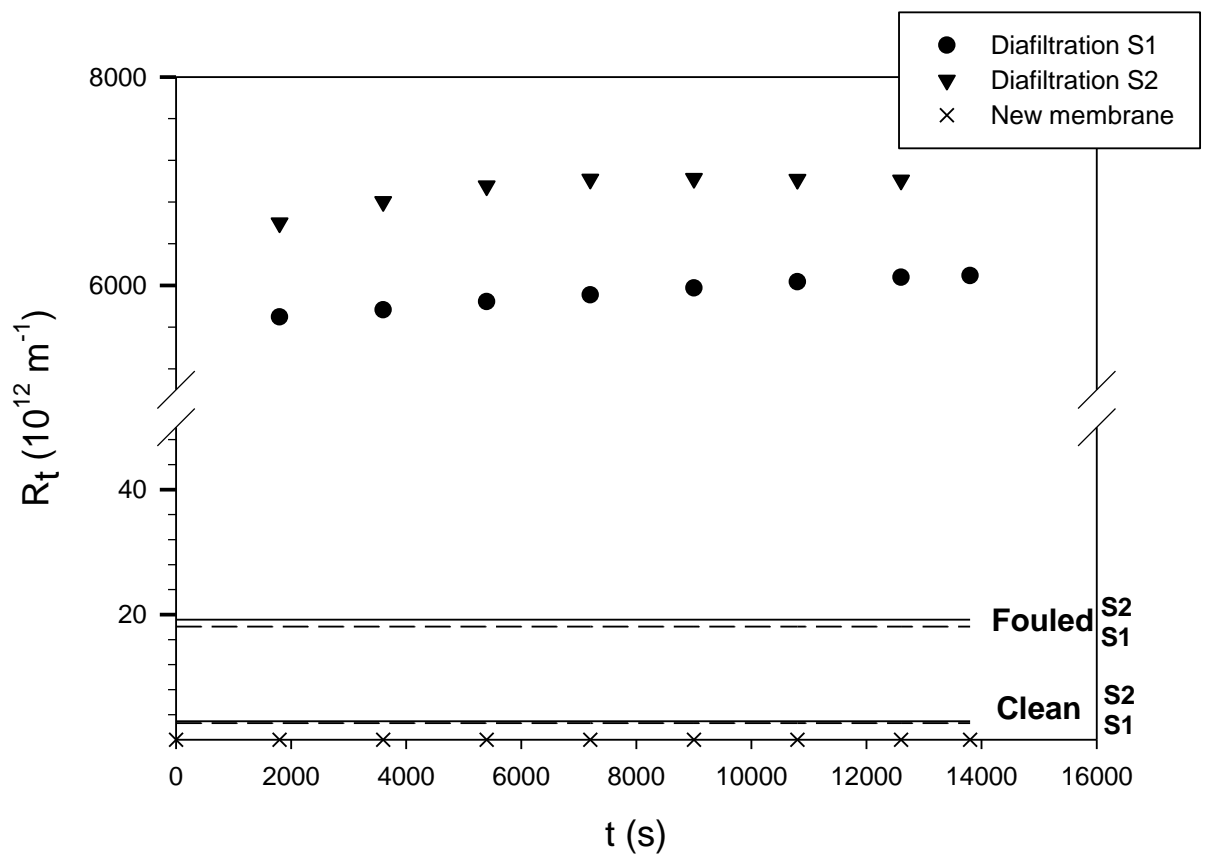

Figure 10. Total resistance evolution vs. time for the two b-glucan liquid extracts (S1 and S2) used

A lower cake formation would be desirable, since this new layer decrease the efficiency during the process in terms of saccharide removal, although it is easily cleaning.

\section{CONCLUSIONS}

In this work it was systematically studied the starch removal from a $\beta$-glucan liquid extract obtained after the ultrasound assisted extraction. It was optimized the enzyme dose and incubation hydrolysis at two different temperatures using the thermostable amylase Bialfa T. At $55 \stackrel{\circ}{\circ}$ more than $90 \%$ of the starch present in the solution was removed, not being detected any effect on the molecular weight of the extracted $\beta$-glucan and using a significantly lower dose than that recommended by the enzyme supplier. In a second step, the enzyme was dosed during the ultrasound assisted extraction process $\left(7 \mathrm{~min}, 55^{\circ} \mathrm{C}\right)$, where the concentration of starch was ten times lower that the concentration measured with no enzyme addition. The reduction of the hydrolysis length and the integration of the extraction of $\beta$-glucan and starch removal in one single step done in the ultrasound assisted extraction vessel at 55을 $\mathrm{C}$ are the major achievements of this work, as operation times and energy consumption are dramatically reduced.

The use of diafiltration process, as the final step for the $\beta$-glucans purification, is an appropriate process, since almost a complete purification of them (table 6) is achieved (it has been confirmed the absence of $\beta$-glucans in the retentate). Despite membrane fouling, a quite good percentage of saccharide removal is obtained. In the analysis of the viability of the 
process was observed that, although the membrane becomes fouled at the beginning of the process, with a decrease in permeability value, it was recovered after the cleaning process. However irreversible fouling was observed in the membrane, after several processes, which has to be optimized. Other membrane materials must be considered in future works.

\section{NOMENCLATURE}

$\mathrm{C}_{0, \mathrm{i}}-$ Initial concentration of the specie i $(\mathrm{g} / \mathrm{L})$

$\mathrm{C}_{\mathrm{p}}$ - Permeate concentration $(\mathrm{g} / \mathrm{L})$

$\mathrm{R}_{\mathrm{obs}}$ - Observed retention

$\mathrm{L}_{\mathrm{p}}$ - Specific permeability ( $\mathrm{m} /$ bar $\left.\cdot \mathrm{s}\right)$

$J_{w}-$ Pure water flux $(\mathrm{m} / \mathrm{s})$

$\Delta \mathrm{P}-$ Transmembrane pressure $(\mathrm{Pa})$

$R_{m}-$ Membrane hydraulic resistance $\left(m^{-1}\right)$

$R_{\text {total }}$ Total resistance $\left(\mathrm{m}^{-1}\right)$

$J_{v}-$ Filtrate flux per area unit $(\mathrm{m} / \mathrm{s})$

$\mathrm{t} / \mathrm{V}$ - ratio filtration time versus filtrate volume

$\eta$ - viscosity (Pa.s)

MW - Molecular weight $(\mathrm{kDa})$

\section{REFERENCES}

[1] C.S. Brennan, L.J. Cleary, The potential use of cereal (1-3,1-4)- $\beta$-D-glucans as functional food ingredients, J. Cereal Sci. 42(2005) 1-13.

[2] M. Irakli, C.G. Biliaderis, M.S. Izydorczyk, I.N. Papadoyannis, Isolation, structural features and rheological properties of water-extractable $\beta$-glucansfrom different Greek barley cultivars, J. Sci. Food Agric. 84 (2004) 1170-1178.

[3] Federal Drug Administration, 21 CFR Part 101.Food labeling, health claims; soluble dietary fiber from certain foods and coronary heart disease, Federal Register70-246 (2005) 7615076162.

[4] European Food Safety Authority Panel on Dietetic Products, Nutrition and Allergies, Scientific opinion on the substantiation of a health claim related to oat beta-glucan and lowering blood cholesterol and reduced risk of (coronary) heart disease pursuant to Article 14 of Regulation (EC) No 1924/2006, EFSA Journal 8 (2010) 1885. 
[5] C. Laroche, P. Michaud, New developments and prospective applications for $\beta-(1,3),(1,4)$ glucans, Recent Pat. Biotechnol. 1 (2007) 59-73.

[6] Ó. Benito-Román, E. Alonso, S. Lucas, Optimization of the $\beta$-glucan extraction conditions from different waxy barley cultivars J. Cereal Sci. 53 (2011) 271-276.

[7] Ó. Benito-Roman, E. Alonso, M.J. Cocero, Ultrasound assisted extraction of $\beta$-glucans from barley, LWT-Food Sci.Technol. 50 (2013) 57-63.

[8] Ó. Benito-Román, E. Alonso, M.J. Cocero, Pressurized hot water extraction of $\beta$-glucan from waxy barley, J. Supercrit. Fluids 73 (2013) 120-125.

[9] R. S. Bhatty, Extraction and enrichment of (1-3),(1-4)- $\beta$-D-Glucan from barley and oat brans, Cereal Chem. 70 (1993) 73-77.

[10] R. S. Bhatty, Laboratory and pilot plant extraction and purification of $\beta$-glucans from hullless Barley and oat brans J. Cereal Sci. 22 (1995) 163-170.

[11] F. Temelli, Extraction and functional properties of barley $\beta$-glucan as affected by temperature and pH, J. Food Sci. 62 (1997) 1194-1197.

[12] Z. Burkus, T. Temelli, Effect of extraction conditions on yield, composition, and viscosity stability of barley $\beta$-glucan gum, Cereal Chem. 75 (1998)805-809.

[13] M.S. Izydorczyk, L.J. Macri, A.W. MacGregor, Structure and physicochemical properties ofbarley non-starch polysaccharides-I.Water extractable $\beta$-glucans and arabinoxylans.Carbohydr.Polym. 35 (1998) 249-258.

[14] M.S. Izydorczyk, J. Storsley, D. Labossiere, A.W. MacGregor, B.G. Rossnagel,Variation in total and soluble $\beta$-glucan content in hulless barley: effects of thermal, physical and enzymic treatments, J. Agric. Food Chem. 48 (2000) 982-989.

[15] A. Lazaridou, C.G. Biliaderis, M. Micha-Screttas, B.R. Steele, A comparative study on structure, function relations of mixed-linkage (1-3),(1-4) linear $\beta$-D-glucans, Food Hydrocolloids 18 (2004) 837-855.

[16] M. Papageorgiou, N. Lakhdara, A. Lazaridou, C.G. Biliaderis, M.S. Izydorczyk, Water extractable (1-3,1-4)- $\beta$-D-glucans from barley and oats: an intervarietal study on their structural features and rheological behavior, J. Cereal Sci. 42 (2005) 213-224.

[17] W. Li, S.W. Cui, Y. Kakuda, Extraction, fractionation, structural and physical characterization of wheat $\beta$-D-glucans,Carbohydr.Polym. 63 (2006) 408-416. 
[18] S.H. Knutsen, A.K. Holtekjølen,Preparation and analysis of dietary fiber constituents in wholegrain from hulled and hull-less barley,Food Chem. 102 (2007) 707-715.

[19] A. Lazaridou, T. Chornick,C.G. Biliaderis, M.S, Izydorczyk, Sequential solvent extraction and structural characterization of polysaccharides from the endosperm cell walls of barley grown in different environments,Carbohydr.Polym. 73 (2008) 621-639.

[20] R.F. Tester, X. Qi, J. Karkalas, Hydrolysis of native starched with amylases, Anim.Feed Sci. Techn. 130 (2006) 39-54.

[21] V. Gekas, G. Baralla, V. Flores, Applications of membrane technology in the food industry, Food Sci. Technol. Int. 5 (1998) 311-328.

[22] A. Patsioura, C.M. Galanakis, V. Gekas,Ultrafiltration optimization for the recovery of $\beta$ glucan from oat mill waste, J. Membr. Sci. 373 (2011) 53-63.

[23] R.C. Kuhn, F. MaugeriFilho, V. Silva, L. Palacio, A. Hernández, P. Prádanos, Mass transfer and transport during purification of fructooligosaccharides by nanofiltration, J. Membr. Sci. 365 (2010) 356-365.

[24] L. Palacio, C.C. Ho, P. Prádanos, A. Hernández, A.L. Zydney, Fouling with protein mixtures in microfiltration: BSA-lysozyme and BSA-pepsin, J.Membr. Sci. 222 (2003) 41-51.

[25] K. Listiarin, W. Chun, D.D. Sun, J.O. Leckie,Fouling mechanism and resistance analyses of systems containing sodium alginate, calcium, alum and their combination in dead-end fouling of nanofiltration membranes,J. Membr. Sci. 344 (2009) 244-251.

[26] J.C. Schippers, J. Verdoux, The modified fouling index, a method of determining the fouling characteristics of water, Desalination 32 (1980) 137-148. 


\section{CHAPTER 7}

\section{Evaluation of the $\beta$-glucan}

\section{extraction intensification from}

barley: energy balances of different extraction procedures 



\title{
Evaluation of the $\beta$-glucan extraction intensification from barley: energy balances of different extraction procedures
}

\begin{abstract}
In previous works the authors have studied the technical feasibility of different extraction methods to isolate $\beta$-glucans form waxy barley: stirred tank, ultrasound assisted extraction (UAE) and pressurized hot water (PHW) extraction. It was evaluated the influence of the process parameters on the extraction yield and on the molecular weight of the extracted $\beta$ glucans. The obtained results revealed that each method presents advantages and disadvantages over the others, but all of them led to good extraction results. In order to get a clear basis for the comparison between all the studied processes, the energy consumption in each of them, expressed in kWh per gram of $\beta$-glucan extracted, has been evaluated. UAE comes out the best process from an energetic point of view, with $0.14-0.17 \mathrm{kWh} / \mathrm{g} \beta$-glucan and extractions lasting from 3 to 15.9 minutes, that represents a dramatic reduction of the extraction times compared to the stirred tank extraction ( $3 \mathrm{~h}, 0.27 \mathrm{kWh} / \mathrm{g} \beta$-glucan), and it is possible to assert that the UAE supposes a real process intensification. PHW process was seen as the highest energy consumer (6.0kWh/g $\beta$-glucan). In spite of the good results in extraction time reductions and the lack of pretreatments to obtain high molecular weight (MW) $\beta$-glucan, PHW resulted to be an unfavorable process from an energetic point of view, mainly due to the low barley to water ratio (1:50) used during the extraction.
\end{abstract}

Keywords: energy, process intensification, $\beta$-glucan, polysaccharides, barley, extraction 


\section{INTRODUCTION}

Mixed linkage $\beta$-glucans, $(1 \rightarrow 3),(1 \rightarrow 4)-\beta$-D-glucans, or simply $\beta$-glucans, are a sort of nonstarchy polysaccharides that can be found in several varieties of cereals, such as barley, oat, rye and wheat, in concentrations from 0.5 to $11 \%$ in dry basis. $\beta$-glucans are high added value polysaccharides due to the good effects they have on human health, regarding to the control of cholesterol and glucose levels in blood (Wood, 2007). The $\beta$-glucan extraction exhibits important mass transfer limitations (Benito-Román et al., 2011); therefore novel extraction procedures are required to enhance the final extraction yield compared to the conventional extraction procedures, based on stirred tanks.

The authors have deeply studied the extraction of high molecular weight $\beta$-glucans from barley, proposing different extraction procedures: stirred tank (Benito-Román et al., 2011), ultrasound assisted extraction - UAE - (Benito Román et al., 2013) and pressurized hot water PHW extraction (Benito-Román et al, 2013). In all the aforementioned works the authors have studied the influence of the process parameters on the extraction yield and molecular weight of the extracted polymers. Besides, the authors have considered the results of the stirred tank extraction as a basis for the comparison: the results obtained in the new studied processes have been compared to those obtained in the stirred tank, in order to study the technical feasibility of the new processes. Results from the stirred tank revealed that $\beta$-glucan extraction processes were difficult, as important mass transfer limitations were found (internal diffusion and external transport) so very low particle sizes and high stirring rates were required to provide a good contact between solvent and barley. Moreover, $\mathrm{MW}$ of the extracted $\beta$-glucan was very low, as the $\beta$-glucanases had not been deactivated and were free to act on the $\beta$ glucan backbone. As a first approach to limit the activity of the $\beta$-glucanases, barley was pretreated: it was boiled in ethanol $(80 \%, v / v)$ for two hours. The so pretreated barley was extracted in the stirred tank, under the same conditions proposed as optimal $\left(55^{\circ} \mathrm{C}, 3\right.$ hours, $1000 \mathrm{rpm})$. The result was an increase of the MW of the extracted $\beta$-glucan from 55 to $431 \mathrm{kDa}$, but also a dramatic decrease of the extraction yield, from $73.4 \%$ to $41.5 \%$. The higher MW of the extracted $\beta$-glucans in this case, causes an important increase in the viscosity of the suspension and mass transfer is hindered. In order to overcome the mass transfer limitations, $\beta$-glucans were extracted from the pretreated barley by means of the ultrasound technology: US are known to improve mass transfer (lida et al, 2008; Rodríguez-Rojo et al, 2012) as probes the number of works that have used them to extract polysaccharides from natural matrix (Vilkhu et al, 2008). $\beta$-glucans were successfully extracted by means of US at $55^{\circ} \mathrm{C}$ and 
operational parameters were optimized in order to maximize extraction yield, molecular weight or both at the same time (Benito Román et al, 2013). Essentially, UAE represents a dramatically reduction in extraction time (the proposed extraction times were in the range 3 to 15.9 minutes), keeping the extraction yield and the MW obtained in the stirred tank process.

Moreover, another novel process for $\beta$-glucan extraction has been proposed using pressurized hot water (PHW) as solvent. PHW term refers to the water in the liquid state above $100^{\circ} \mathrm{C}$ and pressurized in order to maintain the liquid state. PHW favors mass transfer and weakens hydrogen bonds, resulting in an improvement in the release of $\beta$-glucans form barley. The extraction time $(15-75 \mathrm{~min})$ and the temperature $\left(135-180^{\circ} \mathrm{C}\right)$ were optimized in a batch-mode operation, leading to an extraction yield of $53.7 \%$ and $200 \mathrm{kDa}$ under the optimum conditions $\left(155^{\circ} \mathrm{C}\right.$ for $18 \mathrm{~min}$ at $\left.50 \mathrm{bar}\right)$. This high MW $\beta$-glucan was obtained from non-pretreated barley, which simplifies the overall $\beta$-glucan recovery process as the time and energy consumed during $\beta$-glucanase deactivation were eliminated.

US and PHW lead to a dramatic reduction of the extraction times, and in this sense it is possible affirm that they both represent an intensification of the extraction process of $\beta$ glucans from barley. In order to be able to talk about a complete intensification of the recovery process an outlook to the energy consumptions must be done. To the best of our knowledge, this is the first attempt to evaluate energy consumption in such a kind of process, and there is not any previous study in the literature about energy consumption for a $\beta$-glucan isolation process. The energy consumed during the raw material pretreatment (milling and $\beta$-glucanase deactivation) and the energy consumed in the extraction stage should be considered. The measured energies should be expressed as kWh of energy consumed per gram of extracted $\beta$ glucan ( $\mathrm{kWh} / \mathrm{g} \beta$-glucan) and expressed in monetary units ( $€ / \mathrm{kg}$ of $\beta$-glucan). The purpose of this work is to evaluate the energy consumed in the three previously studied extraction processes and evaluate the intensification that these new processes (UAE and PHW) represent against the conventional stirred tank process, in terms of energy.

\section{MATERIALS AND METHODS}

\subsection{Raw material}

A waxy hulled barley cultivar, named D24, was used as raw material for this study. The main composition of this barley is shown in table 1 , before and after the pretreatment to deactivate $\beta$-glucanases according to procedure described in section 2.3. 
Table 1. Chemical composition of barley D24 before and after ethanol pretreatment to deactivate $b$ glucanases

\begin{tabular}{|l|c|c|}
\cline { 2 - 3 } \multicolumn{1}{c|}{} & $\begin{array}{c}\text { D24 } \\
\text { non pretreated }\end{array}$ & $\begin{array}{c}\text { D24 } \\
\text { pretreated }\end{array}$ \\
\hline Lipids (\%) & $2.79 \pm 0.18$ & $1.86 \pm 0.16$ \\
Protein (\%) & $18.2 \pm 0.2$ & $13.0 \pm 0.2$ \\
Starch (\%) & $50.3 \pm 3.2$ & $58.7 \pm 3.0$ \\
$\beta$-glucans (\%) & $6.02 \pm 0.37$ & $6.25 \pm 0.25$ \\
\hline
\end{tabular}

\subsection{Milling process}

Barley was milled in a cutting/impact laboratory mill (MF10, IKA; power 1000W). By means of this apparatus only one milling fraction was obtained. The particle size of the milled barley was measured (Malvern Mastersizer 2000; Malvern Ltd.), resulting in $240 \pm 4 \mu \mathrm{m}$.

\section{3. $\beta$-glucanase deactivation}

Barley after milling was boiled in ethanol $(80 \%, v / v)$ for two hours in order to deactivate $\beta$ glucanases. $130 \mathrm{~g}$ of barley were suspended in $780 \mathrm{~mL}$ of aqueous ethanol in a $\mathrm{L}$ flask, and heated by means of an electric mantle (power 530W, potentiometer was set at $20 \%$ ).

\subsection{Extraction procedures}

\subsubsection{Stirred tank extraction}

$20 \mathrm{~g}$ of barley were suspended in $200 \mathrm{~mL}$ of water in a jacketed glass reactor (1litre, Afora). Temperature was kept constant (at $55^{\circ} \mathrm{C}$ ) by means of a heating water bath (Lauda Ecoline Staredition E100, Lauda; power 1500W), while solid-liquid mixture was suspended by means of mechanical stirring at 1000rpm (RZR2021, Heidolph; power 27W). Results of extraction yield and molecular weight from not pretreated barley, obtained under those conditions in a process named as ST1, were $73.4 \pm 1.2 \%$ and MW $55 \mathrm{kDa}$ respectively. When barley was pretreated with ethanol (process ST2), $41.5 \pm 1.4 \%$ and $431 \mathrm{kDa}$ were the obtained results.

\subsubsection{Ultrasound assisted extraction (UAE)}

$20 \mathrm{~g}$ of barley flour were suspended in $200 \mathrm{~mL}$ of water and located in a $250 \mathrm{~mL}$ jacketed vessel. The suspension was sonicated by means of the UP400S Ultrasonic Processor (400 watts, $24 \mathrm{kHz}$; Hielscher), equipped with a $22 \mathrm{~mm}$ titanium probe. A cold water flow in the jacket was used to maintain $55^{\circ} \mathrm{C}$. Three different process parameters (amplitude, extraction time and cycle) were changed in order to obtain conditions that would maximize extraction yield, MW or both simultaneously. The extraction conditions obtained when pretreated barley was used, as well as the obtained results are summarized in table 2 : 
Table 2. Extraction conditions and results of different ultrasounds assisted extraction processes

\begin{tabular}{|c|c|c|c|c|c|c|}
\hline \multirow[b]{2}{*}{ Process ID } & \multirow[b]{2}{*}{$\begin{array}{c}\text { Maximized } \\
\text { Response }\end{array}$} & \multicolumn{3}{|c|}{ Process Variables } & \multirow{2}{*}{$\begin{array}{c}\text { Yield } \\
(\%)\end{array}$} & \multirow{2}{*}{$\frac{\mathrm{MW}}{\text { (kDa) }}$} \\
\hline & & $\begin{array}{c}\text { Amplitude } \\
\text { (\%) }\end{array}$ & $\begin{array}{l}\text { Time } \\
(\min )\end{array}$ & $\begin{array}{l}\text { Cycle } \\
(-)\end{array}$ & & \\
\hline UAE1 & Extraction Yield & 100 & 15.9 & 0.9 & $65.6 \pm 1.2$ & $261.4 \pm 7.3$ \\
\hline UAE2 & MW & 60 & 3 & 0.8 & $37.3 \pm 0.7$ & $483.3 \pm 3.2$ \\
\hline UAE3 & Extraction Yield \& MW & 80 & 7.6 & 0.8 & $52.4 \pm 0.9$ & $388.6 \pm 4.6$ \\
\hline
\end{tabular}

\subsubsection{Pressurized hot water extraction (PHW)}

1g of barley flour was located inside the $50 \mathrm{~mL}$ high-pressure view cell (Eurotechnica $\mathrm{GmbH}$ ) through one of the sapphire windows and after its closure, the chamber is filled up with distilled water and heated up by means of electric resistors (1600W). Extraction was done at $152^{\circ} \mathrm{C}$ for 18 minutes, under vigorous stirring (stirrer power $6 \mathrm{~W}$ ). Results obtained under these conditions using not-pretreated barley were $53.7 \pm 1.5 \%$ and $200 \mathrm{kDa}$, and process has been named as PHW1.

\subsection{Energy consumption measurement}

The energy consumption of all the electrical devices was measured by means of the wattmeter (Energy-Check 3000, Voltcraft). The energy was expressed in "watts". In order to calculate the total energy consumed in each complete extraction process, the energies consumed during the pretreatment and extraction stages are added and expressed in $\mathrm{kWh} / \mathrm{g}$ of extracted $\beta$-glucan, using the extraction yields obtained in the laboratory that have been described in sections 2.4.1, 2.4.2 and 2.4.3. Barley pretreatments include milling and ethanol boiling. Finally, it was assumed a price of $0.1492 €$ per $\mathrm{kWh}$ (www.minetur.gob.es) to convert the energy consumed into monetary figures ( $€$ per $\mathrm{kg}$ of $\beta$-glucan extracted); so all the procedures could be compared.

\section{RESULTS AND DISCUSSION}

\subsection{Pretreatment stage consumptions}

The energy required in the $\beta$-glucanase deactivation pretreatment was measured and established in $7 \mathrm{~kJ} / \mathrm{g}$ of barley; the energy required to mill the grains of barley was $3.6 \mathrm{~kJ} / \mathrm{g}$ of barley. 


\subsection{Extraction stage consumptions}

The energy consumed in the stirred tank processes (ST1 and ST2) was derived from the water bath (in a 3 hours experiment a consumption of $29 \mathrm{~kJ}$ per liter of water was measured) used to keep the suspension water-barley at $55^{\circ} \mathrm{C}$ and the electrical motor that moved the stirred (it consumed $282 \mathrm{~kJ}$ ). This stirrer is designed for medium to high viscosity mixing operations, offering a constant power output and increasing the stirring torque in order to keep the stirring rate.

The energy consumed in the UAE was highly dependent on the operation conditions (mainly amplitude and cycle). In a $60 \%$ amplitude process and cycle 0.8 (process UAE2), energy consumed by the device was $108 \mathrm{~W}$; when the amplitude was increased up to $80 \%$ and cycle was 0.9 (process UAE3) the power consumed was $170 \mathrm{~W}$ and at amplitudes of $100 \%$ and cycles of 0.9 (process UAE1) the energy consumed was $240 \mathrm{~W}$. These numbers supposed a consumption of $458 \mathrm{~kJ}$ for process UAE1; 38.9kJ for process UAE2 and 99.3kJ for the process UAE3.

The pressurized hot water extraction process consumed $649 \mathrm{~kJ}$, the highest energy consumption in all the studied extraction processes. The energy consumption was due to the electric resistors used to keep temperature at $152^{\circ} \mathrm{C}$ and the electric motor to stir the suspension.

\subsection{Energy consumed in each extraction process}

The energies consumed in the whole studied process, considering the energies consumed in the pretreatment and extraction stages are summarized in table 3:

Table 3. Energy consumed in the extraction process of $\beta$-glucan from barley studied

\begin{tabular}{|c|c|c|c|c|}
\hline PROCESS & Barley* & $\begin{array}{c}\text { Energy } \\
\text { (kJ) }\end{array}$ & $\begin{array}{c}\text { Energy } \\
\text { (kWh/g } \boldsymbol{\beta} \text {-glucan) }\end{array}$ & $\begin{array}{c}\text { Cost } \\
\text { (€/kg } \boldsymbol{\beta} \text {-glucan) }\end{array}$ \\
\hline ST1 & NP, 20g & 419.1 & 0.113 & 21.9 \\
ST2 & P, 20g & 602.6 & 0.271 & 45.4 \\
\hline UAE1 & P, 20g & 462.1 & 0.164 & 28.4 \\
UAE2 & P, 20g & 272.0 & 0.169 & 29.3 \\
UAE3 & P, 20g & 332.5 & 0.147 & 26.0 \\
\hline PHW1 & NP, 1g & 653.5 & 6.04 & 901.6 \\
\hline
\end{tabular}

*KEY: NP, barley not pretreat; $P$, barley pretreated

From table 3 it can be seen that in the stirred tank extraction process the energy consumed was $0.27 \mathrm{kWh} / \mathrm{g} \beta$-glucan ( $45.4 € / \mathrm{kg}$ of $\beta$-glucan) when using pretreated barley and $0.11 \mathrm{kWh} / \mathrm{g}$ $\beta$-glucan (21.9€/kg of $\beta$-glucan) when barley was not pretreated. The energy required in the $\beta$ glucanase deactivation step is high, making the stirred tank process to require $602.6 \mathrm{~kJ}$ instead 
of $419.1 \mathrm{~kJ}$. However, there is a higher difference in the specific energy ( $\mathrm{kWh} / \mathrm{g}$ of $\beta$-glucan) consumed in the two processes, due to the lower extraction yield achieved when using the pretreated barley. These results reveal the importance of having high extraction yields in $\beta$ glucan recovery processes: the decrease in the extraction yield due to the high viscosity suspension formed when using pretreated barley led to have a process that consumed twice more energy per gram of $\beta$-glucan extracted, and hence increasing the total cost of the $\beta$ glucan recovery process. To have a higher extraction yield when using pretreated barley is required if the stirred tank process is desired to be competitive and economically sustainable. As there are important mass transfer limitations derived from the high viscosity and these limitations were not overcome by the conventional stirred extraction methods, alternative methods are needed.

Pretreated barley was used in all the studied UAE conditions. The energy consumed in all of them was lower than that consumed in the stirred tank process. The energy consumed was lower since the extraction times were dramatically reduced, that in addition to the relatively high extraction yields achieved in this process (37.3-65.6\%) lead to a process technically and economically sustainable; as the energy consumed expressed in kWh per $g$ of $\beta$-glucan extracted was in the range $0.15-0.17$, almost half of the energy used in the stirred tank process. The best results were obtained in the process carried out in the conditions selected to maximize both extraction yield and $\mathrm{MW}$, were the energetic cost were found to be $26 €$ per $\mathrm{kg}$ of extracted $\beta$-glucan. Under these conditions extraction yield and molecular weight are high in all the cases, being the most suitable alternative to extract $\beta$-glucans from barley. From these results, it can be affirm that the UAE is a more efficient technology than the conventional stirred extraction processes, since lower energy inputs lead to higher extraction yields. Energy consumption and extraction times are dramatically reduced which supposes a real process intensification of the $\beta$-glucan extraction process from barley.

The results for the PHW process are in contrast with those obtained for the UAE. In the PHW process the energy needed to extract $\beta$-glucan was dramatically increased, up to $6.04 \mathrm{kWh} / \mathrm{g} \beta$ glucan vs $0.11 \mathrm{kWh} / \mathrm{g}$ of $\beta$-glucan in the stirred tank process (ST1), fifty times higher, which unadvised the use of PHW to extract $\beta$-glucans from an economical point of view, despite the other advantages. PHW shows good results in terms of MW and extraction yield compared to the stirred tank process, shorter extraction time and no pretreatment is required to deactivate $\beta$-glucanases. However, if a closer view is done to the energy consumed in the extraction step, it can be seen that the value of $653.5 \mathrm{~kJ}$ for the PHW1 process is higher than that required in the stirred tank process, but not 40 times higher, as it is found for the specific energy $\mathrm{kWh} / \mathrm{g} \beta$ - 
glucan. The major drawback of the PHW must be found in the ratio solvent to barley used in this process: $1 \mathrm{~g}$ of barley in $50 \mathrm{~mL}$. This ratio is extremely high compared to the ratios used in the other studied processes (which is 1:10), and this is the reason of the high expenses calculated for the PHW process. Therefore, in order to make profit of the advantages derived from the PHW use, lower solvent to barley ratios must be used. The use of lower ratios in addition to the dramatic reductions in operation times to obtain high molecular weight $\beta$ glucan (18 minutes, $200 \mathrm{kDa}$ ) without a previous pretreatment step to deactivate $\beta$-glucanases will make of PHW a competitive process to isolate $\beta$-glucans. The fact of get rid of the pretreatment step will save time and reagents, as no ethanol will be required. Reduction of times and the no necessity of a pretreatment step will lead to a process intensification achieved by means of the PHW process. It is also possible to perform the extraction of $\beta$ glucans from barley using PHW in a flow operation, by using a fixed bed extractor. Results revealed a similar extraction yields than that in the batch PHW process studied in this work. Another advantage of the fixed bed extraction lays on the higher MW obtained, as the time that $\beta$-glucan is exposed to the high temperatures is reduced, since once the $\beta$-glucan is dissolved it abandons the reactor.

\section{CONCLUSIONS}

The study of the energy consumed in different $\beta$-glucan extraction processes showed that the use of ultrasounds for that purpose involves a real intensification of the extraction, since extraction times as well as the energetic expenses per gram of $\beta$-glucan extracted are dramatically reduced. On the other hand, and although PHW does not need the $\beta$-glucanase deactivation step to obtain high MW $\beta$-glucan, this process shows important economic limitations derived from the high solvent to barley ratios used. This makes the energetic costs extremely high compared to the other processes studied. However, a reduction of this ratio will improve the energetic costs making the PHW to be an attractive process to extract high MW $\beta$-glucans from barley in one single step.

\section{REFERENCES}

Benito-Román, O., Alonso, E., Lucas, S. (2011). Optimization of the $\beta$-glucan extraction conditions from different waxy barley cultivars. Journal of Cereal Science 53(3), 271-276

Benito-Román, O.; Alonso, E.; Cocero, M.J. (2013) Pressurized hot water extraction of $\beta$-glucan from waxy barley. The Journal of Supercritical Fluids 73, 120-125 
Benito-Román, O.; Alonso, E.; Cocero, M.J. (2013). Ultrasounds assisted extraction of $\beta$-glucan from barley. LWT - Food Science and Technology 50(1), 57-63

lida, Y., Tuziuti, T., Yasui, K., Towata, A., \& Kozuka, T. (2008). Control of viscosity in starch and polysaccharide solutions with ultrasound after gelatinization. Innovative Food Science and Emerging Technologies, 9, 140-146

Rodríguez-Rojo, S., Visentin, A., Maestri, D., \& Cocero M.J. (2012). Assisted extraction of rosemary antioxidants with green solvents. Journal of Food Engineering, 109(1), 98-103

Vilkhu, K., Mawson, R., Simons, L., \& Bates, D. (2008). Applications and opportunities for ultrasound assisted extraction in the food industry - A review. Innovative Food Science and Emerging Technologies, 9, 161-169

Wood, P.J. (2007). Cereal $\beta$-glucans in diet and health. Journal of Cereal Science, 46, 230-238 

CONCLUSIONS 

The main conclusions of this work are summarized below:

\section{STIRRED TANK EXTRACTION PROCESS OF $\beta$-GLUCANS}

- In this work $\beta$-glucans have been extracted from two different varieties of waxy barley in a stirred tank extractor (conventional extraction process). Important mass transfer limitations have been demonstrated, as well as other inconveniences such as the low molecular weight (MW) of the extracted $\beta$-glucan (lower than $55 \mathrm{kDa}$ ) and the coextraction of other substances (mainly strach).

- The study of the effect of the process variables on the extraction of $\beta$-glucans from two different varieties of waxy barley (hulled and hulless) allowed to conclude that despite the morphological differences between the two varieties their response to changes in the process parameters was similar. Water was the selected solvent; when $\mathrm{pH}$ was changed not significant differences in the extraction yield were observed, so it was kept around 6.0-6.5. On the other hand, extraction was enhanced with temperatures up to $55^{\circ} \mathrm{C}$. Higher temperatures let to a dramatic increase in the amount of starch co-extracted. In order to maximize the extraction yield particle size of the barley should be below $100 \mu \mathrm{m}$, stirring rate $1000 \mathrm{rpm}, 3$ hours extraction length and solvent to barley ratio of 1 to 8 . Under these extraction conditions, extraction yield from hulless barley (H13) was $62.3 \pm 1.8 \%$ and $73.4 \pm 1.2 \%$ when hulled barley (D24) was used.

- Two different pretreatments have been proposed in order to increase the MW of the extracted $\beta$-glucan: boiling the barley in ethanol in order to deactivate the endogenous enzymes $\beta$-glucanases and selection of milling fractions. The ethanol pretreatment involved a dramatic increase of the MW up to 431kDa; nevertheless the extraction yield fell down to $41.5 \pm 1.0 \%$ when hulled barley was used and to $42.7 \pm 1.3 \%$ y $456 \mathrm{kDa}$ when hulless barley was used. The use of milling fractions (differing in the composition and in the average particle size) led to different extraction yields and MW of the extracted $\beta$-glucans. In order to maximize the $\mathrm{MW}$ of the extracted $\beta$-glucan the coarse bran fraction must be used.

\section{PROPOSAL OF NEW PROCESSES THAT IMPROVE THE EXTRACTION (I): ULTRASOUNDS}

- The ultrasound assisted extraction (UAE) has led to a dramatic reduction of the extraction time (from 3 hours in the conventional stirred tank process to 3-15.9 
minutes in the ultrasound process). Moreover, a dramatic reduction in the energy consumed during the extraction has been achieved: from $1460 \mathrm{~kJ} / \mathrm{L}$ in the stirred tank process to $100-500 \mathrm{~kJ} / \mathrm{L}$ in the UAE process. These results allow to talk about an efficient intensification of the $\beta$-glucan extraction process.

\section{PROPOSAL OF NEW PROCESSES THAT IMPROVE THE EXTRACTION (II): PRESSURIZED HOT WATER}

- The use of pressurized hot water (PHW) as solvent involved an improvement of the MW of the extracted $\beta$-glucan and a reduction of the extraction time compared to the stirred tank process. A batch extraction done at $155^{\circ} \mathrm{C}, 50 \mathrm{bar}$ and 18 minutes length led to an extraction yield of $53.7 \%$ and a MW of $200 \mathrm{kDa}$. This high MW was obtained without pretreating the barley in order to deactivate the endogenous enzymes $\beta$ glucanases.

- Higher temperatures and longer extraction times involved the hydrolysis of the $\beta$ glucan, as it was proved by the analysis of the MW and the analysis of the hydrolysis products (oligosaccharides). These results were presented and discussed by means of the severity factor, a dimensionless number that considers the combined effect of temperature and time. Operation conditions that result in a severity factor $\left(\log R_{0}\right)$ higher than 3.5 , led to molecular weights lower than $100 \mathrm{kDa}$; if severity factor was higher than 4.0 the $\mathrm{MW}$ of the $\beta$-glucan was lower than $50 \mathrm{kDa}$.

- The movement from a batch process to a semi-continuous process (fixed bed extraction) led to a further improvement of the MW. Moreover, a fractionation of the $\beta$-glucan based on the MW was achieved during the extraction. The extraction done in a fixed-bed extractor led to an extraction yield of $52.4 \pm 1.4 \%$, and $\mathrm{Mw}$ in the range 500 to $180 \mathrm{kDa}$.

- Other raw materials such as wheat bran were used as source of $\beta$-glucans. The good results obtained in the PHW processes when barley was used, were also observed for the new raw materials.

\section{DOWNSTREAM PROCESS: CONCENTRATION AND PURIFICATION OF THE EXTRACTED $\beta$-GLUCAN}

The downstream study in the $\beta$-glucan recovery process was done in two steps: enzymatic hydrolysis of the main co-extraction product (starch) and removal of the enzymatic hydrolysis products by means of membranes. 
- In this work, the starch co-extracted was hydrolyzed by the use of amylases (E.C. 3.2.1.1.). Dextrins, oligosaccharides and glucose were the main hydrolysis products. All these substances had lower MW (below 10kDa) than $\beta$-glucan.

- The enzyme dose and the incubation times and temperatures were studied. The results of this study allowed to remove more than $90 \%$ of the starch dissolved in a hydrolysis process done at 55 으 for 9 minutes and dosing $125 \mu$ of enzyme per gram of dissolved starch.

- The enzyme was dosed ( $25 \mu \mathrm{l}$ enzyme/g of barley) during the UAE process ( 7 minutes at 55 -C), being reduced the concentration of the starch dissolved by more than $90 \%$ compared to the process where the enzyme was not dosed. This led to an integration and intensification of processes (extraction and purification) as both of them were done at the same temperature and simultaneously.

- In order to remove the starch hydrolysis products membranes were used. Removal efficiencies (higher than 45\%) of the oligosaccharides present in the liquid were successfully achieved. Although $\beta$-glucan solutions fouled the membrane (polysulfone, MWCO 100kDa) very fast, it could be regenerated, being recovered the permeability.

- The integration of ultrasounds, enzymatic hydrolysis and membrane separation technologies allowed to recover $\beta$-glucans in an effective way. The operation times and the energy consumed compared to the conventional processes were dramatically reduced. The use of these technologies lets the obtaining of $\beta$-glucan concentrates of at least $65-70 \%$, after a 7 minutes UAE process (energy consumed 390kJ/L).

\section{EVALUATION OF THE ENERGETIC CONSUMED}

In the final part of this work it was studied and evaluated the energy consumed in the different processes proposed in this thesis. It was evaluated the energy consumed in the pretreatment step (milling and $\beta$-glucanase deactivation) and in the extraction:

- The UAE process was the most favorable from an energetic point of view: 0.14$0.17 \mathrm{kWh} / \mathrm{g}$ of $\beta$-glucan extracted (versus $0.27 \mathrm{kWh} / \mathrm{g}$ de $\beta$-glucan extracted in the stirred tank process). This result, in addition to the dramatic reduction of the extraction times, lets a real intensification of the $\beta$-glucan extraction process. 
- Although in the batch PHW process it was possible to extract high MW $\beta$-glucan without the need of a pretreatment step, this process was unfavorable from an energetic point of view $(6.0 \mathrm{kWh} / \mathrm{g}$ of $\beta$-glucan were required). The reason for this result must be found in the high solvent to solid ratio used in the extraction (50 to 1). Therefore, the optimization of the solvent to solid ratio is essential to improve the energetic efficiency of this extraction process. 


\section{RESUMEN}

Estudios para la intensificación del proceso de producción de $\beta$ -

glucanos de alto peso molecular a partir de cereal 



\section{INTRODUCCIÓN}

En los últimos años se ha producido un creciente interés por el control de enfermedades tales como la obesidad, la diabetes y el colesterol a través de la ingesta de ingredientes funcionales de origen natural como la fibra soluble o fibra dietética. Este tipo de productos naturales que reclaman tener efectos beneficiosos sobre la salud humana reciben el nombre de nutracéuticos. De entre los diversos tipos de fibra soluble existente uno de los más estudiados ha sido el $\beta$-glucano: de forma general el $\beta$-glucano es un biopolisacárido en el que las moléculas de glucosa (anómero $\beta$ ) se unen mediante enlaces O-glucosídicos. Los $\beta$-glucanos pueden encontrarse en diferentes cereales, hongos o levaduras siendo parte de las paredes celulares y ejerciendo una labor estructural o de reserva energética. En función de cuál sea su origen, el $\beta$-glucano presenta diferencias estructurales que condicionan sus características y sus propiedades nutracéuticas.

El $(1 \rightarrow 3),(1 \rightarrow 4)-\beta$-D-glucano, conocido como mixed-linkage $\beta$-glucan, es uno de los $\beta$ glucanos que más interés ha despertado y que ha dado lugar a mayor número de trabajos de investigación en los últimos años. Este $\beta$-glucano posee, entre otras propiedades, solubilidad en agua debido a su particular estructura formada por bloques de 2 ó 3 unidades de glucosa unidas mediante enlaces $(1 \rightarrow 4)$-O-glucosídicos separados por un único enlace $(1 \rightarrow 3)$-Oglucosídico. La presencia de este enlace $1 \rightarrow 3$ hace que la linealidad de la cadena se vea alterada y que por tanto la solubilidad en agua se vea favorecida. La estructura del $(1 \rightarrow 3),(1 \rightarrow 4)-\beta$-D-glucano se muestra en la figura 1. En función de su peso molecular y de su concentración el $\beta$-glucano produce soluciones de elevada viscosidad, relacionadas con los efectos positivos que se le atribuyen: la reducción de los niveles de colesterol y glucosa en sangre son los efectos reconocidos en sendos claims emitidos por la EFSA (European Food Safety Authority) y la FDA (Federal Drug Administration) en los que se recoge la cantidad de $\beta$ glucano que es necesario ingerir por día para la consecución de estos efectos positivos ( $3 \mathrm{~g} / \mathrm{d})$.

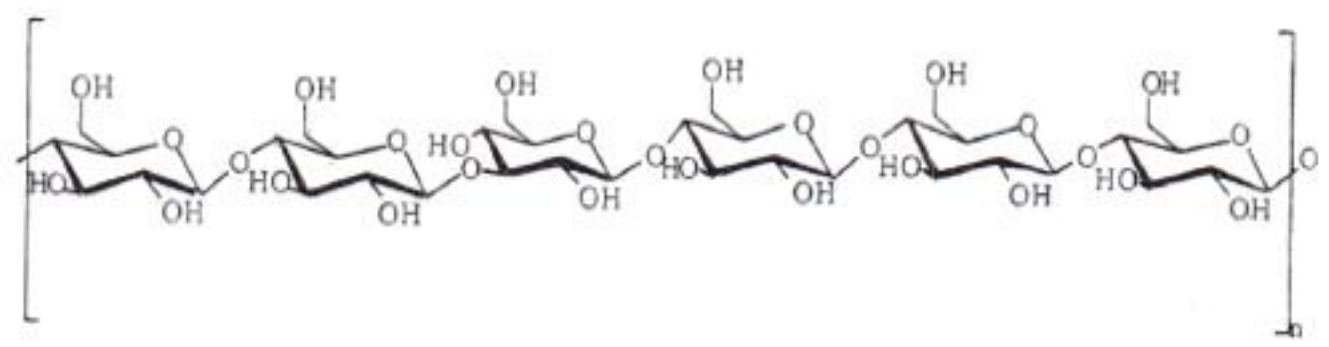

Figura 1. Estructura del $(1 \rightarrow 3),(1 \rightarrow 4)-\beta$-D-glucano 
El $(1 \rightarrow 3),(1 \rightarrow 4)-\beta$-D-glucano se encuentra en cereales, concretamente en la subaleurona y las paredes del endospermo de los granos de cebada, avena, centeno o trigo. El contenido en $\beta$ glucanos depende de la variedad de cereal: en cebadas se encuentra entre un $2-11 \%$ en función de su perfil genético, en avenas el contenido puede estar entre el 3 y $7 \%$, mientras que en centeno y trigo su presencia puede considerarse residual (por debajo del $2 \%$ ). De entre todos los cereales fuente potencial de $\beta$-glucanos es de especial interés la cebada. En paralelo con el interés suscitado por el $(1 \rightarrow 3),(1 \rightarrow 4)-\beta$-D-glucano se ha producido un significativo incremento del desarrollo de nuevas variedades de cebada modificadas genéticamente. Estas variedades, conocidas como cerosas, presentan un contenido en $\beta$-glucanos superior al de las cebadas convencionales (situado entre el 2-3\%) a la vez que un menor contenido en almidón. La presencia en la cebada del $\beta$-glucano en mayores concentraciones así como la presencia de otros compuestos de alto valor añadido como los antioxidantes, refuerzan el atractivo de la cebada como fuente de productos nutracéuticos frente a usos convencionales en cervecería o alimentación animal.

De forma general los procesos para la obtención de $\beta$-glucanos a partir de cereales (cebada y avena, principalmente) son complejos, dado que implican un gran número de etapas; si bien pueden resumirse en tres:

1. Pretratamientos. El objetivo de esta etapa es acondicionar la materia prima para el proceso de extracción. Se puede, a su vez, dividir en dos etapas diferentes en función de cuál sea su objetivo:

- Molienda y selección de fracciones: se trata de reducir el tamaño de partícula del grano de cereal usado como fuente de $\beta$-glucanos. La molienda se puede llevar a cabo en un molino de cuchillas sin separación de fracciones de molienda. En función del tiempo de molienda se controlará el tamaño de partícula finalmente alcanzado en la harina de cebada. Si por el contrario se emplea un molino que permita el fraccionamiento del grano de cereal puede llegarse a diferentes fracciones de molienda, de modo que cada una recoja una parte del grano de cereal. En consecuencia cada fracción tendrá una composición y tamaño de partícula propios.

- Si el objetivo es el incremento del peso molecular del $\beta$-glucano extraído es necesario realizar un tratamiento a la materia prima que permita la 
desactivación de las $\beta$-glucanasas, enzimas endógenos responsables de la despolimerización de los $\beta$-glucanos, y en consecuencia de la pérdida de su peso molecular.

2. Extracción. La selección del disolvente así como las condiciones de operación han de realizarse de tal manera que la selectividad y el rendimiento de la extracción del $\beta$ glucano se vean maximizados. Un correcto estudio de las diferentes variables de operación y una adecuada selección de las condiciones de operación conseguirán estos objetivos y permitirán simplificar la posterior etapa de purificación.

3. Purificación y recuperación del $\beta$-glucano extraído. Durante la etapa de extracción, además de extraerse el $\beta$-glucano de la materia prima, es inevitable que se coextraigan otras especies como almidón y proteínas. En esta etapa se han de eliminar estas moléculas mediante procesos que no afecten al $\beta$-glucano. Por último, una vez purificado el $\beta$-glucano es necesario concentrarlo (es decir, formar un producto sólido rico en $\beta$-glucanos). Para ello puede realizarse procesos como la liofilización o secado en spray, procesos de eliminación del disolvente. Alternativamente puede emplearse un antisolvente, de modo que el $\beta$-glucano precipite: el antisolvente ha de tener la propiedad de ser completamente miscible con el disolvente de la disolución y en él ha de ser completamente insoluble el $\beta$-glucano. El empleo de un antisolvente (alcoholes, por ejemplo) hace que se forme un precipitado rico en $\beta$-glucanos, que una vez separado de la disolución y secado puede ser empleado como aditivo.

Para que los $\beta$-glucanos puedan ser empleados en formulaciones mediante las que puedan desarrollar todo sus potenciales beneficios para la salud es necesario disponer de procedimientos que permitan extraerlos de la materia prima donde se encuentran en bajas concentraciones de forma eficaz. Por ello este trabajo se ha centrado en el desarrollo de procesos de obtención de $\beta$-glucanos a partir de diferentes fuentes, siendo cebada la principal materia prima utilizada. Castilla y León es el mayor productor de este cereal en España (2.1 millones de toneladas en 2012); la presencia de compuestos de alto valor añadido en la cebada y la disposición de procedimientos para su recuperación hace que el interés en el cultivo de la cebada sea mayor frente a los usos tradicionales. Por ello en este trabajo se han estudiado y desarrollado métodos para la extracción de $\beta$-glucanos a partir de cebadas cerosas desarrolladas en Castilla y León. Estas cebadas cerosas han sido desarrolladas por el Instituto Tecnológico Agrario de Castilla y León (ITACYL) y empleadas dentro del contexto del proyecto de investigación "Desarrollo de un procedimiento técnicamente eficaz de obtención de $\beta$ - 
glucanos a partir de cebada" suscrito entre el propio ITACYL y el Grupo de Investigación de Procesos de Alta Presión de la Universidad de Valladolid. 


\section{Objetivos}

El objetivo de esta tesis doctoral es realizar los estudios necesarios para desarrollar un proceso eficaz de producción extractos concentrados en $\beta$-glucanos de peso molecular controlado a partir de cebada. Se pretende obtener concentrados de glucanos de alto peso molecular para cumplir con los requerimientos de su utilización como aditivo alimentario o de bajo peso molecular para su posible utilización en formulación de compuestos activos. Para cumplir este objetivo se han planteado los siguientes objetivos parciales:

- Selección de la materia prima.

- Desarrollo de procesos que permitan obtener diferentes fracciones de molienda con tamaños de partícula y composiciones diferentes

- Desarrollo de procesos que permitan obtener $\beta$-glucanos de diferentes peso molecular en función de su aplicación final

- Desarrollo de procesos de extracción eficientes para la obtención de $\beta$-glucanos, evaluados en términos de rendimiento de extracción, peso molecular del $\beta$-glucano extraído y energía específica consumida en el proceso:

- Estudio de las variables de operación (temperatura, $\mathrm{pH}$, tamaño de partícula, velocidad de agitación, tiempo de extracción, relación soluto:disolvente) en un proceso de extracción convencional (tanque agitado) y propuesta de condiciones que maximicen el rendimiento. Evaluación del efecto de las condiciones óptimas propuestas en el peso molecular.

- Desarrollo de procesos de extracción que mejoren la transferencia de materia y permitan la intensificación del proceso de extracción de $\beta$-glucanos:

- Extracción mediante el empleo de ultrasonidos (ultrasound assisted extraction). Estudio de las condiciones de operación y su efecto sobre el peso molecular y rendimiento de operación en función de la energía específica empleada en el proceso de extracción.

- Extracción mediante el empleo de agua caliente presurizada en un proceso discontinuo como en un proceso de flujo (lecho fijo).

- Estudio de la etapa de purificación y aislamiento del $\beta$-glucano extraído: 
- Estudio de la eliminación del almidón co-extraído mediante el empleo de enzimas amilasas. Estudio del efecto de la temperatura, tiempo de incubación y dosis del enzima en la eliminación de almidón y en el peso molecular del $\beta$ glucano.

- Estudio de alternativas a la etapa de purificación que supongan una intensificación de la misma

- Separación de los productos de hidrólisis del almidón del $\beta$-glucano de alto peso molecular mediante el empleo de un proceso de membranas (ultrafiltración - diafiltración)

- Concentración del $\beta$-glucano purificado mediante el empleo de antisolventes o secado en spray. 


\section{Resultados y Discusión}

El proceso de extracción de $\beta$-glucanos desarrollado en esta tesis doctoral se inició con la selección de la materia prima. La cebada empleada fue desarrollada y proporcionada por el Instituto Tecnológico Agrario de Castilla y León (ITACYL; Valladolid, España). Se dispuso de dos variedades de cebada cerosa correspondientes cosechas del año 2006; una de ellas es conocida como H13 (registrada con el nombre comercial GALIS) y con grano desnudo al no presentar el grano cubierta externa o cascarilla. La otra variedad de cebada empleados, denominada D24 y registrada con el nombre comercial de FIALI, es una cebada "vestida" al presentar cubierta externa adicional. La composición de las cebadas empleadas está recogida en la tabla 1:

Tabla 1. Composición de las variedades de cebada utilizadas en la presente tesis doctoral

\begin{tabular}{|l|c|c|}
\cline { 2 - 3 } \multicolumn{1}{c|}{} & H13 - FIALIS & D24 - GALIS \\
\hline Grasas (\%) & $2.54 \pm 0.16$ & $2.79 \pm 0.18$ \\
Cenizas (\%) & $2.00 \pm 0.13$ & $2.09 \pm 0.11$ \\
Proteínas (\%) & $17.8 \pm 0.4$ & $18.2 \pm 0.2$ \\
Almidón (\%) & $58.5 \pm 3.6$ & $50.3 \pm 3.2$ \\
Amilosa/Amilopectina (\%) & $10.2 / 89,7 \pm 1.9$ & $9.1 / 90,9 \pm 2.0$ \\
$\beta$-glucanos (\%) & $4.64 \pm 0.18$ & $6.02 \pm 0.37$ \\
Fibra dietética (\%) & $15.6 \pm 0.8$ & $21.0 \pm 0.7$ \\
\hline
\end{tabular}

Dada la importancia de la molienda y su empleo como pretratamiento, se realizó la molienda de la cebada en un molino de rodillos Chopin CD1 situado en el Centro Tecnológico de Cereales (CETECE; Palencia, España). La composición, el rendimiento y el tamaño de partícula medio de cada una de estas fracciones de molienda obtenidas se recogen en la tabla 2.

Tabla 2. Composición y rendimiento de las fracciones de molienda utilizadas hasta el momento

\begin{tabular}{|c|l|c|c|cccc|}
\hline Cebada & \multicolumn{1}{|c|}{ Fracción } & $\begin{array}{c}\text { Rendimiento } \\
\mathbf{( \% )}\end{array}$ & $\begin{array}{c}\text { Tamaño } \\
\text { Partícula } \\
(\mu \mathrm{m})\end{array}$ & $\begin{array}{c}\boldsymbol{\beta} \text {-glucanos } \\
(\mathbf{\%})\end{array}$ & $\begin{array}{c}\text { Almidón } \\
\mathbf{( \% )}\end{array}$ & $\begin{array}{c}\text { Proteínas } \\
(\mathbf{\%})\end{array}$ & $\begin{array}{c}\text { Fibra } \\
(\mathbf{g} / \mathbf{1 0 0 g})\end{array}$ \\
\hline \multirow{2}{*}{ H13 } & Salvados Gruesos & $54.4 \pm 0.9$ & $976.2 \pm 15.3$ & $5.3 \pm 0.3$ & $40.6 \pm 2.3$ & $13.9 \pm 0.5$ & $29.0 \pm 1.2$ \\
(FIALIS) & Salvados Finos & $19.8 \pm 0.5$ & $315.7 \pm 5.3$ & $8.1 \pm 0.2$ & $38.0 \pm 3.4$ & $18.7 \pm 0.4$ & $27.8 \pm 1.5$ \\
& Harina & $25.8 \pm 0.6$ & $27.2 \pm 1.2$ & $2.6 \pm 0.6$ & $65.7 \pm 3.2$ & $14.3 \pm 0.6$ & $6.9 \pm 0.4$ \\
\hline \multirow{2}{*}{ D24 } & Salvados Gruesos & $46.2 \pm 1.2$ & $984.8 \pm 12.9$ & $4.8 \pm 0.4$ & $46.8 \pm 1.5$ & $15.6 \pm 0.3$ & $18.2 \pm 1.7$ \\
(GALIS) & Salvados Finos & $22.4 \pm 0.4$ & $345.9 \pm 6.8$ & $6.8 \pm 0.6$ & $40.6 \pm 2.6$ & $17.7 \pm 0.6$ & $22.9 \pm 1.9$ \\
& Harina & $31.5 \pm 0.8$ & $37.4 \pm 1.3$ & $1.99 \pm 0.2$ & $66.9 \pm 2.7$ & $11.4 \pm 0.6$ & $4.3 \pm 0.5$ \\
\hline
\end{tabular}

Se obtuvieron diferentes fracciones de molienda a partir de las cuales extraer los $\beta$-glucanos. El fraccionamiento de la cebada proporcionó fracciones de molienda con composición y tamaño de partícula diferente que han sido empleadas con posterioridad durante el desarrollo de la tesis. 


\section{CAPÍTULO 1.}

Optimización de las condiciones de extracción de $\beta$-glucanos a partiR de diferentes VARIedades de cebada Cerosa en tanque Agitado (Proceso Convencional)

En este capítulo se realizó una revisión bibliográfica de los procesos de extracción de $\beta$ glucanos a partir de cereales. Se encontró una cantidad significativa de trabajos cuyo objetivo era la extracción de $\beta$-glucanos; sin embargo en ninguno de ellos se abordaba de manera sistemática el efecto que varias variables de operación tienen sobre la extracción de $\beta$ glucanos en tanque agitado, ni las posibles interacciones entre ellas.

De acuerdo con la literatura se identificaron como variables de operación afectando al proceso de extracción: temperatura, $\mathrm{pH}$, tamaño de partícula, velocidad de agitación, tiempo de extracción y relación cebada:disolvente. El disolvente mayoritariamente empleado para realizar la extracción se encontró que era agua, con variaciones de pH.

Los experimentos iniciales, en los que únicamente se estudió el efecto de la temperatura, sirvieron para fijar como temperatura óptima de extracción $55^{\circ} \mathrm{C}$ y para determinar que la modificación del pH no era necesaria, trabajando en valores en torno a 6.0-6.5. Esa temperatura, $55^{\circ} \mathrm{C}$, supuso un compromiso entre la cantidad de $\beta$-glucano extraída y la cantidad de almidón co-extraída. Se evaluaron temperaturas superiores, hasta $75^{\circ} \mathrm{C}$, y se observó un incremento de la cantidad de $\beta$-glucano extraída así como un incremento muy rápido y acusado de la cantidad de almidón co-extraído. $\mathrm{A} 63^{\circ} \mathrm{C}$ se produce la gelatinización del almidón, proceso que da como resultado un incremento de la viscosidad de la suspensión. Este fenómeno de la gelatinización hace que a $55^{\circ} \mathrm{C}$ la cantidad de almidón disuelto sea de $1 \mathrm{~g} / \mathrm{L}$, mientras que a 65 y $75 \circ \mathrm{C}$ sea de $10 \mathrm{~g} / \mathrm{L}$ y $11 \mathrm{~g} / \mathrm{L}$, respectivamente.

El estudio del efecto de las variables de operación se llevó a cabo con las dos variedades de cebada disponibles, fracción única. Se estudió el efecto del tamaño de partícula (100, 250 y $500 \mu \mathrm{m})$, la relación soluto disolvente $(5,8$ y 15), la velocidad de agitación $(200,600$ y 1000rpm) y el tiempo de extracción (1, 3 y 5 horas). Se empleó un diseño experimental (arreglo ortogonal $L_{9}$ de Taguchi), y se concluyó que se necesitaban tamaños de partícula muy pequeños $(<100 \mu \mathrm{m})$, velocidades de agitación muy altas (1000rpm) y tiempos de extracción de 3 horas para maximizar el rendimiento de extracción. Se pudo comprobar que el efecto de la relación soluto:disolvente era muy limitado, con lo que la selección del valor óptimo de esta variable debería realizarse con criterios económicos pensando en la posterior etapa de concentración/purificación. Con todo en las condiciones propuestas como óptimas se obtuvo 
un rendimiento de extracción del $62.3 \pm 1.8 \%$ para la variedad H13 y del $73.4 \pm 1.2 \%$ para la D24, con pesos moleculares de los $\beta$-glucanos extraídos de 45 y $55 \mathrm{kDa}$, respectivamente. El mayor rendimiento de extracción detectado para la cebada D24 así como el mayor peso molecular de los $\beta$-glucanos extraídos hizo que fuera la preferida para los futuros experimentos desarrollados en esta tesis.

La principales conclusiones de este trabajo se centran en las importantes limitaciones a la transferencia de materia que tienen los procesos de extracción de $\beta$-glucanos (transporte externo y difusión interna), el bajo peso molecular que tienen los $\beta$-glucanos extraídos $(<55 \mathrm{kDa})$ y en el almidón como principal co-producto de extracción que será necesario eliminar en la posterior etapa de purificación.

Como continuación de este primer capítulo, para incrementar el peso molecular del $\beta$-glucano, se realizó un pretratamiento a la cebada D24, consistente en su ebullición a reflujo total con etanol $(80 \% \mathrm{v} / \mathrm{v})$ durante dos horas. Se realizó la extracción de esta cebada pretratada en las condiciones propuestas como óptimas en el capítulo 1, y se determinó que el peso molecular del $\beta$-glucano extraído era de $431 \mathrm{kDa}$, pero que el rendimiento de extracción caía hasta el $41.5 \pm 1.0 \%$. La elevada viscosidad de la suspensión impedía una buena agitación, lo cual dificultaba la extracción del $\beta$-glucano. Estos resultados, recogidos en el anexo I, revelaron la necesidad de disponer de un método de extracción alternativo que mejorara la transferencia de materia.

En relación a la eficacia de este tratamiento para la inactivación de las $\beta$-glucanasas, se comprobó la actividad residual de las $\beta$-glucanasas durante los 30 días posteriores a la extracción. Semanalmente se tomaron muestras del extracto líquido obtenido a partir de la cebada D24 pretratada, evaluándose el contenido en $\beta$-glucanos del mismo y su peso molecular. La figura 2 recoge estos resultados: se puede ver una progresiva pérdida de peso molecular del $\beta$-glucano lo que indica que el tratamiento con etanol es efectivo para eliminar de forma parcial la actividad de las $\beta$-glucanasas y que a fin de evitar degradaciones en el $\beta$ glucano es necesario completar las siguientes etapas de purificación y aislamiento de forma inmediatamente posterior a la etapa de extracción. 


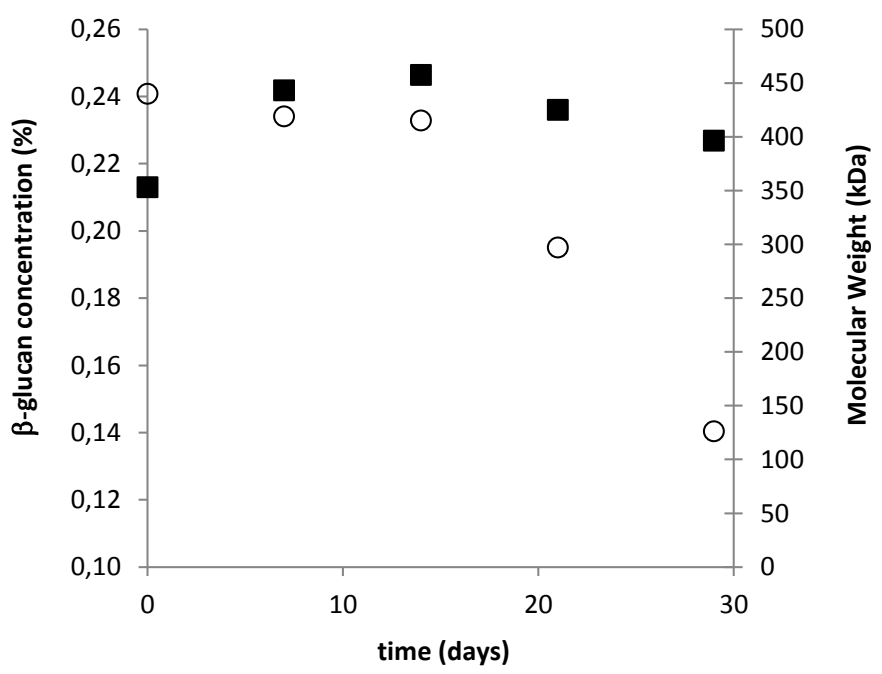

Figura 2. Evaluación de la actividad de la actividad residual de las $\beta$-glucanasas con el tiempo sobre el contenido en $\beta$-glucanos ( $\mathbf{\square})$ y su peso molecular (O)

En el anexo II, continuación de este primer capítulo, se realizaron extracciones a partir de las diferentes fracciones de molienda obtenidas. Se pudo comprobar la importancia de la materia prima en el proceso de extracción, puesto que fracciones de molienda de una misma variedad de cebada dieron lugar a productos enriquecidos en $\beta$-glucanos de composiciones muy diferentes y con pesos moleculares diferentes. La variedad de cebada H13 pretratada con etanol presentó un rendimiento de extracción del $42.7 \pm 1.3 \%$ y $456 \mathrm{kDa}$ de peso molecular. El empleo de fracciones de molienda permitió elevar el peso molecular del $\beta$-glucano recuperado hasta los $728 \mathrm{kDa}$ en el caso del empleo de los salvado gruesos (rendimiento de extracción 41.7\%); mientras que el empleo de los salvados finos permitió incrementar el rendimiento de extracción hasta el 57.5\% (peso molecular 643kDa).

\section{CAPÍtULo 2.}

EXTRACCIÓN DE $\beta$-GLUCANOS ASISTIDA CON ULTRASONIDOS A PARTIR DE CEBADA CEROSA. ESTUDIO DE LAS VARIABLES DE OPERACIÓN.

Los resultados del capítulo 1 indicaron la necesidad de evaluar métodos de extracción alternativos al proceso convencional desarrollado en tanque agitado que permitieran mejorar la transferencia de materia. Como proceso alternativo se propuso la extracción asistida por ultrasonidos. Los objetivos de este capítulo son por una parte la evaluación de la viabilidad del uso de ultrasonidos para extraer $\beta$-glucanos de alto peso molecular a partir de cebada y por otra el estudio del efecto que las condiciones de extracción tienen sobre el rendimiento de extracción y el peso molecular del $\beta$-glucano. Como punto final de este capítulo se propusieron 
unas condiciones de operación que optimizaban la extracción asistida por ultrasonidos de los $\beta$-glucanos.

La extracción se llevó a cabo a $55^{\circ} \mathrm{C}$ empleando un sonicador de 400W (UP400S, Hielscher) con un sonotrodo de $22 \mathrm{~mm}$ fabricado en titanio. Se estudiaron como variables de operación amplitud de oscilación del sonotrodo (60-80-100\%, siendo 100\% una amplitud de oscilación de $100 \mu \mathrm{m})$, el tiempo de operación $(3,10,17$ minutos) y el ciclo $(0.8,0.9$ y 1 ; siendo uno un sonicado continuo y cualquier otro valor inferior a 1 se refiere al sonicado discontinuo o en pulsos). Para realizar la experimentación se realizó un diseño experimental Box-Behnken (15 experimentos en total). En cada experimento se tuvo en cuenta la energía empleada, como producto de la potencia empleada por el equipo de ultrasonidos (función de las condiciones de operación: amplitud, ciclo, temperatura) por el tiempo de operación. Para cada experimento se representó el peso molecular promediado en peso del $\beta$-glucano extraído y el rendimiento de extracción frente a la energía específica consumida (energía por unidad de disolvente empleado). Los resultados se muestran en la figura 3.

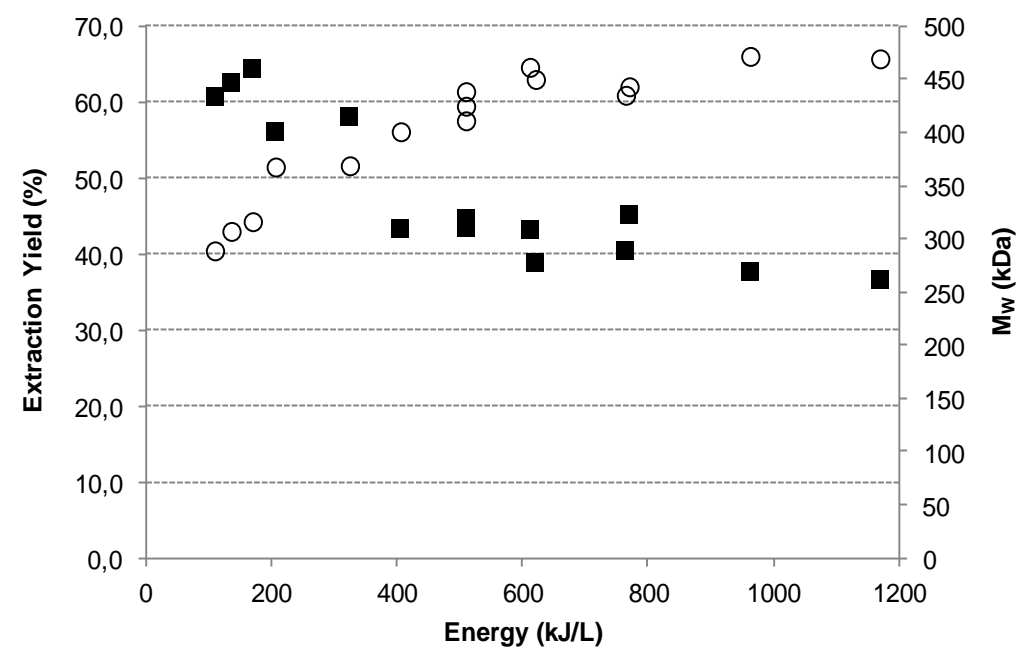

Figura 3. Efecto de la energía consumida en el proceso de extracción con ultrasonidos sobre el rendimiento de extracción $(\mathrm{O})$ y el peso molecular promediado en peso $(\mathbf{\square})$ del $\beta$-glucano extraído

Se pudieron determinar incrementos en el rendimiento de extracción al aumentar la energía empleada, hasta un valor de $600 \mathrm{KJ} / \mathrm{L}$, condiciones a partir de las cuales el incremento de la energía no supuso una mejora en el rendimiento de extracción (66\%). Se observó el comportamiento opuesto para el peso molecular. Incrementos en la energía empleada supusieron descensos en el peso molecular del $\beta$-glucano extraído, lo cual indicó que los ultrasonidos poseen un efecto despolimerizador muy significativo. 
Con todo se determinaron las condiciones que maximizaban el rendimiento de extracción (100\%, 15.9 minutos y ciclo 0.9; energía $1050 \mathrm{~kJ} / \mathrm{L})$, determinándose que el rendimiento de extracción era $65.6 \pm 1.2 \%$ y el peso molecular $261.4 \pm 7.3 \mathrm{kDa}$. Las condiciones que maximizaron peso molecular fueron: $60 \%$, tiempo 3 minutos y ciclo 0.8, empleándose una energía de 97kJ/L. En estas condiciones se llegó a un rendimiento de extracción del $37.3 \pm 0.7 \%$ y peso molecular de $483.3 \pm 3.2 \mathrm{kDa}$. Por último se consideró una situación de compromiso para maximizar ambos, rendimiento y peso molecular. Las condiciones requeridas fueron: amplitud 80\%; 7.6 minutos y ciclo 0.8 , llegándose a un rendimiento de extracción del $52.4 \pm 0.9 \%$ y un peso molecular de $388.6 \pm 4.6 \mathrm{kDa}$, siendo el consumo energético de $344 \mathrm{~kJ} / \mathrm{L}$.

Se pudo concluir en este trabajo que los ultrasonidos son un método adecuado para extraer $\beta$ glucanos frente al proceso convencional $\left(55^{\circ} \mathrm{C}\right.$, 3horas, $\left.1000 \mathrm{rpm}\right)$, dado que se consigue un rendimiento de extracción superior al del proceso convencional manteniéndose el peso molecular pero con unos tiempos de operación muy inferiores (de 3 a 10 minutos frente a 3 horas) y con una reducción significativa en el consumo energético $(500 \mathrm{~kJ} / \mathrm{L}$ frente a $1460 \mathrm{~kJ} / \mathrm{L}$ del proceso convencional). Estos resultados permitieron una intensificación eficaz del proceso de extracción de $\beta$-glucanos.

\section{CAPítulos 3-4-5.}

EMPLEO de AGUA CALIENTE PRESURIZADA COMO DISOLVENTE PARA LA EXTRACCIÓN DE $\beta$-gLUCANOS A PARTIR DE CEREALES

El agua caliente presurizada (PHW, en sus siglas en inglés), es agua a más de $100^{\circ} \mathrm{C}$ que se somete a presión para mantenerla en estado líquido. El PHW presenta mejoras en las propiedades de transporte (viscosidad, difusividad y tensión superficial) frente al agua a baja temperatura y presión atmosférica; además de otras propiedades como el debilitamiento de los puentes de hidrógeno entre el $\beta$-glucano y la matriz donde está atrapado. Estas propiedades pueden ser beneficiosas para extraer $\beta$-glucanos de la matriz de cebada donde se encuentran atrapados. La evaluación del uso de PHW para la extracción de $\beta$-glucanos se realizó en tres etapas:

1. Estudio de la disolución de un concentrado de $\beta$-glucanos de alto peso molecular en agua caliente presurizada. Estudio del efecto de PHW en el peso molecular y en los productos de hidrólisis (capítulo 3)

2. Estudio de la extracción de $\beta$-glucanos a partir de cebada en PHW en un proceso batch. Estudio y optimización de las condiciones de extracción (capítulo 4) 
3. Estudio de la extracción de $\beta$-glucanos mediante PHW en un proceso de flujo: extracción en lecho fijo (capítulo 5)

\section{CAPÍTULO 3. ESTUdIOS DEL EFECTO DE LA PRESIÓN Y LA TEMPERATURA EN LA DISOLUCIÓN DE $\beta$-GLUCANOS EN} AGUA CALIENTE PRESURIZADA

El objetivo de este capítulo es el estudio del fenómeno de disolución del $\beta$-glucano y almidón en agua caliente presurizada (temperaturas entre 120 y $170^{\circ} \mathrm{C}$, tiempos entre 10 minutos y 6 horas a una presión de 20bar). Se dispuso de un extracto sólido obtenido en el laboratorio con un contenido del $36.5 \%$ en $\beta$-glucanos (peso molecular $450 \mathrm{kDa}$ ) y del $25.4 \%$ en almidón. Los resultados obtenidos indicaron que el $\beta$-glucano se disolvía tanto más rápido cuanto más alta era la temperatura; si bien se observó que a cada temperatura le correspondía una cantidad máxima disuelta de $\beta$-glucano conseguida tras un tiempo de operación determinado. La máxima cantidad disuelta se detectó a $150^{\circ} \mathrm{C}$ tras 45 minutos de operación $(2.1 \mathrm{~g} / \mathrm{L})$.

Para cada temperatura estudiada tiempos de operación superiores al óptimo provocaron que la concentración de $\beta$-glucano disminuyera. La evaluación de la evolución de la concentración del $\beta$-glucano se realizó frente al factor de severidad; número adimensional que evalúa el efecto simultáneo que tienen la temperatura y el tiempo de operación, de acuerdo con la ecuación (1):

$$
R_{O}=t \cdot \exp \left(\frac{T-100}{14.75}\right)
$$

La representación de la concentración de $\beta$-glucanos alcanzada en cada una de las condiciones experimentales empleadas frente al logaritmo del factor de severidad puede verse en la figura 4, de la cual puede extraerse que la concentración de $\beta$-glucanos pasa por un máximo a partir del cual un incremento de la intensidad de las condiciones de operación produce un descenso en la concentración de la mismo. 


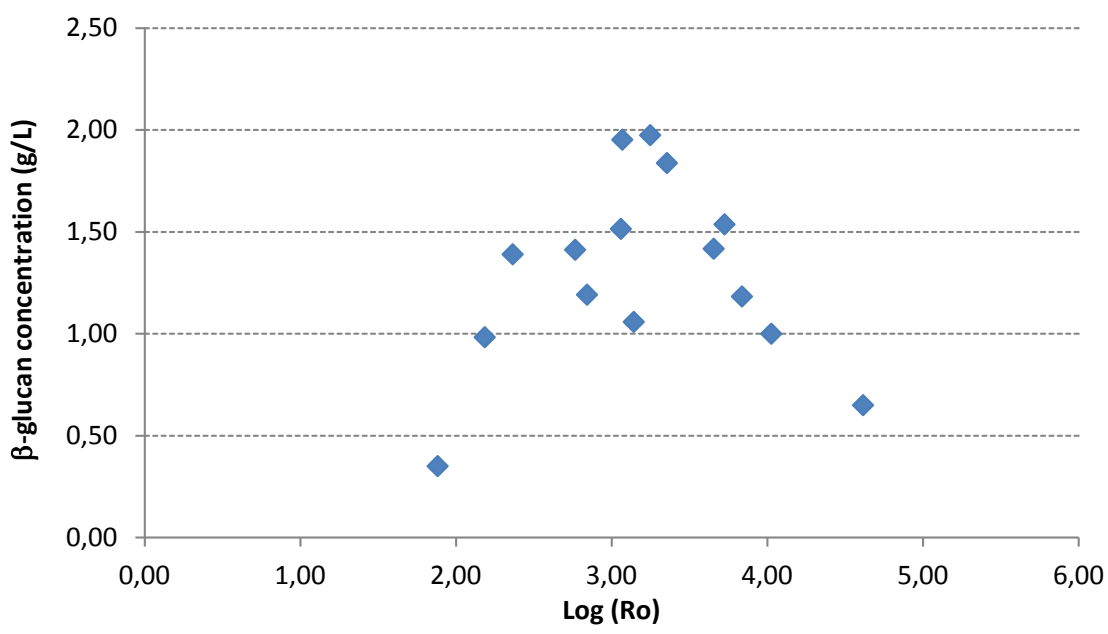

Figura 4. Concentración de $\beta$-glucano alcanzada frente al logaritmo del factor de severidad

Se concluyó que el $\beta$-glucano una vez disuelto comienza a degradarse (hidrólisis), dado que se produce un descenso de peso molecular $\left(63 \mathrm{kDa}\right.$ a $120^{\circ} \mathrm{C}$ tras 75 minutos; $8 \mathrm{kDa}$ a $155^{\circ} \mathrm{C}$ tras 45 minutos y $7 \mathrm{kDa}$ a $170^{\circ} \mathrm{C}$ tras 20 minutos) con respecto a los $450 \mathrm{kDa}$ iniciales. También se comprobó esta degradación con el análisis de los productos de hidrólisis del $\beta$-glucano: celobiosa, glucosa, fructosa y 5-hidroximetilfurfural (HMF).

Con respecto al almidón, se observó un descenso de la concentración en los experimentos a 155 y $170^{\circ} \mathrm{C}$ desde tiempos de operación muy cortos.

En este capítulo pudo concluirse que los $\beta$-glucanos son solubles en agua caliente presurizada, pero que debe realizarse una cuidadosa selección de las condiciones de operación (tiempo y temperatura) dado que unas condiciones demasiado intensas llevan a la hidrólisis del $\beta$ glucano una vez disuelto, como lo prueba el descenso del peso molecular, el descenso en la concentración de $\beta$-glucanos y la aparición de los productos últimos de degradación de las hexosas, como el HMF responsable de dar color marrón a la disolución:

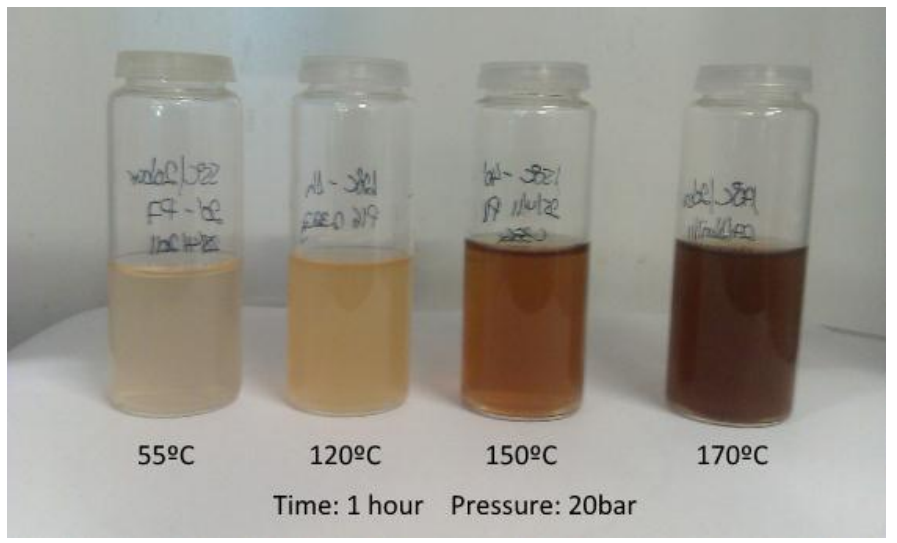

Figure 5. Efecto de la temperatura en el color del extracto líquido 
Los resultados obtenidos en este capítulo se emplearon como base del capítulo 4, en el que se realizó la extracción de $\beta$-glucanos a partir de cebada usando agua caliente presurizada como disolvente.

Capítulo 4. extracción de $\beta$-glucanos en agua caliente presurizada a partir de Cebada cerosa. PROCESO BATCH.

El objetivo de este capítulo es el estudio del efecto de las variables de operación (tiempo, temperatura y presión) en el rendimiento de extracción y el peso molecular del $\beta$-glucano extraído a partir de cebada D24 (fracción única sin pretratar con etanol) usando agua caliente presurizada como disolvente. Se varió el tiempo de extracción entre 15 y 75 minutos y la temperatura de operación entre 135 y $180^{\circ} \mathrm{C}$ a 20bar de presión. En las figuras 6 y 7 se recoge el rendimiento de extracción y el peso molecular obtenidos en cada experimento frente a las condiciones de operación:

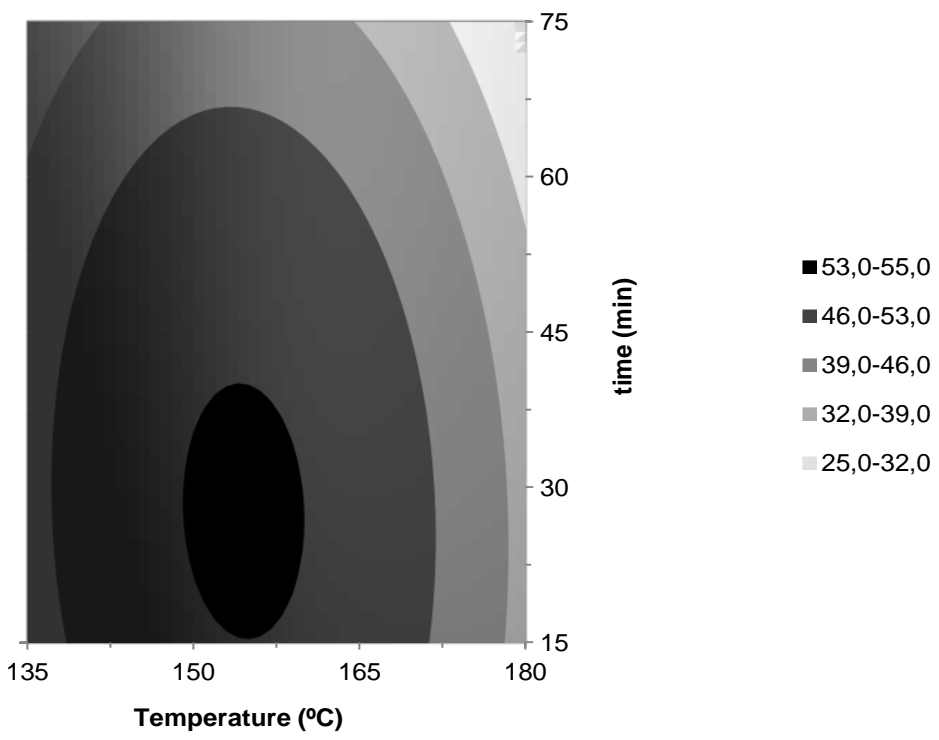

Figure 6. Diagrama de contorno para el efecto de la temperatura y el tiempo en el rendimiento de extracción de $\beta$-glucanos a 20bar. 


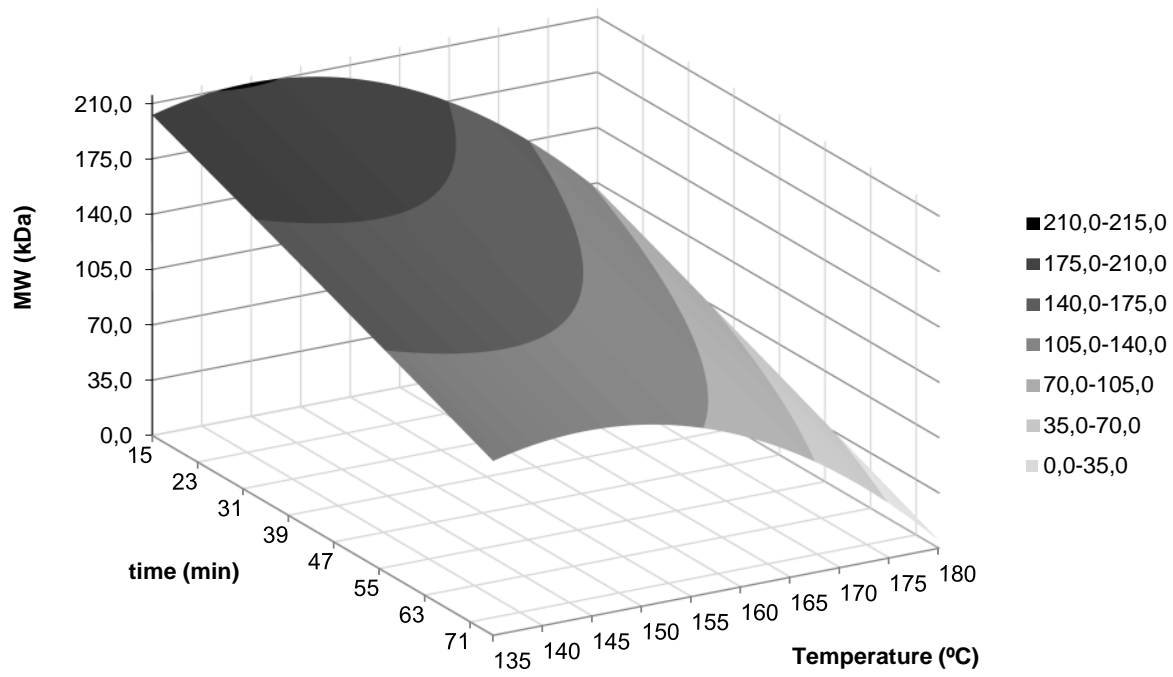

Figura 7. Diagrama de superficie para el peso molecular en función de las condiciones de extracción

La representación del rendimiento de extracción frente al factor de severidad mostró una máximo correspondiente a las condiciones $\left(157.5^{\circ} \mathrm{C}, 45 \mathrm{~min}\right.$; logaritmo del factor de severidad 3.5); valor a partir del cual comienza a descender el rendimiento de extracción. Esto supuso establecer un límite práctico para la extracción de $\beta$-glucanos en PHW: $155-160^{\circ} \mathrm{C}$ y 45 minutos. Por encima de estas condiciones de operación se produce un descenso en el rendimiento de extracción y la aparición de productos de degradación como el HMF, además del descenso del MW del $\beta$-glucano extraído. La pérdida de peso molecular y la aparición de productos de degradación como el HMF revelaron que el $\beta$-glucano que se había disuelto se estaba hidrolizando.

El estudio del incremento de la presión durante la extracción entre 20 y 250 bar se llevó a cabo a $157.5^{\circ} \mathrm{C}$ y 45 minutos de operación. Se observó un incremento del peso molecular con la presión, y un descenso del rendimiento de extracción a presiones superiores a 80bar.

La parte final de este capítulo sirvió para proponer unas condiciones de operación óptimas que maximizaran el rendimiento de extracción y el peso molecular: $155^{\circ} \mathrm{C}, 18$ minutos y $50 \mathrm{bar}$. El rendimiento de extracción alcanzado fue de $53.7 \%$ y un peso molecular de $200 \mathrm{kDa}$, mientras que productos de degradación como el HMF no se detectaron en estas condiciones.

El empleo de PHW como disolvente permitió obtener $\beta$-glucanos de alto peso molecular sin necesidad de pretratar la cebada para inactivar las $\beta$-glucanasas. Además se consiguió extraer $\beta$-glucanos tras un tiempo de operación muy corto (18 minutos frente a 3 horas del proceso convencional), con lo que el empleo de PHW también contribuye a realizar la intensificación del proceso de extracción de $\beta$-glucanos a partir de cebada. 


\section{Capítulo 5. extracción de $\beta$-glucanos de cereales en lecho fijo mediante agua caliente presurizada. (Proceso Semi-Continuo)}

El objetivo de este capítulo es realizar la extracción de $\beta$-glucanos mediante el empleo de agua caliente presurizada (PHW) en un proceso semi-continuo: extracción en lecho fijo. Los procesos de extracción en lecho fijo presentan la ventaja de que una vez disuelto el $\beta$-glucano abandona el extractor, con lo que su permanencia en las condiciones de extracción $\left(155^{\circ} \mathrm{C} \mathrm{y}\right.$ 20bar) es limitada y por tanto su degradación también está limitada. Se dispuso de cebada D24 para hacer la extracción en un reactor de lecho fijo de $50 \mathrm{~mL}$ de volumen situado en el Institute of Thermal Separation Processes de la Universidad Técnica de Hamburgo-Harburg (TUHHAlemania).

Los ensayos iniciales revelaron importantes problemas de flujo cuando la cebada se encuentra con un tamaño de partícula muy fino $(<500 \mu \mathrm{m})$, dado que con el elevado contenido en almidón y las altas temperaturas hacen que se produzca la gelatinización del mismo, con el consiguiente incremento de viscosidad e impedimentos al flujo. Una molienda a mayor tamaño de partícula (tamaño promedio $1 \mathrm{~mm}$ ) permitió el flujo a través del lecho y por tanto la extracción de $\beta$-glucanos, obteniéndose los resultados más favorables a $155^{\circ} \mathrm{C}, 20 \mathrm{bar}, 4 \mathrm{~g} / \mathrm{min}$ de agua y un tiempo máximo de operación de 105 minutos. Las condiciones de temperatura fueron las determinadas en el capítulo 4 de esta tesis. El empleo del lecho fijo para realizar la extracción permitió extraer $\beta$-glucanos (rendimiento situado entre el $45-50 \%$ ) de alto peso molecular; si bien el peso molecular del $\beta$-glucano extraído durante la extracción fue variando así como la cantidad del mismo extraída en cada momento de la experimentación tal y como se recoge en la figura 8. No se encontraron productos de degradación de los $\beta$-glucanos como el HMF, lo que unido al alto peso molecular detectado permite concluir que el lecho fijo permite extraer y preservar el alto peso molecular del $\beta$-glucan, permitiendo un fraccionamiento del mismo. Experimentos realizados a presiones superiores no supusieron un incremento del rendimiento de extracción, tal y como se recoge en el capítulo 4. 


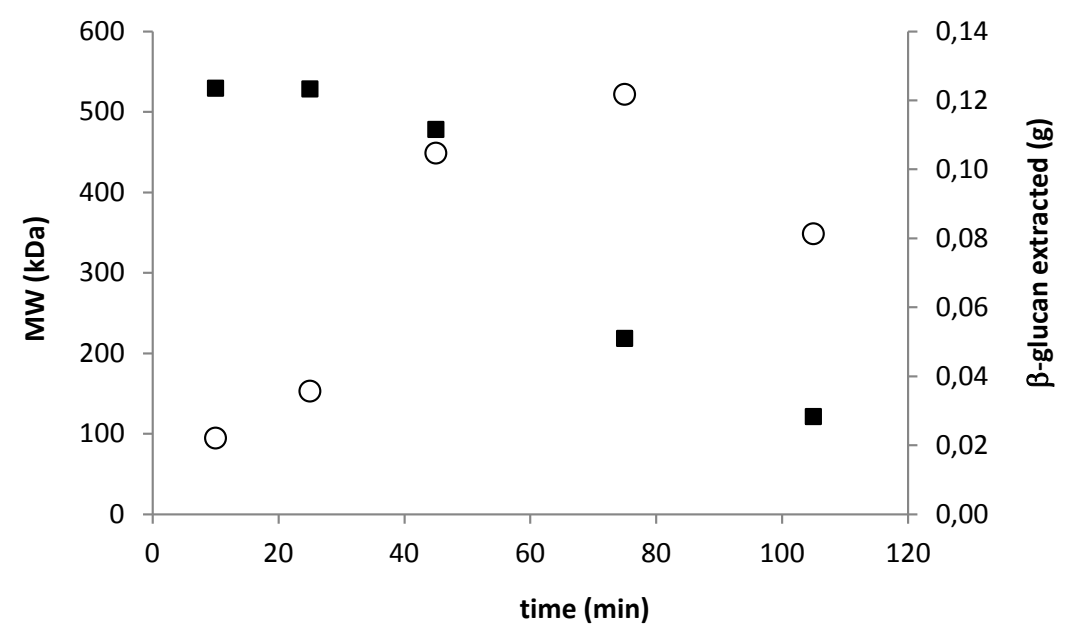

Figura 8. Evolución de la cantidad (O) y peso molecular ( $\mathbf{\square}$ ) de $\beta$-glucano en función del tiempo en un proceso de extracción en lecho fijo $\left(155^{\circ} \mathrm{C}, 20 \mathrm{bar}, 4 \mathrm{~g} \cdot \mathrm{min}^{-1}\right)$

En el proceso de extracción en lecho fijo también se emplearon otras materias primas, como el salvado de trigo ( $1.6 \%$ de $\beta$-glucanos). Se realizó un estudio de extracción a diferentes temperaturas entre 110 y $175^{\circ} \mathrm{C}$ a $20 \mathrm{bar}$ y con un flujo de $4 \mathrm{~g} \cdot \mathrm{min}^{-1}$, concluyéndose que la óptima era $155^{\circ} \mathrm{C}$, observándose un comportamiento similar al observado para la cebada. En estos experimentos se siguió el pH durante la extracción, viéndose que era más ácido a medida que la temperatura de extracción subía y a medida que la extracción se prolongaba en el tiempo. En las condiciones óptimas de extracción $\left(155^{\circ} \mathrm{C}\right)$ se obtuvo un rendimiento de extracción de $87.3 \pm 0.9 \%$ y un peso molecular promedio de $373 \mathrm{kDa}$. El análisis de los productos de hidrólisis (celobiosa, glucosa, fructosa, arabinosa, xilosa, HMF) reveló su presencia en los procesos de extracción más intensos. La figura 9 recoge las curvas de extracción de $\beta$-glucano obtenidas a partir de salvado de trigo a $155^{\circ} \mathrm{C}, 20$ bar durante 150 minutos a tres flujos de operación diferentes, encontrándose que no hay efecto del flujo y por tanto el transporte externo no es limitante. 


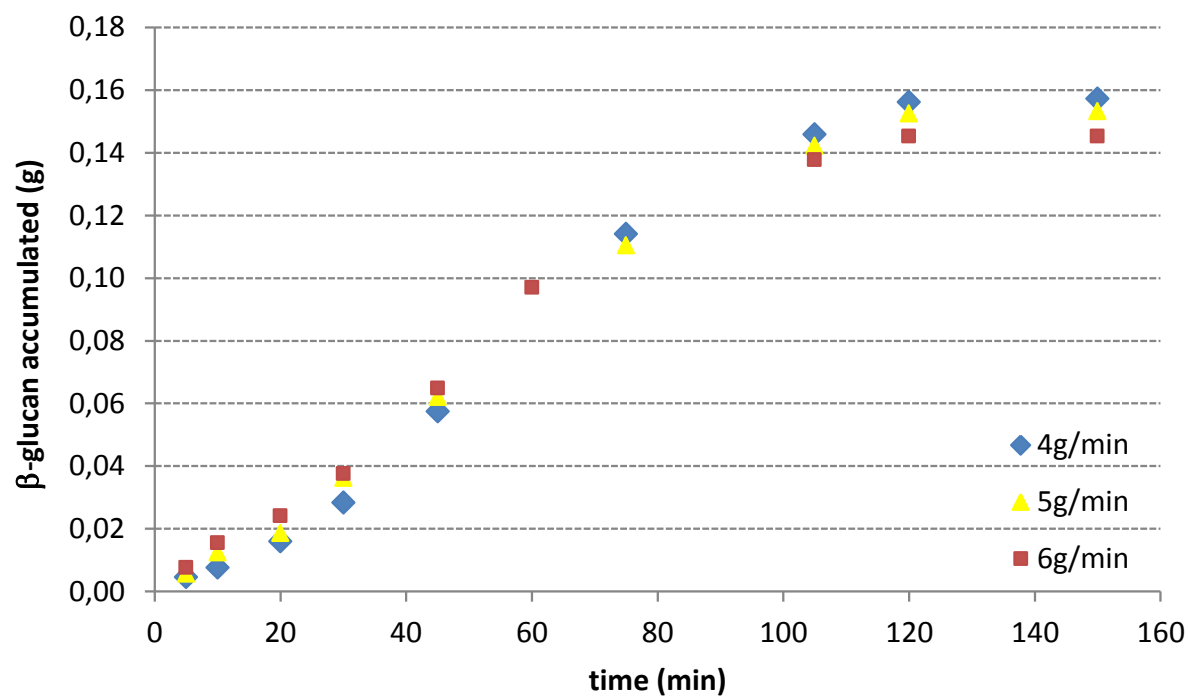

Figura 9. Curvas de extracción de $\beta$-glucanos a partir de salvado de trigo en función del flujo de operación a $155^{\circ} \mathrm{C}$ y 20 bar de presión

El empleo de cebada a la que previamente se le ha eliminado el almidón mediante un tratamiento enzimático ( $\alpha$-amilasa, $85^{\circ} \mathrm{C}$, 4 horas en buffer de fosfato $\mathrm{pH}$ 6.5) permitió obtener un rendimiento de extracción de $35.5 \pm 1.2 \%$ y un peso molecular promedio de $247 \mathrm{kDa}$, en las condiciones de extracción descritas como óptimas $\left(155^{\circ} \mathrm{C}, 4 \mathrm{~g} \cdot \mathrm{min}^{-1}, 20 \mathrm{bar}\right)$.

En este capítulo se pudo concluir que los $\beta$-glucanos pueden ser extraídos de forma satisfactoria de diferentes cereales (cebada, salvado de trigo y cebada desalmidonada), preservándose el peso molecular y evitándose la degradación de los mismos.

\section{CAPítulo 6.}

ESTUdios de INTENSIFICACIÓN DE LA ETAPA DE PURIFICACIÓN Y CONCENTRACIÓN DE $\beta$-gLUCANOS EXTRAÍDOS DE CEBADA

El objetivo de este capítulo es el estudio de la purificación y recuperación del $\beta$-glucano. La extracción con ultrasonidos realizada a partir de cebada H13 dio lugar a extractos líquidos que tenían un contenido en almidón de $5.2 \pm 0.1 \mathrm{~g} / \mathrm{l}$. La forma habitual de eliminar el almidón de los extractos líquidos es mediante el empleo de enzimas amilasas (EC 3.2.1.1). Como consecuencia de esta hidrólisis enzimática, productos de bajo peso molecular (oligosacáridos o glucosa) aparecen en la disolución. Estos productos, de muy bajo peso molecular comparados con el $\beta$ glucano, han de ser eliminados de la disolución habitualmente mediante procesos costosos como la diálisis. En este capítulo se estudia la eliminación del almidón, la eliminación de los productos de hidrólisis y la recuperación del $\beta$-glucano de la disolución. 
Los procesos convencionales de hidrólisis de almidón en extractos de $\beta$-glucanos emplean $\alpha$ amilasa termoestable (habitualmente Termamyl 120L) en procesos a $95^{\circ} \mathrm{C}$ durante al menos 1 hora. En este trabajo de tesis se han evaluado diferentes enzimas comerciales, evaluando su eficacia en la eliminación de almidón y su efecto en el peso molecular del $\beta$-glucano extraído. Se evaluaron 4 enzimas, seleccionándose la $\alpha$-amilasa termoestable Bialfa T. Con este enzima

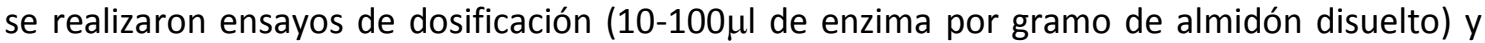
tiempo de incubación (de 3 a 9 minutos) a $95^{\circ} \mathrm{C}$. Se consiguió una eficacia de eliminación del $94 \%$, en un proceso de incubación de 9 minutos con $100 \mu$ l de enzima por gramo de almidón disuelto, sin efecto alguno sobre el PM del $\beta$-glucano disuelto. Como resultado de esta parte experimental, se observó que la eficacia de eliminación del almidón dependía de la cantidad de enzima empleado y no del tiempo de incubación.

El mismo enzima fue probado a una temperatura inferior $\left(55^{\circ} \mathrm{C}\right)$. Se dosificó en un rango entre 60 y $125 \mu \mathrm{l}$ por gramo de almidón disuelto durante diferentes tiempos de incubación. En este caso, dado que la actividad del enzima a $55^{\circ} \mathrm{C}$ es un $50 \%$ inferior a su actividad a $95^{\circ} \mathrm{C}$, sí que se observó un efecto de la dosis y el tiempo de operación sobre la eficacia de eliminación como se muestra en la figura 8 . Se pudo concluir que con una dosificación de $125 \mu \mathrm{l} / \mathrm{g}$ de almidón disuelto y un tiempo de incubación de 9 minutos se puede conseguir una eliminación de almidón del 90\%.

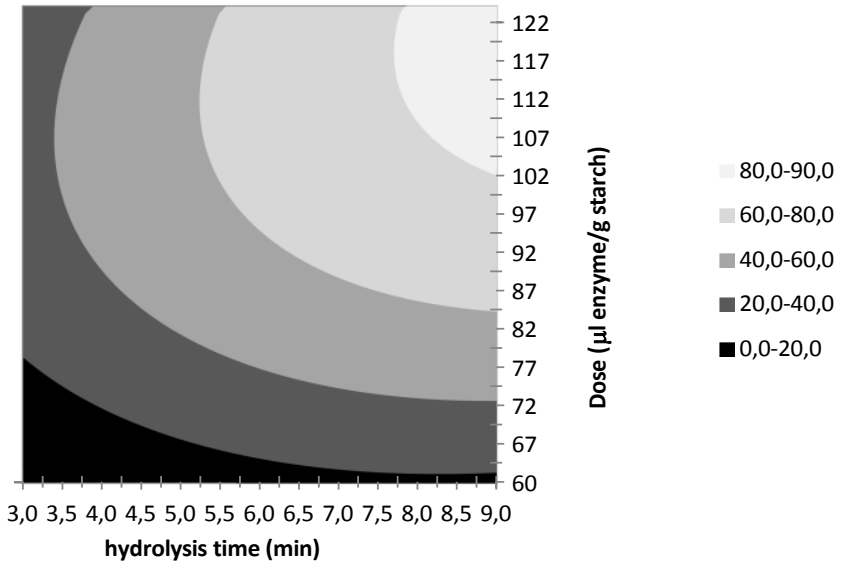

Figura 8. Diagrama de contorno para la eficacia de eliminación de almidón en un extracto líquido mediante Bialfa $T$ a $55^{\circ} \mathrm{C}$ en función del tiempo de hidrólisis y la dosis del enzima

Las dosificaciones empleadas en este trabajo son muy inferiores a las dosificaciones recomendadas por el fabricante del enzima y a las utilizadas por otros investigadores. El hecho de que el almidón se encuentre ya disuelto elimina las limitaciones a la trasferencia de materia: el enzima puede actuar sobre el almidón de forma rápida y efectiva, lo cual reduce la 
cantidad de enzima necesario y los tiempos de incubación. El hecho de poder emplear el enzima a $55^{\circ} \mathrm{C}$ durante tiempos de hidrólisis cortos (inferiores a 9 minutos), permitió la integración del proceso de hidrólisis de almidón con la extracción de $\beta$-glucanos mediante ultrasonidos. Así, durante el proceso de sonicado además de extraer $\beta$-glucano se co-extrae almidón; por ello es posible dosificar el enzima durante la extracción, de manera que el almidón a medida que se va disolviendo sea hidrolizado. Así, mediante esta integración, se consiguió una doble intensificación del proceso de extracción de $\beta$-glucanos a partir de cebada: en la extracción y en la hidrólisis de almidón. Se realizaron ensayos variando la cantidad de enzima añadido (entre 5 y $30 \mu \mathrm{L}$ de enzima por gramo de cebada usada en la extracción) y el tiempo de incubación (entre 1 y 7 minutos, teniendo en cuenta que la máxima duración del proceso de extracción son 7 minutos. Como resultado se tuvo una concentración de almidón de $0.6 \mathrm{~g} / \mathrm{L}$ con un tiempo de incubación de 6 minutos con una dosis de enzima de $30 \mu \mathrm{L} / \mathrm{g}$ de cebada. La concentración de almidón alcanzada sin añadir enzima fue de $5.2 \mathrm{~g} / \mathrm{L}$, con lo que la dosificación del enzima durante la extracción permitió reducir en un $90 \%$ la cantidad de almidón en el extracto líquido. La figura 9 recoge el efecto de la dosis y el tiempo de incubación en la cantidad de almidón disuelto al emplear Bialfa T durante la extracción:

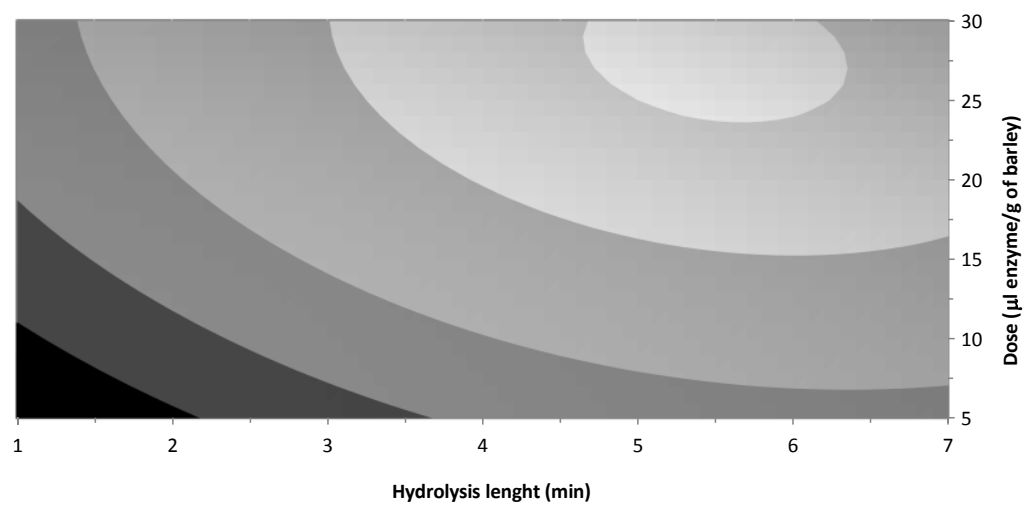

Figura 9. Concentración de almidón tras la dosificación del enzima Bialfa T durante la extracción con ultrasonidos a 55ㅇ․ CLAVE: $\square<0.6 \mathrm{~g} / \mathrm{L} ; \square 0.6-1.2 \mathrm{~g} / \mathrm{L} ; 1.2-2.4 \mathrm{~g} / \mathrm{L} ; \square 2.4-3.6 \mathrm{~g} / \mathrm{L} ; \square 3.6-4.8 \mathrm{~g} / \mathrm{L} ; \mathbf{4}$ 4.8$5.2 \mathrm{~g} / \mathrm{L}$

La parte final de este capítulo se centró en la separación del $\beta$-glucano de alto PM (>240kDa) de los productos de hidrólisis del almidón (PM $\ll<10 \mathrm{kDa}$ ). Se empleó un modulo de ultrafiltración de flujo tangencial, con una membrana de polisulfona con un tamaño de corte de 100kDa. La ultrafiltración se llevó a cabo en modo "diafiltración"; es decir añadiendo agua fresca al retenido (a fin de mantener el volumen de éste constante, así como la concentración de $\beta$-glucanos) al mismo flujo al que se iba retirando por el permeado y de esta manera ayudar a la eliminación de las moléculas de bajo PM del retenido. Se produjo una eliminación del $45 \%$ 
de los azúcares en el retenido, eficacia mantenida a pesar de los cambios en la concentración de la disolución de alimentación de partida. La eliminación de azúcares y la posterior concentración del extracto que contenía el $\beta$-glucano permitieron mejorar la calidad del extracto final, en términos de enriquecimiento en $\beta$-glucanos. El estudio del ensuciamiento de la membrana empleada en el proceso de filtración permitió constatar la rapidez con la que se produce este fenómeno, si bien un adecuado tratamiento de limpieza permitió recuperar la permeabilidad característica de la membrana.

El $\beta$-glucano presente en la disolución purificada y concentrada en el proceso de membranas fue recuperado (precipitado) mediante el empleo de alcoholes como antisolventes; que hacen que el $\beta$-glucano y otros compuestos presentes de alto PM precipiten. Se probaron diferentes alcoholes (metanol, etanol, isopropanol y butanol), observándose que el número de carbonos del alcohol influye en la cantidad de producto sólido recuperado, obteniéndose más cuanto más larga es la cadena. A mayor longitud de la cadena, más productos precipitan, y menor pureza del producto final. Alternativamente se procedió a recuperar el $\beta$-glucano mediante secado en spray. Se seleccionaron las siguientes condiciones de operación: temperatura de entrada del aire $165^{\circ} \mathrm{C}$, flujo de alimentación $0.8 \mathrm{~L} / \mathrm{h}$, temperatura de salida del producto 85 $87^{\circ} \mathrm{C}$, recuperándose un $80 \%$ del $\beta$-glucano presente en la alimentación.

\section{CAPítulo 7.}

Evaluación de la INTENSIFICACIÓn de la extRacción de $\beta$-glucanos a PARTIR de cebada: BALANCES DE ENERGÍA A LOS DIFERENTES PROCESOS DE EXTRACCIÓN

En este capítulo se evaluaron, expresaron (en $k W h$ por gramo de $\beta$-glucano extraído) y compararon los consumos energéticos de diferentes procesos de extracción propuestos a lo largo de esta tesis doctoral (extracción en tanque agitado, extracción asistida por ultrasonidos y extracción mediante agua caliente presurizada -proceso batch-). Se pudo comprobar que el proceso energéticamente más favorable era el que empleaba ultrasonidos (consumo 0.14$0.17 \mathrm{kWh} / \mathrm{g} \beta$-glucano extraído en extracciones entre 3 y 15.9 minutos). Esta combinación de reducción de consumos energéticos y reducción de tiempos de operación frente al proceso de extracción convencional en tanque agitado $(0.27 \mathrm{kWh} / \mathrm{g} \beta$-glucan, 3horas) permite hablar de intensificación del proceso de extracción de $\beta$-glucanos a partir de cebada.

Por otra parte el proceso que emplea agua caliente presurizada resultó ser el de mayor consumo energético por gramo de $\beta$-glucano extraído (con un valor de $6.0 \mathrm{kWh} /$ gramo). Este proceso, a pesar de las ventajas que presenta frente al proceso convencional (como reducción 
de los tiempos de operación y alto peso molecular del $\beta$-glucano extraído sin necesidad de pretratar la materia prima), es desfavorable desde un punto de vista energético. La razón ha de buscarse en la desfavorable relación soluto:disolvente empleada durante la extracción (de 1:50). Este aspecto deberá ser mejorado en un futuro trabajo de cara a incrementar la competitividad de este proceso frente a los otros aprovechando los beneficios de operación que ofrece. 


\section{Conclusiones}

A continuación se presentan las conclusiones más relevantes del presente trabajo de tesis doctoral:

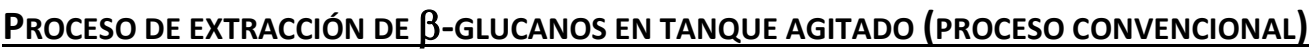

- En este trabajo se han llevado a cabo estudios de extracción de $\beta$-glucanos a partir de dos variedades de cebada cerosa en tanque agitado (proceso de extracción convencional), evidenciándose importantes limitaciones a la transferencia de materia y otros problemas como el bajo peso molecular del $\beta$-glucano extraído (inferior a 55kDa) y la presencia del otros productos co-extraídos (siendo el almidón el principal).

- El estudio del efecto de las variables de operación en la extracción de $\beta$-glucanos a partir de dos variedades de cebada cerosa (vestida y desnuda) permitió comprobar que a pesar de las diferencias morfológicas entre las variedades de cebada su comportamiento frente a cambios introducidos en las variables de operación era similar. El disolvente seleccionado es gua, no obteniéndose diferencias significativas al modificar el pH y por tanto se mantuvo entre 6.0-6.5. Por otra parte la extracción se ve mejorada con la temperatura hasta $55^{\circ} \mathrm{C}$ ya que a temperaturas superiores se produce un incremento muy acusado de la cantidad de almidón co-extraída. Las condiciones de extracción propuestas para maximizar el rendimiento de extracción son: tamaño de partícula inferior a $100 \mu \mathrm{m}$; velocidad de agitación 1000rpm; extracciones de 3 horas de duración y relación soluto:disolvente de 1:8. En estas condiciones el rendimiento de extracción de $\beta$-glucanos a partir de la cebada desnuda (H13) fue de $62.3 \pm 1.8 \%$ y de $73.4 \pm 1.2 \%$ para la cebada vestida (D24).

- Se han propuesto dos tipos de pretratamiento para el incremento del peso molecular del $\beta$-glucano extraído (separación y selección de fracciones de molienda y tratamiento de la cebada con etanol). El pretratamiento con etanol, realizado a fin de inactivar las $\beta$-glucanasas, supuso un gran incremento del peso molecular hasta $431 \mathrm{kDa}$; si bien el rendimiento de extracción descendió hasta el $41.5 \pm 1.0 \%$ cuando se empleó la variedad de cebada vestida y $42.7 \pm 1.3 \%$ y $456 \mathrm{kDa}$ para la variedad desnuda.

- El empleo de fracciones de molienda, con distintas composiciones y tamaños de partícula, permitió llegar a diferentes rendimientos de extracción y diferentes pesos moleculares de los $\beta$-glucanos extraídos, siendo la fracción más recomendable los 
salvados gruesos o subproducto de trituración en el caso de que se busque maximizar el peso molecular del $\beta$-glucano extraído.

\section{PROPUESTA DE ALTERNATIVAS QUE MEJOREN LA EXTRACCIÓN (I): ULTRASONIDOS}

- La extracción con ultrasonidos ha permitido reducir de forma drástica el tiempo de extracción (desde 3 horas en el proceso convencional hasta 3-7 minutos en el proceso con ultrasonidos) manteniéndose el rendimiento de extracción y el peso molecular del $\beta$-glucano extraído. Además, la reducción de los consumos energéticos también se ha visto potenciada, con lo que el empleo de ultrasonidos ha supuesto una eficaz intensificación del proceso de extracción: el proceso convencional desarrollado en tanque agitado presentó un consumo energético de $1460 \mathrm{~kJ} / \mathrm{L}$, frente a $100-500 \mathrm{~kJ} / \mathrm{L}$ en los procesos de extracción con ultrasonidos.

\section{Propuesta de alternativas que mejoren la extracción (II): Agua Caliente Presurizada}

- El empleo de agua caliente presurizada como disolvente ha supuesto una mejora del peso molecular del $\beta$-glucano extraído y una reducción del tiempo de operación en comparación con el proceso en tanque agitado. Un proceso batch desarrollado a $155^{\circ} \mathrm{C}$ durante 18 minutos a 50 bar de presión ha permitido extraer $\beta$-glucanos con un rendimiento del $53.7 \%$ y un peso molecular de $200 \mathrm{kDa}$, obteniéndose este peso molecular sin necesidad de pretratar la cebada para inactivar los enzimas endógenos $\beta$-glucanasas.

- El empleo de temperaturas más altas y tiempos de operación más largos, supuso la hidrólisis del $\beta$-glucano, como se demostró con el análisis del peso molecular y de los azúcares y oligosacáridos, habiéndose discutido estos resultados en base al factor de severidad, que tiene en cuenta la combinación de estas dos variables (temperatura y tiempo). Condiciones de operación que resulten en un factor de severidad ( $\log R_{0}$ ) superior a 3.5 dieron como resultado peso moleculares inferiores a $100 \mathrm{kDa}$; si el factor de severidad se incrementa hasta 4.0 los pesos moleculares descienden por debajo de $50 \mathrm{kDa}$.

- El paso de un proceso batch a un proceso semi-continuo (extracción en lecho fijo) supuso una mejora aún mayor del peso molecular y un fraccionamiento de los $\beta$ glucanos durante la extracción en función de su peso molecular. Además se pudo 
comprobar una menor degradación del $\beta$-glucano extraído, con un rendimiento de extracción similar al proceso batch: $52.4 \pm 1.4 \%$ y pesos moleculares en el rango 500 $180 \mathrm{kDa}$.

- Los buenos resultados obtenidos con agua caliente presurizada se han confirmado también para otras materias primas como son los salvados de trigo.

\section{ETAPA DE CONCENTRACIÓN Y PURIFICACIÓN DEL $\beta$-gLUCANO EXTRAÍDO (DOWNSTREAM PROCESS)}

El downstream process se desarrolló en dos etapas: hidrólisis enzimática del principal producto co-extraído (almidón) y eliminación de los productos de la hidrólisis enzimática mediante un proceso de membranas.

- En este trabajo el almidón co-extraído se ha hidrolizado mediante el empleo de enzimas amilasas (EC 3.2.1.1.), siendo dextrinas, oligosacáridos y glucosa los principales productos de la hidrólisis. Estas especies presentan un bajo peso molecular (inferior a 10kDa) en comparación con el del $\beta$-glucano.

- El estudio de la dosificación del enzima, el tiempo de incubación y la temperatura de operación permitió proponer un proceso en el que mediante la dosificación de $125 \mu$ l de enzima por gramo de almidón disuelto a 55ำ y 9 minutos de periodo de incubación se eliminó el $90 \%$ del almidón disuelto.

- La dosificación del enzima ( $25 \mu \mathrm{L}$ enzima/g de cebada) durante la extracción asistida con ultrasonidos (7 minutos a 55으) permitió reducir la concentración de almidón disuelto en un $90 \%$ con respecto a la obtenida cuando no se dosificó el enzima. De esta manera se consiguió una integración e intensificación de los procesos de extracción y purificación de $\beta$-glucanos a partir de cebada, al realizarse a la misma temperatura y de forma simultánea.

- La separación de los productos de hidrólisis del almidón se llevó a cabo mediante un proceso de membranas (diafiltración), consiguiéndose eliminaciones de más del 70\% de los oligosacáridos presentes en la disolución. Aunque las disoluciones de $\beta$-glucanos ensucian la membrana (polisolfona, MCWO 100kDa) con rapidez, ésta se puede regenerar de forma efectiva, recuperándose la permeabilidad inicial de la membrana.

- La integración de ultrasonidos, hidrólisis enzimática y separación mediante membranas permitió recuperar $\beta$-glucanos de forma efectiva y con una reducción 
significativa de los tiempos de operación y las energías consumidas en comparación con los procesos convencionales. La aplicación de estas tecnologías permite llegar a concentrados de $\beta$-glucanos de al menos $65-70 \%$, obtenidos a partir de extracciones realizadas con ultrasonidos durante 7 minutos (consumo energético 390kJ/L).

\section{EVALUACIÓN DE LOS CONSUMOS ENERGÉTICOS}

En la parte final del trabajo se estudió el consumo energético de los diferentes procesos de extracción propuestos a lo largo de esta tesis. Se evaluaron los consumos energéticos derivados de la preparación de la materia prima (molienda y/o inactivación de las $\beta$ glucanasas) y la extracción:

- El proceso de extracción con ultrasonidos resultó ser el energéticamente más favorable $0.14-0.17 \mathrm{kWh} / \mathrm{g}$ de $\beta$-glucano extraído (frente a $0.27 \mathrm{kWh} / \mathrm{g}$ de $\beta$-glucano extraído en el proceso en tanque agitado); lo que unido a la drástica reducción de los tiempos de operación permite una eficaz intensificación del proceso extracción de $\beta$ glucanos

- El proceso batch con agua caliente presurizada, a pesar de permitir recuperar $\beta$ glucanos de alto $\mathrm{MW}$ sin necesidad de pretratar la materia prima, resultó ser energéticamente desfavorable $6.0 \mathrm{kWh} / \mathrm{g}$ de $\beta$-glucano. La causa se encuentra en la desfavorable relación soluto:disolvente empleada (1:50); por tanto una mejora del rendimiento energético de este proceso pasa por optimizar esta relación soluto:disolvente. 



\section{ANNEX I}

\section{Study of the endogenous}

$\beta$-glucanase deactivation by means

of boiling ethanol 



\section{Study of the endogenous $\beta$-glucanase deactivation by means of boiling ethanol}

The aim of this work is to the endogenous $\beta$-glucanases deactivation by means of boiling ethanol in order to increase the molecular weight of the $\beta$-glucans extracted. Barley flour was boiled with ethanol $(80 \%, v / v)$, prior to extraction stage, for two hours. According to the results obtained by size exclusion chromatography, this treatment increased the molecular weight of the polymers from $32 \mathrm{kDa}$ to $717 \mathrm{kDa}$, leading to much higher viscosity solutions, with a significant increase of the starch dissolved.

\section{INTRODUCTION}

Research on $\beta$-glucan extraction has become more interesting in the last years due to the appeal of these polymers for the human health. The control of cholesterol and glucose concentration in blood is the major benefit $\beta$-glucan can offer (Brennan, 2005). $\beta$-glucans responsible for these beneficial properties are those that have high molecular weight, leading to higher viscosity and special rheological behaviour solutions (Irakli, 2004). The amount of nourishment that contains $\beta$-glucan as an additive has risen significantly, so the FDA (Food and Drug Administration, USA), apart from including $\beta$-glucan in its list of products that contribute to lowering the cholesterol level in blood, has recently indicated how to label those products that contain $\beta$-glucan.

$\beta$-glucans are a kind of non-starchy polysaccharide that can be found in several kinds of cereals, such as barley, oat or rye in concentrations from 2 to $12 \%$ in dry basis. They form part of the dietetic fiber, nevertheless $\beta$-glucans are soluble in water.

Extraction of $\beta$-glucans from cereals presents several difficulties. A typical extraction process involves, at least, three stages (Laroche, 2007): (1) pretreatment of raw cereal, (2) extraction of $\beta$-glucans with suitable solvent and conditions, and finally, (3) a purification-isolation step. Each stage, in turn, involves different steps, increasing both the complexity and the economical costs of the whole process. This is the most limiting factor for the common $\beta$ glucan extraction processes. 
Pretreatment stage can pursue different objectives: first, to deactivate the endogenous enzymes ( $\beta$-glucanases) causing the depolymerisation of $\beta$-glucans. A second objective is to facilitate the later extraction stage, increasing the overall yield of the process: physical treatments, such as sonicating the barley flour suspended in water prior to the extraction stage. This treatment can contribute to free easily $\beta$-glucans into the solvent. Finally, a special milling of the barley can be done in order to produce milling fractions enriched in $\beta$-glucans (Kiryluk, 2000), increasing the amount of $\beta$-glucans extracted.

All these pretreatments can lead to enhance the performance of the $\beta$-glucan extraction process. In this work it was studied the effect that ethanol treatment has on the molecular weight of the polymer extracted.

\section{EXPERIMENTAL SECTION}

\subsection{Materials and methods}

Two varieties of waxy barley (D24 and H13, harvested in 2006) was used in this work. It was supplied by ITACYL (Instituto Tecnológico Agrario de Castilla y León; Valladolid, Spain) and milled to pass through a $500 \mu \mathrm{m}$ sieve. Chemical composition of these varieties of barley can be observed in table 1. Ethanol used for the pretreatment was $96 \%$ (v/v; analytical grade) supplied by Panreac (Spain).

Table 1. Chemical composition (\%) of barley expressed in dry basis

\begin{tabular}{|ccccccc|}
\hline Variety & Starch & $\boldsymbol{\beta}$-glucan & Fats & Dietary Fiber & Protein & Ash \\
\hline D24-06 & $50.3 \pm 3.2$ & $6.02 \pm 0.37$ & $2.76 \pm 0.18$ & $21.0 \pm 0.7$ & $18.2 \pm 0.2$ & $2.09 \pm 0.11$ \\
\hline H13-06 & $58.5 \pm 3.6$ & $4.6 \pm 0.2$ & $2.54 \pm 0.16$ & $15.6 \pm 0.8$ & $17.8 \pm 0.4$ & $2.00 \pm 0.13$ \\
\hline
\end{tabular}

\subsection{Chemical analysis}

$\beta$-glucan determination was done using the "Mixed linkage $\beta$-glucan assay kit" (Megazyme, Ireland), and starch dissolved was determined using a modification of the "Total Stach assay kit" (Megazyme, Ireland) suggested by Megazyme.

Molecular weight of $\beta$-glucans was determined by Size Exclusion Chromatography (HPLC-SEC). The chromatography system consisted of an isocratic pump (Waters 1515), an automatic injector (Waters 717), a guard column (Waters Ultrahydrogel Guard Column) a SEC column (Waters Ultrahydrogel 1000: 7.8x300mm; pore size of 1000Á; exclusion limit 1x106 Dalton) and finally a differential refractive index detector (Waters 410). The column was kept at 35으, 
and flow rate of the mobile phase $\left(0.1 \mathrm{M} \mathrm{NaNO}_{3}+0.02 \% \mathrm{NaN}_{3}\right)$ was set at $0.6 \mathrm{ml} \cdot \mathrm{min}^{-1}$. The $\beta$ glucan molecular weight standards were purchased from Megazyme (Ireland).

\subsection{Experimental procedure}

\subsubsection{Batch procedure for extraction of $\beta$-glucans}

In each experiment, 25 grams of barley were suspended vigorously (1000rpm; Heidolph R2021, Germany) in $200 \mathrm{ml}$ of deionized water for 3 hours at 55ㅇ in a water bath (Ecoline Staredition E100, Lauda, Germany). After the extraction, the mixture was centrifuged for 10 minutes at 5500rpm (Kubota 5100, Japan). Solid material was discarded, while liquid extract was kept at 4 으. All the extraction experiments were carried out in duplicate.

\subsubsection{Endogenous enzyme deactivation by the use of ethanol}

As previous step to the extraction, $75 \mathrm{~g}$ of barley flour were suspended in $750 \mathrm{ml}$ of ethanol $(80 \% \mathrm{v} / \mathrm{v})$ and boiled under reflux for two hours. After the treatment, the barley and ethanol were separated. The barley was dried at $50 \circ \mathrm{C}$ and milled again in order to get homogeneous flour. Subsequently, extraction process was carried out, according the procedure described in section 2.3.1. When this treatment was done, experiment was completed with the purification and isolation of $\beta$-glucans. Liquid extract was incubated at $96 \circ \mathrm{C}$ with $\alpha$-amylase thermostable (BIALFA T, kindly provided by Biocon Española, Spain) for one hour. After centrifugation, an equal volume of ethanol $(96 \% \mathrm{v} / \mathrm{v})$ was added to supernatants in order to precipitate $\beta$ glucans. After having stirred the solution for two hours, the white solid precipitate obtained was separated from the liquid by vacuum filtration. The gum obtained was dried overnight at $60^{\circ} \mathrm{C}$. Once dried, gum was milled, accurately weighted and kept in a sealed glass tube until the moment of being analysed.

\section{RESULTS AND DISCUSSION}

\subsection{Composition of barley after the ethanol treatment}

After the ethanol treatment of the barley, its content in $\beta$-glucan and starch was measured. Results are presented in table 2 . It can be observed a slight change in the composition, as a consequence of the treatment some proteins and fats were extracted. However, no effect was observed in the $\beta$-glucan content: 
Table 1. Chemical composition (\%) of barley after pretreatment, expressed in dry basis

\begin{tabular}{|ccccc|}
\hline Variety & Starch & $\beta$-glucan & Fats & Protein \\
\hline D24-06 & $58.7 \pm 3.0$ & $6.25 \pm 0.25$ & $1.86 \pm 0.16$ & $13.0 \pm 0.2$ \\
\hline H13-06 & $63.1 \pm 2.6$ & $4.76 \pm 0.12$ & $1.45 \pm 0.10$ & $11.9 \pm 0.2$ \\
\hline
\end{tabular}

\subsection{Deactivation of endogenous enzymes by action of ethanol}

The use of ethanol deactivated most of the $\beta$-glucanases present in the raw cereal. The barley refluxed with ethanol was extracted, leading to a $\beta$-glucan extraction yield of $38.5 \pm 1.1 \%$, significantly lower than that achieved when barley was not boiled with ethanol $(62.3 \pm 1.8)$ for barley $\mathrm{H} 13$ and $41.5 \pm 1.0 \%$ for barley D24 (73.4 $\pm 1.2 \%$, when barley was not pretreated). Starch concentration present in the liquid extract was much higher in the case of barley treated with ethanol $(3.2 \pm 0.1 \mathrm{~g} / \mathrm{l}$ vs $1.1 \pm 0.1 \mathrm{~g} / \mathrm{l}$ when barley was not for barley $\mathrm{D} 24$ and $9.6 \pm 0.6 \mathrm{~g} / \mathrm{l}$ vs $1.8 \pm 0.3 \mathrm{~g} / \mathrm{l}$ for barley $\mathrm{H} 13$ with and without treatment, respectively.). Viscosity of the liquid extract was very high, being difficult to keep the barley in suspension. A purification-isolation step was performed, leading to a gum rich in $\beta$-glucan. The composition and molecular weight of the polymers extracted from barley $\mathrm{H} 13$ can be observed in table 2 .

Table 2. Composition of liquid and solid extract obtained from barley H13 pretreated and not pretreated with ethanol

\begin{tabular}{|l|ccc|ccc|}
\cline { 2 - 7 } \multicolumn{1}{c|}{} & \multicolumn{3}{c|}{ Liquid Extract } & \multicolumn{3}{c|}{ Solid Extract $^{1}$} \\
\cline { 2 - 7 } \multicolumn{1}{c|}{} & $\begin{array}{c}\text { Extraction } \\
\text { (\%) }\end{array}$ & $\begin{array}{c}\text { Starch } \\
\text { (g/l) }\end{array}$ & $\begin{array}{c}\mathbf{M W}^{\mathbf{2}} \\
\mathbf{( k D a )}\end{array}$ & $\begin{array}{c}\beta \text {-glucan } \\
\mathbf{( \% )}\end{array}$ & $\begin{array}{c}\text { Starch } \\
(\%)\end{array}$ & $\begin{array}{c}\text { MW } \\
\text { (kDa) }\end{array}$ \\
\hline $\begin{array}{l}\text { Barley NOT } \\
\text { pretreated }\end{array}$ & $62.3 \pm 1.8$ & $1.8 \pm 0.3$ & $<45$ & $38.9 \pm 2.5$ & $2.6 \pm 0.7$ & 32 \\
\hline $\begin{array}{l}\text { Barley } \\
\text { pretreated }\end{array}$ & $38.5 \pm 1.1$ & $9.6 \pm 0.6$ & 396 & $39.2 \pm 1.1$ & $3.3 \pm 0.1$ & 410 \\
\hline
\end{tabular}

1. Solid extract obtained after purification-isolation step from liquid extract, by addition of ethanol, immediately after the extraction stage.

2. Molecular weight measured after having let the liquid extract for 8 days at $4{ }^{\circ} \mathrm{C}$.

According to table 2 , this treatment decreased almost completely the activity of the $\beta$ glucanases during the extraction stage, leading to a polymer 30 times higher quality in terms of molecular weight. However, in spite of the treatment of barley with ethanol, some residual activity of the $\beta$-glucanases was still present in the liquid extract, causing as a result, a partial depolymerisation of the $\beta$-glucans dissolved (MW decreased from 410 to $396 \mathrm{kDa}$ in eight days). These results make necessary to perform a purification-isolation step immediately after the extraction stage to prevent the action of residual $\beta$-glucanases present in the liquid. 
Extraction from pretreated barley D24 resulted in a $\beta$-glucan that had a molecular weight of $431 \mathrm{kDa}$, compared to the $55 \mathrm{kDa}$ measured when barley was not pretreated.

The residual activity of the $\beta$-glucanases was evaluated. The liquid extract obtained from barley D24 was placed at 4 으 for 30 days, being taken one sample of liquid every seven days. This sample was analyzed, and molecular weight and $\beta$-glucan concentrations were compared. Results are shown on figure 1 :

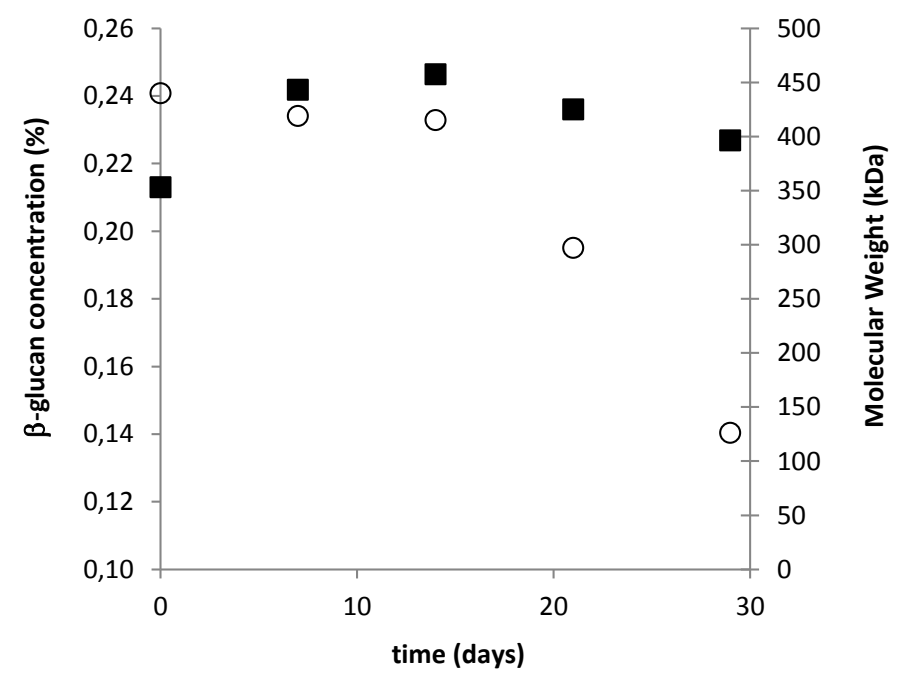

Figure 1. Time evolution of the concentration $(\square)$ and molecular weight $(O)$ of the extracted $\beta$-glucan at $4^{\circ} \mathrm{C}$, in order to determine the residual activity of $\beta$-glucanases

Results from figure 1 reveal that the treatment to inactivate $\beta$-glucanases was effective, as the molecular weight was significantly increases. However a dramatic decrease of the molecular weight was observed after 15 days; this indicates that the purification isolation step must be done after the extraction, in order to prevent the degradation of the $\beta$-glucan.

\section{CONCLUSIONS}

The pretreatment studied in this work, the boiling of barley with ethanol previously to the extraction, successfully deactivated most of the $\beta$-glucanases, enzymes responsible for the depolymerisation of $\beta$-glucans. The result was a polymer extracted with $\mathrm{MW}$ higher than $400 \mathrm{kDa}$ for both varieties of barley. Nevertheless, barley pretreated with ethanol showed to have lower $\beta$-glucan extractability: extraction yield was reduced for almost $50 \%$. This was probably due to the difficulty for keeping the barley in suspension into the solvent: viscosity was much higher because of the presence in the liquid of very high molecular weight $\beta$-glucan and greater starch concentration. In further work the stirring system will have to be improved, as new procedures for mass transfer enhancement must be provided. 


\section{REFERENCES}

Brennan C.S.; Cleary L.J. (2005). The potential use of cereal $(1 \rightarrow 3,1 \rightarrow 4)-\beta$-D-glucans as functional food ingredients. Journal of Cereal Science, 42(1), 1-13.

Irakli M., Biliaderis C.G., Izydorczyk M.S., Papadoyannis I.O. (2004). Isolation, structural features amd rheological properties of water-extractable $\beta$-glucans from different Greek barley cultivars. Journal of the science of food and agriculture, 84, 1170-1178.

Izydorczyk M. S., Storsley, J., Labossiere D., MacGregor A. W., Rossnagel B.G. (2000). Variation in total and soluble $\beta$-glucan content in hulless barley: effects of thermal, physical and enzymic treatments. J. Agric. Food Chem., 48: 982-989.

Kiryluk J., Kawka A., Gasiorowski H., Chalcarz A., Aniola J. (2000). Milling of barley to obtain $\beta$ glucan enriched products. Die Nahrung, 44 (4), 238-241.

Laroche, C.; Michaud, P. (2007). New developments and prospective applications for $\beta-(1,3)$ glucans. Recent Patents on Biotechnology, 1, 59-73. 


\section{ANNEX II}

\section{$\beta$-glucan enriched products}

\section{obtained from different barley}

milling fractions and their mixtures 



\title{
$\beta$-glucan enriched products obtained from different barley milling fractions and their mixtures
}

\begin{abstract}
The effect of the milling on the extraction of $\beta$-glucans has been studied with a hull-less waxy genotype barley cultivar $(\mathrm{H} 13$, with a $\beta$-glucan content of $4.64 \pm 0.16 \%$ and a $58.5 \pm 3.6 \%$ of starch). Barley was milled in a Chopin CD1 mill, obtaining three different milling fractions: brans (50\% w/w; $4.5 \% \beta$-glucan), reduction flour (20\% w/w; $6.6 \% \beta$-glucan) and break flour (30\% w/w; $2.4 \% \beta$-glucan). Differences between fractions were found in particle size, composition, as well as in the extraction yield and the molecular weight of the $\beta$-glucan isolated (up to $723 \mathrm{kDa}$, according to the GPC results obtained). The best results were obtained when reduction flour was used as source of $\beta$-glucans: the product contained $28 \%$ of $\beta$-glucan $(643 \mathrm{kDa})$ and $39 \%$ of starch, showing a total $\beta$-glucan recovery of $63.6 \%$ and a gum yield of $16.6 \%$. Mixtures of brans and reduction flour contributed to increase the average $\beta$-glucan recovery up to $60 \%$, expressing the importance of having a homogeneous raw material with a lower particle size distribution as possible to perform successfully a $\beta$-glucan extraction process. According to these results, milling fraction, considered as a pretreatment of barley, contributes to make easy and more efficient the final $\beta$-glucan recovery, because leads to lower particle size flours and to a more quality product in terms of higher molecular weight.
\end{abstract}




\section{INTRODUCTION}

$\beta$-glucans are a kind of non-starchy polysaccharide that can be found in several kinds of cereals, such as barley, oat or rye in concentrations from 2 to $12 \%$ in dry basis. They form part of the dietetic fiber, nevertheless $\beta$-glucans are soluble in water. Research on $\beta$-glucan extraction has become more interesting in the last years due to the appeal of these polymers for the human health. The control of cholesterol and glucose concentration in blood is the major benefit $\beta$-glucan can offer (Brennan and Cleary, 2005). $\beta$-glucans responsible for these beneficial properties are those that have high molecular weight, leading to higher viscosity and special rheological behaviour solutions (Irakli et al., 2004).

Although the amount of procedures reported in literature to obtain $\beta$-glucan enriched products is large, all of them can be grouped in two categories as it is suggested by Vasanthan and Temelli (2008): those experiments carried out in dry conditions, and those performed in wet conditions. Dry processing technologies include dry milling and sieving techniques (Kiryluk et al., 2000), achieving a final product that contains a $15.2 \%$ in $\beta$-glucan, as the best result, and dry milling and air classification (Vasanthan and Bhatty, 1995). Wet procedures are more complex, since they involve at least two or three stages (Brennan and Cleary, 2005): cereal bran or flour is used as raw material, which is put in contact with a solvent (usually water, basified water or semi-alcoholic solution), obtaining an aqueous extract as a result. This aqueous extract contains other species apart from $\beta$-glucan (such as starch, proteins and fats), making necessary a purification step. For this purpose, $\beta$-glucans are precipitated by addition of an alcohol as anti-solvent, or separated by other procedures. The precipitate obtained in this way, once isolated and dried, results in a product that contains from 20 to $70 \%$ of $\beta$ glucan.

The purpose of the present work is to combine dry processes (milling and fractionating of cereal grain) as a previous step with wet techniques (deactivation of $\beta$-glucanases with ethanol, extraction with hot water, $\beta$-glucan precipitation, filtration and drying) in order to obtain $\beta$-glucan enriched products. By using milling techniques it will be possible to obtain homogeneous flour (particle size) with a higher concentration of $\beta$-glucan, that facilities the further extraction stage and allow to obtain a final enriched $\beta$-glucan product with higher molecular weight. 


\section{EXPERIMENTAL SECTION}

\subsection{Materials and methods}

In this work a hull-less waxy genotype barley cultivar (H13), has been used. This barley, harvested in 2006 and with a $\beta$-glucan content of $4.64 \pm 0.16 \%$ and a $58.5 \pm 3.6 \%$ of starch, has been supplied by ITACYL (Instituto Tecnológico Agrario de Castilla y León; Valladolid, Spain). This barley was milled using a Chopin-CD1 mill (Chopin, France) placed at CETECE (Centro de Tecnología de Cereales; Palencia, Spain). Three different milling fractions were obtained: bran (particle size above $0,8 \mathrm{~mm}$ ), including hulls when hulled barley was milled, very heterogeneous; reduction flour (particle size between $0.16-0.5 \mathrm{~mm}$ ) and break flour (particle size under $0.16 \mathrm{~mm}$ ). After milling, brans yielded $50 \%$ approximately, reduction flour $20 \%$ and break flour the remaining 30\%. When using Chopin CD1, barley was milled at constant moisture (15.5\%). Chemical composition of each milling fraction is presented in Table 1.

Table 1. Composition of the milling fractions, milled at constant moisture of $15.5 \%$.

\begin{tabular}{|c|l|cccc|}
\hline $\begin{array}{c}\text { Barley } \\
\text { Sample }\end{array}$ & Milling Fraction & $\begin{array}{c}\boldsymbol{\beta} \text {-Glucan } \\
\text { (\%) }\end{array}$ & $\begin{array}{c}\text { Starch } \\
\mathbf{( \% )}\end{array}$ & $\begin{array}{c}\text { Protein } \\
\text { (\%) }\end{array}$ & $\begin{array}{c}\text { Dietary Fibre } \\
\text { (g/100g) }\end{array}$ \\
\hline \multirow{3}{*}{ H13 } & Bran & $5.3 \pm 0.3$ & $40.6 \pm 2.3$ & $13.9 \pm 0.5$ & $29.0 \pm 1.2$ \\
& Reduction Flour & $8.1 \pm 0.2$ & $38.0 \pm 3.4$ & $18.7 \pm 0.4$ & $27.8 \pm 1.5$ \\
& Break flour & $2.6 \pm 0.6$ & $65.7 \pm 3.2$ & $14.3 \pm 0.6$ & $6.9 \pm 0.4$ \\
\hline
\end{tabular}

\subsection{Chemical analysis}

$\beta$-glucan and starch determination was done using the "Mixed linkage $\beta$-glucan assay kit" and the "Total Starch assay kit", respectively. Both of the kits were supplied by Megazyme, Ireland. Dietary fibre was determined by means of the Total Dietary Fibre assay kit (Megazyme). Proteins were quantified according to the Kjeldahl reaction to determine the total nitrogen (proteins were calculated by multiplying the total nitrogen times 6.25 ). Starch and $\beta$-glucan concentration was also determined in the liquid extract, being expressed in both cases in percentage of the total liquid extract obtained. Both species were analysed in the final gum product.

The extraction process efficiency was evaluated according the following definition:

$$
\% \text { Extraction yield }=\frac{\text { wt.of } \beta \text {-glucan in the liquid extract }}{\text { wt.of } \beta \text {-glucan in the initial flour }} \times 100
$$

Moreover, two parameters were introduced in order to compare the results obtained with those reported by other researchers: Gum yield and $\beta$-glucan recovery (this parameter quantifies the efficiency of the overall $\beta$-glucan extraction process) 


$$
\begin{gathered}
\% \text { Gum yield }=\frac{\text { wt.of solid extract }}{\text { wt.of initial flour }} \times 100 \\
\% \beta \text {-Glucan recovery }=\frac{\text { wt.of } \beta \text {-glucan in the solid extract }}{\text { wt.of } \beta \text {-glucan in the initial flour }} \times 100
\end{gathered}
$$

Molecular weight of $\beta$-glucans was determined by Gel Permeation Chromatography (GPC) according the following method: the chromatography system that consisted of an isocratic pump (Waters 1515), an automatic injector (Waters 717), guard column (SB-G Shodex) and a GPC column (SB-804 HQ Shodex) and a differential refractive index detector (Waters 410). The column was kept at $35 \circ \mathrm{C}$, and flow rate of the mobile phase $\left(0.1 \mathrm{M} \mathrm{NaNO} \mathrm{N}_{3}+0.02 \% \mathrm{NaN}_{3}\right)$ was set at $0.5 \mathrm{~mL} \cdot \mathrm{min}^{-1}$. The $\beta$-glucan molecular weight standards were purchased from Megazyme International Ltd. (Ireland), and were in the range 40 to 359kDa. Extractions with each milling fractions were conducted in duplicate. $\beta$-glucan and starch analysis of each extract were performed in duplicate.

\subsection{Experimental procedure}

\subsubsection{Endogenous enzyme deactivation by the use of ethanol}

As previous step to the extraction, and after the milling process, $80 \mathrm{~g}$ of barley sample were suspended in $500 \mathrm{~mL}$ of ethanol $(80 \% \mathrm{v} / \mathrm{v})$ and boiled under reflux for two hours with continuous stirring. After the treatment, the barley and the ethanol were separated. Barley was dried at $90{ }^{\circ} \mathrm{C}$ and milled again in order to get homogeneous flour. Subsequently, extraction process was carried out, according the procedure described in section 2.3.2.

\subsubsection{Batch procedure for extraction of $\beta$-glucans}

Extraction was carried out in a $1 \mathrm{~L}$ jacked vessel. In each experiment, 25 grams of barley were suspended vigorously (500rpm, Heidolph RZR 2021 stirrer, Germany) in 200mL of deionized water for 3 hours at 55ㄷ (Ecoline Staredition E100, Lauda, Germany). After the extraction, the mixture was centrifuged for 10 minutes at 5000rpm (Kubota 5100, Japan). Solid material was discarded, while liquid extract was kept at $4{ }^{\circ} \mathrm{C}$. All the extraction experiments were carried out in duplicate. $\beta$-glucan precipitation was done by adding an equal volume of ethanol $(96 \%, v / v)$ to the liquid extract. The white solid product obtained was separated from liquid by vacuum filtration, and set at $60^{\circ} \mathrm{C}$ overnight. Once dried, gum was milled and kept in a sealed glass tube until the moment of being analysed. 


\subsubsection{Mixture of milling fractions}

Different combinations of milling fractions were tried. Initially, brans and reduction flour were mixed together after milling the barley. Break flour was no considered, due its lower content in $\beta$-glucan. The resultant product contained $71 \%$ of brans and $29 \%$ of reduction flour. Three different mixtures were studied: mixture $A$, in which brans were milled in order to obtain more homogeneous fraction and subsequently mixed with the reduction flour. In mixture B, both milling fractions were mixed together and then re-milled. Finally, mixture $\mathrm{C}$ resulted from mixing the two fractions with no further milling. In the three cases, after having obtained the desired mixture, samples were pretreated with ethanol, as described in paragraph 2.3.1, and extracted $\beta$-glucans according to 2.3.2.

\section{RESULTS AND DISCUSSION}

\subsection{Milling fractions}

Important differences were observed when extraction was performed from milling fractions, compared to those results got from unique milling fraction of barley ("flour") obtained with a grain mill without fractioning. These results are shown in Table 2.

Table 2. Composition of the products obtained from H13 barley milling fractions

\begin{tabular}{|l|c|c|c|c|c|c|}
\hline \multicolumn{1}{|c|}{ Sample } & $\begin{array}{c}\text { Extraction yield } \\
\text { \% }\end{array}$ & $\begin{array}{c}\boldsymbol{\beta} \text {-glucan } \\
\%\end{array}$ & $\begin{array}{c}\text { Starch } \\
\%\end{array}$ & $\begin{array}{c}\text { MW } \\
\text { kDa }\end{array}$ & $\begin{array}{c}\text { gum yield } \\
\%\end{array}$ & $\begin{array}{c}\beta \text {-glucan recovery } \\
\%\end{array}$ \\
\hline Brans & 41.7 & 34.0 & 40.1 & 728 & 6.7 & 44.1 \\
Reduction Flour & 57.5 & 27.7 & 39.1 & 643 & 16.6 & 63.5 \\
Break flour & 71.5 & 23.8 & 48.2 & 720 & 7.2 & 59.9 \\
\hline Flour $^{1}$ & 42.7 & 36.7 & 29.5 & 456 & 4.7 & 32.7 \\
Flour $^{2}$ & 62.8 & 33.7 & 4.4 & 45 & 4.3 & 29.6 \\
\hline
\end{tabular}

Flour: Unique milling fraction ( $d p=0.5 \mathrm{~mm}, 4.64 \pm 0.18 \%$ of $\beta$-glucan and $58.5 \pm 3.6 \%$ of starch)

${ }^{1}$ flour with ethanol pre-treatment ${ }^{2}$ flour without ethanol pre-treatment

Higher extraction yield was obtained when lower particle size and more homogeneous milling fraction was: this is explained by the fact that break flour, despite of having the lowest $\beta$ glucan content, gave the best extractability of $\beta$-glucans $(71.5 \%$, which is an excellent result with a high $\mathrm{MW}, 720 \mathrm{kDa}$ ). Starch concentration in the final product was the highest: $48.2 \%$. However, $\beta$-glucan extraction from brans was more difficult, due to its wide particle size distribution. This represents a challenge because brans represent the $50 \%$ of the milling fractions obtained, with a slightly higher content of $\beta$-glucans than barley as a whole $(4.54 \%$ vs 4.32\%). Reduction flour extraction yield was intermediate, as the particle size distribution is between brans and break flour. This fraction has the higher $\beta$-glucan content, but it represents 
only the $20 \%$ of the three milling products. The yield of each milling fraction may be modifying by means of optimization process of milling parameters. Milling the barley at different moistures did not reveal important differences neither in yields nor in composition of each fraction.

H13 flour extraction yield was around $44 \%$ when was pretreated with ethanol, substantially lower than that achieved from barley not pretreated with ethanol (62\%). Ethanol pretreatment increased the molecular weight of the $\beta$-glucan extracted by five times, and hence increased the viscosity leading to an important decrease of the stirring efficiency. When performing the extraction from milling fractions, important increases of the extraction yield were obtained as well as in final $\beta$-glucan recovery. Total $\beta$-glucan recovery was in the range 44 to $63.5 \%$, almost twice the recovery achieved when using just flour. Gum yield obtained in all the cases was around $50 \%$ higher than the obtained when working with the raw barley flour.

Despite of the important increase in the $\beta$-glucan recovery, amount of starch was increased dramatically. The use of ethanol pretreatment enhanced the molecular weight but allowed that starch co-extraction. In order to upgrade the final product, part of this co-extracted starch will have to be removed by following an enzymatic treatment. Molecular weight of the polymers extracted was increased when the fractionating milling was performed. Barley flour pretreated with ethanol lead to a polymer of $500 \mathrm{kDa}$, high compared to the obtained when barley was not pretreated with ethanol. But the further milling to obtained fractions with different compositions and particle size lead to another increase of the MW, up to 700KDa.

\subsection{Mixtures of milling fractions}

Three different mixtures of brans $(71 \% \mathrm{w} / \mathrm{w})$ and reduction flour $(29 \% \mathrm{w} / \mathrm{w})$ were tested. Significant differences were observed when varying the pretreatment procedure and the way of executing the milling, as can be seen in Table 3 .

Table 3. Characterization of products obtained from mixtures of barley milling fractions

\begin{tabular}{|c|c|c|c|c|c|c|}
\hline Sample & $\begin{array}{c}\text { Extraction yield } \\
\text { \% }\end{array}$ & $\begin{array}{c}\boldsymbol{\beta} \text {-glucan } \\
\%\end{array}$ & $\begin{array}{c}\text { Starch } \\
\%\end{array}$ & $\begin{array}{c}\text { MW } \\
\text { kDa }\end{array}$ & $\begin{array}{c}\text { gum yield } \\
\%\end{array}$ & $\begin{array}{c}\beta \text {-glucan recovery } \\
\%\end{array}$ \\
\hline Mixture A & 60.3 & 22.8 & 49.6 & 650 & 15.6 & 58.8 \\
Mixture B & 49.7 & 29.3 & 41.4 & 588 & 7.9 & 39.6 \\
Mixture C & 45.0 & 35.8 & 32.6 & 741 & 6.0 & 35.1 \\
\hline
\end{tabular}


Best results in terms of $\beta$-glucan recovery were achieved when mixture $A$ was used. $58.9 \%$ of the initial $\beta$-glucans present in the raw material were recovered in the final product. Extraction yield was high (60.3\%), and higher than that achieved when brans and reduction flour were extracted separately: $41.7 \%$ and $57.5 \%$, respectively (see Table 2). Also gum yield was extremely high: $15.6 \%$. Particle size of brans seems to be the most limiting factor for the extraction to be successful. However, this lower particle size facilitates the extraction of starch, and hence, there is a high concentration of starch in the final product (around 50\%). Mixtures $B$ and $C$ showed a similar behaviour when were extracted: similar extraction yields, $\beta$-glucan recovery and compositions of solid product obtained. Mixture B (brans and reduction flour were mixed together and subsequently milled) results were slightly better: extraction yield $50 \%$, with a total $\beta$-glucan recovery of $40 \%$.

The particle size and in the homogeneity of the raw material could explain this fact: in mixture A brans were milled separately and later mixed with the reduction flour. This sequence of operation allowed has a more accurate control of the particle size achieved when milling. This means the lower particle size improves the extractability of $\beta$-glucans being this effect on $\beta$ glucan extraction more important than the initial concentration of $\beta$-glucans in the raw material.

\section{CONCLUSIONS}

In this work the effect of the milling on the extraction of $\beta$-glucans from a hull-less waxy genotype barley cultivar has been studied. Barley was milled in a Chopin CD1 mill, obtaining three different milling fractions: brans $(50 \% \mathrm{w} / \mathrm{w}, 4.5 \% \beta$-glucan, $\mathrm{dp}>0.8 \mathrm{~mm})$, reduction flour (20\% w/w, 6.6\% $\beta$-glucan, $0.16<\mathrm{dp}<0.8 \mathrm{~mm}$ ) and break flour $(30 \% \mathrm{w} / \mathrm{w}, 2.4 \% \beta$-glucan, $\mathrm{dp}>0.8$ $\mathrm{mm})$. Important differences between fractions were found in the extraction yield and the molecular weight of the $\beta$-glucan isolated. Best results were obtained when reduction flour was used as source of $\beta$-glucans: the resulting product contained $28 \%$ of $\beta$-glucan (643 kDa) and $39 \%$ of starch, showing a total $\beta$-glucan recovery of $63.6 \%$. Mixtures of brans and reduction flour contributed to increase the average $\beta$-glucan recovery up to $60 \%$, expressing the importance of having a homogeneous raw material with a lower particle size distribution in order to perform successfully a $\beta$-glucan extraction process. According to these results, milling pretreatment of barley, contributes to make easy and more efficient the final $\beta$-glucan recovery, because leads to lower particle size flours and to a more quality product in terms of higher molecular weight. 


\section{ACKNOWLEDGEMENTS}

This work has been carried out with the economical support of the coordinated research project ITACyL-Universidad de Valladolid, ref: VA-14-C2-1.

\section{REFERENCES}

Benito, O.; Lucas, S.; Alonso, E. (2009). Study of the effect of different pretreatments on the performance of the extraction of $\beta$-glucan from barley. Chemical Engineering Transactions, 17, 927-932.

Brennan C.S.; Cleary L.J. (2005). The potential use of cereal $(1 \rightarrow 3,1 \rightarrow 4)-\beta$-D-glucans as functional food ingredients. Journal of Cereal Science, 42(1), 1-13.

Irakli M., Biliaderis C.G., Izydorczyk M.S., Papadoyannis I.O. (2004). Isolation, structural features amd rheological properties of water-extractable $\beta$-glucans from different Greek barley cultivars. J. Sci. Food Agr., 84, 1170-1178.

Kiryluk J., Kawka A., Gasiorowski H., Chalcarz A., Aniola J. (2000). Milling of barley to obtain $\beta$ glucan enriched products. Die Nahrung, 44 (4), 238-241.

Vasanthan T.; Temelli, F. (2008). Grain fractionation technologies for cereal $\beta$-glucan concentation. Food Research International 41, 876-881.

Vasanthan, T.; Bhatty, R.S. (1995). Starch purification after pin milling and air classification of waxy, normal, and high amylose.Cereal Chemistry, 72(4), 379-384. 


\section{CURRICULUM VITAE}

ÓSCAR BENITO ROMÁN 



\section{ÓSCAR BENITO ROMÁN}

Curriculum Vitae (January 2013)

\section{Personal Information}

DNI: 71271700-J

Nationality: Spaniard

Date of birth: 27-August-1983

Address: Calle Vitoria 139, 11ํㅡ. 09007-Burgos (Spain)

Phone number: +34 646590537

E-mail: obenito@iq.uva.es or osbenet@gmail.com

\section{CurRent Status}

- From November 2010: PhD Student at Department of Chemical Engineering and Environmental Technology, University of Valladolid (Spain), supported by the FPIUVa fellowship program of the University of Valladolid

- Research topics:

- Development of processes to extract polysaccharides ( $\beta$-glucans) from barley

- Process intensification (ultrasounds assisted extraction)

- Pressurized hot water extraction

- Purification processes: enzymatic hydrolysis and membrane technology

- Chemical Engineer (2001-2007). University of Valladolid

- Bachelor thesis: Institute of Environment and Resources, Technical University of Denmark (DTU). Topic: "Effect of temperature and medium on power generation in a microbial fuel cell (MFC)". Supported by the ERASMUS program of the European Union.

- Master of Research in Process Engineering and Systems (2009-10). University of Valladolid, 60 ECTS.

- Master thesis: "Optimization of the extraction conditions of $\beta$-glucan from waxy barley".

- Other Academic Information:

- SOCRATES/ERASMUS Intensive Course on "Basics, Developments, Research and Industrial Applications in High Pressure Chemical Engineering Processes". École des Mines d'Albi-Carmaux, Francia. July 2007; 5 ECTS. 
- Course on "Audit techniques in a system of food quality". Fundación General, Universidad de Valladolid. November 2008; 32 hours.

- Course on "Project Management". Fundación General, University of Valladolid. November 2008; 32 hours.

- Course on "Industrial properties: Patents and utility models". Fundación General, University de Valladolid. May 2009; 4 hours.

- Languages:

- Spanish: native

- English: high level, written and spoken

- French: medium level, written and spoken

\section{ReSEARCH AND Work CAREeR}

- June 2007 - May 2010: Department of Chemical Engineering and Environmental Technology (UVa). Research grant in the project "Development of a Technically Efficient process to obtain $\beta$-glucan from barley". High Pressure Processes Group. Research Project supported by the Regional Government of Castilla y León (Spain)

- July-August 2006: Productos Capilares L'Oréal (Burgos), Quality Control Department. Position: Laboratory Assistant.

- July-August 2005: Productos Capilares L'Oréal (Burgos), Internship at the Quality Control Department.

\section{- RESEARCH PROJECTS:}

- "Desarrollo de un proceso técnicamente eficaz de obtención de $\beta$-glucanos a partir de cebada" (Junio 2007-Mayo 2010). Junta de Castilla y León. Importe 55.000€. Referencia: VA-14-C2-1

- "Formulación de productos alimentarios mediante secado en spray" (3 meses 2010). AB-BIOTICS Producciones industriales de microbiotas S.L. (Barcelona). Importe 10.000€. (Artículo 83 LOU). Gestor: Fundación General Universidad de Valladolid

- "Pruebas de extracción y caracterización de $\beta$-D-glucanos" (16/11/2011 23/7/2012). Biofactoria Naturae et Salus S.A. con CIF A-095223762. Importe 39850€+IVA. (Artículo 83 LOU). Gestor: Parque Científico Universidad de Valladolid.

\section{- $\quad$ RESEARCH WORKS CO-DIRECTED}

- "Estudio de la solubilidad de $\beta$-glucanos en agua caliente presurizada". Alexandra Martín Cortés. Julio de 2011, Universidad de Valladolid. Calificación: $9.2 / 10$. 
- "Isolation of value added products from waxy barley by sequential extraction and hydrolysis". Nugroho Saputro Budi Mulia. Abril 2012, Technical University of Hamburg Harburg (Alemania). Calificación Sobresaliente.

- "Estudios de hidrólisis enzimática de almidón". Miguel Polo. Marzo 2012, Universidad de Valladolid.

- "Pressurized hot water extraction of $\beta$-glucan from barley". Sandra Janssen. Calificación 9.0/10. Septiembre de 2012, Universidad de Valladolid.

- "Concentración de $\beta$-glucanos mediante membranas de ultrafiltración". María Andérez Fernández. Calificación 9.0/10. Septiembre de 2012, Universidad de Valladolid.

\section{ReseARCh PAPERS}

Benito-Román, Ó; Alonso, E.; Cocero, M.J. (2013). Pressurized hot water extraction of $\beta$ glucans from waxy barley. The Journal of Supercritical Fluids 73, 120-125

Benito-Román, Ó.; Alonso, E.; Cocero, M.J. (2013). Ultrasound assisted extraction of $\beta$-glucans from barley. LWT-Food Science and Technology 50, 57-63

Benito-Román, O.; Alonso, E.; Lucas, S. (2011). Optimization of the $\beta$-glucan extraction conditions from different waxy barley cultivars. Journal of Cereal Science 53, 271-276

Min, B.; Benito Román, Ó.; Angelidaki I. (2008). Importance of temperature and anodic medium composition on microbial fuel cell (MFC) performance. Biotechnology Letters, 30(7), 1213-1218

Benito O., Alonso E., Ciudad Bautista F.J., Sanz Calvo M.A., and Lucas S.Y. (2010), Beta-glucan enriched products obtained from different barley milling fractions. Chemical Engineering Transactions (21) 691-696. DOI: 10.3303/CET1021116

Benito Román, O.; Lucas Yagüe, S.; Alonso Sánchez, E. (2009). Study of the effect of different pretreatments on the performance of the extraction of $\beta$-glucans from barley. Chemical Engineering Transactions (17), 927-932. DOI: 10.3303/CET0917155

\section{CONTRIBUtions to CONFERENCES}

- Lectures:

$11^{\text {th }}$ European Conference of Chemical Engineering, Berlín (Germany). Benito-Román, Ó.; Alonso, E.; Cocero, M.J. Ultrasound Assisted Extraction of $\beta$-glucan from barley. 25-29 September 2011.

- Posters:

FLUCOMP V - 5a Reunión de Expertos en tecnologías de fluidos comprimidos, Burgos (Spain). Benito, Ó.; Martín-Cortés; A.; Alonso, E.; Cocero, M.J. Efecto de la Presión y Temperatura en la Solubilidad de $\beta$-glucanos de Cebada en Agua. 15-17 June 2011 
$1^{\text {st }}$ Iberian Meeting on Natural Bioactives Entrapment for the Food Industry Challenges and Perspectives, from nanotechnology to bioavailability, Lisbon (Portugal). BenitoRomán, Ó.; Alonso, E.; Cocero, M.J. Effect of Pressure and Temperature on the Extraction of 6-glucans from Barley with Hot Pressurized Water. 12-13 May 2011

CHISA 2010, 19 ${ }^{\text {th }}$ International Congress of Chemical and Process Engineering, Prague (Czech Republic). Beta-glucan enriched products obtained from different barley milling fractions. O. Benito, E. Alonso, S. Lucas. August 2010.

ICHEAP-9, $9^{\text {th }}$ International Conference on Chemical \& Process Engineering, Rome (Italy). Study of the effect of different pretreatments on the performance of the extraction of beta-glucan from barley. Ó. Benito, S. Lucas, E. Alonso. 10-13 May 2009.

AIChE Annual Meeting 2008, Philadelphia (USA). Optimization of the extraction process of $\beta$-glucans from barley. Ó. Benito, E. Alonso, S. Lucas. 16-21 November 2008.

CHEMPOR 2008, 10th International Biological and Chemical Engineering Conference, Braga (Portugal). Effect of operating conditions on the extraction of $\beta$-glucans from barley. Ó. Benito, S. Lucas, E. Alonso. 4-6 September 2008.

FLUCOMP 3, 3a Reunión de Expertos en tecnologías de fluidos comprimidos, Madrid (Spain). Ó. Benito, S. Lucas, E. Alonso. Impregnación de madera de Haya Europea con compuestos biocidas en medio supercrítico. 9-10 February 2009

\section{Short Stays in other Research Centers}

NAGOYA UNIVERSITY (Japan). Graduate School of Chemical Engineering (Prof. Motonobu Goto)

- Fixed bed extraction of $\beta$-glucan, using pressurized hot water and supercritical $\mathrm{CO}_{2}$ as solvent

- 3 months stay (September-December 2012)

TECHNICAL UNIVERSITY OF HAMBURG-HARBURG (TUHH). Institute for Thermal and Separation Processes (Prof. Dr.-Ing. Irina Smirnova)

- Study of the extraction of $\beta$-glucan from cereals, in a fixed-bed extractor (semi continuous process) using pressurized hot water as solvent.

- 3 months stay (September-December 2011)

TECHNICAL UNIVERSITY OF DENMARK (DTU). Institute of Environment and Resources (Prof. I. Angelidaki)

- Topic: development of microbial fuel cells (MFC)

- 6 months stay (october 2006 - april 2007), Erasmus Program 